University of South Florida

DIGITAL COMMONS

@ UNIVERSITY OF SOUTH FLORIDA
Digital Commons @ University of

South Florida

$1-1-2001$

\title{
TMA Handbook: A Guide to Successful Transportation \\ Management Associations
}

CUTR

Follow this and additional works at: https://digitalcommons.usf.edu/cutr_nctr

\section{Scholar Commons Citation}

CUTR, "TMA Handbook: A Guide to Successful Transportation Management Associations" (2001).

Research Reports. 211.

https://digitalcommons.usf.edu/cutr_nctr/211

This Technical Report is brought to you for free and open access by the National Center for Transit Research (NCTR) Archive (2000-2020) at Digital Commons @ University of South Florida. It has been accepted for inclusion in Research Reports by an authorized administrator of Digital Commons @ University of South Florida. For more information, please contact digitalcommons@usf.edu. 


\section{TMA Handbook}
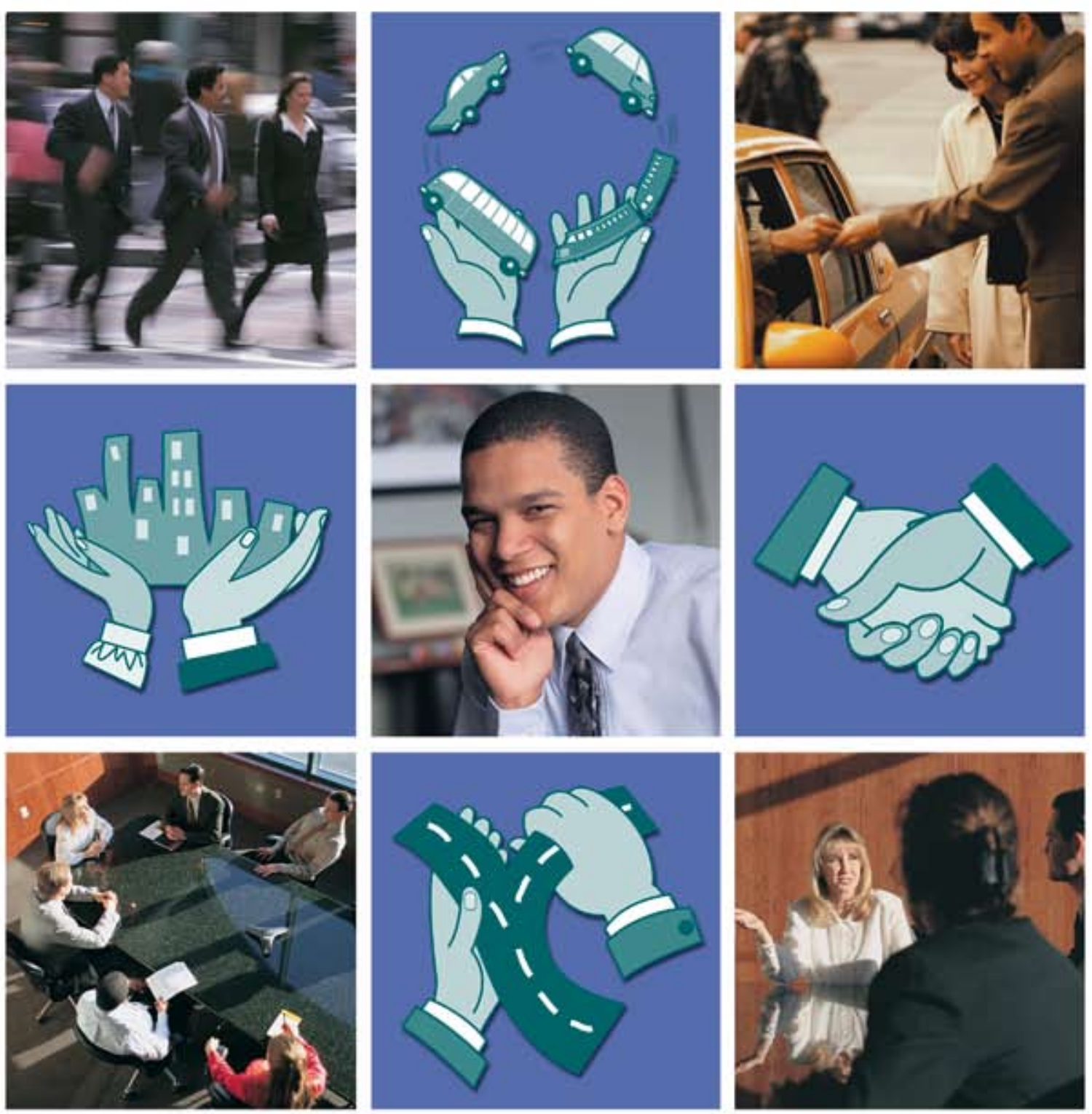

\section{A Guide to Successful}

Transportation Management Associations 
Contributors/Purpose and Use of the Handbook

\section{- Section I:About TMAs-An Overview}

The Problems That TMAs Address...

Defining Transportation Management Associations ................................................................................................. I-9

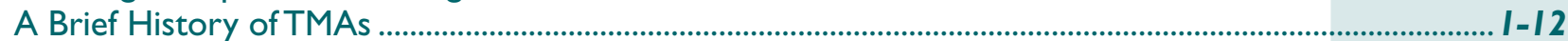

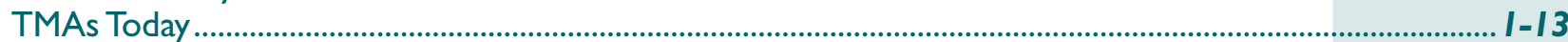

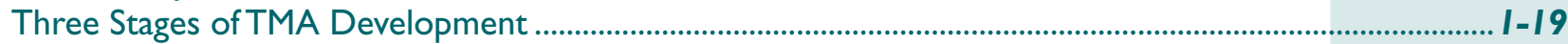

\section{- Section 2:The Possibilities-TMA Exploration and Feasibility}

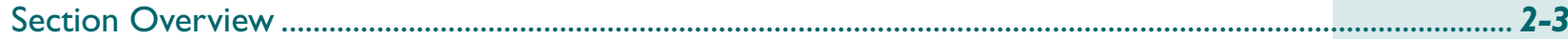

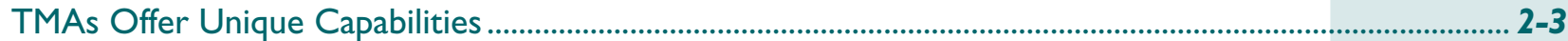

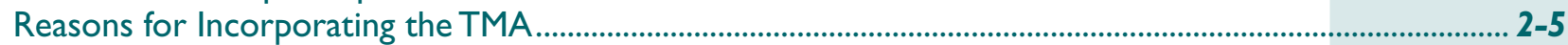

TMA Exploration —Conditions that Indicate TMA Feasibility ........................................................................ 2-5

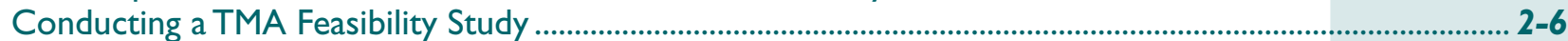

TMA Formation-Building Commitment and Consensus for Solutions and Services .................................... 2-9

\section{- Section 3:TMA Development-Building Relationships and Alliances}

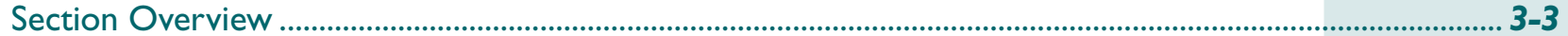

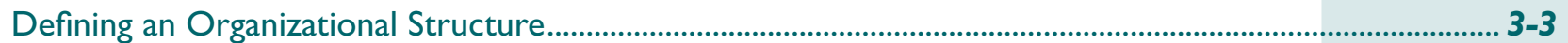

Articles of Incorporation and Bylaws......................................................................................................................... 3-5

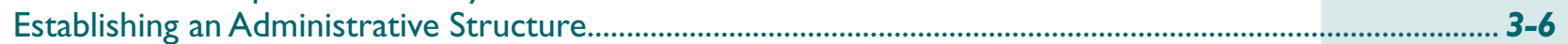

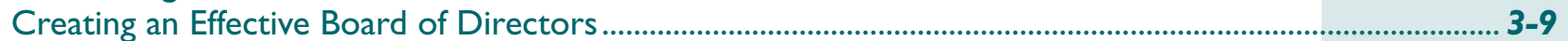

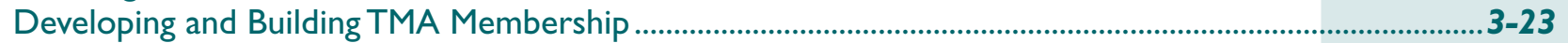

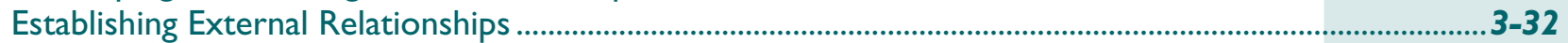

\section{- Section 4:TMA Development-Planning and Evaluation}

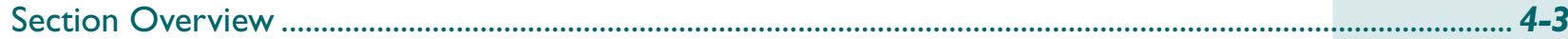

Beginning with the End in Mind-TMA Performance Evaluation ................................................................4-3

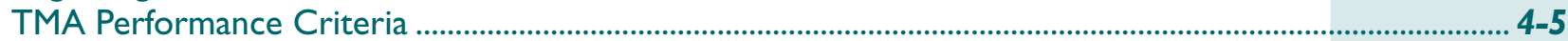

Initial Work Plan Development Considerations-Data Collection.................................................................4- I I

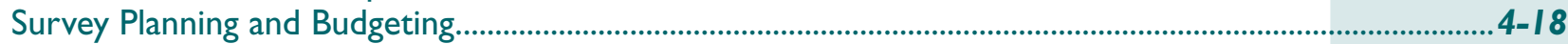

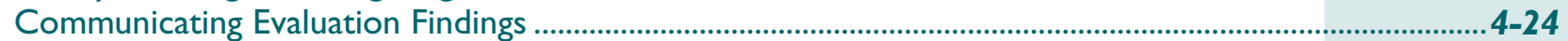

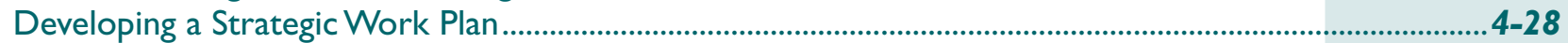

\section{Section 5:TMA Development-Financial Management and Service Delivery}

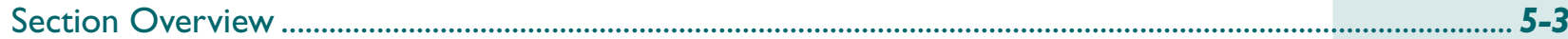

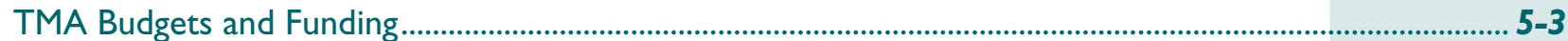

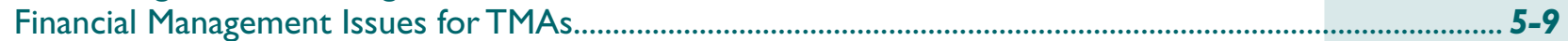

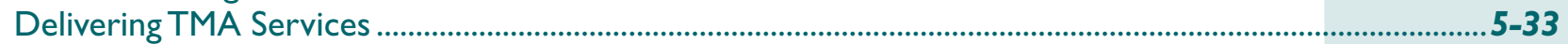

\section{Section 6:Appendix}

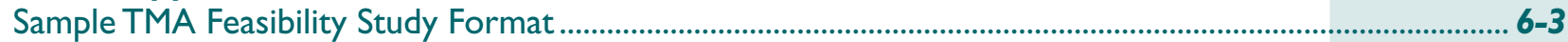

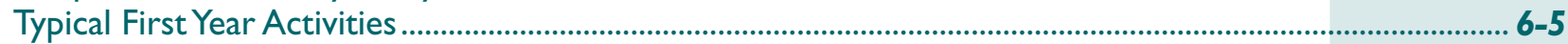

Defining Responsibilities of Board and Staff,Activity Answer Key....................................................................... 6-7

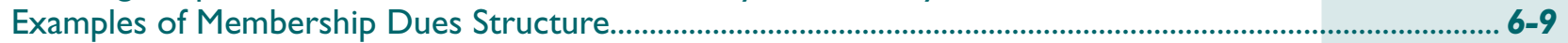

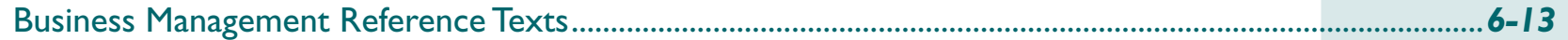

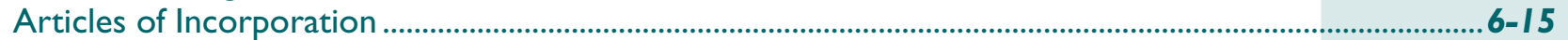

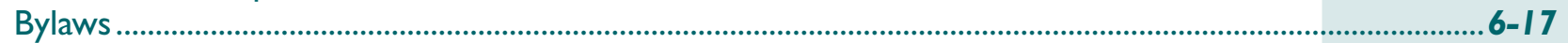

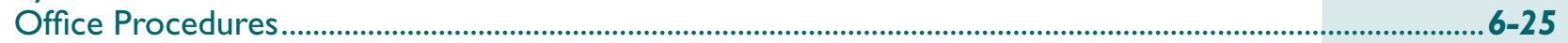

Sample Job Description -TMA Executive Director/Manager (4 examples) .....................................................6-33

Sample Job Descriptions—Other Positions (5 examples).....................................................................................6-37

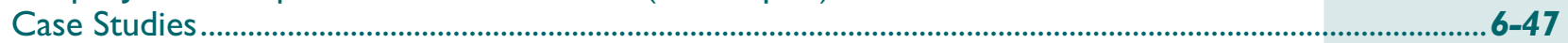

The Evolving TMA: Results from the 1998 ACT TMA Council Operational Survey......................................6-59

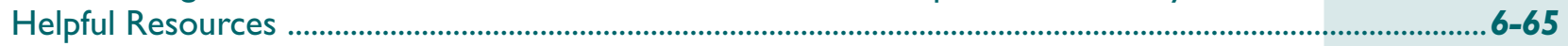




\section{Contributors}
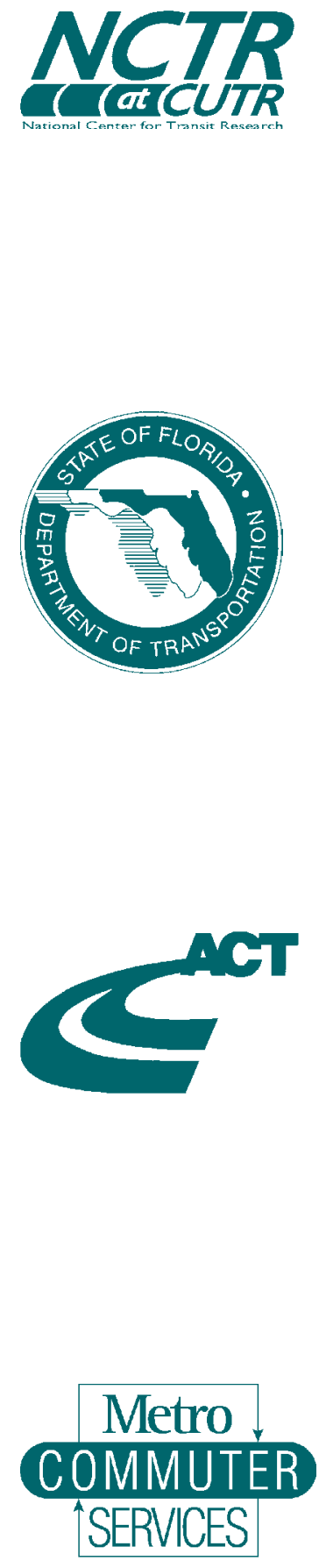

It's going to work!
The development of the "TMA Handbook: A Guide to Successful Transportation Management Associations," was a collaborative process. It was written and designed by the National Center for Transit Research's (NCTR) National TDM and Telework Clearinghouse on behalf of and with the assistance of the Association for Commuter Transportation's TMA Council.The NCTR National TDM and Telework Clearinghouse is a project of the Center for Urban Transportation Research at the University of South Florida, College of Engineering, in Tampa, Florida.

The Florida Department of Transportation provided additional funding support for the writing of the updated Handbook. Metro Commuter Services of the State of Minnesota funded the printing of the TMA Handbook. The Association for Commuter Transportation handles the distribution and sales of the Handbook.

Special thanks goes to the TMA Handbook Update Committee of the Association for Commuter Transportation TMA Council who provided direction, guidance, review of the drafts and printing assistance. Committee members included:

- Christopher Park, Executive Director,Warner Center TMO,Woodland Hills, California

- Donna M. Smallwood, Manager, Planning \& Research, CARAVAN for Commuters, Inc., Boston, Massachusetts

- Phyllis Pacyna,Transportation Director,Tampa Downtown Partnership, Tampa, Florida

- Patty Carlson, Manager, Metro Commuter Services, St. Paul, Minnesota

- Theresa Cain, Assistant Manager, Metro Commuter Services, St. Paul, Minnesota

Contributors included the following staff from the Center for Urban Transportation Research, College of Engineering, University of South Florida:
- Sara Hendricks, Research Associate, Principal Editor
- Phil Winters, TDM Program Director
- Francis Cleland, Senior Research Associate
- Tony Ferraro, Research Associate
- Wendy Castleberry, Layout and Design
- Danielle O'Connor, Graduate Research Assistant
- Kellie Spurgeon, Graduate Research Assistant
- Francis Wambalaba, Senior Research Associate, Reviewer
- Laurel Land, Research Associate, Reviewer

Special thanks also goes to TMAs nationwide who provided helpful advice, examples and case studies, and for responding to the 1998 ACT TMA Council Operational Survey cited in the Handbook.

This updated TMA Handbook is based upon the previous work of those who produced earlier editions.

- The 1994 edition was produced by Commuter Transportation Services, Inc. Los Angeles, CA, with grants from the United States Department of Transportation, Federal Highway Administration and the Federal Transit Administration with the cooperation of the Los Angeles County Metropolitan Transportation Authority and the State of California, Department of Transportation. The TMA Handbook was prepared by: Lori 
Diggins, COMSIS Corporation; Bonnie Bensimon, Leigh Fortson, Jill Smolinski and Harlan West of Commuter Transportation Services, Inc.; Elham Shirazi, Transportation Consultant; Donna Carter, Frank Wilson \& Associates; and Phyllis Martinez, Illustrator. Contributors included the Association for Commuter Transportation (ACT) TMA Council; Diane Davidson, Brentwood Area TMA and ACT TMA Council Chairperson, 1993; and Christopher Park, Warner Center TMO and ACT TMA Council Chairperson, 1994.

- The 1989 edition, "TMA Handbook:A Guide to Forming Transportation Management Associations," was produced by Commuter Transportation Services, Inc., Los Angeles, $\mathrm{CA}$, and the Southern California Association of Governments, with a grant from the United States Department of Transportation, Urban Mass Transportation Administration. The Handbook was prepared by Eric Schreffler, Harold Katz, and members of the Southern California TMA Handbook Advisory Committee.

You may order copies of the TMA Handbook by using the order form available on the ACT website at www.actweb.org and sending it with payment to:

Association for Commuter Transportation

P.O. Box 15542

Washington, D.C. 20003-0542 


\section{Purpose and Use of the Handbook}

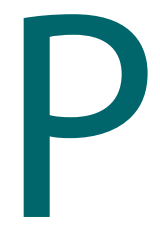

ublic-private partnerships that address localized transportation issues operate under a variety of organizational structures, depending upon the nature and duration of the problems addressed, the selected mission, the members involved and the sources of funding. These organizations can vary in legal formality, including ad hoc task forces, committees within other agencies and private nonprofit organizations. Sometimes an informal committee evolves into a private nonprofit organization.

This TMA Handbook discusses the formation, operation and ongoing development of formally structured TMAs - those that have incorporated as private nonprofit organizations. The reason for the emphasis upon private nonprofit TMAs is because the majority of TMAs that responded to the 1998 ACT TMA Council Operational Survey identified themselves as $50 \mathrm{I}$ (c) organizations. The TMA Handbook strives to address the more complex organizational issues experienced by legally incorporated TMAs; however, the comprehensive information contained in this Handbook is also useful and relevant to TMAs of other organizational types.

In 1989, Commuter Transportation Services, Inc. (CTS) produced the first edition of the TMA Handbook, designed to provide information to assist groups that were considering forming, or had begun the process of creating a Transportation Management Association (TMA).The original handbook, targeting the development of new TMAs, was well received and widely distributed to TMAs throughout the nation.

The second version of the TMA Handbook was published in 1994 with the purpose of providing information needed at various stages in a TMA's life cycle, including exploring TMA feasibility,TMA formation and ongoing TMA operations. The second version was produced by Commuter Transportation Services, Inc. in coordination with many contributors.

This newest update of the TMA Handbook incorporates the recognition that in the future, more updates will follow, due to the continually changing environment in which TMAs operate. As a result, the three-ring binder format of the Handbook is intended to enable the reader to add updated notes and case studies. Specific data that describe current operational characteristics of TMAs, as gathered from the 1998 ACT Survey, have been placed in the Appendix for easy referral and later updates. The TMA Handbook preserves the practical "how-to" tone that was established in the previous editions.

Some transportation professionals seek a tidy definition of the term, "TMA," to determine funding eligibility and for other purposes.TMAs appear to defy such a neat definition but perhaps the most defining characteristics of TMAs are their diversity and flexibility. The updated TMA Handbook contains a discussion of TMAs, relative to differences in institutional organization, purpose, funding, membership and location, recognizing that all have equal legitimacy. It is argued that the value of TMAs partly stems from this degree of flexibility through which a public-private partnership is empowered to meet its particular needs.

As we wrestle with the definitional boundaries of a TMA, we argue that TMAs should not be defined as "TDM organizations" or "rideshare organizations." While TMAs have traditionally used transportation demand management strategies, including ridesharing assistance and promotion, this is unnecessarily limiting. It tempts TMAs to select a strategy even before it is determined what should be accomplished.

While the updated TMA Handbook adds a brief discussion of other "tools" available to TMAs, including Transportation Systems Management (TSM), this is not a guidebook on TDM or other techniques. It is recommended that the reader pursue the many excellent texts and publications on TDM, as well as TSM, that are available. The emphasis of the updated TMA Handbook is to provide guidance on how to accomplish transportation-related goals through a partnership; after all, a TMA is an organization of people working together. 


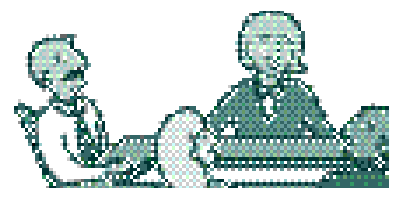

New information was added to the TMA Handbook, particularly regarding financial management issues ofTMAs and regarding monitoring and evaluation of TMA program performance. The issues involved in running a TMA are similar to, and as challenging as, running a small business. For example, the decisions that TMAs make regarding how they track and report their financial condition can have a direct bearing on the success of the TMA.The results of monitoring and evaluating a TMA may make the difference between winning a new operating grant and staying afloat, or losing grant funds and closing its doors. The no-nonsense discussions on these and other topics will help TMA staff and board members understand the complexity of the effort and the many decisions and trade-offs that must be made.

The TMA Handbook is divided into five sections:

$\begin{array}{cl}\text { Section I: } & \text { About TMAs-Overview } \\ \text { Section 2: } & \text { The Possibilities-TMA Exploration and Feasibility } \\ \text { Section 3: } & \text { TMA Development-Building Relationships and Alliances } \\ \text { Section 4: } & \text { TMA Development-Planning and Evaluation } \\ \text { Section 5: } & \text { TMA Development-Financial Management and Service } \\ \text { Delivery } & \\ \text { Section 6: } & \text { Appendix }\end{array}$

Section I introduces the TMA as an organization, describes the roles TMAs can play in transportation and air quality management, presents a brief history of development and gives an overview of TMAs today.

Section 2 presents a process to explore the need and potential for creating a TMA, and to develop support for its formation.

Section 3 provides information on options for selecting a legal organizational framework, establishing a professional staff, developing a board of directors and building organization membership.

Section 4 addresses how the TMA lays the groundwork for accomplishing its mission. These tasks include determining goals and objectives, establishing a means for carrying out program monitoring and evaluation and developing a strategic work plan.

Section 5 discusses issues relating to funding sources, budgeting, financial management and TMA service delivery.

Section 6 is an Appendix that provides references and resources useful to TMAs throughout their development.

Throughout the Handbook, readers will find references to the "Sample TMA." This is a fictitious TMA, created to provide illustrative examples. 


\section{About TMAs- An Overview}

- The Problems that TMAs Address

- Defining Transportation Management Associations

A Brief History of TMAs

- TMAs Today

- Three Stages of TMA Development 


\section{Defining}

\section{The Problems That TMAs \\ Address}

Many Americans rely heavily on their cars for personal travel. However, motor vehicle travel has brought problems as well as convenience and opportunities. Traffic congestion in some areas has reached crippling levels. Driving alone, especially during commuting hours when travel speeds are stop-and-go, greatly contributes to traffic congestion and air pollution. Vehicle-related air pollution threatens both the environment and health of community members. In more than 100 urban areas nationwide, levels of pollutants, caused mainly by motor vehicle emissions, exceed federal clean air quality standards. Poor access to centers of commerce impedes employee recruitment and hurts business. Lack of public transit service, bicycle facilities, sidewalks and other transportation facilities severely limit the mobility of citizens who do not drive. Poorly managed parking supply in a downtown can waste valuable real estate, discourage use of transportation alternatives and hinder commercial revitalization.

The growth in TMAs over the past 20 years stems from the knowledge that business influence and resources can be more effective when collectively applied. The development of a properly-conceived, efficiently-operated and adequately-funded TMA can be an important component of an area's efforts to address a wide variety of transportation-related problems.

A review of the literature finds a wide range of definitions for transportation management associations. In California, the South Coast Air Quality Management District (SCAQMD) emphasizes the formal nature of many TMAs as well as an implied purpose. SCAQMD defines a TMA as:

“...a private/nonprofit association that has a financial dues structure joined together in a legal agreement for the purpose of achieving mobility and air quality goals and objectives within a designated area."

In Florida, the geographical service area is also included in the definition. TMAs are:

“...public/private partnerships formed so that employers, developers, building owners, and government entities can work collectively to establish policies, programs and services to address local transportation problems. TMAs realize their potential in addressing traffic congestion, air quality, and occasionally, employment issues through TDM strategies. TMAs are established within a limited geographical area to address the transportation management needs of their members. TMAs are expected to obtain private sector financing in addition to public funding."2

These are two of the many definitions of TMAs. For some definitions, the term "transportation management association" is often used interchangeably with "business nonprofit organization." Yet there are several varieties of TMAs, including those serving residential areas, which are not commonly considered TMAs. As discussed throughout the Handbook, TMAs serve a variety of roles and markets, and thus seem to defy a single definition.TMAs need not be based upon ridesharing programs. In fact, some experts think that the opportunity for continual public and business community involvement in transportation issues may supplant the ridesharing services that many TMAs were formed to provide.

Why does it matter what definition we use? For individuals looking to form a TMA, recognizing and appreciating the differences may help select the model that deals with the problems that the proposed TMA is intended to address. Some definitions may be overly prescriptive in the types of services offered by TMAs. These prescribed services may not be the best solution or even appropriate for problems in your service area. For those who

\footnotetext{
'http://www.aqmd.gov/trans/doc/ercp/ecrp07.html

${ }^{2}$ Florida Dept. of Transportation, Commuter Assistance Program
} 


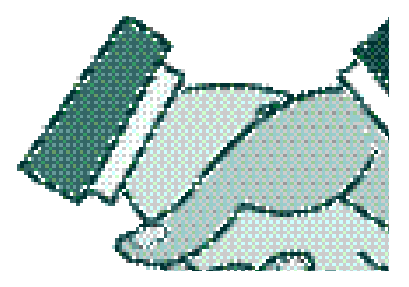

manage an existing TMA as a staff member or board member, understanding the differences may help improve its performance.

In reality,TMAs function as a "family," with each member having its own mix of characteristics. For example,TMAs encompass many types of institutional structures, including both ad hoc groups and formal, independent nonprofit corporations. TMAs may be composed of different mixes of public and private sector representatives. The service areas may be as small as a major activity center or as large as a countywide program. Funding may come from private sources, such as developer fees and member dues, or grants from the public sector.TMAs may serve as an advocacy channel for all types of transportation improvements or be a service provider for a particular market, such as mid-day shuttles for hospital employees.

As a means of defining TMAs, some may choose to classify TMAs along a continuum that demonstrates one or more characteristics to a greater or lesser degree. If this method is used, it should not be inferred, that movement along the continuum (for example, from an ad hoc group to an independent, nonprofit corporation) is necessarily desirable, inevitable or should be a long-range goal. One set of TMA characteristics is not necessarily better than another.

The following table illustrates the various characteristics of TMAs and how there may be different mixes of these characteristics. For example, a TMA may be an independent business league, serving a particular corridor with mixed sources of funding that provides TDM and Transportation Systems Management (TSM) services. Or, it might be a subsidiary of a business league operating under private leadership, serving a major activity center with private funding that advocates a particular transportation solution. In effect, there is a myriad of possible combinations.

Perhaps part of the difficulty in defining a TMA is the changing nomenclature that may reflect

\section{Characteristics of TMAs}

\begin{tabular}{|l|l|l|l|l|l|} 
Institutional & Tax status/Purpose & Leadership & Area & Funding & Services \\
\hline Independent & $\begin{array}{l}\text { Charitable } \\
\text { education }\end{array}$ & $\begin{array}{l}\text { Private } \\
\text { majority }\end{array}$ & Activity Center & Private & $\begin{array}{l}\text { TDM } \\
\text { only }\end{array}$ \\
\hline Subsidiary & Social welfare & $\begin{array}{l}\text { Public } \\
\text { majority }\end{array}$ & $\begin{array}{l}\text { County/City/ } \\
\text { Regional }\end{array}$ & Public & $\begin{array}{l}\text { TDM, } \\
\text { TSM }\end{array}$ \\
\hline Ad hoc & $\begin{array}{l}\text { Business league } \\
\text { Unincorporated }\end{array}$ & $\begin{array}{l}\text { Private only } \\
\text { Public only }\end{array}$ & Corridor & Mix & $\begin{array}{l}\text { Advocacy } \\
\text { Other }\end{array}$
\end{tabular}

changing times and/or the degree of institutional permanence that the TMA is expected to have. In some parts of the country, Transportation Management Initiatives (TMIs) were formed as a means of distinguishing between a formal program and one that may be either a short-term project (akin to a task force) or simply a branch office of a regional commuter assistance program that has its own advisory committee of businesses. In effect, the TMI concept is simply a subset of the TMA family.

TMAs also are sometimes called Transportation Management Organizations (TMOs). Generally, most people think the terms TMO and TMA are the same. It is widely believed that the TMO acronym was adopted by the industry as a reaction to the co-opting of the "TMA" acronym. The Intermodal Surface Transportation Efficiency Act (ISTEA) assigned the TMA acronym to "Transportation Management Areas." These TMAs mean an urbanized area with a population over 200,000. For the purposes of this Handbook, TMOs and TMAs will be considered to mean the same thing, and the term TMA will be used hereafter. 


\section{Recommended Definition}

Defining TMA by recognizing the differences may help a new TMA clarify its role and help an existing TMA plan its future. For example, the issue of institutional permanence of the TMA is critical to understanding how TMAs can be designed. In effect, planned obsolescence is a viable option for some and almost a foregone conclusion for others, if funding disappears.

SomeTMAs dissolve or quickly de-activate when energies are focused on raising funds. The departure of key staff near the end of the funding cycle also contributes to failure. Even though it is widely conceded that self-supported TMAs will ultimately be the least-adopted form, many public-driven TMAs are required to evolve from government seed funding to fully or substantially private funding.

The definition of a TMA should be general enough to encompass the family of TMAs because it is important to recognize the legitimacy of the variety in existence. The structure of the phrase, Transportation Management Association, suggests three questions to ask:

- Transportation (meaning the business of transporting passengers, goods, materials or the like): is the organization's focus on moving people and goods?

- Management (meaning the act, manner or practice of managing, handling, or controlling something): is the emphasis on taking control of the existing methods or approaches for handling transportation problems?

- Association (meaning an organized body of people who have some common interest, activity or purpose in common): Is there an organized group involved?

Using these questions as a guide, a recommended definition could be expressed this way:

A Transportation Management Association (TMA) is an organized group applying carefully selected approaches to facilitating the movement of people and goods within an area.TMAs are often legally constituted and frequently led by the private sector in partnership with the public sector to solve transportation problems.

One pertinent observation on the above definition is that, strictly speaking,TMAs need not have a focus on Transportation Demand Management (TDM). Rather than one necessarily implying the other, they both simply come from common semantic roots. Thus, an organization promoting carpooling can be a TMA just as surely as a group that advocates traffic signal coordination. In practice, of course, it is most likely that TDM will be a key tool for managing the system. Indeed, well-plannedTMAs stress the importance of managing demand as well as supply of the transportation system. Requiring TDM activities to take place before calling a particular organization a "TMA" seems to be unnecessarily restrictive.

The concept of management is central to TMAs,TDM andTSM. Satisfactorily answering the question,"How will I know TMAs are really working?" is undoubtedly the biggest obstacle to the widespread acceptance of TMAs by employers and funding agencies alike. The comfort level with TMAs may be increased as other common forms of transportation management strategies, (such as TSM), can be shown to meet the needs of businesses.

Understanding that any one TMA is part of a family of many types, readers will observe that the TMA Handbook appears to apply only to the more formal, incorporated type. The TMA Handbook emphasizes issues experienced by TMAs of a more complex organizational type; however, aspects of each section of the Handbook apply to all. For example, information on how to recruit board members can also apply to recruiting volunteers for an ad 
hoc advisory type of TMA.

A Brief

History of

TMAs

\section{Early Programs}

The first TMAs created in the early 1980s, such as the Greater Princeton TMA in New Jersey, were initiated by groups of employers that banded together to advocate local transportation issues. Others, like The Rideshare Company in Connecticut, were formed to save money through cooperative delivery of transportation services. Some, like the Bishop Ranch Transportation Association in California, were started by developers who were required to mitigate trips as a condition of a development agreement with a local government planning agency.

As the 1980s progressed, government agencies began looking to these early TMAs as models of cooperative business arrangements. Thus, they started supporting the development of TMAs with public grants. In the mid 1980s, the Urban Mass Transportation Administration (UMTA), now the Federal Transit Administration (FTA), began funding TDM implementation partnerships.

Grants were awarded to help fund the start-up or early operation of the Baltimore-Washington International Airport (BWI) TMA, the Greater Princeton TMA in New Jersey, and The Rideshare Company in Connecticut. Seattle METRO also received grants in 1986-87 for development and support of the Bellevue TMA, one of the nation's first TMAs. The Suburban Mobility Initiatives (SMI) program, designed to provide grants for TDM implementation projects, awarded TMA formation grants to nearly 20 groups between 1988 and 1990.

Many early TMAs in the 1980's started to implement required TDM strategies through negotiated trip-reduction agreements between a city and a developer or landowner. Some of these agreements also required future employer tenants to participate in TDM programs, but because cities generally have been reluctant to regulate employers, most did not assure their participation through binding agreements.TMAs became mechanisms for ensuring the ongoing participation of tenants in the TDM programs.

Although UMTA's funding encouraged TMA development, the number of TMAs grew substantially when other public agencies also began to offer funding.The states of Massachusetts, California, and New Jersey initiated funding in 1987 and 1988, and had funded 46 TMAs by 1991. Florida, Pennsylvania, and New York also funded TMA development. Numerous city and county governments in Maryland, New Jersey, Pennsylvania, and California also provided grants to new TMAs, often matching federal or state money.

The federal Clean Air Act Amendments (CAAA) of 1990 adopted TDM as an instrument of areawide pollution control. Pursuant to CAAA, the Employee Commute Options (ECO) mandate, promulgated in 199I by the U.S. Environmental Protection Agency, required all businesses employing more than 100 workers in ten severe non-attainment areas for ozone to implement trip reduction programs designed to reduce the employees' average vehicle passenger occupancy by 25 percent. The requirement was modeled after Southern California's Regulation XV, enacted in 1987. Providing technical assistance in meeting these requirements became the heart of many TMA programs.

The Intermodal Surface Transportation Efficiency Act (ISTEA) of I99I changed the way all metropolitan areas in the United States look at transportation issues, embracing TDM as a tool of regional congestion management. ISTEA required that congestion management systems examine all possible alternatives to increasing capacity before the decision is made to build new roads. Alternative mode features were required to be incorporated into the planning and design of new roads. 


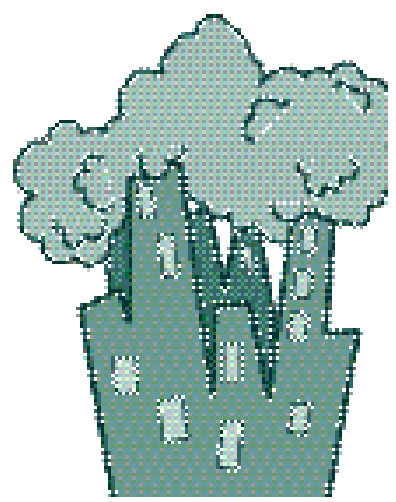

\section{TMAs Today}

\section{Where TMAs Are Located}

The missions of transportation management associations were bolstered by ISTEA and regulatory requirements because it gave reasons for employers and local governments to want to participate in TMAs, as well as providing a market for the services of TMAs. ISTEA also provided funding opportunities, especially through the Surface Transportation Program, the Transportation Enhancement Activities Program and the Congestion Mitigation and Air Quality Program to initiate projects, including the start-up of TMAs.

Strong opposition to the federal ECO requirement developed and in December 1995, the U.S. Congress repealed the federal ECO mandate.At the same time, the Southern California Air Quality Management District adopted Rule 2202, replacing Regulation XV.The new rule no longer required employers to reduce employees' vehicle trips but only emissions resulting from work trips. As a result, some TMAs folded.

Employers in California are now given a menu of options with which to satisfy the requirement, such as scrappage of old, polluting vehicles, and purchase of clean fuel vehicles. While employer trip reduction programs remain a valid method of fulfilling the requirement, they are optional and voluntary instead of mandatory.

During the 1990's, three federal legislative acts have enabled employers to offer their employees a range of commute benefits that provide incentives to reduce drive-alone commuting. These are the Energy Policy Act of 1992, the Taxpayer Relief Act of 1997 and the Transportation Equity Act for the 2 I $^{\text {st }}$ Century (TEA-2I), passed in 1998. These actions gave TMAs more tools and services to provide to the commuter market, as well as a need for TMAs to provide information and technical assistance. In 1999,Vice President Al Gore announced the kick-off of the federal government's Commuter Choice Initiative, in which employers implement programs that provide incentives for employees to exercise choice in selecting their commute mode. This is providing a strong direction for TMA programs and services.

Most of the earliest TMAs - those initiated by private businesses-have remained active and productive. Others, generally those that resulted from the "push" of a public agency grant rather than the "pull" of the demand of the business community, have struggled or ceased to exist.As the number and experience ofTMAs have increased, both private groups initiating TMAs and the public agencies that help support them have learned a great deal about the factors necessary for success.

TMAs today share many characteristics, but can differ because of geography, goals, management practices, products and services and specific markets. We will explore both the similarities and differences throughout this Handbook.

TMAs are located throughout the nation where transportation problems have become hazardous to the environment or lifestyle. The ACT TMA Council Operational Survey contains information regarding the location of survey respondents. While the survey does not provide a complete picture of the total number of TMAs in the United States and their locations (not all TMAs are members of ACT) the latest survey information does indicate that TMAs exist throughout the nation. States represented by five or more TMA survey respondents include California, Massachusetts, Florida, New Jersey and Colorado.

TMA activities and roles may differ due to the type of development or land use in their service areas. However, most TMAs are formed in one of three geographic settings:

- Suburban (existing or new)

- Central Business District (CBD) 


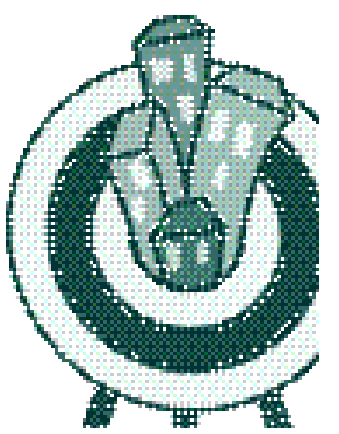

TMA Goals
- Other areas

\section{Suburban}

TMAs in suburban areas serve non-CBD activity centers with solutions to transportation problems. Most were formed primarily to provide centralized, coordinated services to current employers, to assist employers in developing and implementing in-house TDM programs and to address localized transportation problems.

Some TMAs are formed in new suburban areas. A few serve residential areas, but most are primarily emerging in commercial developments. Developers are sometimes the catalysts in their formation. In new suburban areas, TMA formation is generally seen as a mechanism to mitigate traffic or air quality impacts of planned development. In some cases, agreements with local government agencies require developers to mitigate trips to a new site or surrounding area.A TMA might be initiated to assist in this effort.

\section{Central Business District (CBD)}

Many TMAs are located in CBDs or downtown areas. In addition to working with employers and employees, these TMAs often work with managers of multi-tenant buildings and with retail merchants concerned with customer access. CBD TMAs often focus more on transit promotion and parking management than do suburban TMAs, because there is usually better transit access and more constraints on employee parking in the CBD than in suburban areas.

\section{Other Areas}

A few TMAs serve developments located in areas other than typical suburban or CBD settings. Regional or countywide TMAs sometimes play a significant role in area-wide transportation planning and advocacy, and a lesser role in local service delivery. Corridor TMAs tend to focus on accommodating transportation needs of members along a highway corridor or mitigating impacts of highway reconstruction. Industry TMAs serve a single type of employer (such as hospitals or airports) within a region or area, and develop services and programs unique to employers and employees in that industry.

Most TMA goals include reducing traffic congestion and increasing mobility. Public sector representatives in a TMA particularly favor the goal of reducing motor vehicle trips. Some TMAs also adopt goals relating to the enhancement of transportation facilities, land use planning and economic development. While some goals are more common than others, there are no "right" or "wrong" goals. More importantly, each board and membership should adopt goals that they can embrace as beneficial and pertinent to the issues of the TMA service area and worthy of their efforts to achieve.

TMAs can fulfill many roles according to the needs and interests of their members, and the availability of funding.

\section{Broker or Provider of Services}

Many TMAs are brokers, coordinating delivery of services to customers through employers, developers, or local governments. Other TMAs are direct providers of services to 


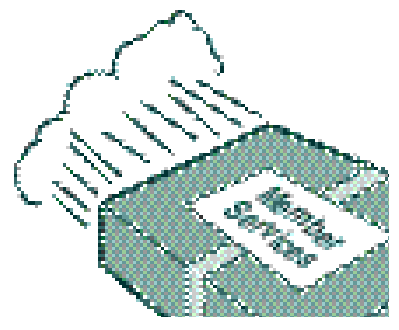

selected markets.

\section{Consultant}

Many TMAs act as consultants to provide transportation advice and technical support for programs that can be implemented collectively or by individual businesses.

\section{Watchdog}

TMAs fulfill the role of observer and monitor of conditions relating to transportation, access, business climate and other topics of interest to the membership.

\section{Information Clearinghouse}

Nearly all TMAs effectively serve as providers of information to businesses on important transportation issues and options for engaging in the dialogue.TMAs also provide information regarding local requirements and regulations, as well as the availability of services.

\section{Forum for Consensus Building}

Through its membership, the TMA serves the role of a forum for consensus building regarding the nature of the problem and steps to address it. This consensus building role empowers the TMA membership to act effectively and as one voice.

\section{Advocate}

Many TMAs fulfill the advocacy role on behalf of the goals of the TMA for addressing transportation issues, within various venues, such as participation in local transportation planning and economic development processes. Many TMAs have developed credibility with local planning agencies, enabling TMAs to promote better long-term transportation and land use planning.TMAs that have made this a priority are often a persuasive voice in local planning, resulting in improvements in local transportation services and facilities.

\section{Educator}

TMAs can serve the role of educator to benefit a broad audience of employers, developers, public agencies and customers about the nature of transportation problems that exist in the service area, and the range of solutions and strategies that can be employed to address them. As educator, the TMA is in a good position to focus attention on the links between transportation and land use, air quality, work force accessibility and related topics.

\section{Regulatory Monitor}

Today and in the future, more cities may employ negotiated agreements or adopt tripreduction ordinances that require employers, developers or landowners to implement TDM programs. TMAs can serve the role of monitoring ongoing participation of tenants in TDM programs.

Enforcing developer programs can be difficult, and some speculative developers do not continue their support after the building or complex is fully leased.A speculative developer might quickly sell the project to a third party or put it under the control of a management firm that is not involved in the original agreement. Likewise, economic conditions can affect a developer's willingness to continue support of transportation programs and services provided by a TMA. In these situations, it is beneficial to form established relationships with the network of building and leasing agents in the area. 


\section{TMA Services}

The National TDM and Telework Clearinghouse at the Center for Urban Transportation Research at the University of South Florida, hosts a web site that contains a national trip reduction ordinance database. To locate this resource, go to www.nctr.usf.edu/clearinghouse.

Most TMAs start with minimal resources. Many directors said financial constraints plagued their programs for years. For this reason, the services (although not necessarily the goals) are relatively modest, especially in the early years.

The ACT TMA Council Operational Survey provides information regarding the kinds of services provided by TMAs across the nation. The latest Survey results are summarized in the Appendix.

The list below provides examples of the most common types of services that TMAs provide. Although most of these services are focused on members, some TMAs also provide services for non-members, based upon nonprofit status.

- Vanpool subsidy program

- Discounted transit passes

- Rideshare and transit promotion

- Promotional events

- Promotional materials development and distribution

- Regional and local advocacy

- Guaranteed ride home program

- Rideshare matching

- Employee transportation coordinator training

- Trip reduction planning

- Vanpool services

- Site design

- Shuttle services

- Parking pricing and management

Services that are successful are those that are:

- Responsive to a particular problem of a selected market

- Developed for the purpose of achieving the TMA's goals and objectives

- Properly administered

- Tailored to customer needs through careful market research

\section{Transportation Demand Management}

Most TMAs emphasize use of Transportation Demand Management (TDM) strategies as part of their program of services. As the name implies, the purpose of TDM is to manage the demand for motor vehicle travel, rather than the more expensive alternative of increasing the supply of transportation services (typically road building). The TDM emphasis of TMAs may have originally resulted from UMTA's grant funding of TMAs as TDM implementation programs in the mid 1980s. 


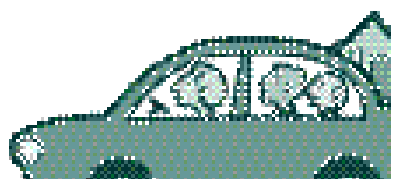

TDM efforts reduce motor vehicle trips by:

- Accommodating the same number of people in fewer motor vehicles (e.g. transit, carpooling/vanpooling, and cycling/walking)

- Eliminating trips entirely (e.g. working at home)

- Shifting the timing of trips from the most congested periods to less busy times (e.g. flextime)

TDM strategies easily lend themselves to reduce, eliminate or alter daily trips to and from a place of employment by employees, referred to as commuters. The commute trip is usually targeted by TDM strategies because it is the largest proportion of the total trips taking place during the peak periods of traffic congestion (ordinarily defined as 7-9 a.m. and 4-6 p.m. or some variation thereof). The commute trip is also characterized by the same set of commuters traveling along a fixed route from the same origin (home) to the same destination (work or school) every day. The habitual characteristics of the commute trip make it an effective target for the application of TDM strategies, such as vanpool formation among employees. As a result, employers are traditional TMA members and their employees are traditional users of TMA services.

The interest in TMAs by employers stems from the realization that transportation problems, such as traffic congestion, negatively affect business. Employers understand that corporate decisions about location, parking, work hours and employee benefits influence their employees' commute behavior, and that they can act collectively with other employers, through the TMA, to improve conditions.While TDM strategies can be applied successfully to a single work site, such as an office building, TMAs apply TDM strategies to a carefully defined service area that can be:

- A city, county or region

- A highway corridor

- A small local area, such as an employment center, hospital complex or university campus

It is important to note that while TDM strategies are usually applied to commuters at employment sites within the TMA service area, it is essential that the TMA take a close look at the transportation problems of concern to their membership. The problems might not involve employees commuting to and from work but instead, for example, large numbers of students driving to and from a university campus. As one class period ends and another begins, severe traffic congestion can erupt.

Another example might be tourist traffic circulating throughout the downtown, causing traffic congestion. A TMA service area might not have a traffic congestion problem at all, but rather a parking and access problem that might involve a retail shopping development or a courthouse complex to where large numbers of citizens are reporting for jury duty. In summary,TDM programs are not "one size fits all." Each TMA must select and tailor the appropriate tools to address an accurately defined problem. Some of these tools may be from the TDM toolbox.

The TDM toolbox includes strategies that encourage use of alternatives to driving alone. Alternatives include:

- Carpools and vanpools

- Public and private transit 


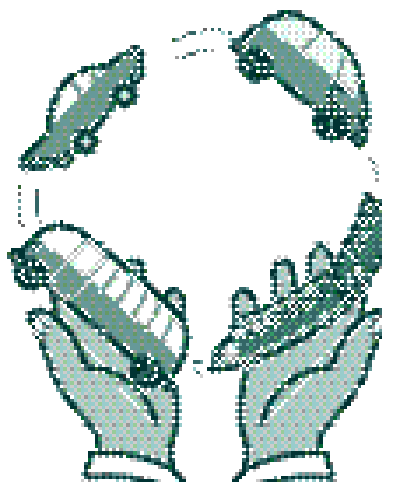

- Bicycling and walking

- Alternative work arrangements

Alternative work arrangements are programs that reduce the number of commuting days or that shift commute travel to non-peak hours. Alternative work arrangements include:

- Compressed work week, in which employees work a full work week in fewer than five days

- Telecommuting, in which employees work one or more days at home or at a satellite work center closer to their homes

- Flexible work schedules, in which employees shift their work start and end times to less congested times of day

TDM strategies also include improvements in transportation services, financial incentives, information dissemination and marketing activities that heighten travelers' awareness and/ or interest in using alternatives. They also include support services that make the use of alternatives more convenient or that remove psychological impediments to using alternatives. Some examples of TDM strategies are:

- Transportation service improvements, such as shuttle buses and vanpool programs

- Financial incentives, transportation allowances or subsidies for transit riders

- Congestion pricing

- Tax incentives for employers

- Parking management programs, including parking pricing and supply reduction

- Priority treatment for ridesharers, such as preferential parking, high occupancy vehicle (HOV) lanes and freeway ramps

- Information and marketing of transit schedules, ridematching, and other options

- Support services, such as guaranteed ride home programs

- On-site amenities, including automated teller machines (ATM), covered, secure bicycle storage, clothes lockers and showers, and quality child care

- Land use planning-related activities

\section{Trip Reduction}

A goal of many TMAs is to reduce motor vehicle trips. A few TMAs have documented measurable trip reduction in their areas using TDM strategies. These reductions have generally been about two to five percent. It is important to note that a reduction of this seemingly minor magnitude can have the impact of noticeable traffic congestion alleviation, particularly if the reductions occur during peak periods of travel.

It is important to keep in mind that overall trip reduction in the area depends on what programs and services are implemented, and the number of employers and commuters that participate in them. Trip reduction tends to be higher in regulated environments than in non-regulated environments, because more employers participate in TDM programs.

TMAs with successful trip reduction also tend to have greater financial resources, and use the funds to implement TDM programs that provide tangible commute alternatives and incentives, such as vanpool and express bus services, and carpool and transit subsidies. 
Most successful TMAs also conduct extensive market research on travel needs of local commuters and market their programs in a targeted, cost-effective manner.

\section{Transportation Systems Management}

Transportation Systems Management (TSM) is the use of low cost improvements through construction, operational, and institutional actions, to improve operational efficiency and make the most productive and cost-effective use of existing transportation facilities, services and modes. TSM actions include traffic engineering improvements, traffic control improvements, freeway management strategies, priority treatment for high-occupancy vehicles, parking management, and transit service improvements.

Traffic engineering improvements include channelization, left or right turn lanes, one-way streets, reversible traffic lanes, intersection widening, bus turnout bays, and improved signing and pavement marking. Traffic control improvements are designed to reduce travel delay and stops, while also improving average speeds on arterial roadways and freeways.

These strategies include coordination of traffic signals, continuous optimization of timing plans, use of bus priority signal control systems, and implementation of computer-based traffic control and freeway traffic management.

While TMAs do not implement traffic engineering improvements, they can play a decisive role in advocating the kinds of improvements that optimize operational efficiency of the system. An effective TMA is aware of specific transportation problems in its service area. These problems may be site specific rather than system wide.An example of this might be poor sight distance at a particular approach to an intersection, which is causing traffic delays due to frequent accidents. The TMA can bring transportation problems in its service area to the attention of the municipality. A well-informed TMA membership understands the advantages of the use of TSM under the right circumstances and can support a transportation engineering department's desire to employ these solutions in the midst of general public outcry for higher cost road widening.

Effective TMAs also have the wisdom of understanding that there are trade-offs in the use of various strategies. For example, the use of a TSM strategy in a downtown, such as creating one way streets or optimizing traffic signals, may speed up automobile traffic, but also have the unintended effect of making downtown streets less safe for pedestrians to cross.

\section{Three Stages of TMA Development}

Each TMA develops at a rate and in a way that is unique to the conditions that precipitate its development. Some TMAs, primarily those in areas with severe transportation-related problems and strong support from private businesses, form spontaneously and grow rapidly. For others, growth is much slower. Regardless of how quickly they grow, all TMAs pass through three stages of organizational development as they move from initiation to maturity:
- Exploration
- Formation
- Operation

Although described here as three distinct stages, the lines between the stages can be vague, with some overlap in activities. For example, a TMA in the formation stage could be completing some exploration tasks while starting some operation tasks. Development is most accurately viewed as a continuum. 


\section{Exploration}

\section{Formation}

\section{Operation}

Exploration is the stage at which the timing and need for a TMA is studied. Is a TMA the ideal organizational approach for accomplishing the mission? Under what conditions is it feasible to create and sustain a TMA?

For example, the group that is considering forming a TMA must develop a core group of supporters and begin to define problems and solutions. In some cases, the group might also pursue formation tasks, such as drafting bylaws and developing a work plan, but the focus is on deciding whether or not a TMA makes sense. In general, operating funds have not been secured and it is not certain whether a TMA will form.

Several tasks must be accomplished during the exploration stage:

- Identifying and developing consensus on the nature of the problem(s)

- Understanding area travel patterns and needs of identified markets

- Defining a geographic scope as it relates to the problem, markets and travel patterns

- Establishing a clear organizational mission

- Determining if a public-private partnership can address the problem(s)

- Gauging level of support for the development of a TMA

- Identifying possible funding sources

These tasks are basic to a TMA's success because they deal with the "why" and "how" of the TMA's formation. Identifying specific, tangible problems and developing consensus on the problems are especially important during this stage of development. Many TMAs flounder during their first year because problems haven't been adequately defined to render solutions.

Formation begins after the initial exploration indicates the need for a TMA. This stage answers the question, "Now that we want a TMA, what will it look like and what will it do?", and proceeds to make that vision a reality. During this stage (lasting between I 2 and 18 months), the core group expands support, plans services and sets up the organizational structure.

TMAs in the formation stage usually focus on the following activities:

- Establishing a core membership and steering committee

- Obtaining initial funding commitments

- Establishing legal and organizational structure

- Initiating marketing and membership development

- Identifying and developing member services

- Generating awareness and interest among targeted markets

- Fostering public-private relationships

The operation stage includes two categories of activities:administration and service delivery. Administration refers to the ongoing efforts needed to maintain membership and funding, running the office and serving the board of directors. Service delivery refers to providing services to members and other selected markets. Operation is characterized by a maturation of the organization, development of stable, ongoing, private funding from membership sources, and a track record of service delivery. 
The primary activities of an operational TMA are:

- Developing and delivering member services

- Maintaining and expanding membership

- Maintaining office functions

- Monitoring and evaluating program and service progress

An important but often overlooked activity for operationalTMAs is monitoring and evaluating its effectiveness. Many TMAs monitor what they do, but few document how they are doing.This is important, as it provides information needed to refine services and sell service benefits to potential members.

The primary challenges of TMAs at this point are promoting member interest, promoting TMA services, documenting the TMA's effectiveness, maintaining stable, ongoing funding and maintaining and developing services. 



\section{The Possibilities TMA Exploration and Feasibility}

- Section Overview

- TMAs Offer Unique Capabilities

- Reasons for Incorporating the TMA

- TMA ExplorationConditions that Indicate TMA Feasibility

- Conducting a TMA Feasibility Study

- TMA FormationBuilding Commitment and Consensus for Solutions and Services 



\section{Section Overview}

\section{TMAs Offer Unique Capabilities}

Now that you have background information on the development of TMAs, it's time for the first stage of development-TMA exploration.

The exploration phase is designed to answer two fundamental questions. Is a TMA the ideal organizational approach for accomplishing your mission? Under what conditions is it feasible to create and sustain a TMA?

TMA development could more accurately be called the first stage of partnership development, because your investigation may suggest a group other than a TMA should be formed, at least initially.

It is important to know when the formal TMA structure is not suited to carrying out the solutions to transportation problems in your activity center. You might consider forming instead another type of organization that facilitates private sector cooperation. This could be an informal networking group or a transportation committee of a chamber of commerce or some other business association that enjoys widespread name recognition and respect. This could more effectively convey your TMA program of services to a new market, composed of the existing membership of the host organization. There may be programmatic and financial benefits to locating the TMA within an existing organization. These kinds of initiatives can evolve into an independent TMA. The nature of the transportation problem and the solutions that the TMA wants to implement may suggest a particular organizational structure and degree of formality.

During exploration, you identify conditions that are conducive and challenging to TMA development. If the study shows it is feasible to form a TMA now, you can develop a preliminary plan to begin building consensus among key stakeholders, and gain initial commitments to support the emerging TMA.The areas of exploration, conditions, feasibility studies, and early commitments are discussed below.

Is a TMA the ideal organizational approach for accomplishing your mission? This question cannot be answered without having first developed a strong sense of what must be done to address an issue or problem.

Understanding the problem and identifying solutions require gleaning interpretations of the problem and the solutions from different perspectives. From the government point of view, the problem may be traffic congestion and violations of air quality standards. From the private business point of view, there may be no concern whatsoever about traffic congestion but great concern regarding employee tardiness and the difficulty of recruiting entry-level employees. While both these private business concerns may have their roots in traffic congestion, the solution, from that business owner's point of view, must meet the needs of particular employees.

As a result, an understanding of the problem and an identification of potential solutions should come from not just the conduct of transportation studies (which will frame the problem and solutions in global terms), but also from interviews with area business owners and with representatives of local commerce or other groups that represent those affected by the problem, such as community groups, employees, residents and others.

By knowing what TMAs potentially have to offer, it is possible to determine if a TMA can play a role in addressing transportation issues. Generally, if the problems to be solved require unique organizational capabilities, custom tailored services for specific groups or consensus building activities, then the creation of a TMA may be the right choice. 


\section{Unique Organizational Capabilities}

\section{Custom Tailored Services That No Other Organization Provides}

\section{Information, Dialogue and Consensus Building Capabilities}

\section{Advocacy Capabilities}

\section{Mechanism for Regulatory Enforcement}

The membership and the board of directors represent a unique set of financial resources, professional skills, talent and influence that can be brought to bear on the problem. Organizationally,TMAs also combine the strengths of both the private and public sectors acting cooperatively to achieve specific objectives.

The membership has the power to act collectively. The membership represents a market needing particular services. That market is highly concentrated in a particular area. TMAs have the organizational capability to implement TDM strategies, based upon their unique membership characteristics.

If the nature of the transportation problem can be defined within a particular area, affecting a particular segment of people and requiring a collective effort to solve, then the TMA may be able to offer solutions.

TMAs have the capability of providing services that are custom tailored to their particular market, such as shuttles for office park employees or vanpools for second and third shift workers.

TMAs can save members money by pooling the efforts of employers, developers and other businesses in support of a transportation service.

TMAs are in a good position to monitor and communicate relevant current affairs. Businesses have a need for timely information on transportation issues that affect their businesses, presented in laymen's terms. The public sector also has a need to be sensitized to private sector concerns. TMAs can provide a bridge for understanding the private sector point of view.

TMAs are venues for bringing parties together to engage in dialogue. Where there is a need for collective action, TMAs provide a forum for consensus building.

In a regulatory environment, the private sector may need to exercise a collective voice on their behalf when interacting with a regulatory agency. The TMA can provide such advocacy.

The private sector may also desire advocacy on behalf of transportation improvements to their area. In particular,TMAs can be effective in advocating for Transportation Systems Management (TSM) strategies to improve traffic circulation and transportation service to an area. Examples of TSM improvements might be bus turnout bays, signal coordination, computer-based traffic control, reversible traffic lanes and intersection reconfiguring.

From the public sector point of view,TMAs are favored as a means to assist enforcement of trip reduction agreements. Where negotiated agreements between a city and a developer or landowner require the participation of future employer tenants in TDM programs, the city may view the TMA as a mechanism for monitoring and ensuring such participation.

TMAs have the knowledge to provide low-cost technical support to businesses, especially in a regulated environment. For example, trip reduction regulations placed upon employers generate the need for transportation studies, information and guidance for satisfying requirements. 


\section{Reasons for Incorporating the TMA}

\section{TMA}

Exploration-

Conditions that Indicate TMA

Feasibility

\author{
A Well-Defined \\ Problem
}

\section{Solutions and Sufficient Resources to Carry Them Out}

\section{Private and Public Sector Support}

Going the extra mile to formally incorporate as a legally recognized nonprofit organization has its benefits, if the funding and expertise to successfully maintain such an organization exist.

- A private nonprofit corporation has greater autonomy in defining and carrying out its mission than a committee within another organization.

- A stand-alone organization that functions well has the potential to enjoy greater visibility of its actions and legitimacy of its position on transportation issues. An informal network or a committee within some other organization that is not created with the primary function of addressing transportation may not have the same visibility or legitimacy.

- By formally incorporating, the members of the board are one step removed from personal liability.

- The nonprofit tax status may open doors for receiving funds that could not be obtained any other way. For example, it may be necessary to be a nonprofit corporation in order to apply for various grant funding opportunities. Corporations can give to recognized nonprofit organizations as a tax deductible expense.

Under what conditions is it feasible to create and sustain a TMA? The experiences of many groups in establishing TMAs suggest that certain elements are characteristic of success in TMA development. The primary elements are:

- A well-defined problem

- Solutions and sufficient resources to carry them out

- Private and public sector support

- Sufficient target market(s)

To enlist the support of people in a position to influence change in travel behavior, make sure there is a reason for their involvement. Does a transportation-related problem, especially one that is ongoing, exist in your area? Be sure to clearly identify the problem, e.g., lack of transportation options, poor access, congestion, air pollution, a regulation, growth management issues that impact individuals or businesses, access to labor or customers, and so on. Is the business community aware of the impact that the problem has on their businesses? It is also important that potential markets for services experience the problem. These potential markets could be some subset of employees, students, tourists, or any group of travelers that is involved with the identified problem.

Would a TMA in your area offer viable solutions to problems and have the financial and political ability to implement or influence others to implement those solutions? A TMA is not a strategy; it is only as effective as the programs made available through it.

Is there support from both the private and public sectors? Successful TMAs are generally initiated through the "pull" of the private sector, rather than the "push" of the public sector. To enlist support, you must offer fairly priced products and services that fulfill the needs of customers and appeal to the self-interest of markets in your service area. 


\section{Sufficient Target Market(s)}

\section{Existing Legal or Regulatory Transportation Requirements}

\section{Conducting$$
\text { a TMA }
$$$$
\text { Feasibility }
$$$$
\text { Study }
$$

Most successfulTMAs begin with a private sector "champion" who believes in the need for a TMA and who can exert positive peer pressure to expand its membership. Not only is a champion important, but also an initial committee or board who works together to get the TMA started. The champion cannot do all the work alone.

Next, is there one or more markets - a customer population large enough and located in sufficient density within your service area that needs and can adequately support a particular program provided by your TMA? Also, is there an adequate member base? For example, customers might be employees who want to use a ride matching service. The member base might be employers that identify with the activity center and are willing to financially support the TMA.

While not essential, conditions are often favorable to TMA development where legal or regulatory requirements exist.Are employers and/or developers in the service area required to implement work site TDM programs? For example, these requirements could be made through local trip reduction ordinances, parking ordinances, and negotiated development orders. If so, the requirements can offer additional opportunities and broaden the market for membership.

Effective TMAs can offer substantial benefits to members, area commuters, other defined markets and the public sector; ineffective TMAs can do more harm than good.An unfortunate consequence of ineffective TMAs is that Transportation Demand Management, Transportation Systems Management and other strategies, as well as the power of public-private partnerships, could lose credibility in the eyes of the business community or public. This could make it more difficult to implement future programs and lessen the possibility of cooperative transportation activities.

Some early TMAs fell into traps that led to their dissolution or ineffectiveness. Some were formed before the private sector embraced its role in both the problem and the solution. Others folded because real and immediate problems were not clearly defined and/or feasible solutions not identified, or they lacked a solid consensus and support of the board and membership.

If stakeholders cannot agree on the nature and extent of the problem, it will be hard to agree on solution strategies. TMAs have been formed and dissolved after several years with stakeholders still wondering what the problems were or who was supposed to benefit from a solution.

Groups considering forming TMAs can save the frustration of a failed attempt if they thoroughly and honestly examine their situations and build an early consensus on what they can, and want to accomplish. These steps are the focus of a TMA feasibility study.

The feasibility study should identify the existing conditions under which a TMA would be formed, assess the applicability of the TMA concept to local conditions, and perform some preliminary organizational, service, and financial planning. With this information, proponents of the TMA will more successfully enlist the commitment of potential members and build early consensus for solutions.

There is no single approach for preparing a study, but the questions posed here should be answered and a consensus on the problems and solutions should be developed.As a guide, the following elements of a feasibility study are suggested. The Appendix also contains an example of a feasibility study format. 


\section{Typical Components of a TMA Feasibility Study}

To conduct a thorough feasibility study, form a TMA steering committee for the following activities:

- Collect and analyze preliminary data on area development conditions and transportation problems from the local transportation planning department, as well as the problems perceived by those who experience transportation problems, such as employees, employers, business leaders and other groups.

- Clearly define transportation-related problems that the business community could participate in solving.

- Identify a core group of key businesses and public agencies with the greatest probability of involvement.

- Educate other business leaders about the problems and begin to build a broad consensus for solutions.

- Investigate services and products a TMA could provide which are not currently being provided or not being provided cost effectively.

- Develop a preliminary work plan of TMA services, activities and benefits.

- Develop a preliminary financial plan, i.e., funding sources, budget and cash flow projections.

- Develop preliminary private sector funding for operations.

- Develop a preliminary plan for monitoring and evaluation.

Answering the following questions will provide a more complete picture of the feasibility of TMA formation.

\section{What are the existing conditions in the area?}

Document the following conditions for the proposed service area:

- Travel patterns that are characterized by problems, the groups of travelers that experience those problems, and the time of day the problems exist.

- Trip-reduction ordinances or other regulations affecting employers in the area

- Local and regional traffic and growth patterns

- Public and private parking conditions

- Existing transportation services and facilities available within your service area

\section{What is the proposed TMA service area?}

It is important to define the geographic scope of the proposedTMA.This helps public funding agencies and service providers gauge the relationship of the TMA to other businesses. Typically, a TMA service area is an activity center that features a concentrated population of employees and businesses. Less typically, if your TMA is to be trip origin-based, the service area might include densely developed residential areas.

Defining the geographic scope requires some professional judgment on your part to study the locations and proximity of activity centers relative to each other. Businesses contained within the service area boundaries should feel as though they can identify with being a member of the activity center due to sharing common problems or unique locational characteristics.

Including businesses that do not identify themselves as part of an activity center will not 


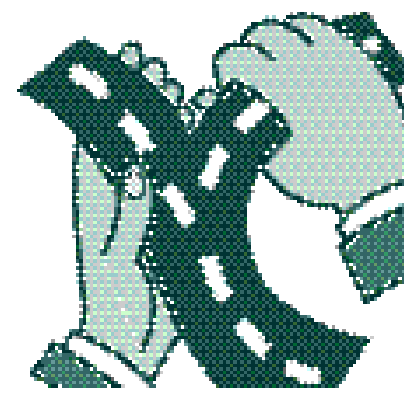

result in their participation in the TMA because they may neither suffer from a traffic-related problem nor share an interest in the solutions for which the TMA will require their support in implementing. The service area should be focused enough so that everyone agrees on the problem definition, but large enough to include everyone with a stake in the solution.

\section{What transportation-related problems do people in the area experience?}

It is important to understand the nature, urgency, and specificity of the transportation problem(s), perceived by prospective members, to gain their initial and ongoing support as well as to identify solutions. The problem(s) should be defined in exact terms. For example, "Second and third shift hospital and service employees of companies located along ABC Boulevard have no transportation alternatives if they do not own private automobiles," or "Twenty percent of retail merchants located at XYZ Shopping Mall say they cannot recruit entry level employees because public transit does not serve the Mall.” Do not use general terms, such as "lack of mobility."

\section{Which of these problems can the TMA address and in what ways?}

How would the local situation have to change before the business community would consider the problems solved or at least controlled? Then, how could the change happen and what is the business role in such solutions? A TMA will not be able to solve all transportation problems alone, but by working with other local public agencies, it may be able to address some of them.

\section{What TDM, TSM and other strategies should be implemented?}

Identify the alternative strategies a TMA could use to address the problems. If possible, quantify the impact that each strategy would have in alleviating the problem.Also, if possible, prioritize the strategies based on effectiveness and cost. Some TMAs provide a "laundry list" of services and build unrealistic expectations that they cannot deliver.

\section{How much would the business community be willing to pay?}

The TMA must be able to support both day-to-day operations and delivery of services. Obtain funding commitments from the business community and from other sources. It is important to document direct funding such as member dues and grants, the value of loaned staff, and in-kind services and materials. Also, draft a game plan for long-term funding support, beyond the formation phase.

\section{Is a TMA the most appropriate response or organization?}

If answers to the previous questions seem unrealistic, consider alternative options-such as a new or strengthened Employee Transportation Coordinator network - that might respond to the problems in a less formal way. Develop pros and cons of each option and choose the best course. If TMA formation is warranted, begin to develop the following elements that are described later in this Handbook:

- Description of the specific organizational structure

- Strategic work plan

- Schedule for implementing services and mobility improvement strategies

- Financial plan and cash flow projection

- Evaluation and monitoring plan

While the feasibility study can provide a solid foundation for gaining commitments from 


\section{TMA}

\section{Formation- \\ Building \\ Commitment \\ and Consensus \\ for Solutions \\ and Services}

\author{
Establish a Core \\ Membership \\ and Steering \\ Committee
}

\section{Obtain Initial Funding Commitments}

TMA proponents and prospective members, once a decision has been made to proceed with forming the TMA, seven main activities will guide the process:

- Establish a core membership and steering committee.

- Obtain initial funding commitments.

- Establish legal and organizational structures.

- Initiate marketing and membership development.

- Identify and develop member services.

- Generate awareness and interest among targeted markets.

- Foster public-private relationships.

The early "buy-in" of a core group is crucial to assure the formation process stays on track and that commitments and consensus are solidified. Prior to beginning the formation tasks, establish a steering committee to guide the TMA's development. This steering committee might be assembled from a core group of members from businesses and the sponsoring organization (if there is one) that oversees or conducts the feasibility study.

Alternatively, a newly recruited core of TMA members could be assembled to guide the formation process. The need for this core group should not be underestimated, since staff rarely has been hired at this point, and any consultant used for a feasibility study or initial planning may be finished with its work. Even if staff has been hired, be cautious about delegating responsibility to new staff or a consultant.

Develop your core private membership base and public sector support so it gives a financial base to support activities during the first two to three years. Examine various possibilities for membership dues, service fees and public sector grants.

If the public sector is not an active participant or funder of the feasibility study, the steering committee might approach the appropriate state, regional and local agencies for support.

Research the availability of public sector grants very early in the exploration stage. Some states offer formation grant funding, and some local agencies provide funding for formation or initial service delivery. Many regions can designate state and federal funds for any use to meet the region's mobility demands.

Political support is also necessary to assure the TMA has "clout" in the area's policy-making arenas. Consider offering "ex officio" or full memberships to any key public agencies in the TMA. Some TMAs invite staff of key elected officials to serve on the board, while others maintain close contacts through their executive directors. Obtaining political support can assist your efforts to secure discretionary funding.

Section 5, under "TMA Budgets and Funding," provides a discussion of the elements of a budget and the various sources of funding available to a TMA. Section 5, under "Financial Management Issues ofTMAs," provides example statements of functional expenses, balance sheets, and cash flow statements. 


\section{Establish Legal and Organizational Structure}

\section{Initiate \\ Marketing and Membership Development}

There are a number of options for the organizational structure of a TMA. If the mission to be accomplished does not require the organizational formality of a private, nonprofit organization, the steering committee may elect to organize an ad hoc group or create a committee within another established organization, such as a chamber of commerce. If the steering committee decides to legally incorporate, there will be decisions to make regarding the type of $50 \mathrm{l}$ (c) status that will best serve the mission of the organization.

If formal incorporation is desired, then articles of incorporation and bylaws must be drawn up. A board of directors must be established for which a statement of duties should be devised.

Office procedures should also be developed. Examples of articles of incorporation, bylaws, and office procedures are included in the Appendix.

The roles and responsibilities of the board of directors and staff must be clearly delineated. These determinations provide the guidance for the bylaws, the office procedures and the job descriptions of a new staff. Typically, a TMA has at least a full-time executive director or manager and a full-time or part-time administrative assistant. An advertising and hiring process must be undertaken to establish the staff.TMAs also often have standing committees and volunteer assistance, for which written guidance on duties and work expectations are helpful.The Appendix also contains job descriptions and duty statements for paid staff, committees and volunteers.

The steering committee will also have to establish an office and set up an accounting system.

These tasks are discussed in detail throughout the remainder of this Handbook, but especially at the beginning of Section 3, under "Defining an Organizational Structure," "Articles of Incorporation and Bylaws," and "Establishing an Administrative Structure."

Section 3 also includes an activity for helping define the roles and responsibilities of the board of directors and staff, for which an "answer" key is included in the Appendix.

Setting up an accounting system is discussed in detail in Section 5, under "Financial Management Issues for TMAs."

Initial marketing activities of a TMA focus upon understanding the needs and the nature of the potential membership and its customers, such as employers, commuters and other groups. Prior to TMA formation, the earlier feasibility study has provided enough information to identify the existence of one or more problems that a TMA can address.

Now, the new TMA should verify and refine its understanding of the problems through market research focused upon identified selected markets. This data collection, or background scan of existing conditions often includes surveys, such as focus groups, mail or telephone surveys and personal interviews. It also constitutes the baseline conditions against which progress can be measured, after the implementation of member services. This is a good point in time for staff to have been hired to guide the conduct of this stage in the formation process of the TMA. These activities are discussed in detail in Section 4, under "Initial Work Plan Development Considerations-Data Collection."

With the assistance of the board, staff will also concentrate attention upon recruiting members. This involves communicating benefits and services that the TMA has to offer to those who potentially can provide funding and other resources to the TMA in return. Membership development includes knowing potential members' concerns and needs, translating those 


\section{Identify and Develop Member Services}

\section{Generate Awareness and Interest Among Targeted Markets}

\section{Foster Public- Private Relationships}

concerns and needs into services and solutions, and promoting those services and solutions to a carefully developed list of potential members. These activities are discussed in detail in Section 3 under "Developing and Building TMA Membership."

The identification and development of member services starts with defining the TMA's mission and establishing goals for the organization. Member services goals might include assisting members with solving site-specific transportation problems, providing transportation services or helping members comply with mandated travel-reduction requirements through a transportation management program. A determination of how the goals will be accomplished is made by drafting one or more objectives for each goal and selecting measures of performance for each objective. The staff is now ready to devise a work plan after objectives and performance measures are established.

The work plan details the actual activities that will take place over a specified period of time, usually a year, to accomplish the objectives. These activities include specific member services such as providing transportation services, providing information, advocacy and consulting. The work plan includes the assignment of responsibilities and a timeline for accomplishing the tasks. A detailed discussion about identifying and developing member services is found in Section 4, under "Developing a Strategic Work Plan" and in Section 5 under "Delivering TMA Services."

Generating awareness among potential members and customers requires an advertising strategy to reach the identified market and persuade them to "buy" the TMA's services. Service advertising might include devising an initial information campaign, offering introductory incentives and hosting promotional events.

Information on how to develop promotional materials is found in Section 3, under "Developing and Building TMA Membership." A discussion about service advertising is found in Section 5, under "Delivering TMA Services."

The development of sound public-private working relationships is crucial to the TMA's ability to execute its mission, and must be accomplished internally as part of the effective functioning of the board of directors, and externally in the formation of alliances with organizations and agencies.

Staff can set the stage for the development of these working relationships by highlighting the commonalities of interests and concerns among the private and public sector representatives brought to the TMA table. Section 3 contains a discussion, "Creating an Effective Board of Directors," which provides useful information for fostering a successful team. Section 3 also contains a discussion, "Establishing External Relationships," which concerns developing partnerships among other groups, potentially benefitting the TMA. 



\section{TMA Develop- ment-Building Relationships and Alliances}

- Section Overview

- Defining an Organizational Structure

- Articles of Incorporation and Bylaws

- Establishing an Administrative Structure

- Creating an Effective Board of Directors

- Developing and Building TMA Membership

- Establishing External Relationships 



\section{Section Overview}

\section{Defining an Organizational Structure}

This section concerns building the human "infrastructure" needed to support a TMA.This includes finding the right people and setting up the organizational policies and procedures that enable people to work successfully together. People participate in a TMA in a number of ways - staff, members, board members, and those cooperating through allied organizations.

In the early months of a new TMA, a primary objective of the core members and initial staff will be establishing a sound organizational structure and membership base.TMA formation does not occur overnight. You may be anxious to begin the "real work," but allow adequate time to accomplish these necessary formative tasks. Remember to recognize and accommodate what these tasks will demand from the TMA staff. As participants develop sound working relationships, more time can be devoted to service implementation.

For mature TMAs, there is the recognition that membership development, board recruitment, organizational networking and the recruitment and professional development ofTMA staff are all continual efforts.

A primary characteristic that distinguishes TMAs from other transportation partnerships is their organizational formality. TMAs have a structured governance, an organized membership, and many have a recognized legal status.

TMAs may evolve from an ad hoc public-private transportation effort, but one of the earliest tasks of forming a TMA is the creation of a formal infrastructure.

Some TMAs are part of another, multi-purpose organization-generally a chamber of commerce or other business group. Such TMAs do not typically have an independent corporate status. Others are independent partnerships with an independent corporate status. Both options have advantages that should be considered.

Developing a TMA within an existing organization might be appropriate if the membership desires and has the ability to assume transportation management activities. The benefit of developing a TMA within an existing organization is that many elements are already established, including the decision-making structure, existing membership base, budgets and financial controls and working relationships with other organizations. In addition, the TMA can often be housed in and use the services of the parent organization.

Existing groups that could be a candidate "host" or "parent" include private business associations, such as chambers of commerce and developer or business park associations. This option may present potential problems; however, because the parent organization's roles and relationships might conflict with the TMA's mission, constrict its efforts and activities, or detract from members' goals.

If a new organization is formed, the TMA may have a more refined mission, committed membership, and dedicated staff. The downside, however, is that the activities of forming the new organization will absorb time and resources that could be devoted to problem solving and service development.

If the TMA will be part of an existing organization, then its legal status will be pre-defined. If you are choosing a legal status for an independent TMA, explore all options and select wisely, because the legal status can be difficult to change later.

The IRS code covering nonprofit corporations designates three types of organizations that could apply: $50 \mathrm{I}(\mathrm{c})(3), 50 \mathrm{I}(\mathrm{c})(4)$, and $50 \mathrm{I}(\mathrm{c})(6)$.

Certain nonprofit designations prohibit a TMA from undertaking lobbying activities and soliciting non-taxable contributions. Organizations with $50 \mathrm{I}$ (c)(3) status can accept tax- 


\section{Characteristics of 50 I(c) Organizations}

\begin{tabular}{|c|c|c|c|}
\hline & $50 I$ (c) (3) & $50 I$ (c) (4) & $50 I$ (c) (6) \\
\hline $\begin{array}{l}\text { Type of } \\
\text { Organization }\end{array}$ & $\begin{array}{l}\text { Corporation, community chest, } \\
\text { fund, or foundation }\end{array}$ & $\begin{array}{l}\text { Civic league or social welfare } \\
\text { organization }\end{array}$ & $\begin{array}{l}\text { Business league, association, } \\
\text { etc. }\end{array}$ \\
\hline Profit / nonprofit & Nonprofit & Nonprofit & Nonprofit \\
\hline $\begin{array}{l}\text { Membership } \\
\text { status }\end{array}$ & No & Yes, public & Yes, private \\
\hline & & $\begin{array}{l}\text { May be deductible as a trade } \\
\text { or business expense }\end{array}$ & $\begin{array}{l}\text { May be deductible as a trade } \\
\text { or business expense }\end{array}$ \\
\hline \multirow[t]{2}{*}{ Fundraising } & $\begin{array}{l}\text { If the donor receives goods, } \\
\text { services, or other benefits of value } \\
\text { in return for a donation, the cost } \\
\text { is not tax-deductible }\end{array}$ & & $\begin{array}{l}\text { Primarily supported by member- } \\
\text { ship dues }\end{array}$ \\
\hline & $\begin{array}{l}\text { May establish separate fund for } \\
\text { donations }\end{array}$ & & $\begin{array}{l}\text { Other income from activities } \\
\text { related to exempt purpose }\end{array}$ \\
\hline \multirow[t]{2}{*}{ Political activity } & $\begin{array}{l}\text { Not allowed to lobby or participate } \\
\text { in political activity / campaigns }\end{array}$ & $\begin{array}{l}\text { May be allowed to participate in } \\
\text { some political activities (lobby) }\end{array}$ & May lobby to influence legislation \\
\hline & $\begin{array}{l}\text { May be allowed to conduct certain } \\
\text { voter education activities or public } \\
\text { forums }\end{array}$ & $\begin{array}{l}\text { Not allowed to participate in } \\
\text { political campaigns }\end{array}$ & $\begin{array}{l}\text { May contribute to political } \\
\text { campaign in favor of, or } \\
\text { opposed to, any candidate }\end{array}$ \\
\hline \multirow{5}{*}{$\begin{array}{l}\text { Indirect lobbying } \\
\text { efforts (allowed) }\end{array}$} & No more than $5 \%$ of expenditures & & \\
\hline & Make available study/research results & & \\
\hline & Provide technical assistance & & \\
\hline & $\begin{array}{l}\text { Communicate with non-legislative } \\
\text { officials }\end{array}$ & & \\
\hline & $\begin{array}{l}\text { Appear before legislature when } \\
\text { pending decision affects existence of } \\
\text { organization }\end{array}$ & & \\
\hline \multirow[t]{4}{*}{ Other } & $\begin{array}{l}\text { Must conform to Articles of } \\
\text { Organization (IRS 557) }\end{array}$ & & \multirow{4}{*}{$\begin{array}{l}\text { Required to notify members of } \\
\text { the amount of their dues that is } \\
\text { non-deductible because of } \\
\text { lobbying expenditures, or pay a } \\
35 \% \text { proxy tax }\end{array}$} \\
\hline & $\begin{array}{l}\text { Assets must be permanently dedicated } \\
\text { to exempt purpose }\end{array}$ & & \\
\hline & $\begin{array}{l}\text { A state or municipal organization may } \\
\text { qualify if it is organized as a separate } \\
\text { entity from the government unit that } \\
\text { created it }\end{array}$ & & \\
\hline & $\begin{array}{l}\text { If the organization possesses } \\
\text { governmental powers, it does not } \\
\text { qualify }\end{array}$ & & \\
\hline
\end{tabular}




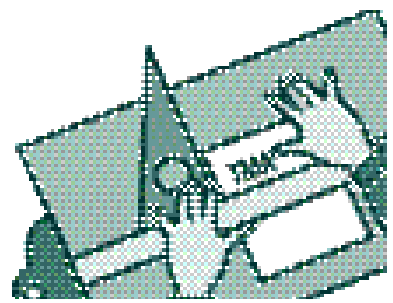

\section{Articles of Incorporation and Bylaws}

deductible contributions from members and non-members, but are expected to provide services to the general public. This status may encourage the participation of groups and individuals who cannot deduct business expenses, but the status is not easy to obtain and commute management efforts must serve all commuters who wish to utilize the TMA's services. Lobbying efforts are also strictly limited with a charitable status. The I998 ACT Survey found that 48 percent of all respondents identified themselves as $50 \mathrm{I}$ (c)(3) organizations.

Other nonprofit corporate statuses for TMAs include the 50I(c)(4) civic organization, (23 percent of the TMAs responding) or $50 \mathrm{I}$ (c)(6), business league ( $21 \%$ percent of TMAs responding).These types of organizations serve only members, and dues are considered a business expense. Chambers of commerce are generally designated as $50 \mathrm{I}$ (c)(6).

The appropriate status will likely depend on the decision whether to serve only member employees or the general commuting population. Most TMAs focus on business members. These members' contributions to the TMA are deductible as business expenses on corporate income taxes.

Therefore, the decision of whom to serve will likely outweigh the consideration of charitable donations by business members. For more information on non-profit statuses, consult the federal government publication, IRS No. 557, referenced in the Appendix. Similar information for your state may be available through your state tax office.

If a TMA chooses to incorporate, then articles of incorporation are drafted. This document is brief and is the chief organizing document to which all others must conform. It must be filed with your state Department of Corporations and generally contains the official name of the TMA, the purpose of the TMA, a clause stating what happens to assets if the TMA dissolves, the address of the principal office and the names and addresses of the board of directors. Any changes to information in the articles of incorporation must be filed with the Department of Corporations.

The bylaws are subordinate to the articles of incorporation, but they are the primary governing document of most TMAs because they contain the operational detail.They define the rules and procedures under which the TMA, its officers, and members will operate. Bylaws describe who will govern the TMA (board of directors, officers, and committees), their duties, terms, powers, how they are to be selected, and when elections are to be held.

Bylaws may also define categories of membership, dues and other fees assessed on each category, and rights and powers of members. Other bylaw elements may include: financial procedural requirements (such as recordkeeping procedures and annual audits), staff posi-

\section{Organizational Development Tips}

- Seek professional legal advice on the appropriate organizational structure and legal status, and consult with the IRS for clarifications on non-profit status.

- Assess short and long term advantages and disadvantages of independent status versus associating with an existing organization.

- Keep decision-makers apprised of activities and progress.

- Encourage members to choose a respected upper-level decision maker within their organization as the TMA representative. 


\section{Establishing an} Administrative Structure

\section{Executive Director or Manager}

tions authorized by the TMA, procedures for calling and conducting regular and special meetings of the board and/or membership, the identification of standing committees and the procedures for amending the bylaws. Examples of articles of incorporation and bylaws are provided in the Appendix.

Sometimes a TMA will also draft standing rules. Standing rules are subordinate to the articles of incorporation and bylaws, and outline procedures for how committees will conduct business, achieve resolutions, document attendance and other procedures. They are adopted by a vote of the board, documented in the minutes and stand until rescinded.

The keeping of meeting minutes is a necessary part of operating a $50 \mathrm{l}$ (c) organization. Minutes record attendance and state whether a quorum exists.A quorum must be reached in order for the board to conduct official business. The minutes record motions made, accepted and voted upon. Minutes also record elections and votes on bylaw and standing rule changes. Minutes contain a brief summary of standing and ad hoc committee reports.

Forming and operating a TMA is labor-intensive and requires personal attention to members and their constituencies. Therefore, the staff is the center of the organization and must be carefully selected.

The TMA staff is generally headed by an executive director or manager who is responsible for overseeing and conducting daily activities. In many start-up TMAs, the executive director is the only staff member and wears many hats. Duties of a director may include:

- Maintaining daily office functions

- Preparing a business plan (service plan, marketing plan, and financial plan)

- Securing funding agreements

- Soliciting new members

- Monitoring transportation policy and program initiatives

- Providing support to member companies' transportation coordinators

- Designing, producing, and distributing marketing materials

- Coordinating surveys

- Helping employers develop and implement work site TDM programs

- Monitoring the TMA's progress against the business plan

- Coordinating and supporting the board of directors and committees

- Attending meetings of key public and private task forces and organizations

- Interacting and fielding inquiries from other TMAs and organizations

Because the director position demands a broad set of skills, most directors bring a variety of work and educational backgrounds to their positions, including transportation, marketing, public relations, public service, planning, sales, nonprofit management, finance and others. 


\section{Paid Staff}

Volunteer and Contract Staff
Many TMAs employ at least one full-time staff member in addition to the director. In most cases this is an assistant, but some also employ rideshare or transportation coordinators, marketing and membership coordinators, and project managers who work on a full or part-time basis. Sometimes administrative staff is contracted, borrowed from a member or public agency, or hired from a temporary employment service. TMAs that are housed within another organization may share administrative staff on an informal basis.

A strong network of volunteer staff who might be employees of member companies or interns from nearby universities, can greatly assist in the day-to-day activities. Public agency staff may also volunteer time on a project basis or as staff advisors.

Establishing an office and day-to-day management procedures are important tasks. If the TMA will be part of another organization these tasks will probably be unnecessary. To set up the office:

- Arrange for office space, telephone service, and other utilities.

- Obtain furniture (purchased, leased, or donated in-kind).

- Acquire a copier, fax, computers, printers, modems, and other equipment and software, including training if necessary.

- Select property and liability insurance.

- Purchase start-up office supplies.

To establish internal office management systems and policies:

- Establish an employer information database.

- Set-up a filing system.

- Arrange for an accounting system or utilize bookkeeping or accounting services.

- Develop staff policies and procedures (sick leave and vacation policies, staff evaluation schedule).

It is not necessary to postpone all other TMA formation tasks until your office and procedures are completely in order. Even though it may take time to set up your office, choose equipment that will best meet your long-term needs. Perhaps the first investment is a computer and appropriate software.

If you do not have expertise in computers, office equipment, insurance, accounting systems and staff policies, ask for guidance from a member or professional. Members can also be sources of in-kind donations for much of the office supplies and equipment, including furniture, computers, telephones, and office supplies.

\section{Office Set-Up Tips}

- Recognize that office start-up is an important task and will absorb time, especially during the first few months.

- Explore opportunities for in-kind donations of equipment, furniture, and supplies from members.

- Ask for advice on insurance, computer equipment, and other office needs that require special knowledge or expertise. 


\section{Employee Transportation Coordinators}

A common strategy of many TMAs is the formal development of a network of Employee Transportation Coordinators (ETC) or liaisons who promote the services of the TMA.Traditionally, an employee is appointed by a company to serve as an ETC to develop, implement, or administer an employee transportation program. Sometimes this person's job includes ETC duties, while others are considered to be volunteers. Duties might include registering employees for a guaranteed ride home program, coordinating the formation of ridesharing arrangements, promoting the use of public transit, and tracking employee participation in an employee transportation program.

The advantage of having ETCs is that they are positioned to successfully do all the promotional work within the company that they know so well. If they are committed to achieving the goals of the TMA, enthusiastic and articulate communicators, and believe in the value of the service they are promoting, they can successfully sell services to fellow employees, to a degree far beyond what the TMA staff would ever have time or influence to do. A good ETC can use to full advantage one of the best promotional tools - word of mouth positive testimonials from satisfied customers within a peer group.

There are a few considerations regarding ETC networks. Ideally, the network would consist of an "army" of knowledgeable and enthusiastic promoters of services. In reality, finding such persons is not that easy. Persons who have been appointed or "volunteered" to serve as ETCs within their companies may not have their hearts in it. If they represent services to a large organization, their lack of interest may do more harm than good. If possible, suggest to the CEO or top manager that it would be best to have volunteers or identify persons who might truly enjoy promoting the service. For example, such a person might work in some department other than human resources but have a strong leaning toward environmental interests. He or she might already be commuting to work by bicycle and become a star promoter of a guaranteed ride home program (especially if bicyclists are eligible to use the service). Such a person would also be easiest to train regarding details of the service.

Networks of ETCs take considerable time to develop and maintain. ETCs need ongoing training and education regarding the TMA's underlying goals, the details of services and how to promote them successfully. ETCs must be kept supplied with all the materials they need.You or your staff need to be available to answer questions and troubleshoot problems that arise. Employee turnover makes it a challenge to keep a good ETC, requiring continual development of the network.

Depending upon the target market and type of service offered, the development of an ETC network might nevertheless be worth the effort, especially if the market consists of large employment sites. ETCs can disseminate information by:

- Distributing flyers and brochures to all employees.

- Posting colorful notices on company bulletin boards, in lobbies of area buildings, cafeterias, and other public locations.

- Publishing articles in company newsletters.

- Sending notices via e-mail and other in-house message systems.

- Making announcements at staff meetings and other company gatherings. 


\section{Staffing Tips}

- Carefully recruit and hire staff with expertise in both transportation management and organization development.

- Clearly delineate staff responsibilities and board member responsibilities, and give staff the authority to carry out their responsibilities.

- Supplement paid staff with in-kind staff support from members, public agencies, and other volunteers.

- Utilize committees to augment board and staff resources.

\section{Creating an Effective Board of Directors}

\section{Roles and Responsibilities of Board and Staff}

The typical TMA is governed by a board of directors. TMA boards can range in size from four to 20 board members. Officers (chair or president, vice chair, secretary, and treasurer) may be elected by the membership or board. Boards are generally required to meet at least once per year, but in order to accomplish business, boards may need to meet either quarterly or monthly. A rule of thumb for board meetings is to only convene them when an action of the board is required or if discussion of complex issues is needed for decision making purposes. Principles of effective meetings are discussed later in this section.

Most TMA boards are representative of the membership, including key stakeholders, such as large and small employers. Some boards include local government representatives, but most often local government representatives serve as ex-officio (non-voting) members. The general responsibilities of the board are defined in the bylaws but may be further defined by the board and staff.

Effective TMA programs require active board involvement to establish direction for the TMA and support its growth and development. They also must be able to set aside individual agendas to work with other members for the benefit of all. Board members should be knowledgeable or willing to learn about current TMA issues and activities. New board members should understand that their role demands a commitment of time, interest, and support.

The board is supported by a staff, including an executive director (or manager) and one or more paid or volunteer staff members. Staff supports the board by managing the TMA, implementing policies adopted by the board, developing services that foster its goals, and guiding its day-to-day operation in an effective, responsible manner.

It is instructive to compare and draw a distinction between the roles and responsibilities of board members and that of staff.

Major board roles include the following:

- Visionaries-Shaping the mission of the organization for the benefit of members

- Governors-Ensuring sound management

- Sponsors-Supporting the TMA's development, both financially and through their encouragement of other members

- Ambassadors-Carrying the message to others

- Advisors-Providing information, guidance, and expertise

- Boosters-Actively participating in membership development 


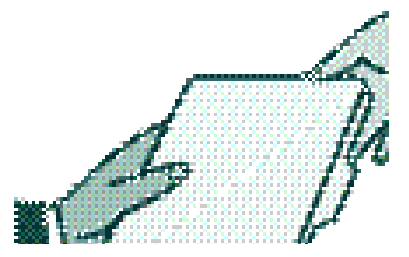

\section{"Our Board Does Too Much"}

Traditional staff roles include:

- Service Developer-Translating goals and objectives into an action plan of service delivery

- Program Implementor-Implementing the action plan

- Financial Manager-Preparing, implementing, and monitoring the financial plan

- Business Manager-Overseeing daily operation of the TMA and its staff

- Marketing Director-Preparing and implementing a plan of increasing awareness, promoting a positive image and promoting membership growth in the TMA

- TMA Representative-Representing the TMA's positions and its members to public agencies, other private groups, and to the community

- Communications Director-Managing the information flow for effective internal and external communication

With the exception of establishing the TMA's mission, goals and policies, the board may delegate other roles to staff. However, task completion requires time and resources. Staff will continuously be frustrated if given directives to "just make it happen," without being given the financial resources and political or legal authority to speak for the TMA.

The key to delegation is to select competent staff and identify the tasks for which they are responsible. In defining the division of responsibility, the board should ask:

- In what stage of development is the TMA?

- How much time do board members realistically have to devote to TMA matters?

- How much control is the board willing to relinquish?

- What staff resources are available?

- How experienced is the staff?

The division of responsibilities between the board and staff depends on the unique characteristics of the TMA: size, expertise and capabilities of staff; staff and board time commitments; individual board members' commitment to the organization; and individual management styles of board and staff members.

Some TMA directors complain when the board strays from its policymaking role and becomes involved in day-to-day operations, such as expecting to review and approve program designs and materials, preparing budgets, and handling staff complaints.

In this case, the board may be composed of the same people who founded the TMA. By virtue of their current and past involvement, they have proven their commitment and gained intimate knowledge of operations. Some of these individuals may have even run the organization while the TMA director was being recruited.

This situation could be improved if the roles and responsibilities of the board and its director are established and well understood. This role definition is best accomplished concurrent with the selection process of the director. This can help determine the type of individual for whom the Board is searching.

The hiring of a full-time director is a key turning point for the TMA. He or she becomes the TMA's expert in all areas of transportation, operations, administration, finance, and personnel. Once the director is hired, the board should begin to transition its focus from day-to-day operations to setting policy. 


\section{"Our Board Never Does Anything"}

For other directors, the board seems ineffectual in leading the organization. It explicitly or implicitly rests all authority with the director. This creates the opportunity for abuse and can foster future problems if the director oversteps his or her bounds of authority in the minds of the board.

Common mistakes made by directors that foster leadership voids include holding meetings when no board action is required, swamping the board with reams of confusing information, and not clearly explaining the actions being requested by the board. At the same time, the director must respect the roles of the board and not seek to co-opt them to expedite a decision. Such actions can alienate the same individuals who helped pull the TMA together in the first place, or cause some board members to quit because they feel they have not made a contribution. Once again these problems could be avoided if the roles of the director and the board are well-defined.

The policy role of the board and the operational role of the staff can be illustrated by the following examples. The board is responsible for fashioning the TMA's strategic plan, but the director makes recommendations and implements the plan once it has been adopted. The director writes the grant proposal but must seek prior board approval to submit the grant. The board approves the budget, formulates policies for financial management and internal control systems, and hires legal counsel and the auditor. The director drafts the budget, assures adherence to financial management policies and systems, and obtains bids for legal and auditing services.

The major board responsibilities include hiring the director, developing a strategic plan that reflects the TMA's mission, monitoring and evaluating the performance of the organization, the director and the finances, and serving as a goodwill ambassador for the TMA.A board member must pay particular attention to financial management processes, financial statements, audit findings, and minutes to fully understand the issues before making decisions.

An effective way for viewing the management and operation of the TMA from a board perspective is to treat the director as the sole employee of the board of directors. The responsibility for hiring, training, managing, evaluating, and disciplining other employees rests solely with the director. Usurping the director's responsibilities will only serve to set a precedent that breeds distrust, diminishes accountability, and wastes a board's best resource-the director.

\section{Guiding Principles for Board-Only Decisions}

Suggested principles for the board might include:

- The board shall govern, not manage.

- The board shall act on all items required by law or regulation.

- Unless requested by the director, the board shall restrict its policies to those that affect the whole organization.

- The board shall maintain the financial integrity of the TMA. 


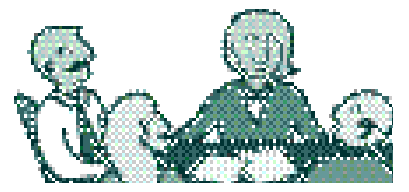

One useful method for clarifying the roles and responsibilities of the board and the director would begin by listing general types of decisions and collectively deciding which party has the decision making authority, which items require prior approval and which decisions made by the director require notice after the fact.

The exercise below' provides a good starting point for discussion between staff and the board regarding appropriate division of responsibilities and communications style. The effective functioning of a TMA, like any non-profit corporation, depends upon an explicit understanding between board and staff regarding the role that each plays. This activity helps define the style of communication that works best for each organization.

Provide a copy of this exercise to each board member to fill out. Independently, have individual staff members fill out the same form. Staff and board members may also want to add some additional scenario items that reflect circumstances that the TMA has already or will have to deal with. Later, compare answers to see where agreement and disagreement exist. The goal is to discuss the areas where there is disagreement and come to some resolution regarding the policy of the TMA for handling similar circumstances.

It will be clear that some of the items, especially in cases of articulating policy, are clearly the responsibility of the board. If staff were to usurp the role of the board in policy setting, the TMA would no longer be benefiting from the expertise of the board members, and there would no longer be a reason for the board members to participate.

Other items, such as procedural matters, are clearly the responsibility of staff. If the board were to usurp the appropriate role of the staff, this would result in micromanagement, an inefficient use of board members' time, and undermining of trust between staff and the board.

Other items represent gray areas where there must be adequate reporting and communication. The Appendix contains a key of recommended answers to this exercise that appies equally well to most non-profit organizations. While these are recommended answers, they are not necessarily the "right" answers that suitably describe an effective working style of a board and staff. It is okay if the board and staff come up with different answers, as long as the board and staff understand and agree.

I The exercise was adapted from the 1993 Board Member Manual,Aspen Publishers, Frederick, Maryland, Pp. $31-32$. 


\section{Defining Responsibilities of Board and Staff \\ ACTIVITY}

As a board/administrator team, review the items on the list below and decide how you would assign the responsibility for each decision. Label each item with one of the following:

$B=$ only the board may make the decision

$\mathrm{A}=$ administrator (director) has complete authority to make the decision

$\mathrm{I}=$ administrator has authority to act and then inform the board

$\mathrm{P}=$ administrator must seek prior approval from the board to act

2
3
4
5
6
7
8

$$
6
$$
Write a grant proposal Submit a grant proposal to a funding source Change board meeting times or frequencies

Decide the administrator will represent your organization at a business function Initiate a total ban on smoking in agency offices

Set minimum salary for new staff

Hire a consultant for a project

Purchase a new telephone system with budgeted funds

_ Send an office secretary to a three-day leadership conference at the organization's expense

_ Plan a board/staff retreat to revise the long range plan

Select a firm to audit your organization's finances

Hold a press conference to announce a new program

H Have the administrator's office redecorated and refurnished

Decide the administrator can go to a weeklong seminar

Hire an employee for an unbudgeted position

6 Approach citizens about serving on an advisory committee

7 Communicate information to another board

Notify contractors of bidding results

_ Decide in which bank(s) to deposit organization funds

Decide how to invest $\$ 20,000$ of surplus funds

Decide which items or services to cut to meet budget demands

Change office records to a computerized system

Give recognition awards to community members for their contributions

__ Lay off a staff member to meet budget

Develop the agenda for board meetings

Award contracts to vendors

Establish guidelines for evaluation of employees

Change the administrator evaluation form

Determine the type and number of clerical positions for the office

Retain legal counsel for the agency

Select a person for an administrative assistant position

__ Establish a flexible work schedule for the administrator

Fire a popular, long-time employee for poor job performance

Exercise adapted from 1993 Board Member Manual, Aspen Publishers, Frederick, Maryland, pp.3 I-32. 


\section{Communication Between Board and Staff}

\section{Board Recruitment}

Establish mechanisms for regular communication between staff and the board (or a subset of the board, such as an executive committee). The director should also have easy access to the president, treasurer, and one or more members of the board to handle emergency situations.

Present periodic written reports to the board in a monthly or quarterly budget, regular updates on annual work and marketing plans, status of recent accomplishments, and a monthly calendar of upcoming events. Where there are detailed reports, always provide brief summaries.

Communication also includes feedback from the board to staff regarding their expectations and assessment of performance. The director reports to the board, and the board, as "supervisor," should conduct a formal evaluation of the director on a semi-annual or annual basis.

More frequent feedback to the director also might be desirable, especially for a new director or board, to ensure both are comfortable with their roles and progress. Many directors work independently and see the board or executive committee only monthly or quarterly. Regular communication, such as bi-weekly phone calls to a designated board member and a monthly status report, can be useful to ensure constructive feedback.

In most non-profit organizations, it is a group of private sector individuals that usually provides the impetus to incorporate. They also serve as board members and hire staff. However, many TMAs and other public-private partnerships that address transportation issues are initiated by government seed funding. The source of the grant funds can strongly influence the initial direction of the organization. The staff exists before the board is created and it is the staff 's job to set in motion the recruitment process for board members.

Recruiting board members is less challenging if your organization is already prestigious or well known.TMAs just starting must contend with the fact that traffic congestion, especially future traffic congestion, is a community problem that does not rate in the same league as child welfare, hunger or emergency issues. They are considered universally urgent, and other organizations have already secured commitments from many community leaders to serve on their boards.

To address the challenge of recruiting board members, it is suggested that the TMA director emphasize the benefits of board participation to the recruit, to the constituencies that he or she represents and to the community at large.

Some of the benefits include:

- Personal satisfaction

- Opportunities to develop professional contacts

- Individual or "team" recognition for accomplishments

- Leadership and managerial development

- Professional knowledge or experience

Emphasize that board members play a key role in shaping programs and services that can provide direct benefits to his or her constituencies and business.Also emphasize the negative impacts of the existing or future problem that the TMA was created to address. Back up your case with facts. Emphasize the importance of proactivity and savings to the community by reducing or avoiding the problem altogether, instead of dealing with its effects later. 


\section{Board Composition}


Manager of volunteers

Professionals in the transportation field

Community outreach/education

administrators

Foundation/fund-raising organization executives

\section{Demographic Representation}

Ethnic/Cultural

Male/Female

Geographic
Expertise in running volunteer organizations

Understanding of organization's mission and programs

Community involvement Audience/supporter development Visibility in the community

Networks/contacts

Functional expertise

Networks/contacts

Visibility in the community

Financial resources

Audience/supporter development Board enrichment/diversity

Program development

Financial resources

Board enrichment/diversity

Access to broader experience/knowledge

Board enrichment/diversity

Audience development

Financial resources 


\section{Maximizing Board Effectiveness}

\section{Appeal To Their Values}

Perhaps the board doesn't represent all the right professional expertise and recognized community leaders, but it may still have the most valuable asset: people wanting to participate and do something worthwhile for the community.

In maximizing board effectiveness, the TMA director has the capability to create an organizational environment for board members, so that their best talents are put to use, their accomplishments are recognized and board members receive feedback that encourages them to continue their efforts.

TMA directors may observe different personality styles of board members that may translate into strengths under the right circumstances. TMA managers can influence or orchestrate these circumstances to bring out the best in board members. It is also a consideration to develop a board composition with a complement of personality styles to compose a strong team, in which each member contributes something special.

For example, persons who are openly competitive, daring and direct may have what it takes to lead the effort to get a tough job done. They may be able to successfully take charge in challenging situations and may have the leadership potential to chair the board.

Other persons may prefer to work as part of a team on tasks that are well defined. Such persons may rather participate than direct. These persons may be very effective in accomplishing the behind-the-scenes tasks of a membership drive or other important activities where there are nuts-and-bolts tasks to be completed. Such persons may make excellent secretaries or treasurers of the board.

Extroverted persons may have the contacts and the charisma to attract new members and recruit new board members. These also may be the best people to handle promotions and public relations matters of the TMA.

Some people may pay close attention to matters of quality and detail. These persons may be effective in the tasks of drafting and amending by-laws and other documents. They may also be good observers and astute regarding changing conditions. These persons may show particular strengths in strategic planning.

The rationale for taking the time to consider the personalities of members, board members and potential members, can be explained by the work of the originator of the Personal Profile System of understanding dimensions of behavior (Dr. John G. Geier, University of Minnesota). This system asserts that all people are motivated to do things for reasons of their own. You cannot motivate a person, but you can create an environment in which people motivate themselves to be successful and productive.

Applying this idea to the work of the TMA board, a TMA director can learn to approach individuals in ways that most appeal to their values and make them more willing to participate. For example, the competitive and daring individual needs to be offered challenging tasks as well as recognition for his or her accomplishments. The methodical team player will get the job done, provided that a solid work program and procedures are in place. The extrovert may present the best image of the TMA in an interview with the press. Devising operational policy might be just the right task for the detail-oriented person.

Sensitivity to board personality strengths and weaknesses can enable a considered approach to organizing committees and building teams. The examples above illustrate how to make the most of the board's talent. The same can be true of downplaying limitations by pairing individuals in teams to minimize one person's weaknesses with another's strengths.Armed with such knowledge, the director can also adapt his or her own behavior to bring out the best in board members. 


\section{Selecting Board Officers}

\section{Board Training}

\section{TMA Committees}

When electing officers, carefully consider members' skills. The president and vice president should be recognized leaders, but also able to build consensus among the membership. They should be good communicators, facilitators, and well-organized managers who work well with the director and staff.

Because staff typically keeps minutes of meetings and manages the TMA's daily finances, the secretary and treasurer seldom need to handle these tasks. More often, these officers function as overseers or monitors, working with staff to ensure the TMA's legal, organizational, and financial records are properly maintained. These officers must be highly organized, attentive to details, and able to work well with staff.

Some people will be serving on a board for the first time. To be effective, they need training and guidance on organization, roles, responsibilities and procedures. If many members are new, they need time to get to know each other and begin to work together, even if they have served on boards of other organizations.

Consider holding a "retreat" or other event soon after the election to orient new members and offer an opportunity for current members to interact informally in a setting where there are no pressing issues. This will also be an opportunity for board members to learn about past activities, as well as ongoing goals and objectives. Before the retreat, prepare and distribute a packet of information about the TMA, the board and its responsibilities, strategic and financial plans, and other materials related to the operation of the TMA.

Recruiting qualified board members is one of many challenges.Another is encouraging active participation in board and TMA activities. Educate members on the "culture" of the TMA as a membership organization that draws its strength and success from collective efforts. Encourage all board members to participate on, and perhaps chair, a committee.Assist them in selecting a committee that needs their particular skills and leadership.

Use board members strategically to accomplish theTMA's goals, but also generate continued interest and enthusiasm for individual efforts. Allow them to show their talents to their best advantage and to receive recognition.

Ensure that the board member understands the assignment and feels comfortable with the time frame and responsibilities associated with the task. If the board member cannot complete the assignment by the deadline, it can cause embarrassment and prevent participation in future projects.

To extend the resources of the board and staff, many TMAs also maintain one or more standing and ad hoc committees.

Standing committees are permanent in duration. For example, an executive committee, composed of the chair, vice chair, secretary and treasurer would provide staff with frequent (perhaps weekly) input. The board chair generally does not serve on any other committee. Other standing committees might include a nominating committee for the ongoing identification of potential new board members, for which the board vice chair would often serve as committee chair, and the finance committee for which the board treasurer would often serve as chair. Other standing committees might include those for:

- Membership/marketing

- Public relations 
- Government relations and legislative monitoring

- ETC recruitment, training and oversight

- Long-range planning

- Evaluation

Ad hoc committees are temporary in duration and are created to address a special issue or accomplish a specific task.

Members of both standing committees and ad hoc committees do not necessarily have to be members of the board or of the TMA, but can include outside experts. However, each committee should include at least one board member, so that committee meetings do not take place without board presence.

The effective use of committees requires respectful consideration of committee members' time and efforts. Committee work is often labor intensive; therefore, board members generally have the time to do an effective job on no more than one committee. The work of a committee should not be trivial but make a clear contribution to achieving the objectives of the TMA's work plan.

\section{Act Upon Committee Recommendations}

With few exceptions, it is important that committee recommendations be approved and acted upon by the board. There is nothing more disheartening to members of a competent committee who have conducted thorough research on their task, only to be stymied by the board or have their recommendations dismissed, second-guessed or not acted upon. Committee members should be made to feel empowered in return for their volunteer efforts; otherwise the board will be unable to find committee volunteers in the future.

There are several things that board and staff can do to ensure the effectiveness of committees. Committee work starts with the strategic plan. The strategic planning process, discussed later in this Handbook, defines important issues that might be best addressed

\section{Tips for Good Board Relations}

- Carefully select members - respected, effective leaders who are committed to work on the board.

- Solidify the board as an effective team for future TMA planning and actions.

- Clearly define roles and responsibilities of the board and the staff and ensure the staff has authority that matches their responsibility.

- Define TMA communications mechanisms and establish strong communication channels. Ensure regular, open communication between staff and board members.

Utilize the skills and influence of board members strategically.

- Use meeting time efficiently - plan agendas carefully, provide needed background material in advance, and focus meeting time on the key decisionmaking items. 


\section{Effective Board Meetings}

by separate committees. The objective to be accomplished by a committee should be determined first, then the board chair recruits someone who is interested and capable of serving as chair for that committee and of developing a work plan to accomplish the objective. Staff should also offer facilitation and coordination assistance to help committee members accomplish their tasks. Finally, committee accomplishments should be recognized and rewarded by the board. ${ }^{3}$

Meetings are one of the most expensive forms of communication. They cost the salaries and time of those in attendance, preparation costs, travel expenses, and the cost of materials, facilities and equipment used during the meeting. The following discussion provides guidelines for conducting an effective board meeting. ${ }^{4}$

Call a meeting only when there is no better, less expensive way to get a job done. If activities of the TMA require the board to meet frequently, such as monthly, then set a regular day to meet, for example, the second Tuesday of the month. This will allow members to plan ahead and reserve the time.

A meeting should be called if the subject is serious, if no one person has all the information, if complex problems need to be solved or if group acceptance of the decision is important to make it work. A meeting should be called if you cannot get the same results from sending a memo or making phone calls or some other form of communication. Call a meeting only if the necessary information is available for the board to act upon and if the board has had sufficient time to prepare.

\section{Define the Meeting Purpose}

Once it has been determined that calling a meeting is necessary, it is essential to define the purpose of the meeting and the outcomes desired from the meeting. Possible outcomes might include achieving consensus, voting on a decision, generating ideas for solving a problem, or obtaining commitments to participate.

\section{Prepare an Agenda}

Once the purpose and desired meeting outcomes are established, then an agenda should be prepared that will achieve the desired outcomes. Develop a clear agenda on topics that require their decisions or are important for them to discuss. Keep the day-to-day operation details off the agenda. Involve the board only if a problem arises or if a noteworthy event occurs. The agenda should place the highest priority item first.Time estimates should appear on the agenda next to each issue.

Discuss the meeting agenda with the board chair prior to the meeting. Be sure he or she understands all the topics, recommendations, and any questions and conflicts you anticipate.

\section{Invite the Right People}

The next step in planning an effective meeting is to make sure the right people are invited. These are the persons with the relevant expertise or information, those who will make

\footnotetext{
${ }^{3}$ Ideas selected from Nancy L. Brown, "Board Effectiveness Workshop; 7 Rules for Using Committees Effectively," Designs in Development, Inc., Seminole, FL. I99I; revised 1994.

${ }^{4}$ The discussion is based on notes from "Management and Productivity Skills," David J. Cyra, CYRA ettc. Workshop presented at the Center for Urban Transportation Research, Tampa, FL, December, 2000.
} 


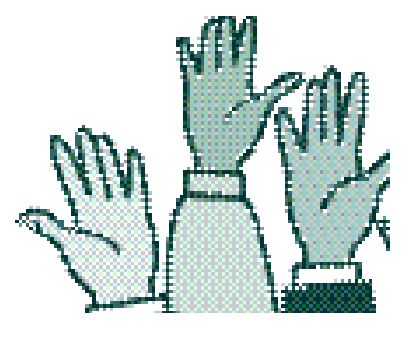

the final decision, representatives who are affected by or will carry out the decision and anyone who might prevent or interfere with implementation of the decision. These may include persons outside the board. If you find that some board members are not needed to accomplish the meeting objective, then review whether the issue to be addressed is really appropriate for a board meeting.

Determine if committee chairs or members are needed at the meeting to present items on the agenda, provide additional background, or answer questions. The board chair should call each committee chair prior to the meeting to learn of motions that may need to be made or issues that require full board discussion. However, do not permit the board meeting to be turned into a committee meeting. Stick to Robert's Rules of Order ${ }^{5}$; it will result in the best use of everyone's time.

An additional consideration in the selection of participants in the meeting is to determine if your organization has an obligation to operate in the "sunshine," as is required in several states. Operating in the sunshine involves ensuring that meetings are open to the public at all times, that public notice is given prior to every meeting, keeping minutes of every meeting and prohibiting board members from having related conversation outside a meeting. State statutes define which entities must operate in this manner. Depending upon the status of government participation in the TMA, nature of contracts and circumstances where the TMA is receiving public funds, sunshine laws might apply. It is recommended that the TMA seek legal advice to clarify any obligation.

\section{Assist in Meeting Preparation}

After the agenda has been prepared and the participants selected, the participants should be sent data and information they need along with the meeting agenda, at least ten days prior to the meeting. If you are sending a complicated document or report, provide a one-page executive summary that defines key points the members need to know at the meeting and recommendations for any action that needs to be taken.

\section{Begin the Meeting with a Statement of Objectives}

At the start of the meeting in which a quorum is present, the board chair should review the agenda items with the board, state the objectives or what the board should accomplish during the meeting, and state how long the meeting will last. If the chair, with the assistance of the director, can stick to the time commitment, then the board members will be more willing to give their undivided attention during the meeting because they know they can trust that it will end on time.

An effective board chair must exercise good meeting facilitation skills. These include:

- Ensuring everyone has a chance to speak and preventing no one from dominating the discussion

- Keeping the discussion on track by preventing participants from digressing

- Disallowing members from criticizing other's ideas during brainstorming sessions

- Discouraging side conversations

During the meeting,TMA staff assists the chair by pointing out board members who have not been recognized. Staff also presents background information and addresses questions as needed.

\footnotetext{
${ }^{5}$ General Henry M. Robert. Robert's Rules of Order Revised. Constitution Society, Austin, TX. 1996.
} 
Handling Conflicts
At the close of the meeting, the board chair should provide a summary of what has been accomplished, assignments given, decisions made, and the date of the next meeting, if a follow-up meeting is necessary. As soon as possible after the meeting, staff should distribute minutes that accurately describe decisions, assignments and due dates.

Board members will be more willing to attend meetings if they feel the time is well spent.

Conflicts occasionally occur between staff and the board or between board members. However, a disagreement is not necessarily bad. If you handle conflicts diplomatically and professionally, disagreement can be constructive. It can keep the TMA from becoming too complacent, produce effective and creative solutions, and consolidate support of other members for a position around which they can rally.

Disagreement, however, is damaging when it results in a power struggle between two board members, fragments the board into intractable factions, or ends in personal attacks on one or more members. Recognize when constructive disagreement crosses the line to destructive conflict. Unresolved conflict can paralyze the board and erode the growth and success of the organization. Also recognize, whenever possible, a conflict in the making. If you see a problem on the horizon, quietly prepare key members in advance.

If a conflict occurs during a meeting, delay confronting the antagonizer until later, when you can minimize the possibility of creating an embarrassing situation. Allow everyone to "save face." Then, assess the seriousness of the disagreement. Try to resolve the problem by talking to the members individually and then together, perhaps with the president or someone who could help to arbitrate.

Sometimes conflict, especially when it is repetitive, signals the need for recognition. Try giving the difficult member a task or responsibility that will satisfy his or her need for attention and keep from causing future problems. If the conflict or disruption persists even after private discussion, consider trying one of the following, less subtle, tactics:

- Allow peer pressure from other members to set a tone for more professional behavior.

- Create a credibility gap around the member.

- Use a strong member who has the support of other members to deliver a public defeat.

Although these solutions might seem harsh, they might be necessary to keep conflict and dissension from continuing and causing problems with other members. Finally, if a problem arises, don't let the dissenting member contaminate the relationships among other members or between the board and staff. Keep communication open and cordial and let members know steps are being taken to resolve the conflict in an amicable manner. 


\section{Developing and Building TMA Membership}

\section{A Business That Sells Services}

\section{Membership Recruitment Stages}

Many TMA directors cite membership development as the toughest part of their job. This is especially true in the first year or two when there isn't a track record of success and the TMA has not yet established name recognition. Later, after the TMA is established and has a positive reputation in the area, it becomes easier to reach new businesses. Developing membership includes:

- Defining your membership base

- Determining potential members' concerns and issues

- Clarifying membership benefits

- Developing promotional materials

- Contacting potential members

- Developing outside marketing and publicity channels

- Hosting periodic membership development events

The above activities are listed roughly in the order in which they might be performed, but there will be overlap between some of the activities. These activities should also be reviewed or conducted anew in conjunction with your previous year's evaluation findings and the current year's strategic work plan development, as described in Section 4.

Members join the TMA at different times for different reasons. The core members who start the TMA become involved because they see problems they believe it could solve. These members are visionaries and pioneers; they are concept-driven.

A second, usually much larger group of members join when the TMA develops services. These service-driven members join because they perceive potential, tangible benefits for using the TMA's services.

The third "show me" group are sold on membership only after seeing documented results from TMA membership.Although members can be divided into these three broad categories by their primary focus, all are ultimately interested in what the TMA offers them and what it accomplishes or allows them to accomplish.

To be truly successful at membership recruitment, a TMA must think of itself as a business that sells services to satisfy defined needs of member markets. A market-driven TMA identifies who its members and potential members are, and then defines and meets their needs.

Membership recruitment goes through stages. The TMA's first year is often a busy time for building membership. It is likely only a small number of potential members in the area were reached during the exploration stage. Further, the director and core members are energetic, enthusiastic promoters. The pay-off for these efforts can be a solid base of membership support.

After awhile, membership growth might be slowing. Perhaps all the companies first identified have been contacted, and those with the most interest have become members, while others express no interest in joining. As membership renewal time approaches, it may be that current members begin to reassess the value of their membership. Some might begin to question the benefits they receive relative to the dues they pay. Don't be discouraged by these challenges or assume that organizations that did not join earlier won't enlist now. 
Defining Your Membership Base
Recognize, however, that a TMA must continue to evolve to meet the changing and expanding needs of current and new members. Membership development during TMA operation means retaining current members, continually updating the pool of potential members to include new companies arriving in the area, contacting those new companies, and recontacting organizations that were not sold on membership during the initial drive.

MostTMAs strive for broad participation and cooperation of many public and private groups throughout their service areas. The members not only provide funding for the TMA, but also serve as important resources in organizational development and service planning.

\section{Private Employers, Developers, Building Managers, and Land Owners:}

- Participate as private sector members

- Implement site-specific TDM programs

- Refer potential members

Private Business Organizations (e.g. chambers of commerce):

- Participate as private sector members

- Serve as organizational "host" to TMA

- Facilitate community-based TDM promotion

- Refer potential members

\section{Municipalities, Counties, and Other Government Agencies:}

- Participate as employer members

- Participate as associate (non-voting) members

- Provide TMA seed funding

- Provide ongoing support for specific projects

- Serve as organizational "host" to TMA

- Develop and coordinate regional and local TDM programs

- Provide technical assistance to TMA

- Refer potential members

\section{Transportation Service Providers:}

- Participate as employer members

- Participate as associate (non-voting) members

- Assist with service planning, development and provision

- Refer potential members

\section{Other Community Groups:}

- Facilitate community-based TDM promotion

- Refer potential members 


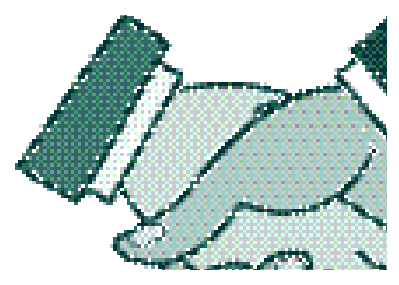

Membership composition varies by the TMA's area and focus. For example, a high percentage of developers and land owners might be represented in a TMA located in a new suburban area where few employers are present.

If there are many multi-tenant buildings or small shopping centers in the area, consider a membership category for multi-tenant developments. The property owner could be the primary member and services can be provided to all tenants of the building for free or a nominal fee. Position membership as a service that building managers can offer to increase the attractiveness to new tenants.

Employer size is often an issue during the membership recruitment process. While it is true that employers with many employees offer the most efficient opportunities for trip reduction, the TMA's impact may be broadened by including smaller sized businesses through building owner and manager members.

\section{Identifying Potential Members}

Develop and maintain a current list of employers, developers, municipalities, and other potential members by using many sources. Utilize referrals from the members or other groups. For example, referrals of developers might be received from the city permitting department.

Identify potential member companies through:

- TMA board and member referrals.

- Local and state agencies that administer trip-reduction ordinances.

- Regional ridesharing agencies.

- Chambers of commerce and other local business groups.

- County economic development bureaus.

- Business directories for the area (often in library reference section).

- County building, zoning, and land use planning departments.

- Local business journals.

- Building and property managers' tenant lists.

This section addressed the subject of developing TMA membership and presented a list of typical TMA members. Now, this basic list can be modified to reflect unique characteristics of the service area.

Be open-minded when identifying potential markets. For example, few TMAs target apartment building managers. If, however, the area includes this type of development, working with apartment managers might influence the travel patterns of a group of commuters that might not have been reached otherwise.

Within a traditional membership category, there may be groups that were missed earlier. For example, perhaps retail stores in a shopping mall were not targeted during the TMA's formation. Now, when membership growth among the initial group is stable, seek out new potential members.

Keep the membership list current. Identify and add companies that have relocated to the area. Contact government offices that issue business licenses, agencies that issue building and occupancy permits, local newspaper and business journal notices of corporate relocations, and referrals from members and other groups such as chambers of commerce. If possible, contact potential members even before they move in. There may be an opportunity to as- 


\section{Determining Potential Members' Concerns and Issues}

sist corporate relocations to the area by orienting new employees to local transportation and commuting options.

Determine potential members' transportation concerns. Prepare background information on the topics businesses are most likely to find relevant to their circumstances and be prepared to describe how the TMA's services can help.

Transportation concerns could include:

- Complying with local, state, or federal transportation or air quality regulations

- Experiencing site-specific transportation problems, such as access, parking or areawide growth

- Encountering difficulties in recruiting or retaining employees

- Desiring to participate in local transportation planning processes

- Experiencing customer (primarily retail businesses) and supplier access problems

Strategically, a TMA's actions can be classified as one of four types. The TMA may have activities in more than one area.

- Current services for current markets

- New services for current markets

- Current services for new markets

- New services for new markets

\section{Strategic Direction Grid ${ }^{6}$}

\begin{tabular}{l|l|l}
\hline \multicolumn{1}{l|}{} & Current Services & New Services \\
\cline { 2 - 3 } Current Markets & Market Penetration & Service Development \\
\hline $\begin{array}{l}\text { New Markets } \\
\text { tion }\end{array}$ & Market Development & Service Diversifica- \\
\end{tabular}

\section{Current Services for Current Markets}

The TMA can increase market penetration of existing services to current markets (e.g., conduct a breakfast meeting for businesses on current services). This also includes the important considerations of keeping existing clients happy by always striving to do a better job. It is easier to maintain a business relationship with an existing customer than to find a new customer.

\section{New Services for Current Markets}

Expand the TMA's "product line" to satisfy additional needs of the members already being served (e.g., introduce a matching transit subsidy program for TMA members). By developing new services that are valuable to existing members, their interest and enthusiasm in the TMA can be maintained while attracting new members. For example, if the TMA already

${ }^{6}$ The Breen Consortium, Inc. “Air Quality and the Role of the TSM Organization." Sponsored by the New York State Energy Office, Midlothian,VA. January 1992. p.37 


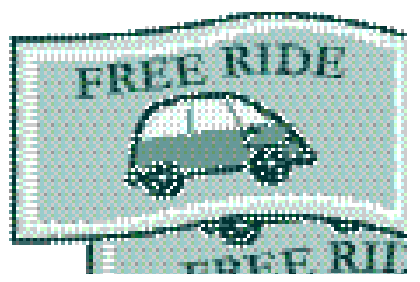

TIF RI sells transit passes, it could also offer transit route assistance as a new service, where the most convenient route on a transit map is highlighted, and a personalized itinerary is prepared. These tangible benefits can make TMA membership more valuable to current and potential members.

\section{Current Services for New Markets}

The TMA can seek to enter new markets with current services (e.g., send its monthly transportation alert newsletter to neighborhood community associations). If the TMA currently markets its services only to employers based on some criterion, such as those with 100 or more employees, try marketing services to smaller employers too. It may be necessary to repackage the service to appeal to another market, but the service would essentially be the same.

\section{New Services for New Markets}

The TMA can diversify by offering new services to new markets (e.g., develop a School Pool program for secondary schools in its service area). It may be possible to attract retailers as members by offering a shuttle service from residential areas to a commercial district where customer parking is limited. Retailers joining the TMA could be given shuttle tokens to distribute to shoppers who patronize the stores. Free advertising for the retailers could be provided in shuttle schedules.Although otherTMA members might not need this service, it could open a new market for membership.

Whatever membership and service development ideas are considered, it is important to match TMA services (existing or new) to specific needs of particular markets.

Sometimes the need and its solution will be obvious, but in most cases, it will be necessary to do some marketing research. A TMA can use techniques borrowed from consumer product marketing and opinion research to define the needs and services that members and potential members may want. Surveys, individual interviews and group interviews are the most common, as discussed in Section 4, Initial Work Plan Development Considerations-Data Collection.

By using such methods, issues of concern to members and potential members can be explored while examining their opinions and attitudes about various solutions to those concerns.

For example, the following questions could be asked of current TMA members:

- What transportation issues particularly concern you?

- How serious is the concern?

- What are the benefits of TMA membership?

- What TMA services have you used and how often?

- Which services are most and least valuable?

- What additional services would interest you?

- What form should new services take?

Research could also target a subset of the market, that is, potential members:

- What transportation issues particularly concern you and how serious is the concern?

- What (if anything) do you know about the TMA and how did you learn about it? 


\section{Clarifying Membership Benefits}

- If you know of the TMA, why have you not joined?

- Which of the TMA services might you use and how often?

- What services not offered would interest you?

- How much would you be willing to pay for general membership or as fees for specific services?

\section{Ongoing Membership Development Tips}

Periodically assess existing members' needs.

Be open-minded when identifying potential markets.

Explore needs of non-members through written and telephone surveys and conversations during membership recruitment calls.

- Use both formal and informal periodic surveys to explore members' needs.

Business leaders join TMAs for a variety of reasons. All must see something of value in joining the TMA. Although being a good corporate citizen will motivate some businesses, most look for economic benefits. The three primary groups targeted by many TMAs are employers, developers/property managers, and local governments.

\section{"What's in it for Employers?"}

Benefits to employers include:

- Cost savings by utilizing centralized programs (rideshare matching, vanpool program, transit information, guaranteed ride home)

- Assistance on transportation-related problems such as parking shortages, labor market or customer access, regulatory compliance

- Access to information on transportation topics that affect businesses (air quality regulations, transportation services or programs, land-use or transportation planning activities)

- Access to local governments for input in planning and programs

- Opportunities to share information and work with other employers on group transportation programs

- Advocacy on local or regional transportation issues

- Improved image of the employer in the community

- Opportunity for developing new business contacts

\section{"What's in it for Developers?"}

Benefits to developers and property managers include:

- Cost savings by utilizing centralized programs

- Assistance on local transportation-related problems

- Access to information on transportation topics that affect businesses

- Access to local governments for input in planning or programs 


\section{Developing Promotional Materials}

- Advocacy on transportation issues

- Opportunity for developing new business contacts

- Mechanism for implementing additional transportation services for existing and prospective tenants

\section{"What's in it for Local Governments?"}

Benefits to municipalities and other local governments include:

- Assistance in the development of area-wide TDM programs for local government employees and area businesses and residents

- Access to a cohesive group of businesses to implement municipal transportation programs

- Forum for developing business support for future transportation services, programs, and legislation

- Mechanism to respond to growth management concerns and desires to manage the transportation system more efficiently and meet environmental goals

As with other businesses, in order to be effective, services and products of the TMA must be promoted. Develop materials that inform potential members about the TMA and compel them to join. The goal is to deliver a message that strikes a persuasive chord with the target audience.

Select one or a combination of media for outreach and promotion, based upon careful consideration of the best way to reach the particular chosen market. For example, the demographics of the particular commuter market might closely resemble the listening audience of a particular radio station. If the market consists of commuters who drive along a particular corridor, consider a billboard campaign along that highway. Better yet, permanent roadway information signs that list a toll free number might achieve longer lasting promotional results.

Most importantly, do not choose a medium first and then try to figure out how to use it to reach the target market. Instead, first determine the media to which the target market pays attention, then figure out how to use those particular media. Do not feel compelled to use all available media for the sake of reaching everyone.This will only spread resources too thin to gain any results.

\section{Promotional Material Distribution}

Also consider the logistics of distributing promotional materials. For example, a letter campaign may seem inexpensive initially, but its success partially depends on the labor that goes into assembling an accurate mailing list. Posters are also initially inexpensive, but the success of posters depends on whether there are available bulletin boards and kiosks that are noticed by the target market. It is usually necessary to get permission to post them, if they are on private property (such as an employment site). If they are not underneath a protective glass case, posters will be written on, ripped, rained upon, blown away by wind or removed within a short period of time. This means they must frequently be replaced, which takes time and labor.

For visual materials, use graphic design and writing professionals early in the development process whenever budget permits. A trained designer/graphic artist creating the overall look, and a writer or editor constructing good copy can provide a professional product. If a member has a graphic designer on staff, ask if he or she can develop materials as an 


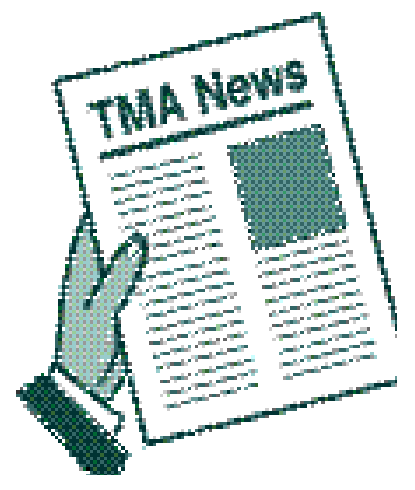

in-kind service.

Written materials should be brief and to the point, written in clear, non-technical language. Tailor written content to appeal to the interests of each different audience: CEOs, middle managers, ETCs, commuters, and others.

\section{Developing a Consistent Image}

Developing a consistent image throughout the promotional materials enhances recognition and recall of the TMA. Image includes the logo, color scheme (bright and trendy or more traditional corporate), size and form of the materials, type of paper, and typeface. Each element should contribute to the desired image.

If there is more than one promotional piece, they should be coordinated as part of a family of materials to maximize recognition and recall. Many TMAs prepare a new member packet containing a general information brochure describing the mission and goals, activities, and member services and benefits; a letter of welcome; and a list of other members. Brochures on individual TMA services could also be developed to be used separately or in combination with more general materials.

Some members will join only after they see successful results. These members can be big boosters because they have been won over by proof of success. To persuade them to join, however, the TMA's accomplishments must be documented. This is where efforts in program evaluation pay off. Refer to Section 4, in particular, Communicating Evaluation Findings.

Consider producing an annual report or other collateral materials that provide facts and figures on trips reduced, cost savings to employers, ridesharing matches among employees, number of parking spaces saved, or any other measure of success that appeals to the target audience's needs.

Document successes of individual members and highlight the TMA's role in their accomplishments. Ask members to write testimonial letters. Or even better, ask the members to contact potential members and sell TMA membership.

\section{Contacting Potential Members}

Telephone calls and letters are the quickest way to make contact with employers and other organizations. This sales aspect can be frustrating because it often involves cold calling. Use referrals from members or others as much as possible to increase the likelihood that calls will be taken and letters read.

Make a list of the top priority companies, usually the largest employers, and contact them first. However, don't overlook the smaller sized firms. Consider several methods to contact potential members:

- Breakfast or lunch meetings, or other events

- Peer-to-peer contacting

- Letters and calls from the director

- Newsletters sent to non-members

- Referrals from government agencies or others

Always follow up initial phone calls with a letter of thanks, an invitation to a future event, and an information packet. Here are some suggestions for initial contact and followup. 


\section{Initial Contact}

Ask a TMA member who knows another potential member to pave the way for the staff's phone call. Or ask the member to invite the potential member to breakfast or lunch to introduce the TMA. Join them if possible. If there are no TMA member contacts, make the initial call or send an information packet. Target the call or letter to a name, not just a title. (It can be obtained by calling the main phone number and asking for the name of the president, CEO, or head of human relations.)

\section{Follow-up Contact}

If letters are sent, follow up a week later with a call to discuss the TMA and to request a visit. Follow up all calls with a letter and information about the TMA. Send a "Thank you for your time" letter to companies reached. Send an "I'm sorry I couldn't reach you... Please let me introduce the TMA" letter to companies that have not responded. Meet with the potential member as soon after the call as possible.Ask a TMA member with similar interests and issues to those of the potential member to accompany you on the visit; a satisfied member can be the most effective salesperson.

\section{Membership Contact Tips}

\section{Developing Outside Publicity Channels}




\section{Hosting Membership Development Events}

\section{Articles For Local Publications}

Suggest ideas to the reporters for stories on the TMA or important transportation issues. Stories can be both timely (e.g., initiation of new services or programs, business-transportation legislation) and general (e.g., typical congestion issues). Send draft articles to local newspapers, magazines, business or other trade publications, and local newsletters. Ask them to send a copy prior to publication so their edits can be checked.

TMAs often host events to introduce their activities to the business community. They can take place day or night in the form of receptions at local hotels, arts centers, or members' offices, or at breakfast meetings with a few members and potential members. If possible, hold the event during an appropriate time, such as Rideshare Week, or when initiating a new transportation program (e.g., new transit service). Enlist the participation of corporate, political, or government leaders to encourage businesses to attend.

Keep the event short and focused. One hour for a breakfast meeting, and up to two hours for an after-work reception. If a program includes a speaker, begin the program half an hour into the event to allow for late-comers.

Provide name badges to all guests and mark members' badges with a ribbon so potential members will know to whom they can direct questions. Ask members to make special efforts to include guests in conversations and to introduce non-members to members.

In order to be effective, the TMA must establish sound working relationships with local public agencies and officials and private groups that can support its goals and activities. In any service area, there may be many organizations involved in transportation issues. Determine which groups are involved in transportation issues and establish partnerships that benefit the TMA.

These groups may include:

- State and local governments, such as city, county, and state departments of transportation; planning, zoning, and business development departments; and regional or metropolitan planning organizations

- Transportation and air quality regulators

- Elected officials, such as mayors, city and county council members, state and federal legislators

- Transportation and commute management service providers, such as public and private transit agencies, vanpool providers, regional ridesharing agencies, taxi companies, and others

- Chambers of commerce and other business associations

- Local media, such as newspapers, business and community publications, television and radio stations

- Commute management professional associations/other TMAs

- Network of Employee Transportation Coordinators (ETCs)

\section{Other TMAs}

Understand the role that all these organizations play to determine the most beneficial relationships. Identify the most appropriate liaison from each organization, establish effec- 


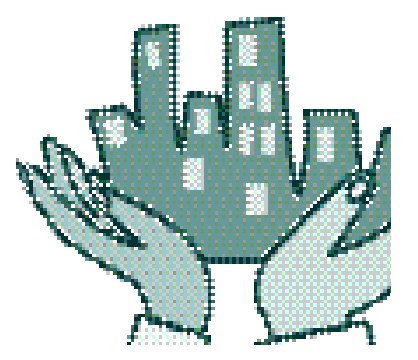

tive communication, attend meetings, and participate in their activities. Also join in activities of peer groups, such as chambers of commerce, commute management associations, regional ridesharing agencies, transit agencies, and ETC and TMA networks.

TMAs offer a variety of services to its members and in many cases, to nonmembers, even in areas with regional rideshare providers. It is essential to clarify service roles between regional programs and TMAs.

Peer groups can provide professional referrals that expand the business community's awareness of the TMA, but also can support the staff and members by sharing ideas. Some TMA networks may also submit joint proposals and win grants from funding agencies to provide services and conduct regional marketing activities. In these cases, it is very useful to draft an agreement that describes how the participating TMAs will coordinate and communicate with each other. This is helpful in easing friction arising from "turf" issues.

Finally, cultivate the media. Good publicity about the TMA and its activities can aid in attracting members, but also increase positive visibility and credibility. 



\section{TMA Development- Planning and Evaluation}

- Section Overview

aeginning with the End in Mind-TMA Performance Evaluation

- Initial Work Plan Development Considerations-Data Collection

- Survey Planning and Budgeting

- Communicating Evaluation Findings

- Developing a Strategic Work Plan 



\section{Section Overview}

\section{Beginning with the End in Mind-TMA Performance Evaluation}

Each stage of TMA development offers special challenges. In the exploration stage, the founders identify problems and build consensus for solutions. In the formation stage, the staff and board secure funds, create an organization and develop membership.

The operation stage also presents challenges. The TMA must maintain the support and enthusiasm of existing members, attract additional private and public support, provide services, manage daily operations and plan for the TMA's future.

This section starts with a discussion of "beginning with the end in mind."' Too often, evaluation of the TMA is an afterthought-left until the year's program is over.As a result, it may be difficult or impossible to evaluate because measures of program effectiveness were not initially established and the necessary data were not collected.

A sound evaluation provides the kind of information that enables the board and staff to steer the program toward success. It provides the feedback necessary to rule out ineffective courses of action and fine tune programs that show potential. Having reliable evaluation results often are required to meet performance criteria outlined in contractual agreements and to secure continuation of funding or win additional funds.

Properly documented program outcomes are also a convincing source of information for retaining existing members, and promoting your organization and services to potential board recruits, new members and the general public.

It is recommended that evaluation methods be established concurrently with work plan development, so that monitoring activities can begin immediately after your program year begins. Starting with the end in mind encourages clarity in the development of goals, objectives and the tasks selected to achieve those objectives. Considering evaluation in the beginning gets a developing work plan off to a good start.

This section includes a description of an evaluation composed of performance criteria developed specifically for TMAs originally developed by CUTR for the Florida Department of Transportation as the TMA Self Evaluation Program. Following the program evaluation method is a discussion of information collection methods, specifically the range of survey types and how to plan, budget and communicate findings of surveys. This information will be useful in documenting existing base line conditions against which future program performance will later be compared. This is not meant to make staff experts in the design and implementation of surveys. This takes specialized training and experience. Rather, the discussion of surveys is intended to help staff learn how to communicate their needs to market research professionals and interpret and use the results of surveys.

Following the discussion of communicating evaluation findings is a section on developing a strategic work plan.

By beginning the TMA work planning with considerations of evaluation, it will be easier to identify what is important to do and how to do it. The example described here is just one way to approach evaluating the TMA that will help ask the kinds of questions that point to ways of improving performance and getting the budget year off on the right start.

Originally developed as the TMA Performance Criteria ${ }^{2}$ for the Florida Commuter Assistance Program, the set of seven criteria described below are a basis for assessing a TMA program

\footnotetext{
I Phrase is taken from Stephen R. Covey, "The 7 Habits of Highly Effective People," Fireside Publishers, August 1990.

2 Center for Urban Transportation Research, College of Engineering, University of South Florida, "TMA Evaluation Program," prepared for the Florida Dept. of Transportation. Tampa, FL, February I5, 1995.
} 


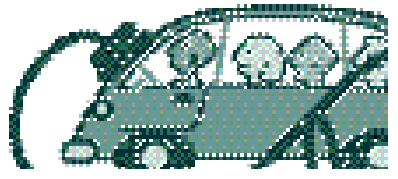

and for giving feedback to the TMA. In addition, these criteria offer many important roles in strengthening program effectiveness:

- Designing an evaluation encourages examination of the clarity of TMA objectives, the ease with which they can be measured, and the possibility of achievement

- Redirecting efforts when it is determined that elements of the program have or do not have desired results

- Demonstrating to the public the diligence and effectiveness of the TMA

- Supplying powerful factual information for public relations campaigns

- Helping other TMAs to anticipate problems in implementing similar programs and provide yardsticks against which others may measure their success

- Enhancing the TMAs performance through focusing on dual, results-oriented goals

- Delivering ever-improving value to customers, resulting in positive gains toward achieving program goals

- Improving overall TMA operational performance (e.g., lower cost per person served)

These criteria are:

- Corporate Leadership and Involvement

- Suitability of Goals and Objectives

- Development and Deployment of Strategic Plan

- Financial Management Systems

- Degree of External Visibility

- Effectiveness of Programs

- Measure of Member Satisfaction

An eighth category, "Other," is suggested so that consideration can be given to other important bases for evaluation that are unique to the TMA.

Address each of the criteria as it relates to the TMA's mission, goals and objectives. Keeping in mind all those who will be interested in reviewing the evaluation, such as board members, TMA members, funders, etc., attempt to anticipate reviewer questions. The more complete a picture is provided of methods, measures, implementation and evaluation factors, the more it will encourage meaningful feedback from those reviewing the evaluation.

It helps to understand the difference between measures and indicators. All criteria call for results based upon data using key measures and/or indicators. Measures and indicators both involve measurement related to performance. When the performance can be measured directly, such as number of persons placed into carpools and carpool formation rate, the term "measure" is used.When the overall performance may not be evaluated in terms of one type of measurement, and two or more measurements are used to provide ("indicate") a more complete picture, the term "indicator" is used.

For example,"creativity" is not easily described in terms of a single measurement.Awards for marketing materials and increased awareness provide two indicators of creativity. However, the effectiveness of this creativity on travel behavior would require measuring changes to market share gain from introduction of these creative products or services. 


\section{TMA}

\section{Performance Criteria}

\section{TMA Overview}

Prior to addressing the seven performance criteria, drafting an overview of the TMA is recommended. This is a summary of the TMA, addressing what is most important to the TMA and the key factors that influence how it operates. This will help reviewers understand why the TMA exists, who is involved, what are the TMA's products and services, and what resources are being brought to bear on the problems. The TMA Overview should describe:

- The nature of the TMA's operation: products and services

- Principal customers (e.g., commuters, employers, etc.) and their special requirements

- A description of the TMA's service area (such as activity center or corridor)

- Key customer requirements (for example, prompt response or accurate information) for products and services. Briefly note significant differences in requirements among customer groups or markets, if any

- The TMA's relationship to other transportation providers (e.g., transit agency) or organizations (e.g., MPO)

- The TMA's staff composition, including: number, type, level of education, etc.

- Major equipment, facilities, and technologies used

- Types and numbers of suppliers of goods and services (e.g., third party vanpool operators, taxi operators for the guaranteed ride home program). Indicate the importance of suppliers, and other TMAs, and any limitations or special relationships that may exist in dealing with such suppliers

- The regulatory environment within which the TMA operates, including non-profit status, contractual arrangements, concurrency requirements, etc.

- Other factors important to the TMA, such as major new directions, major changes taking place in the industry, new alliances, etc.

\section{Corporate Leadership and Involvement}

The leadership criterion examines the TMA's board of directors and executive director's personal leadership and involvement in creating and sustaining a customer focus, clear and visible values, and high expectations.

Reinforcement of the values and expectations requires substantial personal commitment and involvement. The leaders must take part in the creation of strategies, systems, and methods for achieving excellence.The systems and methods need to guide all activities and decisions of the TMA.Through their regular personal involvement in visible activities, such as planning, communications, review of TMA performance, and recognizing employees for quality achievement, the board members serve as role models for staff.

Board of Directors and Executive Director Leadership-Review the board of directors' and executive director's roles and responsibilities in developing goals and objectives.

How might these roles be changed to enhance leadership?

- Identify board activities for leading and/or receiving training. What training is needed that could be offered in the future?

- Describe financial and operational performance monitoring systems including types, frequency, content, and use of reviews and who conducts them. Get feedback from the board on how they believe these systems could be improved. How might the progress and financial reports, as provided by the director, be made clearer and 


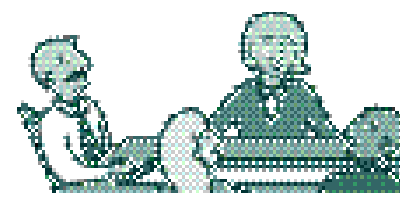

more informative?

- Review the process of identifying and selecting new board members including identifying the skills and characteristics that are important to the TMA and comparing the strengths and weaknesses of the existing board. How can the board recruitment process be improved?

- List all TMA committees including their missions, names of committee members, affiliations, and types (private/public). Are objectives and tasks appropriately allocated to standing or ad hoc committees? How have board members participated? Have the committees effectively executed their work in a timely manner? Are there too many committees, stretching board members too thin or are there tasks that are not currently being addressed by committees?

- Consider how the board evaluates and improves the executive director's effectiveness. Review the board's most recent performance review form used for evaluating the executive director as his or her duties relate to the performance of the TMA. What feedback from the board could help the director improve performance?

\section{Board of Directors' Community Involvement}

- Review board interactions with local and business community leaders on TMA issues.

- Consider such communications with national, state, trade associations, other TMAs, and professional organizations.

- Review director interactions with local and business community leaders on TMA issues.

- Are the right community leaders being targeted?

- Are there better or more efficient ways to maximize public contact, given the limited time of board members?

\section{Suitability of Goals and Objectives}

This criterion examines the process of setting goals and objectives. Major emphasis is placed on developing an understanding of why the TMA chooses its mission, goals, objectives, and activities.

Scope and Management of Performance Data and Information-Review the types of data and information that are used to measure the TMA's performance in achieving the TMA's goals and objectives. Are there better data sources and types of data available to measure accomplishment of objectives? Are better methods available to collect the data?

Benchmarking-Benchmarking refers to information about other TMAs that can be used for comparison and best practices. There are two major premises underlying benchmarking. First, for their key programs or services, TMAs need to know where they stand relative to other TMAs or commuter assistance programs, and the best practices for similar activities among other TMAs.

Second, comparative benchmarking information provides impetus for significant (sometimes "breakthrough") improvement, and alerts TMAs to new practices. It is anticipated that the existence of benchmark information for many of the TMA programs or services may not be readily available. TMAs may request the assistance from the National Transportation Demand Management and Telework Clearinghouse (see Helpful Resources section in Appendix) in seeking benchmark information. 


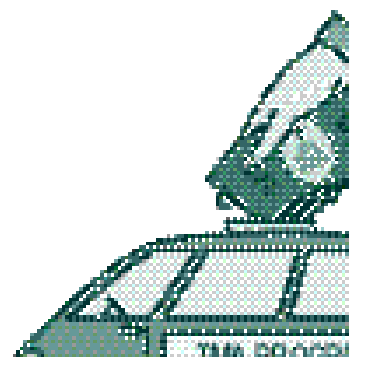

In the use of benchmarks, it is suggested that the TMA:

- Review its rationale for selecting benchmarks.

- Review the process used for obtaining and using comparative information.

Benchmarks might include:

(I) Information obtained from other organizations

(2) Information obtained from a review of the literature

(3) Evaluation by independent organizations

Consider how this benchmarking information is used to set objectives and improve performance.Are objectives set too high or too low, based on comparable programs of other TMAs?

Analysis and Uses of Data to Develop Goals, Objectives, Products and ServicesManagement based upon facts is a core concept in the criteria. The criteria call for a wide variety of data, both nonfinancial and financial, to guide a TMA's actions toward beneficial results. Despite their importance, however, individual facts do not usually provide a sound basis for action or priority.

Action depends upon understanding cause and effect and the relationship between processes and results. Process actions may have many resource implications; results may have many cost and revenue implications.

- Consider the key steps in the processes for delivering services and how performance at each step is tracked and maintained. For example, the TMA may re-evaluate how it delivers its guaranteed ride home program. The old method may have required the commuter to pre-register, receive prior approval to use the program from the Employee Transportation Coordinator, pay taxi fare and get reimbursed, and have to wait one hour for the only approved taxi cab provider. After evaluating the customer's experience, the TMA might arrange to have several taxi cab providers accept vouchers for direct payment by the TMA.

- Consider how processes have been or can be improved to achieve better quality, response time, and operational performance. Review how each of the following is used or considered:

(I) Process simplification (e.g., data entry and mailing sent by same person)

(2) Benchmarking information (e.g., how long it takes other TMAs to fill requests)

(3) Research and testing

(4) Use of alternative technology (e.g., voice mail access to commute information)

(5) Information from customers, within and outside the TMA

- Consider how the TMA receives and uses planning input from others such as a regional commuter assistance program, MPO, etc. Are there any lost opportunities?

- Consider how new and/or modified products and services are designed and introduced to meet both customer needs and performance requirements. Factors that might need to be reconsidered in design include: cost, privacy concerns, convenience, third-party capabilities and support for Employee Transportation Coordinators.

- Consider how the TMA's products and services are designed and managed so that current customer and member requirements are met and continuously improved (e.g., surveys of employers determined they want real-time access to a transportation advisory system for major reconstruction projects). TMA services also might 
include providing information to employers on transportation issues such as parking, bus pass sales, etc.

\section{Development and Deployment of Strategic Plan}

The strategic planning criterion examines the TMA's strategic (e.g., 3 years) planning process and how the goals and objectives and annual work plans are integrated into the overall long range plan. Include how this process integrates customer and member requirements and how plans are carried out. Also discuss how progress is shared with key stakeholders such as the MPO and transit agency.

\section{Strategic Plan Development}

Review the process used to examine the TMA's strengths and weaknesses, as well as opportunities for and threats to the TMA.

\section{Implementation of Strategic Plan}

- Review how the budget, staff, and volunteer resources are allocated to carry out the plan, and how the TMA relates the current year work program to the strategic plan.

\section{Coordination with Regional Transportation Organizations}

- Consider how the TMA ensures alignment of its plans and activities with area long range transportation plans, and how the TMA communicates its plans and reporting progress to the board, MPO, and other stakeholders.

\section{Local Transportation Service Supplier Quality and Support}

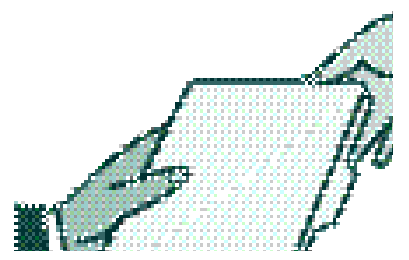

- Review how the TMA's quality requirements are defined and communicated to the TMA's suppliers (e.g., taxi cab providers for guaranteed ride home programs) or suppliers to its customers (e.g., third-party vanpool provider).

- Determine whether or not the TMA's quality requirements are met by transportation providers.

- Consider how performance information is fed back to suppliers.

\section{Financial Management Systems}

This criterion examines the TMA's financial management systems, and provides information that can supplement an audit. The criterion addresses financial performance via two major avenues: (I) emphasis on improved productivity and lower overall operating costs; and (2) support for TMA strategy development, decisions, and innovation.

Care should be exercised when comparing the financial performance of the TMA with that of another.This is because short-term improvements in efficiency may be affected by factors such as accounting practices. Some TMAs historically have higher measures of efficiency levels than others as a nature of their market. For example, high density, bedroom communities 30 miles from a downtown and partially served by high occupancy vehicle lanes are fertile areas for carpool and vanpool formation. Therefore, vehicle miles of travel reduced could be expected to be significantly higher than a TMA near the center city.

The time interval between quality improvement and overall financial improvement depends upon many factors. This interval is not likely to be the same from one TMA to another. Though improved quality and productivity are likely to improve a TMA's overall effective- 


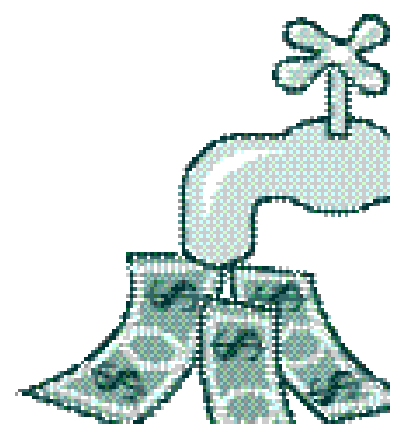

ness and efficiency, its financial performance also depends on environmental factors and public policies. Efficiency depends upon many external factors, such as local, national, and international economic conditions and business cycles. Such conditions and cycles do not have the same impact on all types of programs or on individual TMAs.

Budget Preparation and Monitoring-How are budgets prepared and monitored?

- Review how plans consider cash flow requirements.

- What do the income statement, balance sheet, and statement of cash flows indicate about the financial well being of the TMA?

- Review the TMA's internal control procedures.

- Review the audited financial statements and management letter from the auditor. What actions have been taken to correct deficiencies, if any, identified by the auditor?

- Chart trends of membership levels, new member recruitment, retention, and revenue and in-kind contributions from members.

- Review the dues structure and number of members per category.

\section{Degree of External Visibility}

The external visibility criterion examines your TMA's advocacy, educational, and outreach efforts and how these relate to enhancing the customer service focus of the organization. Also examined is the potential reach of promotional efforts and their impact upon targeted markets.

Promotional Efforts-Consider the process used to determine how the promotions will fulfill the TMA's goals and objectives. What are the direct costs and in-kind contributions of promotional efforts?

Educational Opportunities - Identify opportunities for professional development, including training and conferences for staff and members of the board.

- Review the variety and types of educational opportunities provided to TMA members and their employees or other customer bases. These may include:

(I) Employer site visits

(2) Seminars and workshops offered by the TMA, such as "Effective Cycling"

(3) Special forums with guest speakers

(4) Transportation Days

- Is there an education need that is left unfulfilled?

- Consider how the TMA communicates its goals, objectives, mission statement and product offerings to the customers in the TMA's service area. How does the TMA use these opportunities to enhance its image as an advocate of transportation alternatives? These may include:

(I) News articles written about the TMA

(2) Presentations at public meetings andlor hearings

(3) The use of public service announcements and community television channels

(4) Other outreach activities 


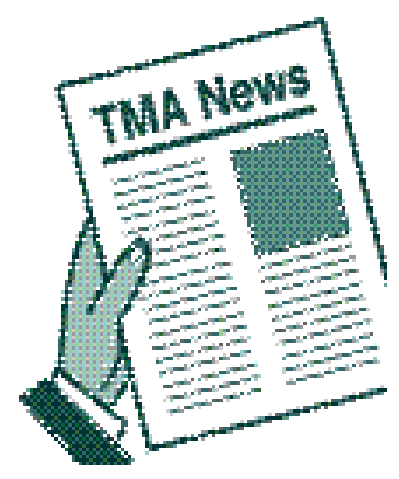

Results of External Visibility Efforts-Review how the effects of promotion, educational outreach and advocacy are measured.

- What impacts are measured, and what process was used to determine which effects should be measured? How can the analysis of these impacts be used to refine and enhance promotional, advocacy, educational and outreach efforts?

- Identify local government policies and programs that support the TMA and/or Transportation Demand Management and Transportation System Management strategies. These may include trip reduction ordinances or congestion management plans that include an active role for the TMA.

\section{Effectiveness of Programs}

The effectiveness criterion examines theTMA's operational performance.A useful evaluation will help determine one or more of the following: $(I)$ the extent to which the program has achieved its stated objectives (e.g., increases in Average Vehicle Occupancy); (2) the extent to which the accomplishment of the objectives can be attributed to the program (direct and indirect effects); (3) the degree of consistency of program implementation with the plan (relationship of planned activities to actual activities); and, (4) the relationship of different tasks to the effectiveness of the program (productivity).

Evaluation Methods-Review the methods for collecting the data for evaluation purposes. The evaluation method and data collection requirements depend on the measures of effectiveness being used. Some of the most commonly used methods involve employee surveys, program participation documentation (e.g., registrations for preferential parking, applications for subsidies), vehicle counts, and time sheets or activity logs.

Product and Service Results-Note current levels of service provided for all key product and service features (e.g., vanpools in operation, customers served, employee transportation coordinators). Compare current levels with appropriate benchmarks.

Determine cost effectiveness for the key results by allocating the expenditures for the period costs to the measures of effectiveness (e.g., cost per person served, cost per vehicle miles of travel reduced, etc.). Compare measures of effectiveness against objectives and benchmark information.

\section{Measure of Member Satisfaction}

The satisfaction criterion examines the TMA's relationships with customers and its knowledge of customer requirements. Also examined are the TMA's thresholds to determine customer satisfaction, current trends and levels of customer satisfaction and retention, and these results relative to other TMAs.

Customer Expectations: Current and Future-Consider how the TMA determines near-term and longer-term requirements and expectations of customers.

- How is the relative importance of specific product and service features determined for different customer groups?

- How are other key information and data such as complaints, gains and losses of customers, and product/service performance used to support the determination?

Commitment to Customers-Review the TMA's commitments to customers regarding its products/services and how these commitments are evaluated and improved. Examples of commitments are product and service guarantees, such as the response time for a guaranteed ride home program or how personal information and confidentiality is maintained. 
- Consider how these commitments:

(I) Address the principal concerns of customers

(2) Are free from conditions that might weaken customers' trust and confidence

(3) Are clearly and simply communicated to customers

- Review how the TMA evaluates and improves its commitments, and the customers' and members' understanding of them, to avoid gaps between customer and member expectations and TMA performance. This should include:

(I) How information/feedback from customers is used

(2) How product/service performance improvement data are used

Customer Satisfaction-Consider how the TMA determines customer satisfaction and customer intentions to use the TMA's services again.

- Note significant differences, if any, in processes for different customer groups or segments.

- Review how customer satisfaction measurements capture key information that reflects customers' likely future market behavior, such as intentions to use the TMA's services again or positive referrals. The TMA's products and services might be provided via Employee Transportation Coordinators (ETCs). Thus, "customers" should also take into account these ETCs.

- Review customer dissatisfaction indicators, including number and type of complaints received.

- Determine trends in the TMA's customer satisfaction and trends in key indicators of customer dissatisfaction.

\section{Other}

In evaluating the TMA, include other important factors, such as major new directions for the TMA or additional qualitative information which is not reflected in the above criteria.

\section{Initial Work Plan Development}

Prior to the development of the first work plan for a new TMA or next year's work plan for a mature TMA, it is advantageous to have a general knowledge of the use of data collection techniques in their many forms. In order to develop an effective work plan, the TMA must understand the needs and nature of its market(s). Surveys are a powerful means to identify issues of importance to constituents, obtain in-depth information on opinions, attitudes and customer experiences, and to generate baseline data on travel behavior, as well as follow-up data on changes as a result of a TMA program. Such considerations are vital to programs that rely upon winning funding, documenting TMA program results and fulfilling grant requirements.

This section describes the different types of surveys that can be used. These include a variety of data collection methods, such as focus groups and mail surveys, as well as sampling considerations. This discussion is not meant to prepare the TMA to design and administer a survey. It is recommended that such work be contracted out to market research experts or provided for by the expertise represented on the board. Instead, this discussion is to enable better articulation of needs to professional survey designers, plan for the work to be accomplished, and understand, use and communicate survey results.

The section immediately following will discuss considerations of survey planning needed prior to work plan development, such as survey scheduling and budgeting. Such knowledge 
will maximize planning options.

\section{Types of Surveys ${ }^{3}$}

There are a number of different types of surveys, each of which have unique characteristics and limitations. The choice of survey method is dependent on the objectives involved in doing the project and budget available. The main types of surveys are:

- Focus Groups

- Written/Mail surveys

- Telephone Surveys

- Personal interviews

\section{Focus Groups}

Focus groups are an excellent alternative if only a very general feel of public interest or support for a particular subject is required, and the researcher wishes to determine which issues of great impact to the community will surface. Because of the small sample sizes involved, this process will not allow for a quantitative estimate of public support, nor will it determine the relative importance of issues raised or topics discussed.Typically two to four focus groups will be held. Cost will vary from $\$ 3,000$ to $\$ 6,000$ per topic, depending on the number of focus groups held, complexity of questions, and other time-related factors.

\section{Written/Mail/E-Mail Surveys}

Written and mail surveys are usually the lowest cost alternative available for quantitative estimation. The surveys allow for a relatively large amount of data to be collected from each respondent. However, written surveys are often subject to low response rates and usually take over a month to collect necessary data.

Costs will vary greatly depending on the level of projectability the researcher is attempting to obtain. To provide a single, reliable estimate for an area, a minimum sample size of 250-300 is recommended. In cases where an independent estimate is required for several segments of the population (such as geographic areas, income levels, etc.), required sample sizes can increase greatly. Usually if a "general idea" is required for sub-segments and an accurate estimate for the population as a whole, a sample size of 125 - I50 per segment is sufficient. The cost for this type of approach can vary from $\$ 5,000$ to $\$ 10,000$ and up, depending on sample size and type required.

E-mail surveys have the advantage of being free but may suffer from the same low response rate as mail surveys and are limited to people who have e-mail and who regularly check for messages.

\section{Telephone Surveys}

Telephone surveys have the advantage of rapidly providing quantitative estimates and tend to have higher response rates than mail surveys.

The major drawback of telephone surveying is the cost involved. Furthermore, the amount of data and complexity of responses that a respondent can provide is limited-two-hour

\footnotetext{
3 This section on survey types, survey planning and budgeting was originally published in " 1999 Commuter Assistance Program Evaluation Manual," prepared for the Florida Dept. of Transportation by the Center for Urban Transportation Research, College of Engineering, University of South Florida, Tampa, Florida, 1999.
} 


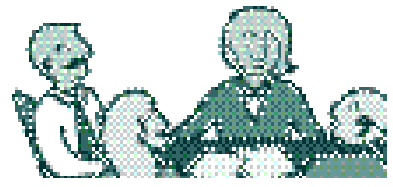

phone interviews are not recommended. Concepts presented need to be fairly simple and straightforward. Sample size guidelines are the same as for written surveys.

The cost for this type of approach can vary from $\$ 7,500$ to $\$ 25,000$ and up, depending on sample size and type required, and length of interview.

\section{Personal Interviews}

Personal interviews are the best alternative when complicated survey formats are required and detailed information needs to be provided to respondents. Costs for this type of interview tend to be extremely high if a quantitative estimate is required, since the usual purpose of using this type of interview is to present fairly complex information to potential respondents, and to be able to judge the nuances of the response.This requires rather skilled (and relatively expensive) interviewers, and also often involves travel expenses.

A table summarizing each of these approaches is on p.xx.

\section{Issues In Sampling}

Many of the issues involved in proper sampling have been touched on in the above sections. This section will deal with each of the issues in more depth. The question of sample sizes will be briefly introduced and covered in detail in the statistics section, directly following this one.

Certain key elements that must be included in any sampling plan:

- Definition of target population

- Issues in proper representation

I) How to ensure proper representation

2) Evaluate how well the sample represents the population

- Sampling efficiency

- Sample size

- Sample sources

\section{Definition of Target Population}

The hypotheses that are being tested will define the target population, at least in a broad sense. The key is to define the target population in such a way that each respondent provides meaningful information.

\section{Proper Representation}

Because most surveys are conducted on a sample of the population rather than the full population, it is vital that the sample selected properly represents the population.

Ensuring proper representation can be done in several ways. The steps should be taken:

- Identify key variables to serve as indicators

- Include measurements of those variables in the surveys

- Devise a random selection process

- In some cases, require that the sample meet quotas on indicator variables

- Weighting results 


\section{Types of Surveys and Characteristics of Each}

\section{Focus}

Groups

\section{Description}

8-10 people discuss topics of interest to client; led by

professional moderator

\section{Applicable Uses}

Issue generation; in-depth

discussion on complex

survey results

\author{
Written Mail/E-Mail \\ Surveys
}

Pre-designed survey mailed

or e-mailed to respondents

General surveying of population; medium-long surveys; simpler survey formats

\author{
Telephone \\ Surveys
}

Pre-designed survey

conducted by

professional

telephone interviewer

\section{General surveying of population; short-medium length surveys; moderately complicated surveys}

Good

Only if adequate response

rates are obtained

Slow

Large sample sizes

can be obtained;

longer surveys possible

Low Response rates/

unrepresentative samples

can occur; slow turnaround
Higher costs; surveys need to be kept fairly short and simple

\section{Personal \\ Interviews}

Survey administered

by individual

professional

interviewer

Interviews with key individuals; long-very long surveys; complicated survey formats

Very Good if enough interviews are completed

Moderate/Slow

Allows more flexibility in interview format, in-depth probing

Very high costs per completed survey; slow turnaround

\section{Costs}

Low/Moderate

Moderate

Moderate/High

Very High

\section{Typical Single Project Cost for Complete Project (Design, Analysis, Report)}

$\$ 3,000$ - $\$ 6,000$, based on complexity of issues and number of groups
$\$ 5,000$ - $\$ 10,000$ and up, based on complexity of survey and number of respondents
$\$ 7,500-\$ 25,000$ and up, based on complexity of survey and number of respondents
$\$ 15,000-\$ 75,000$ and up, based on complexity of survey and number of respondents 


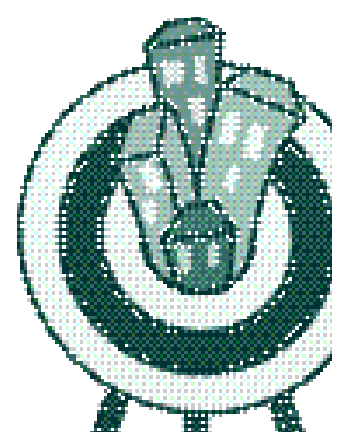

Identify Key Variables-The researcher and the research sponsor should identify those variables that will most likely impact attitudes and behaviors being measured. This is done through a combination of historical data sources (if available) and using the expertise of the parties involved to determine the most important variables. Usually one checks on a limited set of variables, say five or six. These typically include age, income, gender, presence of children, and so forth.

It is important that there be an independent source to measure those variables. Usually, when the entire population of an area is being surveyed, census data serves as a good check on major demographic variables. Breakdowns of census data or tables in the U.S. Statistical Abstracts can also serve as good checks when segments of a population are being surveyed. When the target sample is from an extremely specific database (for instance, a ridesharing database), data must either be culled directly from the database or from historical surveys of that database, if available.

Include Measurements of the Indicator Variables-Clearly, if a variable is to be used as an indicator of proper representation, that variable must be included somewhere in the data collection process. Standard demographics are typically part of any surveying effort, since demographics often impact attitudes and behaviors and are therefore extremely useful in extrapolating results gleaned from a survey of the entire population. Any other variables chosen as indicators, such as number of automobiles, type of housing, and so on, should have a specific question in the survey to collect that data item.

Devise a Random Selection Process-The most common way of ensuring a representative sampling of any given target population is through a random sampling process. In telephone-based surveys, this is often accomplished through a technique known as random-digit-dialing. Commercial services will obtain a list of all working phone exchanges, devise a sample of random numbers fitting those exchanges, eliminate exchanges having a high incidence of business/government telephone numbers, and then use the resulting list as a basis for the sample.

When sampling from databases is involved, there are several possible random selection procedures. Ideally, the sample will be totally random. The process of creating a totally random sample involves:

- Determining the sample base necessary

- Determining the ratio of sample needed to total database size

- Using a random number generator to create numbers between 0 and I, and applying those numbers to each database record

- Selecting as a sample all those whose assigned random number falls below the ratio of sample needed to database size

It should be noted that sample base size, that is, the sample that is drawn to meet the needs of the survey, is usually much larger than the actual required sample size. The reason for this is that there are a large number of non-working phone numbers and/or bad addresses in databases, and that a large percentage of people may not respond to the surveys. A ratio of 10:I for sample base to desired completed surveys is not uncommon.

Use Quotas on Indicator Variables-Another way of essentially forcing a sample to be representative of the population is to set quotas on some or all indicator variables. This is often used in selecting samples for focus groups, and on variables such as male/ female ratio and minimum age (usually 18 or older) for telephone surveys. Using quotas requires that the indicator variables be identified up front in a portion of the survey called a screener. For instance, if a survey were to have quotas set on gender, age, income, and 
presence of children, where a certain distribution in each of those categories was required, those questions would be the first asked in the survey. Interviewing would take place for each category desired until the quota was filled, and then people meeting the filled-quota description would no longer be interviewed.

Weight Survey Results-Survey results are commonly weighted so that indicator variables will match up with independent source data. For instance, if a returned survey has only a 15\% distribution of respondents with three or more cars, and it is known that the target population has $25 \%$ (say, from census data), then the survey results can be mathematically re-weighted to match the $25 \%$ figure. When this is done, all of the responses from the $3+$ car group are re-weighted, not just the indicator variables.All of their opinions and attitudes are made more prominent.

A critical factor in weighting survey results is that there is sufficient sample size within the group being reweighted, particularly when making their opinions more prominent. If there were 5 responses from people with 3 or more cars, weighing them as importantly as 100 responses from other people, would run a severe risk of having unrepresentative results. Confidence in the responses given by the group to be re-weighted should be fairly high. The section on sample size, as well as the section on statistics, will explain the concept of confidence in greater detail.As a rule of thumb, it is probably unwise to re-weight responses from a group with less than 75 respondents.

\section{Evaluating Surveys for Proper Representation}

Once the data have been collected, there will be a distribution of responses on the indicator variables, such as percent male and female, percent in various income brackets, and so forth. In some cases, there may be an average (or mean) value as a check (such as mean number of vehicles, mean number of people per household, etc.).Typically, however, indicator variables are evaluated in the form of distributions.

Checking the responses for proper representation essentially involves making statistical tests on the distributions. Consultants will apply the standard $t$ test and chi-square test to ensure proper representation.

\section{Sampling Efficiency}

Collecting data from respondents costs money, and the more data collected, the more money it costs.A major cost factor is inefficiency in sampling, where, for example, quotas are set and a large number of people are contacted who don't fit in the quotas. Do everything possible to ensure that the sample base is as efficient as possible.

Sampling efficiency can be achieved in many ways:

- If a sample of working commuters is desired, it would be wise not to send surveys to communities that are largely populated by retirees.

- If a sample of people who live in, Atlanta, Georgia is desired, all phone exchanges known to be wholly in Marietta or Decatur should be eliminated.

Commercial databases sometimes contain demographic data that can be used. For instance, a survey of commuters drawn from a demographic database could be restricted to those aged 18-54, if such data is available.

For efficiency purposes, if the data is not available in advance and a screener must be used, the screening section should clearly be the first part of the survey, so that non-qualifying respondents will not be interviewed. 


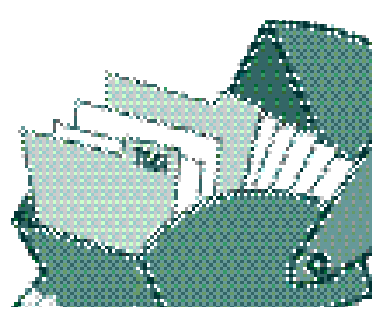

\section{Sample Sizes}

The issue of how many returned surveys are required is fairly complex. The key issue that the TMA director needs to determine is the level of uncertainty that is acceptable in the results.

Survey results are usually presented as a single, specific result, such as " $25 \%$ of the population has 3 or more cars." To be completely accurate, the result might be presented in the following ways:

There is a $95 \%$ chance that between $22 \%$ and $28 \%(25 \%+/-3 \%)$ of the population has 3 or more cars. There is a $90 \%$ chance that between $23 \%$ and $27 \%(25 \%+/-2 \%)$ of the population has 3 or more cars. There is an $80 \%$ chance that....and so on.

There are two elements involved in the uncertainty about survey results - one is a range of results that the "true" result falls in (known as the confidence interval), and the other is the percent chance that the result falls into that range (known as the confidence level). Given a certain sample size that is randomly selected from a population, for any given result - either a percentage or an average - a confidence level and confidence interval can be calculated. The level and the interval are interdependent; that is, the size of the interval depends on the magnitude of the level. For any given result, there is an interval corresponding to an $80 \%$ confidence level, a different (and larger) interval corresponding to a $90 \%$ confidence level, a third (and still larger) interval corresponding to a $95 \%$ confidence level, and so forth.

For the key results coming from the survey, the TMA director needs to decide the size of interval and acceptable confidence level. Usually, the confidence level is determined first (e.g.." "I want to be $90 \%$ confident that all the results..."), and then the acceptable interval is determined ("... are within 3 percentage points or less of the true values.").

\section{Sample Sources}

There are a large number of sources from which to obtain sample addresses or telephone numbers, whose use depends on the objectives of the survey. These include:

- Databases of rideshare club members

- Commercially available databases drawn from magazine subscription lists, sweepstakes entries, telephone directories, etc. These databases can have a surprisingly large number of names matched to addresses and telephone numbers

- Telephone numbers derived from a random-digits process, which is available from a large number of commercial suppliers

- Databases of business addresses and phone numbers are also available from similar sources

For telephone surveys, a TMA would typically contract with a telephone interview vendor, who would in turn select a commercial supplier to provide the database of randomly selected telephone numbers.

The choice of which database to use depends primarily on:

- The objectives of the project and the hypotheses being tested

- The extent to which the database covers the target population defined by the objectives and hypotheses. Beware of using databases that are convenient and close at hand, but may represent a biased sub-sample of your true target population. For instance, a rideshare database clearly does not represent all carpoolers.

- The expected incidence or "hit rate" expected from the database for efficiency purposes, which is important but must not override the cautions noted just above. 


\section{Summary}

\section{Survey \\ Planning and Budgeting}

\section{Survey Timing}

The survey should produce reliable information if all of the above steps are taken, including:

- Properly defined target population

- Random selection process

- Checking for proper representation and re-weighting, if applicable

- Correct sample size drawn

- Correct source chosen for the sample

How useful the information is will depend largely on how well the survey instrument is designed.

Evaluation results are typically desired for new year planning purposes and year-end evaluations. In order to effectively integrate the results of the evaluations into the planning process, the survey must be conducted reasonably far in advance of the planning period. Suggested advance times to start planning the surveys are:

\begin{tabular}{lc} 
Type of Survey & Advance Time to Start \\
\cline { 2 - 2 } Focus Groups & 2 Months \\
E-Mail Surveys & 2 Months \\
Mail Surveys & 4 Months \\
Written, hand-distributed surveys & 2 Months \\
Telephone Surveys & 3 Months \\
Personal Interviews & $6-8$ Months
\end{tabular}

This section will focus on how to plan and fund an evaluation. While this sounds simple, many of the considerations discussed below can have a profound impact on survey costs and data reliability.

Timing can be a key issue in conducting surveys and can have a significant impact on results if not properly controlled. Employee satisfaction studies are usually not conducted immediately after reviews and/or pay increase announcements. Attitudes towards use of commute alternatives can be affected by prevailing weather patterns, such as extreme heat (or in the case of northern areas, extreme cold). Below are some elements of timing to be considered when planning surveys.

\section{Seasonality}

Seasonality can be a major issue in an area like Florida, where there is a high influx of seasonal residents with predictable impacts on traffic levels. Studies evaluating the perceived (or actual) level of congestion will be significantly affected by the season in which they are conducted.

It is not always possible to conduct surveys at "ideal" times, nor is it always possible to determine what an "ideal" time may be. The best approach is usually to do as much as possible to ensure that prevailing conditions are similar when a follow-up survey is conducted. For instance, doing an initial "congestion perception" study during low season, implementing some reduction procedures, and then following up during high season would be methodologically poor, and would probably lead to the conclusion that the policies implemented had actually increased, rather than decreased, congestion. 


\section{Frequency}

Budgets seldom allow for tracking surveys to be conducted more than once a year (if that). In cases where seasonality may be an issue (see above), you may want to consider spreading your interview process throughout the year rather than doing all of the interviews at once. This allows for calculation of a rolling average once you have conducted enough interviews to get a baseline, and may give you fairly up-to-the-minute insight into any new situations that may affect your customers or whoever else you are surveying. However, this approach generally involves more expense, particularly if the surveys are updated every time they are conducted.

\section{Sample Size}

The primary decision made when budgeting for a survey is the determination of sample size. The concept of how sample size affects the precision of results has been discussed previously. The question that a research sponsor must answer is, "How much is the extra precision and certainty from the larger sample size worth?".

As a rule of thumb, to get a "quick and dirty" estimate for a population, a sample size of at least 150-200 should be considered. This allows for a wide range of uncertainty, but generally gives a fair idea of the population's attitude.

For a good, solid estimate of the tendencies of a population, sample sizes of 400 respondents should be considered. Often a sample size of 400 or so may be used to establish benchmarks, and then 200 additional interviews are used as follow-ups to gauge whether there has been any change since the initial study was done.

\section{Planning Survey Projects}

Probably the single most important step in any research project is the initial planning. The survey must meet the data needs of the evaluation that is to be conducted. If the project is poorly planned in the initial stages, there is virtually no chance that it will result in useful data and meaningful, valuable changes in policy and TMA program operations.

There are five essential elements that a TMA director must have firmly in mind when initially organizing a research project:

- Given the evaluation being conducted, what decisions will be made with the results of the survey? Or alternatively, how will current operations, policies, and resource allocations be changed based on the survey findings?

- Given the decisions that are being made with the research, what is (are) the specific hypothesis (hypotheses) that is (are) being tested by the research?

- What are the pieces of data that need to be determined in order to prove or disprove the hypothesis, and in what form should they be measured? Furthermore, since a sampling process is involved, how confident do we need to be of the results? Is it sufficient for the results to be within $5 \%, 10 \%, 50 \%$ ?

- What are the best sources of information? Do data already exist that answer this question? If not, where is the best place to look for it? If surveying is involved, who are the best people to ask questions of and collect data from?

- How much budget is available to conduct the research?

Each of these areas will be discussed in more detail below.

\section{Step I: Identify Decisions to be Made}

The evaluation selection process should be a key step in identifying the decisions that are 


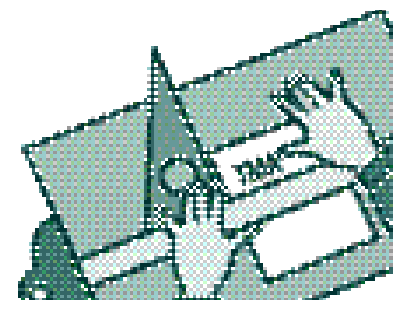

to be made. These decisions should be made explicit at the beginning of the project. This step is unfortunately often omitted from the research process. Even if the TMA director has determined that they will conduct a needs assessment, it is easy to get into trouble by setting vague objectives such as wanting to know the demographics of the rideshare database members. This approach often leads to faulty research design.

Often the TMA director assumes that the personnel in charge of actually conducting the research share the same perception of the project's goals, only to find as the data comes back that some elements were left out or misinterpreted. Or, the director will assume a thorough understanding of the process so that the step of specifying the decisions can be skipped, and he/she needs only to ask for specific data elements. This is a serious mistake- the director often discovers new data elements that are needed and could easily have been identified if the planned decisions had been made explicit.

The TMA director should always ask for information by specifying the decisions to be made, and never merely ask for data. Directors don't want to "know the demographics" just to know them; they want to evaluate specific portions of or processes within their organizations. Perhaps they want to determine which specific actions are required to make programs more effective, such as whether or not new marketing campaigns are needed, or if the entire spectrum of the area's population is being served. If not, they may want to know which ones are underserved and determine if resources should be allocated to target those groups.

It should be noted that in cases where decisions have been made and will not be changed, due to commitments, regulatory requirements, etc., it is wasteful to spend research dollars to determine the decision is right or wrong. The research should be directed towards decisions that have not been made and will be made more effectively with additional information at hand.

The decisions that will be made based on the survey results should be explicitly identified by the TMA director. Will resources be re-allocated and if so, how? If the project is evaluative, how will the evaluation be used to improve operations, policies and procedures, and specifically which operations, policies, and/or procedures are being evaluated? All of this information should be laid out on paper as the first step. Following completion of this effort, the next step is to generate the hypotheses to be tested by the research project.

\section{Step 2: Generate a Hypothesis}

A research project is an experiment like any other; it should test and either confirm or reject a specific hypothesis (or multiple hypotheses). The hypothesis should take the form of a direct statement, as in "Carpoolers have a significantly different set of demographics than people who drive alone", or "75\% of all rideshare database members have a high level of satisfaction with the ridematching service,'high' being defined as 8 , 9, or 10 on a scale of I-I0." The TMA director should identify the decisions to be made by the evaluation (step I above). Then the TMA director and the research project manager should work together on generating the hypotheses that, when tested, will provide the director with information needed for the decisions to be made.

The following elements must be present in any sound hypothesis:

- The measurement that is being made and tested (such as a percentage, or an average rating)

- The scale that the measurement is being made on (for example, the minimum threshold level where a numerical scale is involved, or the actual statements used in categorical scales) 


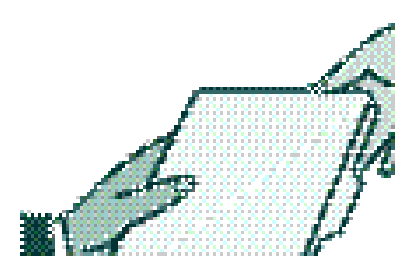

- The source, or target population, from which the information will be drawn (such as "rideshare database members" or "all commuters" or "residents of the 5-county area")

If, for example, a re-allocation of resources to target groups that are under-represented in a ridesharing database (compared to the service area's population) is the decision under consideration, one might generate the following hypotheses:

- The demographics of the ridesharing database are significantly different from the commuter population of the area, specifically in terms of income, age, race, gender, presence of children under age 6. (The list might be lengthened, or some elements might be dropped, but the hypothesis should be explicit.)

- Those demographic groups that are under-represented in the database have a certain minimum threshold interest in carpooling. The minimum threshold interest should also be made explicit: e.g., $20 \%$ of the commuters in the area who are in these groups say they are "somewhat or very" interested in carpooling at least once per week on a regular basis. Or, one might hypothesize that their interest level is not significantly different than the interest level of the demographic groups that are over-represented in the database.

One might also generate a hypothesis about the media that would be most useful to use to reach this population. However, it is also quite possible that few media are available (perhaps just direct mail and newspapers) within the budgets allowed, so that regardless of what the research finds, the same approach will be taken. As mentioned above, it is a waste of time and money to identify and collect data for a decision that has already been made and cannot be changed.

The hypothesis should be specific, and should be a direct statement that will either be confirmed or denied by the research.Vague statements like,"Rideshare database members are satisfied with the service provided to them" are not useful or effective hypotheses, because they leave open to interpretation exactly what "satisfied" means. Does this refer to every database member? Does it refer to an average level of satisfaction, and if so, how is "satisfaction" defined? A better statement would be," $75 \%$ of all rideshare database members will say that they are very satisfied (or will rate their satisfaction at least an 8 on a 10-point scale, if a numerical scale will be used) with the ridematching service provided to them."

\section{Step 3: Identify Data Needed to Prove or Disprove Hypotheses}

Identifying Data Needs-When the hypotheses have been generated, identifying the data needed is actually quite straightforward. By reviewing the hypotheses used above as examples, it is clear that respondent demographics and stated intentions or interests will be included on the questionnaire. It is likely that other hypotheses will have been generated in the planning process as well.

When the necessary data have been properly identified, it is usually fairly straightforward for a survey research professional to create the actual survey questions and response scales and/or categories to be used. While it is certainly appropriate for a TMA director (presumably, this person is not an experienced survey research professional) to review and comment on a questionnaire, it is not advisable for a non-professional to formulate the questionnaire. Issues of response bias, question order bias, skip pattern complexity, response choice formatting and design, types and formats of data needed for certain statistical tests and modeling procedures, standard response scaling used in particular types of questions, etc., are all important in questionnaire design but are not issues with which most TMA directors are or need to be familiar.

The Importance of Control Groups-A control group is a population that is exactly (or as close to exactly as reasonably possible) like the group on which you are measuring the 


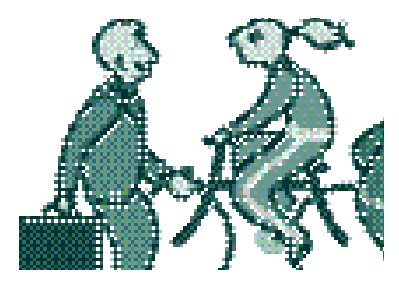

effects of the program, except that it has not been exposed to the program. The measured behavior (such as percentage of people carpooling) should be measured both for the experimental group and the control group to determine the effectiveness of the program. Many experiments skip the step of having a control group by assuming that a control group would have experienced no change in behavior, and thus any measured change in the experimental group is due to the program.

This approach can lead to erroneous conclusions.A major decrease in the price of gasoline, for instance, may reduce the number of people carpooling. If the group that was exposed to the program shows a very small increase in carpooling, it may be concluded that the program was ineffective. However, if it was also known that carpooling within a control group actually dropped by $15 \%-20 \%$ due to the decrease in gasoline prices, a different conclusion might very well be reached.

Due to cost constraints, it is sometimes impossible to conduct a research project with an appropriate control group. Other data sources, such as census data, may have to serve as a surrogate for data from a true control group. It is extremely important, however, to understand the notion of a control group and how results from the control group may impact conclusions reached from research data.

The Concept of Sampling-Usually, a research project will involve conducting tests on a sample of the population rather than every member of the population. This occurs because few TMAs can afford to sample every member of a target population. When this happens, statistical uncertainty is created in the results, based on whether the sample accurately represents the population. This is not a question of proper sample design procedures; it is a fact of the sampling process.

Statistical procedures exist that identify what the probability is of having made an error in sampling, and how large that error might be. Before an experiment that involves sampling is undertaken, the level of potential error to be tolerated must be determined.This is usually based on the importance and economic ramifications of the decision being made with the research results.

\section{Step 4: Identify Information Sources}

There are a number of possible sources for information. To determine demographics, for example, there is a wealth of free data available from the U. S. Census. This includes the standard population and housing surveys. In addition, the Census releases other, more customizable products, such as the Public Use Microdata Samples (PUMS), that allow the user to create customized cross-tabulations of any Census long form data from a $1 \%$ sample of all Census long forms returned.

Many TMAs have a number of evaluative tools available from their own records. These include match rates, number of vans in service, number of companies contacted, number of commuters in the database, and so forth.Traffic count data, available from local governments and Department of Transportation Offices, can also be useful in evaluations and analysis.

In many cases, however, there will be a particular hypothesis that simply can't be proved or disproved by publicly available information, particularly when subjective evaluations (such as satisfaction ratings, ratings of agency responsiveness, and so on) are required. When that situation arises, survey research can provide the means for answering many of these questions.

In a survey research project, it is crucial to ask the right questions. It is equally important to ask those questions of the right people. Identifying those people is the crucial first step in developing the sampling strategy. Suppose it is determined to estimate the interest level in carpooling among commuters who are not currently in the ridesharing database, as shown in some of the examples above. No matter what questions are asked, good estimates will 

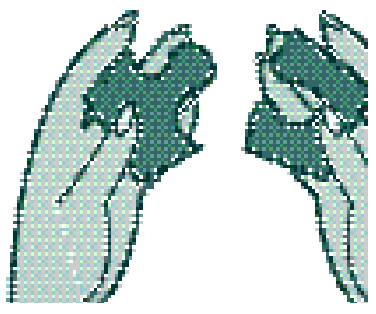

not be achieved by interviewing retirees. The goal of the sampling plan should be to identify commuters and interview them and only them.

The hypothesis or hypotheses should always indicate from where to draw the sample. The hypothesis given above specifically mentions "carpoolers" and "rideshare database members." As mentioned earlier, a sound hypothesis should always contain the source, or target population, from which the information will come. If the hypothesis is properly constructed, determining the correct population should not be difficult.

Actually obtaining responses from people in those groups and verifying that the respondents belonged to those groups may be more of a challenge. If no available sources exist to preidentify the people contacted as belonging to the target population, it may be necessary to include an identification question (often called a screener) in the survey instrument. The screener is essentially a question that verifies the identity of the respondent in relation to the target population. Many surveys have quotas for males and females, for example. Often a TMA director wishes only to obtain survey responses from adults ( 18 or older, or 21 or older). If, as in the case above, one only wants to collect data from commuters, a question very early in the survey would ask something like,"Do you commute to work at least three times per week?" to verify that the respondent was in fact in the target population.

Even when a database identifies a person as a member of a target population, it is often a good idea to verify the information through use of a screener. Sometimes databases are out of date or have errors in the entry of data. Using a screener can avoid unnecessary expenditure of usually scarce research dollars on unwanted responses.

\section{Summary}

By considering each of the above elements and following steps in the proper sequence, the effectiveness of research dollars available can be maximized. At a minimum, adherence to the standards set forth in this section should maximize the TMA's return on their investments in research.

While a TMA can take every precaution and devise a nearly flawless evaluation methodology, the value is lost if the TMA cannot effectively communicate the results of their efforts. This section will focus on ways in which TMAs can communicate evaluation findings to a variety of audiences.

\section{Market Research Tips}

Keep surveys short and simple; ask only questions that are necessary, organize questions logically, and use familiar language.

- Give your survey a professional look and a cover letter that enhances legitimacy.

- Make it easy for people to complete and return survey forms. Make the survey form a self-mailer, or include a postage-paid envelope. 


\section{Getting To Know Your Audience}

To develop an effective evaluation report, the TMAs must first understand who their audience is, what information will be of interest to them, and when the information should be available to satisfy the audience's needs.

Who is the audience for a TMA evaluation report and what do they want to know? Although the audiences for a TMA evaluation report will differ by TMA, a number of groups with interest in the TMA can be identified. These include the following:
- Funders
- TMA Staff
- Board of Directors
- Media
- Service Providers
- Politicians
- Clients
- Community Groups
- Other Interested Parties

Each of these audiences has specific needs from an evaluation. It is up to the TMA to identify what those needs are and to ensure that the information of interest is provided in the evaluation report.

\section{Funders}

This group will want to ensure that the money provided is being used wisely to achieve identified goals. Prior to beginning an evaluation, the TMA should contact its funders to determine specific expectations of the TMA program, and develop an evaluation that measures how those expectations are being met.

\section{TMA Staff}

This is an important audience for TMA evaluation reports because this group is the one that will be most affected by the results. TMA staff can use the evaluation to streamline efforts, to clarify the customer service focus, and to correlate efforts with the achievement of TMA mission and goals. The evaluation should help the director determine if current focus and efforts are achieving desired results.An effective evaluation will help the director refine efforts and target new actions that can help achieve stated goals.

\section{Board of Directors}

The evaluation is important to the board because it helps them determine if their guidance and policy directions are effective in meeting program goals. The evaluation will also help determine future board roles.

\section{Media}

The media will want two things from an evaluation. They will be interested to see if the TMA is meeting its objectives, and they will want anecdotal information that can be used in developing a story. If anecdotal information is good, the media will develop articles or stories that can be an excellent source of program promotion. 


\section{Service Providers}

Third party providers, such as taxi companies for guaranteed ride home, can use TMA evaluation results to improve the services provided on behalf of the TMA. Many of these service providers have specific internal customer service and/or satisfaction goals that they want to achieve. The TMA evaluation can help them define their success.

\section{Politicians}

The TMA evaluation can help politicians determine if the needs of constituents are being addressed.The evaluation can also serve as an educational/promotional opportunity because it can provide the politician with information about TMA activities and services. Ultimately, the evaluation can serve as a decision-making tool.

\section{Clients}

Customers of the TMA are interested in learning about changes in services and how these changes can affect them. They may also be interested in learning how their actions have contributed to the community and/or program success.

\section{Community Groups}

Many community groups will be interested in learning what services of the TMA can be beneficial for their success. They may also be looking for ways in which their group and the TMA can work together collectively to achieve common goals. Finally, community groups may view the evaluation in the context of comparing their achievements with that of the TMA. This can be especially true if the TMA is a private non-profit organization competing for funding.

\section{Evaluation Timing}

When is the best time to conduct an evaluation? The simple answer to this question is when it will be most useful. The better answer would be whenever the evaluation can be used to improve services and the effectiveness of the TMA. In reality, if an evaluation is to be used by all of the potential audiences listed above, then the TMA would have to continuously evaluate its success. Such an evaluation schedule is impossible, so the TMA should prioritize the most important audiences and complete evaluations to coincide with prioritized needs. Even then, the TMA may need to make some important decisions.

For example, if the purpose of the evaluation is to improve service to justify increased funding, then it stands to reason that the evaluation should be completed to coincide with funding cycles. However, budgets are developed after plans and programs have been determined. This often occurs six months before funding is determined. If the evaluation cannot be used to make improvements to service, or used to determine what services should be offered, then the evaluation may be completed too late to justify increased funding levels that reflect new services.

The following local agencies should be contacted to determine when budget and funding decisions are made, and when the TMA should be prepared to make its pitch for funds.

- Metropolitan Planning Organization

- State Department of Transportation

- City and county governments 


\section{Important Considerations In Evaluation}

When developing an evaluation for a particular set of audiences, the TMA should keep in mind several important considerations. Morris, Fitz-Gibbon, and Freeman in "How To Evaluate Evaluation Findings," 4 provide an explanation of these considerations.

\section{Different users want different information-even to answer the same ques- tion.}

A funding agency may accept only valid and reliable test data to prove that a staff training program has been effective, while the personnel participating in the training program would find anecdotal reports and responses from interviews or questionnaires to be the most valid and believable evidence of program effects. Other audiences might require both kinds of information.

\section{Some users do not know what they need.}

In programs where evaluations are mandated by legal requirements, for example, evaluation clients or program staff may see the assessment simply as a trial to be endured, not necessarily as a process that will lead to useful information and enlightened decisions. If the users are not willing to commit to some criteria for measuring success before the evaluation starts, it is highly unlikely that they will accept or use final recommendations. Formative evaluators consistently face the task of helping clients define not only program objectives, but also specific evaluation information needs.

\section{Some users expect the evaluation to support a specific point of view.}

Some people have already made up their minds about the strengths and weaknesses of the program, and they expect that the evaluation will only confirm their opinions. The results of the evaluation may very well not support their preconceptions. So it is vital that the evaluator identify the opinions early on so that potential controversies can be anticipated and reporting procedures can be designed to take them into account.Alerting users to discrepancies between their assumptions and the findings as they emerge, rather than solely in a final report, will make the users more receptive. In fact, an effective evaluation report will contain no surprises, especially with respect to central issues. All of the major questions will have been discussed with program personnel and decision makers from the very beginning, well before the final reporting stage. If the evaluation does not bring these issues to light early, the evaluator loses credibility.

\section{For some users, the information needs change during the course of the evaluation.}

It is not uncommon when a formative evaluation is well under way for the users to identify new information they would like to have. Some trainers, for example, might mention that the computer operators in a pilot training program seem to be learning a new data processing system, but the operators have developed a strong dislike for the system. You might change your evaluation plans to include some attitude measures. Although you cannot constantly alter evaluation plans, try to reserve some small portion of your resources to meet requirements for unexpected information that crops up during program implementation.

As the TMA develops its evaluation, it needs to be aware of these issues and plan accordingly. In most cases, the TMA will have to decide how to best meet the needs of its primary audience, and develop its evaluation program to meet those needs.

4 “How to Communicate Evaluation Findings," Lynn Lyons Morris, Carol Taylor Fitz-Gibbon, and Marie E. Freeman, Center for the Study of Evaluation, University of California, Los Angeles, CA, Pp. I4-I5. 


\section{Documenting Evaluation Findings}

- Transit agencies

- Private foundations

With the exception of private foundations, most of the agencies listed above will be on one of two funding cycles, the fiscal year cycle or calendar year cycle. Many fiscal year cycles run July I-June 30, although federal programs begin a new fiscal year on October I.As the name implies, calendar year cycles run January I-December $3 \mathrm{I}$.

For private foundations, the exact timing of funding decisions varies greatly and the same foundation may make funding decisions multiple times during the year. For example, the Energy Foundation meets three times a year to review proposals for funding decisions, and requires that materials and proposals be submitted at least eight weeks in advance.

Regardless of who is providing the funds for the TMA, all funders will probably require an evaluation of efforts. Immediately upon award of the grant, it should be determined when these evaluation results are due, as well as what will be evaluated and how. If an evaluation measure is to be tracked internally (e.g., number of inquiries about TMA services), the monitoring and/or evaluation should be continuous. Continuous monitoring and evaluation can be especially beneficial if funders require quarterly reports of progress. Again, these requirements should be spelled out when the grant is provided.

Once evaluations are complete, the TMA must decide how best to convey the results of the evaluation. A well-designed and carefully managed evaluation can be wasted if the results are not presented in a clear and understandable format. It is also important to remember the potential audiences for the evaluation results and what reporting format will be most useful to meet their needs.

While most TMAs will disseminate evaluation results in technical reports and/or quarterly progress reports, other forms of communication can also be used. Following is a list of potential communication media for evaluation results.

- Technical report

- Executive summary

- Brochure

- Press release

- Trade journal article

- Memorandum

- Public workshop

- Conference/seminar presentation

- Face-to-face discussion

Among all of the audiences for a TMA evaluation report, the funders, board members, and TMA staff will have the most interest in a full technical report. Since two of these three audiences have other duties beside TMA oversight, the technical report should be clear and concise, as well as technically credible. A well-written technical report will become a reference manual for this audience.

For politicians, the media, community groups, and clients, the preferred written document will be the executive summary. Even funders and staff will use the executive summary for their own needs. Therefore, the executive summary can be the most important document the TMA will write to disseminate evaluation findings. The summary should be brief, highlight 


\section{Developing a Strategic Work Plan}

the most important findings of the evaluation, and report the major recommendations of the analysis. Supportive graphics that depict the most important results can be beneficial in the executive summary.

Other communications media listed serve specific audience needs. How the TMA chooses to handle the evaluation findings will dictate which of these media will be used and how they will be used. To strengthen these types of reports, the TMA office should try to determine what evaluation findings are the most important to the audience and focus on preparing a report that best meets that need.

The key for most TMA offices is to look at the evaluation and evaluation report as a powerful tool. If the tool is used effectively it can show the diligence of TMA efforts, the impact the TMA has on meeting community goals and service needs, and the importance of the TMA in solving local and regional problems. A properly planned and well-documented evaluation can be an excellent medium for promoting the TMA and increasing awareness of the community on the important role the TMA plays.

Planning is the single most important function of the board of directors, for which the TMA staff provides key support. The planning process enables a TMA to take maximum advantage of new opportunities, while devising measures to address present challenges and taking steps to avoid foreseeable problems.

The solution to common organizational problems is to plan realistically and regularly. The results of the planning process are generally written in a work plan that guides TMA activities for a specific time period. At the end of this period the process is repeated, with the benefit of updated information, and a new work plan is created.

Public funders generally require a work plan as part of a seed funding application, but the plan's primary roles are to guide the TMA and be used as a tool against which the TMA can gauge its accomplishments throughout each year. If you represent a new TMA, plan preparation will likely begin during the exploration stage and continue into the formation stage.

During the first year, the plan will focus substantially on TMA development tasks. Although TMA services will be included, they often can be described only generally at this point. In fact, one activity included in the first business plan will be to further define appropriate TMA services and develop a detailed program for service delivery. Work plans for later years will be more service-oriented, as TMA organization tasks will have been completed.

The work plan serves five purposes:

I. Articulates the mission, goals, and objectives

2. Describes activities related to each objective

3. Assigns staff responsibility for activities

4. Establishes an implementation schedule

5. Defines allocation of resources 


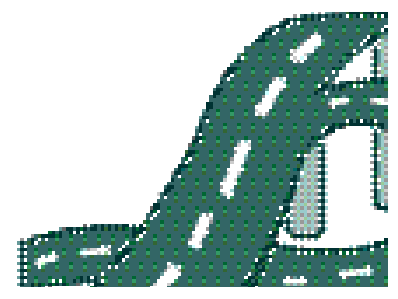

Planning doesn't stop with the writing of the document. Plans are developed under a set of conditions that exist at a point in time with the understanding that things are constantly changing.A TMA must, therefore, regularly review its progress, note any changes in external conditions, and refine its course when necessary, to remain on track.

Planning is an ongoing process with four basic steps:

I. Assessing where you are today: examining the internal and external environment, past successes, and areas that need improvement, financial and staff resources

2. Determining where you want to be at a particular time in the future: staying on track with the TMA's mission, goals, and objectives

3. Defining the steps you will take to get there: specific action plans, responsibilities, and resources

4. Determining how you will know you have arrived: review and evaluation

It sounds simple, but completing these four steps requires research and preparation, serious discussion about difficult issues, consensus building and group decision-making. Building consensus can lengthen the planning process, but it is necessary. Without agreement on key elements, the plan will not have the support needed to make the goals a reality.

During the TMA exploration phase, basic information about services and programs desired by potential members and their employees was collected. Research might have included interviews with business leaders, employer and employee surveys, and other research designed to assess the transportation needs and problems of these groups. If the TMA has been in existence for a few years, much of the data and information needed can be supplied from last year's monitoring and evaluation activities.

Take stock of the TMA's present status and examine internal and external conditions that could affect the TMA and its progress. The fact that a TMA has been established suggests that changes needed to be made. Examine the internal environment first. This includes:

- Past activities, accomplishments, and difficulties

- Strengths and weaknesses

- Resources and support

- Internal organizational constraints (e.g., bylaws)

The external review should examine outside forces that could affect the TMA, for example:

- Specific transportation-related problems or issues

- Impacts of these issues on various groups

- Programs of other organizations that compete with or complement the TMA

- Government initiatives, such as regulations, programs, and services

- Economic or political conditions

The need for this information cannot be overemphasized. Although most TMAs are nonprofit organizations, they are most importantly businesses, selling products to customers. If the TMA offers products and services no one wants, or charges too much for services, it will fail for lack of sales. A TMA's activities must, therefore, be market-driven, rather than service-driven, and must develop services that satisfy market demands. 
If members are primarily employers subject to trip-reduction requirements, one marketable service could be assistance in complying with the requirements. On the other hand, if the TMA's area is a new development and members are primarily developers, offering presentations on the TMA's services for new tenants' employees could be a desirable service. If members are concerned about growth and economic development issues, local and regional transportation and land use planning services may be useful. In short, develop desirable, effective services to attract new members and keep existing members.

Some of this information can be assembled prior to the first planning session and provided to members as part of a pre-planning orientation packet. During the planning process, discuss how each of these forces could positively or negatively affect the TMA, and identify those on which the TMA should capitalize and which must be overcome or accommodated.

After you examine the present, project the future. Devote adequate time to answering the following questions that are fundamental to the TMA's mission, goals and objectives:

- What business does the TMA want to be in the future?

- Which of the problems identified earlier should the TMA address?

- For whom does the TMA exist?

- Who benefits from TMA activities and services and might be willing to buy what it is trying to sell?

- What does the TMA hope and intend to achieve?

\section{Define the TMA's Mission}

\section{Establish Goals}

The mission is not a list of activities, but rather a description of why activities will be undertaken. A mission is important because it keeps activities productively focused, directs resources, and communicates a unified concept of the organization. A mission statement should be concise, active and focused. Most are only a few sentences. An effective mission statement will express a vision that is:

- Results-oriented rather than process-oriented

- Forward thinking and problem-solving

- Clear, simple, direct, and realistic

- Flexible enough to accommodate change

An example of a TMA mission statement might be: "To reduce peak period vehicle travel and enhance public mobility and air quality in the TMA area, through implementation of joint public-private transportation management efforts."

Goals are specific result-oriented achievements that support the mission statement. Some TMA goals might include:

- Reduce trips and congestion, ensuring access to the area

- Enhance transportation options and services

- Establish transportation policies favorable to members

- Provide support to individual members

- Increase membership, funding, or organizational stability

- Increase employer and employee awareness 


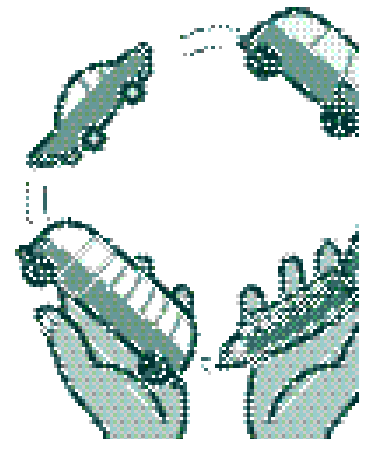

Objectives are the specific means to accomplish goals. Objectives must be, in some way, measurable and realistic, in order to determine the extent to which goals have been achieved. Often a TMA will have more than one objective per goal.

Although the mission of the organization should not change from one year to the next, goals and objectives often do. That's because they reflect accomplishments from the previous year and must incorporate the changing needs of the market to move the organization forward.

One TMA's goals will not be exactly like those of any other TMA, but some goals are universal. Reducing single occupant vehicle commuting or reducing peak period vehicle travel are common goals among most TMAs. Similarly, nearly all TMAs provide member services and set goals for these activities. Most TMA goals fall into one of five categories:

I Mobility enhancement

2 Member services

3 Information exchange

4 Transportation planning advocacy

5 TMA operation and administration

\section{Mobility Enhancement}

The central focus of a TMA's existence is the provision, coordination, and promotion of actions that enhance mobility in the specific service area. Typically, these actions include a variety of Transportation Demand Management (TDM) as well as Transportation Systems Management (TSM) tools.TDM-related actions alter the demand for travel by affecting total traffic volume, travel mode share, or distribution of travel over different times of day.TSM goals relate to the use of low cost improvements to increase the efficiency of roadways and transit services, such as retiming traffic signals or re-designating traffic flow.

Examples of traditional mobility enhancement goals are:

- Reduce traffic congestion along major arterials within the service area

- Minimize peak-hour traffic

While TMAs have traditionally served as the organizational vehicle for implementing TDM, there is nothing that should prevent a TMA from adopting a mission and goals that address transportation issues using methods and actions outside the realm of TDM.TMAs may also choose to focus upon market segments other than commuters to achieve objectives. For example, a TMA may select traffic generated from school or university sites to institute staggered class scheduling or "school pools." A TMA might also focus upon services for visitors where heavy tourism affects mobility.

\section{Member Services}

In addition to performing specific TDM activities, which can be offered to both members and the public at large, mostTMAs also provide certain services only to members. Examples are assistance on transportation problems, information or program incentives, help with compliance of regulations, or other services unique to the needs of members. Member services goals might be to:

- Assist members with solving site-specific transportation problems

- Assist members in complying with mandated travel-reduction requirements through 
a common transportation management program

\section{Information Exchange}

TMAs typically provide information on transportation issues, programs and activities to members and potential members. A TMA might consider adopting information exchange goals similar to the following:

- Conduct public information and educational activities about transportation conditions and opportunities

- Increase general awareness of commuting options, TMA services, and transportation issues and programs

\section{Transportation Advocacy}

Many TMAs are also interested in encouraging in-house staff and members to participate in local planning for transportation services, facilities and land use.Transportation advocacy goals might be to:

- Advocate and support improvements to local and regional transportation services and facilities

- Participate in the effective planning and implementation of area transit or highway construction and reconstruction projects

\section{TMA Operation and Administration}

The final category of goals includes those related to the smooth daily operation of the TMA, and planning for the future. Marketing, planning, and membership development are often included under this general goal, although many TMAs define separate, specific targets for membership in a marketing or membership development plan as a subsection of the business plan. Examples of these general goals are:

- Establish an effective and continuing TMA organizational structure

- Ensure TMA financial self-sufficiency and ongoing operation

\section{Developing Objectives and Choosing Performance Measures}

To accomplish each goal, one or more related objectives are drafted. Objectives are more specific statements of how a goal will be reached. Clearly written objectives provide a time frame during which the objective will be accomplished and means of measuring the result, commonly referred to as performance measures.

Properly drafted objectives also incorporate an understanding of baseline conditions in the area to which the objectives will be applied. The baseline provides a reference point from which you can measure change. Information on baseline conditions can be collected during the conduct of a TMA feasibility study, if the TMA is new. Data collected on baseline conditions is also part of the monitoring and evaluation aspects. This is discussed earlier in this section under "Initial Work Plan Development Considerations-Data Collection.” For example, if a mobility enhancement goal is, "Reduce traffic congestion along major arterials within the service area," an objective might be to "Alter mode share to reduce single-oc- 


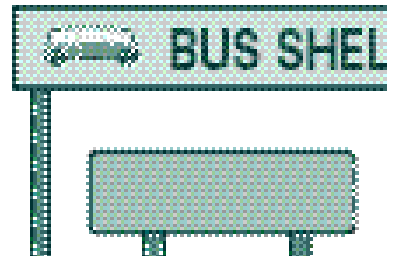

cupant vehicle travel by three percent by the end of the program year."

Performance measures for this objective could include:

- Percent mode share in service area for carpool/vanpool

- Percent mode share in service area for public transit

- Percent mode share in service area for bicycling

- Percent mode share in service area for walking

- Percent mode share in service area for telecommuting

Each one of these performance measures suggests different actions to accomplish the objective. For example, an action to increase the percent mode share in the service area for carpooling, vanpooling, public transit, bicycling or walking might be to provide a guaranteed ride home program (discussed as an example later in this section, under TMA Service Delivery).Alternatively, an action to increase telecommuting mode share might be to provide technical assistance to employers whose business could yield productivity gains and save on overhead costs by instituting a telecommuting program.

It is important to select performance measures before selecting actions for the work plan. This is because it is possible to select an action which a performance measure cannot be identified, or for which the performance measure is too expensive or too difficult to collect data. How then can it be demonstrated that a positive outcome resulted from the work plan implementation? In a competitive funding environment, it is important to document TMA program effectiveness and results to increasingly skeptical funding agencies and duespaying members. It is crucial to develop a work plan and monitoring system that enables convincing measures and documents program results.

In the above example, the objective includes reducing SOV mode share by 3 percent. It is of value to specify in the objective the degree of change that the actions seek to accomplish, in this case, three percent. By reaching a specified target, success is clear. The degree of change specified in the program objectives should be carefully considered, such that it is ambitious but also realistic. If it is set too low, the program will underachieve. If it is set too high, there is a risk of hurting morale by having "failed" to reach the objective.

\section{Benchmarking for Realistic Objectives}

Use benchmarking to set realistic objectives. Benchmarking involves finding other programs with similar objectives that have been applied to service areas with comparable characteristics. Based upon other programs' previous experience, there is some sense of what might be realistic to expect. This information can be found by networking with other TMAs or contacting the National TDM Clearinghouse at CUTR for case study information. Benchmarking is not a precision exercise, but provides ballpark comparisons for setting realistic program targets.

\section{Trend of Continual Improvement}

TMAs commonly strive to achieve goals and objectives relating to travel behavior change. Because travel behavior changes are difficult to achieve and maintain, it is recommended that the emphasis in measuring performance should be upon a trend of continual improvement. Incorporating a philosophy of demonstrating continual improvement into the development of program objectives will establish a more reasonable tone to the program and help maintain participant morale by recognizing incremental gains. 


\section{Work Plan Development}

While a TMA's mission, goals, and objectives form the foundation, a work plan is necessary to define the activities and services needed to achieve the objectives. A work plan serves five functions:

I. Documents the TMA's mission, goals, and objectives

2. Describes activities related to each objective

3. Allocates resources to achieve objectives

4. Assigns staff responsibility for each specific step

5. Establishes an implementation schedule

To develop the work plan, it is necessary to decide:

- Activities that will allow the TMA to meet its objectives

- Total resources of money, staff time, in-kind support, and influence that can be devoted to the plan

- Tasks that require participation from other groups, such as transit agencies, local governments, businesses, or commuters

\section{Traditional TMA Activities}

TMA activities have traditionally fallen into five categories:

I. Exchanging information

2. Providing transportation services

3. Promoting transportation services

4. Advocating for improved transportation services

5. Offering consulting services to members

A service package might include some of these services, as well as others unique to members' needs.

Exchanging Information-Many employers join a TMA to receive information about transportation initiatives, services, and activities. They can be the transportation "eyes and ears" of local transportation issues, while learning about new public and private transportation services, local ordinance requirements and other transportation-related topics. TMA information activities might include:

- Publishing periodic newsletters and special bulletins and maintaining a web site

- Sponsoring transportation meetings, seminars, and workshops for members and others

- Serving as a one-stop information center

- Developing and conducting training courses

- Organizing and supporting an information-sharing network using email

Providing Transportation Services-A small but growing number of TMAs directly provide transportation services and tangible incentives to commuters and other markets. For example, in many areas employee commute alternatives are limited.TMAs can provide additional transit, vanpool, and other transportation services or coordinate the planning 


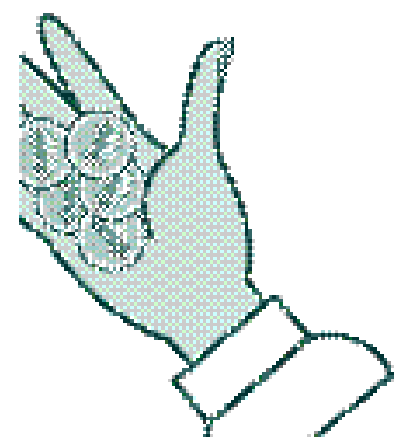

and provision of these services by several local employers. Services and activities in this category include:

- Offering carpool and vanpool formation assistance, such as advertising empty seats and processing paperwork

- Subsidizing commuting alternatives, such as empty seat subsidies

- Operating vanpool services, express buses, shuttles, and other services

- Developing or coordinating new transit services

- Providing support services, such as guaranteed ride home or transit pass sales

- Facilitating the coordination of TDM services by several employers

Promoting Transportation Services-By providing services at work sites, TMAs can support employers, property owners and developers and tenant managers who implement transportation programs. Some ideas for specific service promotions are:

- Organizing and conducting on-site commuter information fairs and other events

- Acting as a transportation coordinator for employers

- Participating in new-hire employee orientation sessions

- Preparing commuter information materials that employers can distribute to employees

- Stocking "take one" displays for commuter information at work sites

- Preparing work site-specific transit maps and individual transit and bicycle routing maps

- Hosting multi-company vanpool formation sessions

- Buying "give away" promotional items in bulk for distribution to members

- Coordinating the purchase and/or distribution of transit passes

Advocating for Improved Transportation Services-Many employers and developers join a TMA to influence transportation service and facility planning and/or influence development of legislation and regulations on commuting issues.

Advocacy can include:

- Working with transit agencies to develop new services, or adjust existing schedules or routes for more effective operation

- Working with local governments to ensure that TDM strategies are incorporated into new transportation projects and air quality objectives

- Monitoring local transportation conditions and advocating needed improvements at bottleneck points and congested locations

- Participating in the transportation and land-use planning processes of city and county planning organizations

- Lobbying local and state governments for transportation policies, legislation, and regulations

Offering Consulting Services to Members-Many TMAs provide transportation consulting services to members, helping them develop and implement employment site 


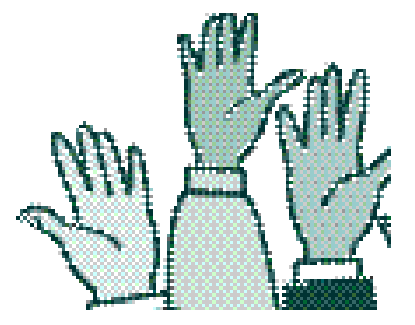

TDM programs, solve site-specific transportation problems, and meet local ordinance requirements. Consulting activities might include:

- Conducting employee surveys and work site analyses

- Analyzing survey and site review results

- Guiding the selection of appropriate TDM strategies

- Developing, reviewing and implementing trip reduction plans

- Guiding the development of new services such as guaranteed ride home programs, vanpool services, shuttles, telecommuting, alternative work hours, parking management, and others

\section{Assign Responsibilities}

The work plan must also establish who will be responsible for each activity-the executive director, board of directors, committees or individual members? If a TMA has only one staff member, be particularly careful to share work assignments among the board, committees, and others to avoid staff overload. Since some activities will require the participation of people outside the TMA, such as a transit agency or local government, define who will coordinate the participation of those groups.

\section{Prepare Implementation Schedule}

As resources are allocated for each activity, compromises will need to be made based on priority and budget. Decide when each activity should be accomplished. Identify what must be undertaken immediately and what can wait until later. Organize the steps sequentially to identify steps to take first. Define a reasonable time schedule that allows progress in each area, but does not overwhelm personnel resources. For some activities, be specific to the quarter, month and even the day. For activities that cross several months or quarters, define the date to begin the activity, the date it will be finished, and dates of any critical, intermediate milestone activities.

Often the start date of an activity is determined by "backing out" the time the activity will take from the date the activity must be finished. For example, when developing an information brochure needed by mid-August, start the project in early May to allow time to select a graphic artist, produce text for the brochure in mid-June, review the graphic artist's design in mid-July, and send the brochure to the printer by the end of July. These key intermediate activities are the milestones.

The implementation schedule also should note prerequisite activities, such as:

- Making an organizational change (e.g., bylaws change)

- Developing a new organizational relationship (e.g., partnership with transit agency)

- Conducting research or collecting other information (e.g., survey)

- Disseminating information (e.g., notice, announcement, or invitation)

In preparing the schedule, consider how quickly each activity should progress and how the timing will affect progress in other activities. Establish reasonable completion dates for activities. To ensure that activities are occurring on schedule, prepare a master time line or calendar for all activities and review it regularly.

\section{Plan for Contingencies}


Start the process early in the TMA's life and keep the cycle going through the year.

- Establish a solid policy and strategic planning framework including setting clear goals and objectives.

- Make planning sessions informal and fun - get away from the routine.

- Leave each planning session with steps to be accomplished and individual assignments for follow-through.

- Utilize committees to develop background information and prepare recommendations, and create ownership among members.

- Train yourself and your members to think strategically all year-not just during planning sessions.

As the final step, develop a contingency plan. Goals and objectives were developed under a set of assumptions. Contingency planning tries to prepare for unexpected and unlikely occurrences. In constructing a contingency plan, consider potential variations in the assumptions used in developing the original plan. Plan what to do if a variation occurs. For example:

- What if a market doesn't materialize or changes dramatically?

- What if competition is encountered?

- What if the regulatory climate changes?

- What if the economic environment changes?

- What if expected financial support does not appear?

All of the questions might not be answered immediately, but simply asking them can be useful to identify where the TMA might encounter problems. Continue to review these contingencies as the year passes, then refine, add, or delete them as new information becomes available.

\section{Host a Planning Retreat}

Planning is not a quick exercise. Assume at least two full days will be needed, even to establish the basic framework.

Ideally this time will be scheduled as a single session, perhaps over a weekend. A retreat might not be feasible for all TMAs, but it is highly preferable to conduct planning in as few working sessions as possible. By concentrating the planning time, the time is minimized for review of previous sessions and for members to "get into the mood."

Establish a Planning Agenda-If members cannot devote two days of uninterrupted time, then hold several sessions each, at least four or five hours long. Schedule them closely together, such as over a two or three week period. Since each session must build on the ones before it, members will be more likely to remember the discussion from previous sessions if they are held over a shorter time period.

Don't rush through the planning process. Each step is an important building block to developing a plan that is reasonable, realistic, and acceptable to all members. If members need 
additional time to feel comfortable with their decisions, stretch the process to additional sessions. Avoid however, "paralysis by analysis" that can occur if members are reluctant to commit to any given course of action. Endless discussion and delays in completing the plan can lead to frustration for those who want to move ahead.

Described below is a possible outline for three planning sessions. Progress in any single session depends on the TMA's stage of development (newerTMAs might need more time), the amount of preparation staff, members, and committees are able to do before the meeting, and the ability of the group to discuss issues freely and openly and to reach consensus.

- Session One-During the first session, acquaint the members with the planning process, identify key issues, and create a common vision of direction. Review the TMA's internal and external environment. Discuss likely challenges and opportunities during the coming year. Emphasize the need to recruit potential markets, develop new programs, and achieve the mission and goals.

- Session Two-Begin by reviewing the mission and goals defined earlier.Then review the TMA's strengths and weaknesses. With this as background, define key objectives and brainstorm activities to support the objectives.

- Session Three-Review the objectives and activities defined in session two and continue development of the action plan. Prioritize activities and assign responsibility and resources to each. Outline a schedule for completing each activity. Explore contingency strategies and establish a process for staff to monitor the plan periodically and report progress and problems to the board.

- Follow-up-An important step in any planning process is follow-through on the previous planning session discussions and decisions. Planning is not an end in itself. Rather, it is the first step in an ongoing process. Simply identifying key issues, or even solutions, is meaningless unless decisions are implemented. During the meetings, members might need more background information on a topic before proceeding with a decision. If so, hold that decision to the next session, or make a conditional decision subject to change if new information warrants. Assign a staff, board member or group of members to research the topic and prepare materials for the next meeting.

After each session, summarize the discussion, decisions made, and assignments for follow-up. Prior to the next session, circulate the summary, with any additional materials produced. Use the summary as a springboard for the next session.

After the plan is complete, the board should present the plan to the full membership for their review and comments. It may be desirable to present key planning decisions, such as mission statement, goals and objectives, and activities to the members during the planning process, but avoid having this turn into another full planning session.

Create a Supportive Planning Environment-The environment in which planning sessions are held can influence their success. Here are some suggestions for organizing effective planning sessions.

Encourage Open Discussion and Teamwork—Use settings and seating arrangements that encourage eye contact, teamwork, and easy conversation.

Make it Informal and Fun-Hold the session in an informal setting completely removed from the usual meeting locations to allow members to concentrate on issues with few distractions. Meet at a board members' home or a hotel conference location. Encourage casual dress. Use games and exercises to build teamwork and keep members interested.

Use An Outside Facilitator-Consider asking a trained facilitator to conduct the session instead of the president or other officers. A skilled facilitator might be better able to draw 
out issues from members, smooth any arguments or dissension, and build consensus. Staff should participate in the discussion rather than conduct or facilitate the session.

Provide Background Materials and Record the Discussion-Provide any background materials prior to each session so members can prepare for productive discussions. Use flip charts to record members' thoughts and ideas. 



\section{TMA Develop- ment-Financial Management and Service Delivery}

- Section Overview

- TMA Budgets and Funding

- Financial Management Issues for TMAs

- Delivering TMA Services 



\section{Section Overview}

\section{TMA Budgets and Funding}

\section{Annual and Multi-Year Budgets}

The previous section discussed considerations of program monitoring and evaluation and data collection for purposes of market research, measuring baseline conditions and program results. The previous section also discussed important considerations regarding communicating evaluation findings and developing a strategic work plan.

Section 5 builds upon these previous discussions by adding the next set of considerations that make the strategic work plan a reality: translating the plan into effective service delivery, finding the funds to pay for it and establishing accounting methods to track financial status.

At one time or another, nearly all TMAs worry about funding, or more accurately the lack of it. Budgets vary dramatically by the size of the area served, number of members, stage of development, services offered, and sources of funding.

Cash flow is often a big problem in the TMA's early months. This means TMAs do not start out with a sufficient reserve to support the start-up and ongoing expenses of staff, office equipment and upkeep, research and marketing, and other business development functions until revenue from sales (membership) grows.

In later months and years, lack of funding can limit services provided. Members may want shuttle services, transit discounts, vanpool programs, information materials and other services, but the TMA's budget may not support these services. The TMA must expand services to increase membership, but to expand services, the TMA must have a larger membership base.

A TMA must ultimately work within its budget or find additional sources of funding. Potential problems can be minimized, however, if finances are planned and managed properly. Accurately and realistically estimating revenues and expenses, seeking out and developing all possible sources of funding, and carefully monitoring financial progress are keys to assuring financial stability.

Most TMAs seek advice from a competent accountant to establish a financial system. Most directors do, however, keep their TMA's financial records without substantial difficulty. It is not necessary to acquire an overly sophisticated financial system but the following minimum elements should be included:

- Annual and multi-year (2 to 4 year) budgets

- Cash flow projection

Annual and multi-year budgets are important financial documents. A budget is simply a list of the projected income and expenses for a time period, generally one or more years, but with income and expenses balanced to avoid overspending.

Budgets show both expenses and income. Expenses generally are divided into three basic categories:

- Operations

- Marketing and promotions

- Member services 
Income categories can include both private and public sources:

- Membership dues

- Fees for services

- Public seed funding grants and private start-up contributions

- Public service operation and study grants, and private contributions

- In-kind contributions

Define categories and sub-categories of income and expenses in sufficient detail to track financial progress, but not in so much detail that excessive time is spent tracking expenditures. Whenever possible, large expense categories should be broken down into more easily monitored sub-categories. For example, an item of "office expenses" is too broad, but "paper clips" is too detailed. Compromise with a few office expense items (rent, telephone/utilities, office supplies, and office equipment).

It is often difficult to develop a realistic budget in the first year because there may be unknowns in both expenses and revenues. Therefore, budget conservatively and monitor everything closely. This experience will help to prepare more accurate budgets in future years.

Develop budgets for both short-term (one year) and longer-term (two to four year) periods. The multi-year budget will include the current year's budget and project revenues and expenses beyond the current year. The short-term budget is clearly important for day-today financial management, but for financial stability and self-sufficiency, it is necessary to plan for multiple years of operation. Revenue and expense items for later years will not be as detailed as the current year, but will give an early warning about potential financial problems and allow adequate lead time to seek and develop additional sources of funding to support new services.

The 1998 ACT Survey of TMAs collected data on the breakdown of expenses incurred. Interestingly, the results show such a wide variation in budgeting that it is difficult to generalize. Among TMA respondents, the percent of the budget programmed for marketing and promotions ranged from 2-70 percent, with an even distribution between this high and low. Similarly, the surveyed TMAs alloted anywhere from 3-85 percent of their budgets for member services, with an even distribution between this high and low.

\section{TMA Operations}

Operations expenses are those incurred in administering the day-to-day activities of the TMA. Staff salaries are the largest operations expense item, and the largest single expense item for most TMAs. This is not surprising, since most TMAs provide labor-intensive commute management information and support services.

Related overhead can also absorb a substantial portion of the budget. This includes: office space, furniture, equipment, telephone and other utilities, postage, office supplies, insurance, staff travel, dues and subscriptions, and other office management functions.

Typical first year staff include a full-time director and part-time assistant. Director's salaries vary by location, but generally range from $\$ 30,000$ to $\$ 60,000$ per year.

Staff expenses also generally include payroll "burden" or "fringe." Payroll burden covers federal and state payroll taxes, but also expenses for staff vacation and sick leave, health insurance, and other employee benefits. Common fringe benefits provided to TMA staff include:

- Paid holidays 


\section{Marketing and Promotion}

\section{Transportation, TDM, and Member Services}

\section{Funding Sources}

Funding sources and amounts vary substantially from one TMA to another. These sources include:

- Membership dues/assessments

- Fees for services/user fees

- Seed funding and start-up grants

- Ongoing service operation and study grants

- Private contributions

- In-kind contributions (non-cash)

- Other revenue sources

\section{Membership Dues/Assessments}

Most TMAs receive some portion of their funding from membership dues. Membership dues typically account for 30 to 75 percent of a TMA's income. Dues structures vary for each TMA. Examine the potential member market and the value of the TMA's services in order to create a dues schedule that is appropriate and reasonable for members. Also examine the TMA's projected expenses to determine if the proposed dues will provide sufficient resources for activities. 
Most TMAs establish pre-determined dues categories. The advantage of this structure is that members know how much they will pay. The disadvantage is that the TMA's ability to cover expenses is uncertain and dependent on the number of members the TMA can attract.A small number of TMAs use an "expense sharing" dues structure, in which the TMA determines the amount of revenue needed to cover expenses and then divides that amount among members (current and projected).

Most TMAs set different dues for distinctly different types of members. Common dues categories are: employers, developers/property owners, local governments, and sometimes others such as non-profit groups and business associations. By structuring dues in this way, the TMA can account for differences in benefits offered to each group. Ideas for possible dues structures for each of these groups are as follows:

Employers and Developers-Employers' and developers' dues are most often determined by the size of their company or development project. TMAs located in areas with large amounts of undeveloped land might also assess dues for landowners based on the amount of land owned.

Some TMAs require all members to pay the same fee while others require companies to pay the same small base membership dues, plus additional fees for certain special services performed by the TMA, such as employee surveys and rideshare matching.

Graduated fees are commonly assessed in one of three ways:

- \$”“ per employee (for employers), \$” X" per square foot of building space (for employers or developers), or \$ “X" per parking space

- Range of size, such as $\$ 500$ for companies with I-50 employees and $\$ 1,000$ for 5 I150 employees

- A small flat fee plus a graduated portion, such as $\$ 250$ plus $\$ 5$ per employee

Local Governments-Local government groups or agencies are often TMA members. Local governments are both employers who can benefit from the TMA's services, and important players in the TMA's public-private partnership. Because of this dual role, local governments often do not fit easily into an employer member category and local governments might pay a flat fee dues rate, if they are voting members. If local governments do not vote, they pay no dues. Most local governments pay no dues if they have no employees able to use TMA services.

Other Members-Many TMAs have other members, including groups and individuals, to whom the TMA provides few direct services. Often they are grouped under a category such as "associates," "affiliates," or "supporters." Dues for these groups, when covered by a separate membership category, are usually set at a lower annual level. This category is often designated as non-voting. While it is important to evaluate each member individually to determine the most appropriate membership category, affiliate groups might generally include private transportation service providers, transportation and real estate consultants and attorneys, realtors, and business groups such as chambers of commerce. Members of an affiliate category for whom voting is important can join as employer members with an appropriate fee.

\section{Fees for Services/User Fees}

Some TMAs generate income from fees charged for services, which can be an important source of private funding. Fees are generally charged for special services, such as employee surveys or preparing trip-reduction plans that are time-intensive and needed by only a segment of the membership. The TMA could also offer some or all of these services to 


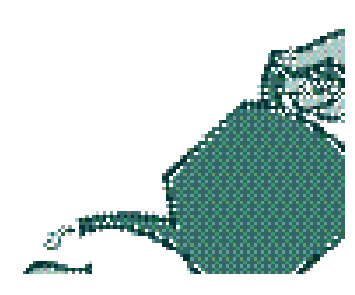

non-members at higher fees.

Some services for which TMAs charge fees include:

- Employee surveys

- Trip-reduction plan preparation

- Ridematching

- Workshops and seminars

- On-site TDM promotions

- Vanpool leasing

- ETC training

- Shuttle operation

\section{Seed Funding and Start-up Grants}

Federal and some state governments, regional agencies, and cities have implemented programs to provide start-up funding for new TMAs. Some programs require private sector match funding. As a general rule, government funds are not intended to support ongoing operations, but serve as seed funding (one to three years) to start a new TMA.The federal Congestion Mitigation and Air Quality (CMAQ) program is an example of a funding source that has been used for this purpose.

Public seed funding has played a significant role in the evolution of manyTMAs. Prior to 1995, the Federal Transit Administration funded the development of several TMAs, ranging from $\$ 25,000$ to over $\$ 100,000$ per year. Several states also implemented formal programs providing grants (most 50/50 match) to qualifying private organizations or emerging TMAs.

More recently, the State of New Jersey provides a total of $\$ 2.8$ million annually to its TMA Program, 100 percent of which is from the federal CMAQ program. Eight TMAs are eligible for $\$ 350,000$ each. The State of Colorado now requires TDM as part of all corridor studies. As a result, TMAs in the Denver area expect to receive $\$ 40,000$ to $\$ 70,000$ per year for the next seven years to mitigate construction impacts of a light rail corridor. In the State of Florida, seed funding has been available for the initial three years of TMA start-up, with up to 50 percent of the TMA budget provided by state funds during year I. During years 2 and 3, the state match drops to 40 percent and 30 percent respectively. Ongoing funding at the level of 25 percent of the TMA budget, up to $\$ 50,000$, whichever is less, is available based upon meeting eligibility criteria.

In the State of California,TDM used to be addressed on a state-wide basis, but is now addressed at the county level.The Southern California Association of Governments (SCAG) is providing three TMAs up to $\$ 40,000$ annually for a number of years to promote a regional ridesharing incentive program. It is possible to secure Air Quality Management District funding if TMA program results are properly quantified. In Colorado, four TMAs have been seed funded for up to three years with regional funds.

The City of Denver, Colorado offers $\$ 25,000$ per year to TMAs indefinitely, based upon eligibility. In the City of Sacramento, California, TMAs receive some funds from development ordinances or special taxes. Four TMAs in Atlanta, Georgia, obtain funds as being part of a community improvement district, in which property owners are taxed based on square footage.

The Tri-County Metropolitan Transportation District of Oregon (Tri-Met) in Portland offers matching funds totaling $\$ 250,000$ per year to TMAs that have secured CMAQ grants 


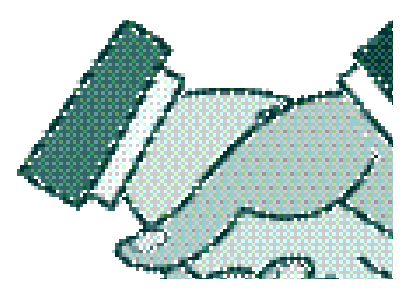

for vanpooling programs. The annual matching proportions are $10 \%$ for the first year, 33\% for the second, and $67 \%$ for the third year that the CMAQ funding is in place. Receipt of matching funds from the city are conditioned upon the TMA meeting CMAQ requirements, completing a feasibility study, securing a letter of funding commitment, and having a business champion.

SeveralTMAs have received substantial contributions from local developers, business associations, and/or large employers to assist in the initial development of the TMA. In later years, these supporters typically have continued paying dues, either along with other businesses or as the sole TMA funder. Although seed funding can be a valuable source of funding for a newly established TMA, the TMA should strive to establish funding sources that ensure stable, predictable funding.

\section{Ongoing Service Operation and Study Grants}

Few TMAs are able to support operation expenses such as shuttles and vanpools, demonstration projects or conduct special planning studies from general revenues. Instead,TMAs generally fund these services and activities through public grants and private contributions from employers and developers. Some public agencies offer grants for delivery of specific services, such as ridematching. The support can be provided as cash or in-kind donations. In other cases, public agencies contract with a TMA to perform services, such as bus pass sales and promotions.

Public agencies also provide one-time grants, often funded through developer impact fees, other traffic mitigation funds, or tax revenues earmarked for transportation programs. Because the sources of these grant funds often restrict their use, most of these grants are used for planning or evaluation studies, purchasing capital equipment (e.g., shuttle buses), or marketing. Service operation grants are typically given for a short demonstration period rather than for ongoing operation.

\section{Private Contributions}

Employers, developers, merchants, and other businesses can also be sources for funding services. Contributions from private groups primarily take one of two forms: direct cash contributions or subsidies to employees or patrons through purchase of passes or other vouchers. Employers and developers can also fund special studies

\section{In-Kind Contributions}

Many TMAs receive in-kind contributions from members, public agencies, business groups, and others. In-kind contributions can include: office space, furniture, equipment, postage, printing, clerical and professional services (legal, accounting, graphic design), and TDM planning assistance (local governments). Maximize the use of in-kind services and donations to reserve cash resources and minimize potential cash flow problems. However, be sure to assess potential impacts of in-kind funding on public grants. Some public agencies restrict the amount of in-kind services a TMA can claim as a match against public funds.

\section{Other Revenue Sources}

TMAs have become very creative in searching for funding sources. Some have been able to take advantage of tax revenues or developer funds for ongoing operation. A few TMAs receive ongoing funding from local tax sources. Another possible revenue source is the Common Area Maintenance (CAM) assessments included in employer tenants' leases. These assessments, generally used for grounds keeping, building maintenance, utilities, and other facilities, have been expanded to provide revenue for several TMAs. Employers join the TMA when they sign a lease, pay dues through the CAM, and have access to all the TMA's services. 


\section{Financial Management Issues for TMAs}

Though similar to a small for-profit business, nonprofit TMAs face different challenges from an accounting and financial management point of view. At the same time, the accounting systems for nonprofits have much in common with their for-profit brethren, though there are some significant differences.

The discussion below is not intended to be the definitive source for all the financial issues and accounting procedures to be followed by a TMA. It is not a substitute for qualified legal and accounting expertise. The discussion highlights the major issues of nonprofit financial management so a new TMA Board or a new TMA executive director with limited accounting experience can begin to understand the financial management processes and issues that can have a direct bearing on the long term success of that TMA.

\section{Difference-Source of Income}

One noted difference between the for-profit and nonprofit accounting world is the source of the income. Nonprofit TMAs receive much of their funds through donations and grants. Donors who make contributions to TMAs that qualify for tax-exempt status under Section $50 \mathrm{I}(\mathrm{c})(3)$ of the Internal Revenue Code are entitled to receive tax deductions. These donations can come to TMAs in one of three general types: in-kind contributions, special events and membership dues, and pledges.

In-Kind Contribution-Accounting standards require that nonprofits account for contributions of donated materials and services. In addition, volunteer time must be included in the financial statements when either the volunteer time results in the creation or enhancement of non-financial assets, such as volunteer labor to renovate a commuter center or the services volunteered are specialized skills, such as those provided by accountants, lawyers, and craftsmen.

Special Events and Membership Dues-People who pay to attend TMA fundraisers (such as golf tournaments, dinners, etc.) often receive a tangible benefit in return (a round of golf, a meal, etc.). Similarly, membership dues may entitle individuals to use facilities, receive services, etc. The portion of the special event charge or membership dues that represents the fair market value of the benefit received is not tax deductible to the donor. A latter section of this chapter will discuss this fair market value issue and the issue of unrelated business income.

Pledges (Promises to Give) — Industry standards also set down firm guidelines for pledge accounting, requiring that legally enforceable, unconditional pledges be recorded in the accounting records. An unconditional pledge is defined as a contribution that is not reliant on some uncertain future event, such as receiving a matching grant from another source. In addition, the accounting profession has established guidelines for responsibly tracking donations that have been restricted by the donor for a specific use (e.g., starting a new program). The nature of the restriction will determine how these funds are tracked and reported. 


\section{Differences and Similarities Between For- Profit and Nonprofit Accounting}

\section{Difference-Method for Tracking Income and Expenses}

Another common difference between small businesses and small nonprofits is the method selected for tracking all income and expenses. Most businesses track all revenues and expenses by using accrual accounting where revenues are recorded when they are earned and expenses are recorded when the obligations are incurred. A TMA, like many small nonprofits, may choose a simpler method - cash-basis accounting method - to record expenses and revenues. Under a cash-basis system, TMAs only record revenue when the cash is received, and only record expenses when the bills are paid, similar to maintaining one's personal checkbook.

\section{Difference-Reporting Requirements}

Reporting requirements are also different for nonprofits. Nonprofits are required to report their expenses by what is known as their functional expense classifications. The two primary functional expense classifications are program services and supporting activities. Supporting activities typically include management and general activities, fundraising, and membership development. Practices vary widely from organization to organization in the nonprofit sector as to how expenses are categorized by functional areas. In addition, financial information for nonprofits is interpreted differently from for-profit financial statements.

\section{Similarity-Capitalize and Depreciate Fixed Assets}

Similar to for-profit organizations, nonprofits must capitalize and depreciate fixed assets (i.e., purchase of long-lasting, substantial property and equipment such as vans, computers, etc.). Nonprofits must charge a portion of the cost of those items in each year of its useful life.

TMAs can expect their accounting system to change as its needs and resources change. For example, a new TMA may only need to keep an accurate record of activity in its checkbook. However, as the number of transactions increases, the TMA will add manual cash disbursements and receipts journals, but may still prepare monthly reports using a summary sheet of income and expense items. Finally, as the TMA acquires assets other than cash, such as vehicles, accruals are added, and transactions become more complex, a full general ledger system will need to be incorporated.

As their volume and complexity grow, the financial management activities will also require increasingly sophisticated staffing, whether by paid or volunteer staff or a combination of staff and outside service providers.An accounting system is only as good as the staff's ability to put it into practice, and should be designed with its users in mind.

An accounting system consists of records and a series of processes and procedures. The primary goal of the accounting system is to make certain that financial data and transactions are properly recorded and timely, accurate reports necessary for management oversight and planning are produced.

Traditionally, the accounting system includes the following components:

\section{Chart of Accounts}

The chart of accounts is a list of each item which the accounting system tracks. It serves as the table of contents to the general ledger (described below). The chart of accounts is divided into five major categories: 


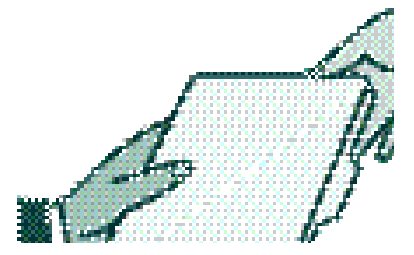

- Assets

- Liabilities

- Net Assets or Fund Balances

- Revenues

- Expenses

Each account is assigned an identifying number for use within the accounting system. At the end of this section, a sample chart of accounts is included.

\section{General Ledger}

The general ledger organizes information by chart of account numbers. In a manual system, summary totals from all of the journals are entered into the general ledger each month, which maintains a year-to-date balance for each account. Data is usually entered into a computerized system only once. The software includes the information in all related reports upon user approval of the entry.

\section{Journals and Subsidiary Journals}

Journals are used to methodically record all accounting transactions before they are entered into the general ledger. Journals organize information sequentially and by transaction type (receipts, disbursements, other). There are several types of journals.

Cash Disbursement Journal-This is a chronological record of checks that are written, categorized using the chart of accounts.

Cash Receipts Journal-This is a chronological record of all deposits that are made, categorized using the chart of accounts.

General Journal-This is a record of all transactions that do not pass through the checkbook, including non-cash transactions (such as accrual entries and depreciation) and corrections to previous journal entries.

Payroll Journal-This is a subsidiary journal, which records all payroll-related transactions. This may be useful as the number of payroll transactions increases and becomes too large to handle reasonably within the cash disbursements journal.

Accounts Receivable Journal-This tracks income accruals. It is used when there are too many entries to track effectively through the general journal.

Accounts Payable Journal-This journal allows a TMA to group expense accruals (e.g., bills) that are too numerous for the general journal.

The process of transferring information from the journals to the general ledger is called posting. Computerized accounting systems often require users to post all income and expense transactions through the accounts receivable and payable journals.

\section{Checkbook}

In very small organizations like some self-standing TMAs, the checkbook may serve as a combined ledger and journal. Most financial transactions will be made through the checkbook, where receipts are deposited and from which payments are made. Not surprisingly, small organizations receiving few or no restricted contributions find it much easier to keep track of financial activity by running all of their financial transactions through a single checking account. Very small organizations, with few deposits and disbursements, may 
prepare reports directly from the checkbook after the balance has been reconciled with the bank balance.

\section{Accounting Procedures Manual}

The accounting procedures manual is a record of the policies and procedures for handling financial transactions. The manual can be a simple description of how financial functions are handled (e.g., paying bills, depositing cash and transferring money between funds) and who is responsible for what. The accounting procedures manual is also useful when there is a changeover in financial management staff. One of the sections of this manual is a detailed "internal control procedure" that states who, how, and when various members of a nonprofit will manage the process.

Each of the above journals plays an important role in the accounting process. The chronological steps below describe the process.

I) Financial transaction

2) Analyze transaction

3) Record transaction in journals

4) Post journal information to general ledger

5) Analyze general ledger account and make corrections

6) Prepare financial statements from general ledger information

\section{Setting Up the Chart of Accounts}

A TMA's chart of accounts should be designed to keep track of financial transactions for reporting and making good financial decisions. Apart from certain practices regarding the numbering system and the order in which information is presented (see below), a TMA can tailor its chart of accounts to its specific needs.

In order to decide what to include in the TMA's chart of accounts, consideration should be given to the following issues:

- TMA's capacity for tracking financial information

- Level of detail required by Board of Directors and funding agencies

- Types of reports that will be prepared

- Financial decisions TMAs will need to make on a regular basis

\section{Essential Reports}

A TMA should begin the design of a chart of accounts by first considering what reports it will need to satisfy contractual requirements as well as help the board of directors manage the organization's finances and make sound decisions. Identification of those reporting requirements will help the TMA determine which categories to include in the reports. For example, the chart of accounts should correlate to the categories in the TMA's budget so a comparison can be made between the budgeted amounts and the actual income and expenses. 


\section{Overview of a Sample Chart of Accounts}

\section{Sources of Income}

The sources of income the TMA receives or hopes to receive may need to be considered. Will the TMA need to distinguish between corporate dues and public sector grants so it can monitor private sector match requirements for public sector grants? Are some contributions restricted to particular programs or types of expenses? Does the TMA expect to earn fees for some services?

\section{Level of Expense Tracking}

The TMA should determine the lowest level of detailed information that it would like from its financial records. Consideration should also be given to how the tracking information would be used. For example, the TMA may wish to track the postage expenses for its marketing efforts separately than general office postage for planning purposes. If the TMA does not plan to analyze its expenditures at this level of detail, it is recommended to combine the two categories. If the TMA operates more than one program, it may wish to track expenses such as long distance phone charges, copying, etc. for each program. Accounting standards for nonprofits require them to report revenues and expenses in three categories: unrestricted, temporarily restricted, and permanently restricted. Therefore, the chart of accounts should support these reporting requirements.

\section{Information Tracking}

The ability and availability of the TMA's bookkeeper to manage a complex number of variables is another major consideration. Training is likely to be required for the bookkeeper to use a TMA's potentially complex chart of accounts. Simpler is better.The TMA can revise the chart of accounts over time as required.

The sample chart of accounts provided at the end of this section shows how a TMA might track revenue and expense items. This sample is intended to be a guide to use for developing a chart of accounts. It is not comprehensive and some of the accounts included in the sample may not be useful to every TMA. Note the following structure of the sample chart of accounts.

Account categories are presented in a standard order, beginning with the accounts presented in the Statement of Position or Balance Sheet. These are described below.

\section{Assets}

Assets are the tangible items an organization has as resources, including cash, accounts receivable, equipment and property. Assets are usually listed in descending order of liquidity from cash to fixed assets such as property and equipment. Traditionally, asset accounts usually start with the number "I."

\section{Liabilities}

Liabilities are obligations due to creditors, such as accounts payable. Obligations that fall due within the next year, called "current liabilities," are usually listed first, followed by longterm liabilities. Accounts payable and payroll taxes payable are usually listed before other payables. Deferred revenue and other liabilities are often further down on the list. Liabilities often begin with the number " 2. "

\section{Net Assets}




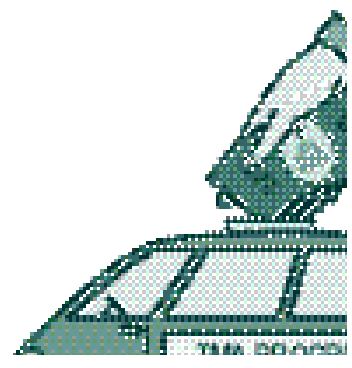

\section{Assets}

1010

$$
\begin{aligned}
& \text { Cash } \\
& \text { 101 I Checking Account } \\
& 1012 \text { Petty Cash }
\end{aligned}
$$

1020 Savings and Temporary

Cash Investment

1030 Accounts Receivable

1040 Allowance for Doubtful Accounts

1050 Pledges Receivable

1060 Grants Receivable

II30 Prepaid Expenses

1610 Land

1620 Building

1640 Equipment

\section{Liabilities}

2010 Accounts Payable

2410 Loans from Trustees

\& Employees

2510 Mortgage Payable

Net Assets

3100 Current unrestricted net assets 


\section{Statement of Income and Expenses}

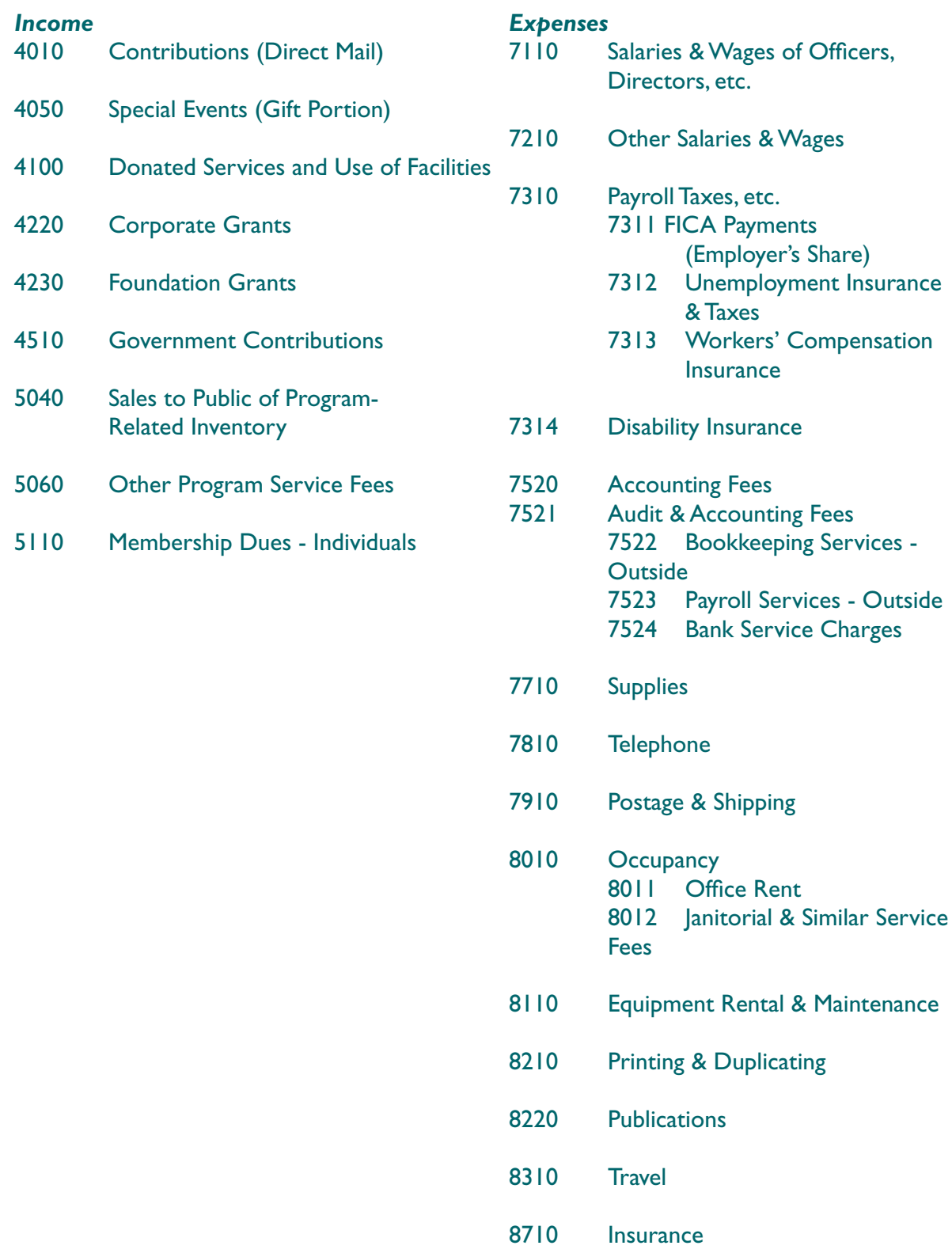




\section{Maintaining the Accounting System}

Key tasks for maintaining the integrity of an accounting system include the following:

\section{Trial Balance}

In a manual system, all balances from the general ledger are computed on a monthly basis to check that debit balances equal credit balances. Financial statements can be prepared using trial balance amounts if debit balances equal credit balances. Computerized systems produce a trial balance as a standard report.

\section{Bank Reconciliation}

Each month, the TMA will need to reconcile the balance in its checkbook with the balance in its account according to its bank. This process has two basic steps:

I. Checkbook entries for deposits and checks are compared with those shown in the bank statement.

2. Bank charges or interest earned are included in the checkbook balance. Outstanding checks are subtracted from the bank's balance and deposited checks not yet reflected in the statement are added in.

\section{Reporting by Functional Classification}

The equivalent of an individual's 1040 Form, the Federal Form 990, requires nonprofits to report expenses by their functional classification. Two primary functional classifications are program services and supporting activities. Supporting activities are typically comprised of management and general activities, fundraising, and membership development.

A TMA's program services are the services and goods being provided to employers, commuters, or members that fulfill the purposes or mission for which the TMA exists. Supporting activities are all activities of a not-for-profit organization other than program services such as contract administration, accounting, etc. Fund-raising activities include publicizing and conducting special fund-raising events such as golf tournaments and conducting other activities involved with soliciting contributions from corporations, foundations, government agencies and others. Membership development activities include seeking new members, collecting membership dues, and maintaining membership relations.

The above classification system was developed to help assess an organization's efforts, including the costs of its services and how it uses resources. Since donors make contributions or provide funds in order to further the TMA's mission, they are concerned that funds are used to achieve the TMA's service goals efficiently.

The practice of allocating expenses can vary from organization to organization. Some expenses for what might seem to be mainly an administrative function, such as the executive director's salary and benefits, may be equitably divided among a range of functional classifications, including individual programs. Generally, reasonable and justifiable methods for allocating the expenses among the various functions should be accepted by auditors.

TMAs may use different allocation methods for various line items. Office expenses such as postage, printing, and advertising can be identified to a specific program. However, some costs such as rent probably apply to the total program. In this case, the TMA can apply an indirect cost rate to spread the expenses over each functional category. The following provides a sample cost allocation methodology to show how this is done. 
The Sample TMA:

A Sample Cost

Allocation

Methodology
Here, the Sample TMA has two major programs: Shuttle Operations and Employee Transportation Coordinator Training. The total expenses are:

$\begin{array}{lr}\text { Executive Director } & \$ 59,000 \\ \text { Shuttle Program Manager } & \$ 45,000 \\ \text { Training Coordinator } & \$ 38,000 \\ \text { Office Manager } & \$ 27,000 \\ \text { Rent } & \$ 12,000 \\ \text { Supplies } & \$ 6,500 \\ \text { Telephone } & \$ 3,450 \\ \text { Postage } & \$ 8,100 \\ \text { Copying } & \$ 9,700 \\ \text { Total Expenses } & \$ 208,750\end{array}$

The Sample TMA uses the following methods for allocating its expenses into functional categories.

\section{Salaries and Fringe}

The Shuttle Program Manager and the Training Coordinator salaries are allocated entirely to programs. The organization calculates hourly pay rates for the Executive Director and Office Manager by dividing their salary and fringe benefits by the number of hours each works in a year. They track their hours using a time sheet and multiplying the number of hours spent on each functional area by the hourly rate to determine how to allocate their salaries to each benefiting functional area.

\section{Rent}

Rent is allocated based on the percent of staff time that serves each function (as determined by staff time sheets). Since 77 percent of staff time supports the program function, 77 percent of the rent is charged to the program function, as well.

\section{Supplies}

Some supplies are clearly related to a specific program (training materials, markers and easels, etc.). These are charged directly to the benefiting programs. Other supplies are allocated using the indirect cost rate.

\section{Telephone}

Telephone expenses are allocated using the indirect cost rate, though if sufficient long distance charges would be incurred, a portion of these costs could be allocated to the particular program.

\section{Postage}

Bulk mailings such as newsletters to shuttle riders that can be easily traced to the shuttle program, would be charged to that program. The remaining postage expenses are distributed using the indirect cost rate.

\section{Copying}

Copying an ETC Handbook, for example, done at the local copy center, would be charged to the training program. Other copying expenses are distributed using the indirect cost rate. 
Statement of Functional Expenses

\begin{tabular}{|c|c|c|c|c|c|c|c|}
\hline & $\begin{array}{l}\text { Shuttle } \\
\text { Program }\end{array}$ & $\begin{array}{r}\text { ETC } \\
\text { Training } \\
\text { Program }\end{array}$ & $\begin{array}{r}\text { Total } \\
\text { Program }\end{array}$ & $\begin{array}{l}\text { Mgmt. } \\
\text { General }\end{array}$ & Membership & $\begin{array}{r}\text { Total } \\
\text { Supporting }\end{array}$ & Total \\
\hline \multicolumn{8}{|l|}{ Salaries and Fringe } \\
\hline Executive Director & $\$ 14,750$ & $\$ 14,750$ & $\$ 29,500$ & $\$ 17,400$ & $\$ 12,100$ & $\$ 29,500$ & $\$ 59,000$ \\
\hline Shuttle Program Manager & 45,000 & & 45,000 & & & & 45,000 \\
\hline Training Coordinator & & 38,000 & 38,000 & & & & 38,000 \\
\hline Office Manager & 7,000 & 10,000 & 17,000 & 8,000 & 2,000 & 10,000 & 27,000 \\
\hline \multicolumn{8}{|l|}{ Expenses } \\
\hline Rent & 4,598 & 4,598 & 9,195 & 1,870 & 935 & 2,805 & 12,000 \\
\hline Supplies & 2,000 & 500 & 2,500 & 3,000 & 1,000 & 4,000 & 6,500 \\
\hline Telephone & 750 & $\mathrm{I}, 500$ & 2,250 & 1,000 & 200 & 1,200 & 3,450 \\
\hline Postage & 500 & 5,000 & 5,500 & 600 & 2000 & 2,600 & 8,100 \\
\hline Copying & 300 & 8,500 & 8,800 & 750 & 150 & 900 & 9,700 \\
\hline Total Expenses & $\$ 74,898$ & $\$ 82,848$ & $\$ 157,745$ & $\$ 32,620$ & $\$ 18,385$ & $\$ 51,005$ & $\$ 208,750$ \\
\hline
\end{tabular}

Total Program Costs

Total Supporting Costs

Total Costs
157,745

51,005

$\$ 208,750$ 


\section{Financial Statements}

Based on these allocation methodologies, the distribution of expenses to functional activities is as follows:

Financial statements are the final products of the accounting process, consolidating all of the TMA's financial transactions for the period. Nonprofits like TMAs are required to prepare three primary financial statements:

I. Statement of Financial Position (Balance Sheets)

2. Statement of Activities (Income Statement)

3. Statement of Cash Flows

Examples for these three financial statements for the Sample TMA, using the accrual-basis method of accounting, is included at the end of this discussion of financial management issues.

In addition, nonprofits must provide information about expenses as reported in their functional classifications (program services and supporting services). Included in each statement is the Statement of Financial Position, current assets, fixed assets, current liabilities, long-term liabilities, and net assets.

The Statement of Financial Position reports amounts of the organization's assets, liabilities and net assets (fund balances) at a specified date. This statement is also known as the Balance Sheet.Assets are property, equipment, and tangible resources the TMA owns and can use to achieve its goals. Current assets include cash accounts, investments, receivables and other items that could be converted to cash within one year. Fixed assets include land, buildings and equipment.

Liabilities are debts of the organization, or what is owed by the TMA to others. Current liabilities typically include accounts payable to vendors, short-term loans due, withheld payroll taxes due, etc. Long term liabilities include long term debt, etc. Net Assets or Fund Balances represent the net difference between the TMA's assets and liabilities. Three classes of net assets must be reported on unrestricted, temporarily restricted, and permanently restricted. Restrictions are determined by the conditions which donors place on their contributions.

Cash-basis and accrual-basis accounting use different criteria for determining when to recognize and record revenue and expenses in the financial records. Depending on the TMA's sensitivity to variations in cash flow, the method used may prove critical to the long-term viability of the organization. Under a cash-basis system, TMA revenues would be recorded when cash is received and deposited. Expenses are recorded in the accounting period when bills are paid. In accrual-basis accounting, income is realized in the accounting period in which it is earned (e.g., once contracted services are provided, grant provisions are met, etc.), regardless of when the cash from these fees and donations is received. Expenses are recorded as they are owed (e.g. when supplies are ordered, the printer finishes your brochure, employees actually perform the work, etc.) instead of when they are paid.

The following example compares the cash-basis versus accrual basis statement. At the end of the TMA's fiscal year (July to June), the TMA's bookkeeper has recorded the deposits and expenditures from its checkbook. A Balance Sheet has also been prepared to show the TMA's assets, liabilities and fund balance. The Statement of Activities, also known as the Income Statement or Statement of Revenue, Expenses and Changes in Fund Balances, reports revenues, expenses, and the resulting change in net assets for the year. Charges are reported for each of the three classes of net assets (unrestricted, temporarily restricted, 


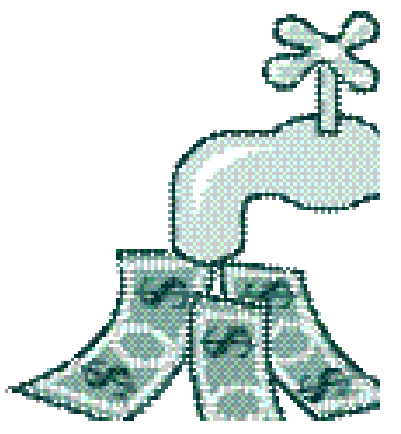

and permanently restricted).

The bookkeeper prepared these financial statements using a cash basis since the information was taken from the checkbook. The next column of figures (accruals) displays some important information that has not been recorded when using the cash basis. For example,

- The state Department of Transportation has given the TMA a grant of up to $\$ 166,364$ to provide employer outreach services and shuttle services in the area (on a monthly reimbursable basis). The TMA provided the services in June for $\$ 16,266$ in eligible costs, but the state DOT check has not been received as of June 30.

- To help manage the cash flow, the TMA's policy is to hold invoices for at least 30 days in order to receive reimbursement from the state DOT.Therefore, the TMA has not paid the advertising agency $\$ 8,000$ for media buys in June or the printer for the new shuttle schedules that go into effect in July. The TMA owes the printer $\$ 1,439$.

- The board and officers' liability insurance premium $(\$ 4,200)$ was paid in March, and covers the period April through March. So, the premium covers another nine months in the next fiscal year $(\$ 3, I 50)$. Also, as of the end of this period, the TMA has already paid for another five months on the hardware and software maintenance agreement at $\$ 253$ per month or $\$ 1,265$. The TMA also paid $\$ 1,000$ in advance for health insurance benefits for the staff.

To take these factors into consideration on the financial statements, revenues and expenses need to be recorded on an accrual basis. Several line items need to be added to the balance sheet in order to update the financial statements. These are:

\section{Accounts Receivable}

This category reports revenues which have been earned, but not yet received. For example, a payment from the state Department of Transportation that has been invoiced, but not yet received is an account receivable. In this case, the TMA has a grant receivable of $\$ 16,266$, since the services have already been provided.

IMPACT:

Increase grant income from the state Department of Transportation by $\$ 16,266$ to $\$ 150,128$

- Increase grants receivable to $\$ 16,266$

\section{Accounts Payable}

Report expenses that are owed to others. The money owed to the advertising agency plus the printer is a $\$ 9,439$ account payable.

IMPACT:

- Increase advertising expenses by $\$ 8,000$ to $\$ 39,560$

- Increase the printing expenses by $\$ 1,439$ to $\$ 10,810$ Increase accounts payable to $\$ 9,439$ 


\section{Prepaid Expenses}

Prepaid expenses report expenses that have already been paid, but are for a future period. In this example, three months of insurance is considered a prepaid, rather than a current, expense.

IMPACT:

- Decrease Salaries and Benefits by $\$ 1,000$ for the prepaid health insurance fringe benefit.

- Decrease board and officers' insurance expense by $\$ 3,150(\$ 4,200 / 12$ months $\times 9$ months) to $\$ 3,357$.

- Decrease repairs and maintenance expense by $\$ 1,265$ to $\$ 3,065$.

Reported on an accrual basis, using the categories described above, the TMA's financial statements now look quite different-and give a different snapshot of the financial health of the TMA - as the following side-by-side comparison demonstrates. For example, the cash basis reporting shows that expenses exceeded revenues by over $\$ 16,000$, whereas the actual “loss” was less than $\$ 4,000$.

This example shows accrual basis statements will give the Board and others a much more accurate and complete picture of the TMA's financial condition. This factor needs to be considered along with the ease of preparing cash-basis statements.

\section{Factors to Consider When Selecting an Accounting Method}

\begin{tabular}{lll}
\hline Factor to Consider & If the TMA has... & $\begin{array}{l}\text { Then use } \\
\text { this method: }\end{array}$ \\
\hline $\begin{array}{l}\text { The extent to which the organi- } \\
\text { zation has payables, receivables, } \\
\text { etc. on an ongoing basis }\end{array}$ & $\begin{array}{l}\text { Few bills or outstanding } \\
\text { grants throughout the year }\end{array}$ & Cash-basis \\
$\begin{array}{l}\text { Expertise and time constraints } \\
\text { of bookkeeping staff }\end{array}$ & $\begin{array}{l}\text { Tightly constrained or lack of } \\
\text { expertise }\end{array}$ & Cash-basis \\
$\begin{array}{l}\text { The extent to which the TMA } \\
\text { needs to monitor cash flow to } \\
\text { pay bills, meet payroll, acquire } \\
\text { services, etc. }\end{array}$ & $\begin{array}{l}\text { Need to closely track ac- } \\
\text { counts payable and receivable } \\
\text { to manage cash flow }\end{array}$ & Accrual basis \\
& & \\
\hline
\end{tabular}




\section{Sample TMA Balance Sheets \\ Cash vs Accrual}

\begin{tabular}{|c|c|c|}
\hline & Cash & Accrual \\
\hline \multicolumn{3}{|l|}{ Assets } \\
\hline \multicolumn{3}{|l|}{ Current Assets } \\
\hline Cash & $\$ 43,046$ & $\$ 43,046$ \\
\hline Grants receivable & NA & 16,266 \\
\hline Prepaid expenses & NA & $5,4 \mid 5$ \\
\hline Total Current Assets & 43,046 & 64,727 \\
\hline \multicolumn{3}{|l|}{ Property and Equipment } \\
\hline Computer equipment & 59,170 & 59,170 \\
\hline Furniture and fixtures & $15,7 \mid 3$ & $15,7 \mid 3$ \\
\hline Highway signs & 2,322 & 2,322 \\
\hline Total Property and Equipment & 77,205 & 77,205 \\
\hline Less accumulated depreciation & 61,900 & 61,900 \\
\hline Net property and equipment & 15,305 & 15,305 \\
\hline Total Depreciation & $58,35 I$ & 80,032 \\
\hline \multicolumn{3}{|l|}{ Liability and Fund Balance } \\
\hline Current liability - accounts payable and accrued expenses & NA & 9,439 \\
\hline Unrestricted fund balance & 58,351 & 70,593 \\
\hline Total Liability and Fund Balance & $\$ 58,351$ & $\$ 80,032$ \\
\hline
\end{tabular}

NA = not applicable for cash-basis accounting systems 


\section{Sample TMA Statement of Revenues, Expenses and Changes in Fund Balance Cash vs Accrual}

\begin{tabular}{|c|c|c|}
\hline & Cash & Accrual \\
\hline \multicolumn{3}{|l|}{ Revenues } \\
\hline \multicolumn{3}{|l|}{ Grants } \\
\hline State Department of Transportation & $\$ 133,862$ & $\$ 150,128$ \\
\hline Transit company & 15,000 & 15,000 \\
\hline City & 7,500 & 7,500 \\
\hline County & 7,500 & 7,500 \\
\hline Membership dues & 8,250 & 8,250 \\
\hline State Department of Transportation Demonstration grant & 6,279 & 6,279 \\
\hline In-kind contributions & 17,040 & 17,040 \\
\hline Other & 5,217 & 5,217 \\
\hline Total Revenues & $\$ 200,648$ & $\$ 216,914$ \\
\hline \multicolumn{3}{|l|}{ Expenses } \\
\hline Salaries and benefits & $\$ 102,496$ & $\$ 101,496$ \\
\hline Advertising and promotion & 31,560 & 39,560 \\
\hline Printing and duplications & 9,371 & 10,810 \\
\hline Telephone & 2,666 & 2,666 \\
\hline Repairs and maintenance & 4,330 & 3,065 \\
\hline Materials and supplies & $|, 92|$ & 1,921 \\
\hline Depreciation & 4,422 & 4,422 \\
\hline Rent & 9,581 & 9,581 \\
\hline Postage & 5,941 & 5,941 \\
\hline Travel & 3,502 & 3,502 \\
\hline Insurance & 6,507 & 3,357 \\
\hline Professional services & 14,253 & 14,253 \\
\hline In-kind expenses & 17,040 & 17,040 \\
\hline Other & 3,268 & 3,268 \\
\hline Total expenses & $\$ 216,858$ & $\$ 220,882$ \\
\hline Excess of expenses over revenues & $\$(|6,2| 0)$ & $\$(3,968)$ \\
\hline Fund balance at beginning of year & $\$ 74,561$ & $\$ 74,561$ \\
\hline Fund balance at end of year & $\$ 58,351$ & $\$ 70,593$ \\
\hline
\end{tabular}




\section{Statement of Cash Flows}

Financial reports must be prepared according to generally accepted accounting principles regardless of the accounting system used throughout the year.

The third basic financial report, the Statement of Cash Flows, shows how the organization's cash position changed during the year. Cash flow information is divided among receipts and disbursements from investing, financing, and operating activities. A cash flow budget or projection should not be confused with a financial statement called "Statement of Cash Flows." The statement describes changes in cash from year-to-year due to operating surpluses or deficits, makes adjustments for non-cash items such as depreciation, and shows increases or decreases in accounts payable and accounts receivable. This statement and other financial statements are usually prepared by your auditor.

Sample TMA

Statement of Cash Flows

Year Ending June 30, 20\#\#

20\#\#

Cash flows from operating activities:

Excess of expenses over revenues

$\$(3,968)$

Adjustments to reconcile excess of expenses over

revenues to net cash provided by operating activities:

Depreciation

$\$ 4,422$

(Increase) decrease in grants receivable

$\$ 4,744$

(Increase) decrease in prepaid expenses

Increase (decrease) in accounts payable and

accrued expenses

Total adjustments

$\$ 8,223$

Net cash provided by operating activities

Cash flows used in investing activities-purchases of property and equipment

Net increase (decrease) in cash and cash equivalents

Cash and cash equivalents at beginning of year

$\$ 39,825$

Cash and cash equivalents at end of year

$\$ 43,046$

Cash flow refers to the timing for received income and disbursing expenses.A budget projects the total income and expenses for a period of time but says nothing about when funds are received or spent. This can lead to problems if income and expenses are not balanced over time. A TMA might have annual income of $\$ 100,000$ and expenses of $\$ 90,000$, but if $\$ 50,000$ is expended in the first three months and only $\$ 10,000$ of the income is received, there will be insufficient cash flow.

The ability to manage the revenue and expenses streams or "cash flow" will allow the TMA to have cash available to pay when needed. Most TMA budgets are prepared on a yearly basis and usually show that income exceeds expenses over the year. However, the TMA could still face financial difficulty and impede its progress toward carrying out its mission if it doesn't consider how monthly or even weekly cash flow fluctuations can impact its ability to deliver services.

Cash flow can be a particular problem for membership organizations because dues are generally paid annually and at the same time of year for all members.Although this simplifies 


\section{Projecting Cash Flow}

\section{Useful Strategies for Adjusting the Timing of Cash Flow}

invoicing and record keeping, the TMA can experience serious year-end cashflow problems until dues for the coming year are received. New TMAs are particularly susceptible to cash deficits because many expenses fall early in the first year. Office furniture and equipment, marketing materials, promotional events, and other one-time costs generally are incurred in the first few months of the TMA's operation. To avoid this distraction from the business of the TMA, cash flow should be projected, monitored, and managed.

As part of the budget process, TMAs can forecast receipts and expenditures by month (or more frequently if necessary). This recognizes where and when sources of income are expected and how much the TMA will spend in each category so that the TMA's management and board of directors can anticipate problems or shortfalls and develop financial strategies for funding the shortages or even investing the surpluses.

This examination begins with a review of the track history of the sources of income and when that income appears. It continues with allowing for adjustments for any anticipated changes that will affect the timing and amount of payments and deposits. These changes might include when the TMA may offer programs or begin an activity (e.g., introduction of a new shuttle service). Other changes could be the identification of new funding sources or the end of previous funding, etc. While the cash flow projection for the coming year will largely correspond to the TMA's budget, accounts receivables from the prior year should come in and some cash may go out for payments made for last year's bills.

For TMAs receiving significant amounts of reimbursable government grants, monitoring cash flow may be critical. Reimbursement processes are known to be notoriously slow and subject to additional delays over disputes, eligibility or arithmetic errors.

As the year progresses, cash flow projections should be updated to reflect changes in plans and programs (e.g., introduction of new service is delayed two months). Over time, the TMA's ability to project cash flow should improve as it compares budgeted cash flows to actual deposits and expenditures.

The importance of understanding cash flow can be shown in a simple example. Assume the TMA is a new organization with no cash in the bank in its first month, but expects to receive $\$ 25,000$ in revenue from a larger developer and spend $\$ 25,000$ in expenses in its first month, paying salary and equipping the office until additional revenue is available. If the check from the developer is received first, the TMA will be able to spend it down as expenses are incurred. If, however, the expenses come in before the check comes, the TMA cannot pay its bills until the cash is received. In this case, the TMA has a problem with the timing of cash flow rather than a shortage of revenue or an excess in expenses.

There are common strategies for dealing with the timing of cash flows, whether it is a cash shortage or a cash surplus.

\section{A Temporary Cash Shortage}

In order to meet a projected temporary cash shortage, a TMA may want to consider any of the following strategies.

- Obtain a loan or line of credit, usually from a bank.

- Time purchases of equipment and other discretionary items to coincide with strong cash balances or finance the purchase of equipment by leasing it or paying for it over time.

- Delay payments to vendors. 


\section{Other Related Documents}

\section{Financial Reports Needed by the Board and Staff}

- Speed up the collection of receivables (money owed or pledged to the TMA).

- Move up a fundraising event.

- Liquidate investments.

- Factor the TMAs' receivables. Factoring involves selling the TMAs' receivable at a discount to an organization that will wait for the payment. Interest charged by the factoring group will depend on the credit worthiness of the organization paying (i.e., not based on the credit worthiness of the TMA) and time between cash is received by the TMA from the factor firm and when the cash is received by the factor firm from the TMA's creditor.

- For dues-paying membership organizations, stagger payment dates throughout the year or bill members in two or more installments.

- Discount dues for members who renew early. A bit of revenue will be lost, but the added interest received from depositing the dues early may offset some of the loss and the improved cash flow will provide peace of mind.

- If the TMA will receive public grants and the money will not be provided as a lump sum at the beginning of the grant period, try to negotiate an arrangement that minimizes potential cash deficits. For example, create a payment schedule of several installments through the year, with the first as an up-front payment. Alternatively, the agency could establish an account against which the TMA could draw funds as needed.

\section{A Temporary Cash Surplus}

A TMA may take one or more steps to take advantage of a projected temporary cash surplus.

- Accelerate purchases such as buying supplies on sale that the TMA will use over the course of the year.

- Make short-term investments in secure investments (certificates of deposit, U.S. Treasury Bonds.)

In summary, when reviewing the TMA's revenue and expense budget, the board should also review the organization's cash flow budget. The review should include any measures related to managing cash flow which involve commitments on the part of the TMA, such as loans or revised terms with vendors.

In addition to the financial statements required for audit purposes, nonprofits are required by federal and state governments to file various information returns to maintain their taxexempt status and document tax compliance. The primary federal reports are the annual Form 990 and Schedule $A$ to the 990 . State governments may require additional reports.

At different times an organization will need different reports to provide information to support its decision making. The reports needed will depend on several things, including the TMA's financial stability, changes during the period, cash flow requirements, and the availability of staff or other professionals to prepare reports, etc.

On an annual basis, most nonprofits, like many TMAs, are required to file the 990 Form and Schedule A with the Internal Revenue Service. Other reports may be necessary at the state or local level to meet its reporting requirements.

\section{Internal Management Purposes}




\section{Using TMA Financial Statements}

- Assess performance over the year

- Identify significant departures from prior year

- Plan for the upcoming year

- Improve the internal control procedures and financial planning of the organization

- Reports needed: Financial statements including the Statement of Activities, Statement of Position, Income Statement for each program, and management letter from the auditor

\section{External Accountability Purposes}

- Financial disclosure to funding and reporting agencies

- Financial disclosure to members and the general public

- Reports needed: audited financial statements for the entire organization, including Statement of Position, Statement of Activities, Statement of Cash Flows, and Statement of Functional Expenses

In a small nonprofit like most TMAs, the board treasurer or outside accountant/bookkeeper might prepare the financial information for all in-house financial statements, and work with the executive director to prepare the narrative with financial highlights to be presented to the board.

The TMA's director should review all reports prior to presenting them to board members to ensure that the financial information makes sense and can be translated into issues and opportunities facing the organization.

The audit and management letter are addressed directly to the board of directors because of its oversight function. Typically, the auditor works with the finance staff to prepare federal and state reports and may be included at board meetings during which presentations are given.

TMA board members, funding agencies and others can learn much about the TMA by examining the financial statements.

Measure the organization's efficiency, using factors such as:

- Units of service such as number of employers or commuter population serviced compared to costs

- Net income from fee-producing programs such as shuttles, carsharing and Employee Transportation Coordinator training programs compared to the fees received from riders, etc.

Evaluate the adequacy of financial resources, often through:

- Cash flow projections

- Comparison of total liabilities or total assets with net assets (formerly called fund balance)

- Liquidity ratios

Analyze significant financial trends by:

- Vertical analysis (looking at a simple line item as a percentage of total revenue or 
expense)

- Horizontal analysis (comparing prior periods with the current period)

TMAs and funding agencies should remember that similar results may have different meanings. For example, the Sample TMA's Statement of Cash Flows shows an operating deficit for the year of $\$ 3,968$. For some, any loss may be a cause for concern. However, a closer examination found that the fund balance was sufficiently high at the beginning of the year. The board may have elected to begin to spend down the balance and this "deficit" may represent that decision.

Ratio analysis can be used to evaluate the TMA's financial health just as they are used in the for-profit world. Ratios are a tool for comparing numbers representing different aspects of a TMA's financial status. The value of the tool is in identifying which numbers to compare, and determining what the comparison might indicate. It is most important to identify the trends in each TMA and analyze changes over time, rather than compare to other nonprofits or TMAs.Accordingly, the significance of the numbers is limited to discussion of "high" and "low" ratios simply to help indicate what the ratio means.

\section{Financial Indicators}

\section{Surplus or Deficit}

In the pursuit of the "bottom line," reviewers of financial statements may naturally check the Statement of Activity first. If income is greater than expenses within a given period the organization has generated a "profit" or rather "net income." Similarly, if expenses exceed revenue, then the TMA has had a "loss" for the period.

Nonprofits are not required to break even for any given period. However, nonprofit organizations may deliberately seek to develop a cash reserve to handle future "rainy days" or even decide to spend down their cash reserves for a specific purpose such as starting a new program. Under the former situation, the TMA's Statement of Activity should reflect an operating surplus. The TMA should analyze the causes of significant unexpected surpluses or deficits and plan for the ramifications.

\section{Budget to Actual for Revenue and Expense}

The comparison of budget to actual revenues and expenses is one of the most commonly used financial health indicators. These comparisons should be made on both a monthly and a year-to-date basis. Significant variations from budget to planned year-to-budget amounts can provide sufficient opportunity to adjust the budget before the situation worsens. Comparison with only the annual budget can cause relatively insignificant variations early in the fiscal year to compound over time. Given the requirements of some TMAs to provide local match money to secure government grants, this may mean that the $\$ 2,000$ less in membership dues than expected in the second month may have a negative multiplier effect when the government grant it was to match cannot be fully tapped. For example, if the TMA was to contribute $\$ 2,000$ in revenues from membership dues to receive $\$ 8,000$ in state funds then this $\$ 2,000$ loss in the second month may actually mean that the TMA will have $\$ 10,000$ less in revenue than originally budgeted.

\section{Functional Expense Ratios}

When completing Federal Form 990, nonprofits must report expenses functionally, broken down into the categories of Program, Management and General Activities, and Fundraising. Donors and agencies that evaluate nonprofit performance often look to see if most of the organization's funds are being used for programmatic purposes. However, different 


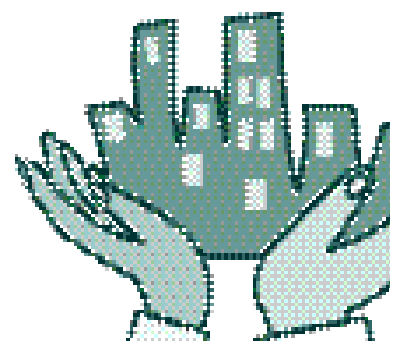

sources recommend differing practices and policies for allocating expenses among the functional expense categories. As a result, it is important to develop consistent guidelines within each organization to determine which expenses go to program support, and which to management and general activities or fundraising. The following is a summary of some functional expense ratios.

Program-To-Total Expense Ratio-The program-to-total expense ratio can be calculated by dividing program expense by total expense. If high, most of the expenses are related to program, relatively little is spent on management or fundraising.

Fundraising-to-Total Expense Ratio-The fundraising-to-total expense ratio can be calculated by dividing fundraising expense by total expense. If low, a small percentage of expenses are spent on fundraising efforts. Prospective donors may draw the conclusion that too high a portion of their contribution will be spent on fundraising, rather than on program services.

Quick Ratio-From the Statement of Position or Balance Sheet, the quick ratio or the short term liabilities coverage ratio helps assess whether or not there will be enough cash to pay bills in the immediate or near future. This is calculated by adding all assets that can be used to pay bills over a specific short period of time (e.g., month or quarter) and compare this with the bills that must be paid within that same period of time. If the quick ratio is high, there may be too much in cash. Some of the assets could be earning more if invested. If the ratio is too low, the TMA may be on the verge of a cash flow crisis and may find itself unable to pay creditors.

Current Ratio-Similar to the quick ratio, the current ratio uses the Statement of Position to determine whether the cash flow is sufficient to cover bills over the next year.This is calculated by dividing the current assets by the current liabilities. The implications are the same as the quick ratio, though caution should be exercised since fluctuations in cash needs during the course of the year may be disguised.

Deferred Revenue Ratio or Net Temporarily Restricted Assets-Deferred revenue traditionally refers to cash that has been received for some restricted purpose that has not yet been met. Under accounting standards, most of these funds will be treated as an addition to temporarily restricted net assets.

To determine the ratio, divide temporarily restricted net assets by the total of cash and savings. If this ratio exceeds I, then the TMA may be spending restricted cash for purposes other than those for which the funding agency intended, or using monies designated for future purposes (such as vanpool rider subscriptions) to meet current expenses.

Fund Balance Ratio or Unrestricted Net Assets Ratio-The fund balance ratio, also called the unrestricted net assets ratio, measures the amount of unrestricted, spendable equity to the organization's annual operating expense. To determine the ratio, divide the expendable unrestricted net assets by annual expenses. If the ratio is low then the organization has little unrestricted, spendable equity available to meet temporary cash shortages, an emergency, or deficit situation in the future. This may be the case even in organizations with significant unrestricted net assets, if the major portion of equity is tied up in fixed assets.

Days Receivables Ratio-How long it takes to receive funds once invoiced can be critical to TMAs facing cash flow uncertainty. The days receivables ratio measures the average number of days it takes to collect on the service performed. This ratio is useful to organizations that earn significant portions of their revenue from reimbursable contracts, fees charged to developers or employers for services, etc.

To determine this ratio multiply the accounts payable by 365 days and divide by purchases. If high, payments taking longer than 30 or 60 days are inconsiderate and may result in friction 
with community vendors. In addition, the organization may be incurring additional costs as a result of late or deferred payments (e.g., late fees, interest expense, etc.).A very long days payables ratio or a sudden increase in days payable may indicate an inability to pay bills.

\section{TMA Financial Management Tips}

- Get expert legal and accounting advice.

- Develop a detailed working budget and cash flow projection.

- Assess expenses and funding needs - be realistic.

- Budget resources carefully and monitor revenue and expenditures regularly.

- Explore various membership classifications and all possible sources of funding.

- Utilize seed funding, if available and needed.

- Assure key funding commitments prior to initiating services.

- Maximize use of in-kind resources and donations.

- Establish strict accounting procedures and maintain detailed, accurate financial records.

- Develop a financial contingency plan.

\section{Financial}

Management in Perspective
Ultimately, the success of the TMA is not solely found in the financial statements; it is found in the TMA's performance against its goals. For example, perhaps a TMA has set a goal to provide shuttle services for 1,000 commuters to a rail station to decrease congestion and air pollution. Determining how many commuters used the shuttle and at what cost is not difficult. These calculations show how efficient the TMA has been in providing the service-not how effective the group has been at improving the quality of life for these commuters by reducing their stress and pollution inhaled.TMA staff, board of directors and fund agencies must not lose sight of the fact that financial indicators are powerful tools for managing, when used in quest of important goals. 


\section{Sample TMA Balance Sheets June 30, 2000 and 1999}

\section{Assets}

2000

1999

Current Assets

Cash

Grants receivable

$\$ 43,046$

16,266

$\$ 39,825$

Prepaid expenses

Property and Equipment

Computer equipment

$\$ 59,170$

$\$ 65,594$

Furniture and fixtures

15,713

$\$ 58,313$

Highway signs

Less accumulated depreciation

$\$ 61,900$

$\$ 57,478$

Net property and equipment

15,305

18,693

$\$ 80,032$

$\$ 84,287$

Liability and Fund Balance

Current liability - accounts payable and accrued expenses

$\$ 9439$

$\$ 9726$

Unrestricted fund balance 


\section{Sample TMA Statement of Revenues, Expenses and Changes in Fund Balance \\ Years ended June 30, 2000 and 1999}

2000

1999

Revenues

Grants

State Department of Transportation

$\$ 150,128$

$\$ 151,968$

Transit company

15,000

15,000

City

7,500

7,500

County

7,500

0

Membership dues

8,250

2,700

State Department of Transportation Demonstration grant

6,279

0

In-kind contributions

17,040

0

Other

5,217

3,664

$\$ 216,914$

$\$ 180,832$

\section{Expenses}

Salaries and benefits

Advertising and promotion

$\$ 101,496$

$\$ 97,959$

Printing and duplications

Telephone

Repairs and maintenance

Materials and supplies

Depreciation

39,560

39,882

10,810

7,946

2,666

2,442

3,065

4,285

I,92 I

2,102

4,422

2,590

Rent

9,58 I

9,581

Postage

5,941

6,037

Travel

3,502

2,273

Insurance

3,357

3,644

Professional services

14,253

3,700

In-kind expenses

17,040

0

Other

3,268

3,834

Total expenses

$\$ 220,882$

$\$ 186,275$

Excess of expenses over revenues

$\$(3,968)$

$\$(5,443)$

Fund balance at beginning of year

$74,56 \mathrm{I}$

80,004

Fund balance at end of year

$\$ 70,593$

$\$ 74,56$ । 


\section{Sample TMA Statements of Cash Flows Years ended June 30, 2000 and 1999}

Cash flows from operating activities:

Excess of expenses over revenues

Adjustments to reconcile excess of expenses over

revenues to net cash provided by operating activities

Depreciation

(Increase) decrease in grants receivable

4,744

(Increase) decrease in prepaid expenses

Increase (decrease) in accounts payable and

accrued expenses

Total adjustments

Net cash provided by operating activities

Cash flows used in investing activities -

purchases of property and equipment

Net increase (decrease) in cash and cash equivalents

\section{Delivering TMA Services}

Many TMAs choose their initial package of TDM strategies and member services casually. Services are unfortunately selected just because other TMAs have implemented them or because the services are easy or inexpensive to implement. TMAs commonly make the mistake of deciding what actions to take without clearly determining whether these actions will address the particular transportation issue(s) of concern.

It is critical to begin the process of service development with a keen understanding of the membership's mobility problems. Services should directly address TMA members' transportation issues. Prior to development and delivery of services, the TMA strategic work plan process (as discussed in a previous section, “Developing a Strategic Work Plan”) will have been completed, in which the TMA has identified its organizational strengths and weaknesses, resources and support, mobility problems within the service area and related services of other organizations and agencies. Based upon this assessment, the TMA has adopted goals, objectives, and selected performance measures, and has identified actions to accomplish the objectives. Some of these actions will be services that solve member mobility needs.

A young TMA with a small budget might determine that their greatest initial utility to the TMA membership is to serve as an information clearinghouse, provide a forum to address transportation issues and build consensus, be a liaison between the private sector and government agencies, provide advocacy for overlooked transportation and access solutions, represent the interests of the service area in long range transportation planning, and serve as a watchdog for transportation problems. Examples of initial TMA services might include organizing transportation fairs and other commuter information services, hosting information meetings, developing a network of employee transportation coordinators, and 


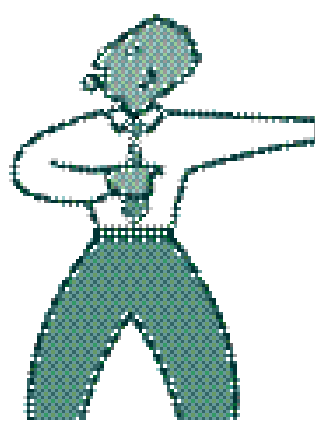

publishing a newsletter.

It is also important to deliver tangible, money and time-saving benefits, delivered in a costeffective manner.

Effective service delivery can include:

- Identifying service concepts that meet membership needs

- Defining service operation and administration

- Promoting services effectively

- Monitoring, evaluating, and refining services

Service design and delivery is a challenge for many TMAs. Some lack the technical expertise to design the services, market them effectively, or evaluate their results. Others do not have the financial or political resources to implement services members want, or that have the greatest impact.

Therefore, it is important to be creative in seeking out assistance and solutions. For example, draw on the expertise of a member's market research staff for guidance in developing or analyzing a survey to identify services most in demand. Or, ask your regional rideshare agency for vanpool formation assistance. Address questions of TMA liability for a shuttle service to a member's attorney or the legal staff of a transit agency.

Obtain funding for a bus stop shelter program from a local tax earmarked for transportation projects. Examine possible sources of assistance and draw on relationships with local agencies and members to create and implement effective services.

Regardless of what members want, most TMAs find their wish list exceeds their pocket book, necessitating tough decisions about which services to provide. Many factors might enter into the decision:

- Total cost of the service, availability of funding and conditions placed upon use of grant funds

- Number of current and potential members that will benefit and the level of benefit the service provides

- Contribution of the service to the TMA's overall goals

- Synergism with complementary services already offered by the TMA

- Potential complement or conflict with services offered by other local programs, such as the transit agency

- Ease and speed with which the service can be implemented and benefits that can be realized

After a decision is made to implement a new service, develop a plan that defines how to provide it. The plan should define the objectives, operations, administration, and sources of funding.

\section{Service Objectives}

An important first step in developing a new service is defining service objectives. Describe how the service will work, identify who will use the service, determine implementation or operation costs, and consider what will ensure quality. Service objectives are devised as part of the goals and objectives that are established during development of the strategic work plan, discussed in Section 4. 


\section{Service Operation and Administration}

\section{Service Financing}

Service objectives serve several purposes. First, it is possible to measure the expected performance against a set of minimum requirements and against the likely performance of other services that could be offered. Second, there will be a clearer idea of the effectiveness of the service as its actual performance is monitored and evaluated. And third, if delivery of the service is contracted, your expectations can be conveyed more clearly to a private vendor.

Service objectives and performance measures will differ among various services. Performance measures can include numbers of people using the services, employer members' costs to operate work site commute programs, the level of influence the TMA has on local planning processes, the number of members of a particular type, or any other criteria related to benefits the service provides. If a TMA operates a midday shuttle, the service objective might be to reach an average ridership of 30 riders per hour by the third month of operation at a pre-determined cost per trip. (Please refer in this section to a previous discussion on setting objectives, selecting performance measures, identifying actions and benchmarking in "Developing Objectives and Choosing Performance Measures.")

After defining service objectives and selecting performance measures, develop a written service plan to convey specific details to users or contractors.

Assume, for example that shuttle ridership retention is a problem and one action to accomplish the service objective is to implement a guaranteed ride home program. The service plan should answer the following:

- Who will be able to use the service? Will it be restricted to only those who use alternative modes five days per week, or will those who use alternative modes less frequently also be eligible?

- How will program eligibility be verified?

- Will it be available only for daytime emergencies or for overtime use as well?

- Will the service be provided by taxi cabs, rental cars, or another method?

- Will there be a maximum dollar benefit or maximum number of rides per budgeted time period?

- Will pre-paid vouchers be provided or will users pay and be reimbursed?

- Will users be required to sign up in advance? Will they sign a liability waiver?

Within the plan, define the responsibilities of each party involved. If contracting with a taxi company for the service, define minimum standards for timeliness of the taxi arrival. If using rental cars, define policies on employees' use of the rental vehicles, and the type of vehicle (e.g., compact car) for which the TMA will pay.

Finally, identify and address legal and liability issues to protect both the TMA and users of the service from damages, for example, requiring potential users to register in advance for the program and sign a service agreement and waiver of liability before they use the service.

Next, determine what it will cost to provide the service, what fee will be charged for the service, if any, and the source of any additional funding needed. Carefully identify both capital and operating costs. Capital costs refer to one-time, up-front costs to purchase equipment, vehicles, and other items that will not recur. Operating costs are ongoing costs such as labor, maintenance, marketing/promotion, administration, and direct incentives.

Include any savings to the TMA, members, and employees. Also incorporate any user fees 
that may be charged. These savings and revenues should be counted against the total cost of the service to define the service's net cost.

Next, identify potential funding sources. Can the service be funded from the TMA's operating budget or will it need funds from another source? Some local, state, and federal government agencies provide service demonstration funding from general revenues or sales taxes dedicated to transportation uses. For example, some TMAs are using federal Congestion Mitigation Air Quality (CMAQ) program funding to initiate new projects.

Members of the business community, employers, developers and merchants can also provide funding, especially if the service directly benefits their employees, tenants, and patrons.

After planning and working out all the details of a new service, develop an advertising strategy.

\section{Tips for Effective Service Delivery}

- Establish objectives for new services and compare expected service performance against the objectives.

- Examine all sources of technical and financial assistance from members and outside groups to ensure the success of your services.

- Before implementing the service, develop a comprehensive plan for its operation and administration; define how it will be provided and used.

- Solicit ideas for new services from TMA members and non-members.

- Market your services thoroughly and creatively.

- Track service use and evaluate service effectiveness.

\section{Service Advertising}

Let potential users know the service exists, especially during the start-up period in order to generate enthusiasm for it. Depending upon the degree of confidence with various aspects of the new service, consider quietly testing the service on a small subset of the overall market to make sure there are no fatal flaws in design and to work out the "kinks" before presenting it to the entire target market through a full-blown advertising campaign.

Service advertising might include the following activities:

- Devise an initial information campaign

- Offer introductory "try it" incentives

- Host special promotional events

- Relate the new service to current programs

\section{Devise an initial information campaign}

Information is an essential element of all advertising programs. But how it is disseminated will depend on the target market. If targeting this new service to existing members, provide information through regular communication channels, such as meetings and newsletters, and special bulletins designed to capture members' attention. If the service also benefits the general business community, broaden advertising channels to include announcements in 


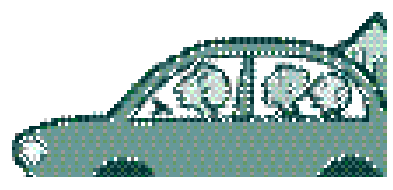

local publications and other media, presentations to business groups, mailings to businesses, and notices distributed through building managers.

To reach employees, for example, identify the best channels through which to work within the company in order to spread the word. No two companies are alike in this regard. Depending upon the company's organization and hierarchy, best results might be obtained through working with the personnel, human resources, or benefits offices. It may also be the parking/security office or some other office within the company.

Generally, the higher the contact is on the organizational ladder, the better.A top manager or CEO can not only identify the best channels for disseminating information, but also ensure managerial support for internal promotion of the service, as well as giving alert to special considerations, such as procedures for working with employee unions. The promotion of a new or existing service can be greatly enhanced with the assistance of an enthusiastic Employee Transportation Coordinator.

Begin to promote a new service three to five weeks before it begins. This is soon enough for the word to spread, but not so far in advance that employees feel they are waiting for the service to begin.

One week before start-up, distribute a second wave of notices, using the same channels as before. These notices should repeat the information, and might also invite employers and/or employees to a TMA-sponsored "kick-off" event.

Explore partnering opportunities with the local transit agency for mutual advertising support. For example, the TMA promotes transit service while the transit agency adds information about the TMA's new guaranteed ride home program on its web site.

\section{Introductory "Try It" Incentives}

Offer incentives that encourage potential users to try the service. These incentives are most often used for "on-the-street" services, such as vanpools and express buses, but could be extended to others as well. Distribute these incentives with information flyers. These incentives could include:

- Coupons for one or more free rides

- Coupons from local merchants for discounts on meals, products, or services to customers who use the service

- Coupons for prize drawings donated by employers or local merchants

- "Bring-a-friend" incentives to encourage current users to tell friends and colleagues about the service

\section{Special Promotional Events}

An important day for any new service is the day it officially begins operation. If the new service is an express bus, a highly visible event could be held. Invite local elected officials, corporate executives, merchants, the media, employees, and any others. Offer free food, hold prize drawings, and include attention-getting activities.

Continue to use special promotions such as periodic prize drawings, contests, and anniversary parties even after the service begins operation. Consider holding a special promotion in conjunction with the annual "Try Transit Week" or other transportation-related events.

Relate the new service to current programs. For example, during the 1990's, federal legislation and actions enabled and expanded the range of commute benefits that employers could offer their employees. Commonly referred to as "Commuter Choice," the Internal 


\section{Review Results}

Revenue Code provides rules to ensure that qualified transportation fringe benefits provided to employees are excludable from gross income. Qualified transportation fringe benefits include transit passes and vanpool benefits. TEA-2I allows for transit and vanpool benefits to be provided in lieu of taxable income, and established a cap of $\$ 100$ for tax-free transit and vanpool benefits in 2002. Promotion of such tax incentives can bolster the appeal of the new service.

The beginning of any new service also means the beginning of monitoring and evaluation. Periodically ask, "Is this service working?" and "Why or why not?" If a service is not producing expected results, shift resources elsewhere by examining the impact of the service and comparing it to the pre-defined objectives.

Collect data to measure whether the service met the objectives. For example, conduct surveys of users and non-users, keep a log tracking use on an ongoing basis, conduct periodic field checks to assess service quality, or use any other system that allows data collection to analyze and measure results. (Please refer to the earlier discussion in this section,"Initial Work Plan Development Considerations-Data Collection.”)

Periodically review the data collected and look for changes resulting from the service. Questions asked could include:

- Who uses the service?

- How many use the service?

- Under what conditions do they use it?

- What did they use before the service was in place?

In addition to examining what change occurred, examine why the change occurred. Was it due to a feature of the service or something else? If no change occurred, were potential users unaware of the service, unable to take advantage of it, or was the service simply not appealing? The evaluation will determine whether the service needs to be modified to make it more effective and increase its appeal. Questions to ask include:

- How well do members, employers, commuters and others know the service?

- What are the reasons for using the service? What are reasons for not using the service?

- What benefits does the service provide to users and others?

- What qualities and features do they like and what would they change?

\section{Identify Changes in the External Environment}

Examine the service environment. Changes in factors outside the TMA's control can influence results. Has the economy taken a turn for the worse? If so, local businesses could be financially strapped and find it difficult to participate in any TMA service, no matter how much they might like the concept.

Additionally, be cautious about attributing the change solely to the service. Has a local transit operator added service since the program started? Do other groups provide TDM incentives that were not provided before? Services provided by others can complement, or compete with a program, dramatically affecting results. Although it can be difficult to quantify the influences of external factors, account for them as much as possible. 


\section{Estimate Program Costs and Savings}

Finally, estimate the financial impact of the program. Examine the effectiveness of the service-Is the service having the desired impact?-and its cost-effectiveness. This requires the total cost, including the cost of planning and implementing the service, and its ongoing promotion and administration. Estimate any revenue the service generates (membership dues or fees for service, for example) and any savings that result from the program, such as employer members' commuter program cost savings.

\section{TMA Service Development Tips}

- Provide services that address the needs of established members and new members-be creative.

- Match services realistically to staff capabilities and resources-do not overextend staff.

- Target a few early, tangible successes.

- Periodically reassess members' needs through surveys and individual discussions, and develop services tailored to members' needs. 

Section 6

Appendix

- Sample TMA Feasibility Study Format

- TMA Formation-Typical First Year Activities

- Board and Staff Roles and Responsibilities, Activity Answer Key

- Examples of Membership Dues Structures

- Business Management Reference Texts

- Sample TMA Articles of Incorporation for a 501 (c) 4 organization

- Sample TMA Bylaws

- Example, Office Procedures

- Job DescriptionsTMA Executive Director/Manager

- Job DescriptionsOther Positions

- Case Studies

- "The Evolving TMA: Results from the 1998 ACT TMA Council Operational Survey"

- Helpful Resources 



\section{Feasibility Study}

\section{Sample TMA Feasibility Study Format}

Adapted from a feasibility study prepared by the Nevada County Business Association in the Sacramento, CA area.

I. Executive Summary and Recommendations

II. Study Area, Proposed TMA Boundaries and Rationale for Selecting Boundaries

III. Existing Conditions

- Growth patterns: population and employment

- Travel patterns and congestion levels

- Parking conditions

- Transportation infrastructure and services

IV. Existing Transportation Alternatives

- Public transportation

- Rideshare matching and promotion

- Employer-based TDM programs

- Other programs and services

V. Travel Patterns and Options of Employees or Other Selected Market(s)

VI. Regulations Affecting Study Area

VII. Transportation Problems and Solutions as Perceived by Key Stakeholders

VIII. Strategies to Address Local Transportation Problems

- Potential TDM,TSM and other strategies

- Relative effectiveness

- Implementation timing and costs

IX. Organizational Options and Recommendations

- Formation of TMA, legally incorporated private nonprofit organization

- Formation of TMA, some other organizational structure

- Expanded services of ridesharing agency

- Enhanced ETC Network

- Other

- Status quo

X. TMA Implementation Plan

- Proposed two-year work plan

- Proposed two-year budget and cash flow

- Proposed implementation schedule

XI. Appendix 



\section{First Year Activities}

\section{TMA Formation-Typical First Year Activities}

\section{Months I-3}

TMA Organization and Administration:

- Formalize steering committee, establish TMA office, and hire TMA staff.

- Adopt bylaws and establish legal status.

- Establish fiscal structure (budget, cash flow, accounting procedures).

- Initiate publicity opportunities.

\section{Membership and Marketing:}

- Identify potential TMA members.

- Establish membership dues structure.

- Initiate contacts with priority potential members and establish "core" TMA membership.

\section{Service Development:}

- Conduct baseline employee survey.

- Establish partnerships with transportation planning/service organizations.

\section{Months 4-6}

TMA Administration:

- Develop detailed work plan of activities and services to achieve goals.

- Begin development of long-term financial plan.

\section{Membership and Marketing:}

- Establish TMA “identity” for outreach to employers and commuters.

- Prepare TMA membership development and TDM promotion materials.

- *Continue outreach to potential members.

- Host first special membership development event.

- Convene initial TMA members' meeting.

\section{Service Development:}

- Identify and begin implementation of initial TMA services for members.

- Develop program to monitor and evaluate TMA activities and services.

- Begin individual employment site commuter promotions.

\footnotetext{
*denotes ongoing activity
} 


\section{Months 7-12}

\section{TMA Administration:}

- Develop 3-5 year financial plan for self-sufficiency.

- Expand publicity opportunities.

- *Maintain office functions.

\section{Membership and Marketing:}

- *Host special membership development events.

- *Host periodic TMA members' meetings.

\section{Service Development:}

- Develop long-term service development plan.

- *Initiate new member services as appropriate.

- *Monitor and evaluate program. 


\section{Role of Board}

\section{Board and Staff Roles and Responsibilities}

\section{Activity Answer Key for Exercise in Section 3, Creating an Effective Board of Directors}

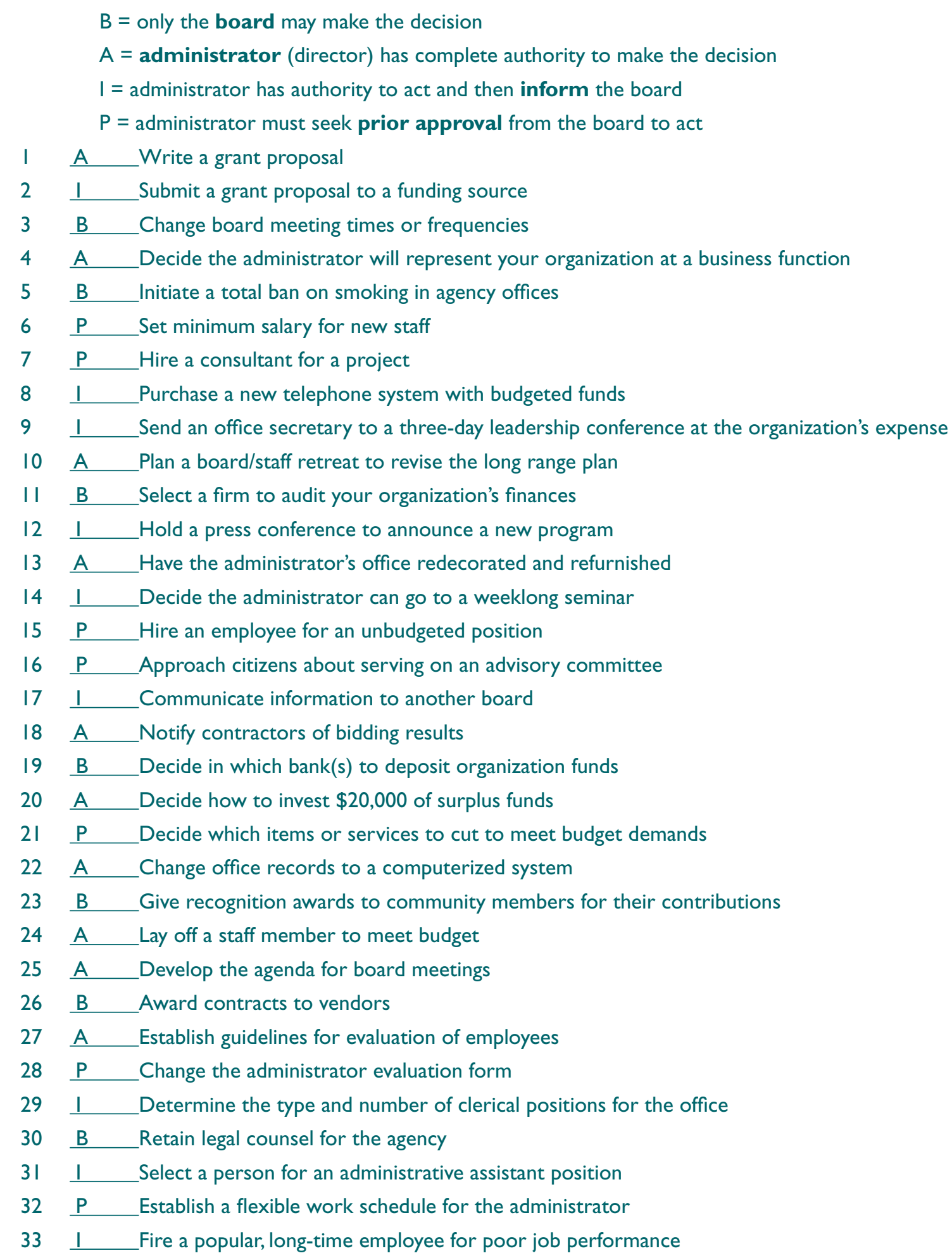

Exercise adapted from 1993 Board Member Manual, Aspen Publishers, Frederick, Maryland, pp.3 I-32. 



\section{Examples of TMA Membership Dues Structure}

\section{Examples: Predetermined Dues by Number of Employees}

\section{The Sacramento TMA}

917 7th Street

Sacramento, CA 95814

Phone: (9I6) 44I-7074

Fax: (916) 443-2672

www.sacramento-tma.org/app-mem.html

* The developer's fee is based on the size of the project and is negotiable with the board.

\begin{tabular}{|l|l|}
\hline \multicolumn{2}{|c|}{ Annual TMA Fee Schedule } \\
\hline Number of Employees & Fee \\
\hline $1-99$ & $\$ 300$ \\
$100-199$ & $\$ 500$ \\
$200-499$ & $\$ 750$ \\
$500-749$ & $\$ 1,000$ \\
$750-999$ & $\$ 1,250$ \\
$1,000-1,999$ & $\$ 1,500$ \\
$2000-2,999$ & $\$ 2,000$ \\
$3,000+$ & $\$ 2,000$ \\
Developer's Fee & $\$ 500-\$ 5,000 *$ \\
Sponsor's Fee & $\$ 5000$ or more \\
\hline
\end{tabular}

\section{Folsom Rancho Cordova El Dorado}

27I Turnpike Drive

Folsom, CA 95670

Phone: (916) 35I-3975

Fax: $\quad$ (916) 35I-3984

www.fredtma.org/memberbenefits.html

\section{Example: Expense Sharing}

\begin{tabular}{|l|l|}
\hline \multicolumn{2}{|c|}{ Annual TMA Fee Schedule } \\
\hline Number of Employees & Fee \\
\hline $1-4$ & $\$ 50$ \\
$5-14$ & $\$ 75$ \\
$15-24$ & $\$ 100$ \\
$25-49$ & $\$ 150$ \\
$50-74$ & $\$ 250$ \\
$75-99$ & $\$ 350$ \\
$100-199$ & $\$ 500$ \\
$200-399$ & $\$ 700$ \\
$400-999$ & $\$ 1,000$ \\
$1000+$ & $\$ 1,800$ \\
Developer's Fee & $\$ 500$ \\
Sponsor's Fee & $\$ 5000$ or more \\
\hline
\end{tabular}




\section{TranSComm (formerly the Interinstitutional TMA)}

609 Albany Street, Basement

Boston, MA 02118-2393

Phone: (617) 638-7473

Fax: $\quad(617) 638-4193$

www.masscommute.com/tmas/itma/index.htm

TranSComm is an example of an "expense sharing "TMA. It was founded in 199I to coordinate the transportation needs of thousands of people who receive care from, are employed by, or study at one of the sponsoring institutions: Boston Medical Center and Boston University Schools of Medicine, Public Health and Dental Medicine and the Boston Public Health Commission. The operating and staffing costs of the TMA are equally divided among the three members.

\section{Example: Developers}

\section{South Natomas Transportation Management Association}

2295 Gateway Oaks Drive, Suite 250

Sacramento, CA 95833-3225

Phone: (916) 646-0928

Fax: $\quad(916) 929-6380$

www.SouthNatomasTMA.org

\begin{tabular}{|l|l|}
\hline \multicolumn{2}{|c|}{ Annual TMA Fee Schedule } \\
\hline Members & Dues \\
\hline Member Companies & $\begin{array}{l}\$ .07 \text { per rentable square foot with annual } \\
\text { minimum due of } \$ 250 \\
\text { Developers }\end{array}$ \\
$\$ .04$ per entitled square foot \\
\hline
\end{tabular}

\section{Example: Local Government}

\section{Cross County Connection Transportation Management Association}

2002D Lincoln Drive West

Marlton, NJ 08053-I530

Phone: (856) 596-8228

Fax: (856) 983-0388

www.ridetheshuttle.com/

\begin{tabular}{|l|l|}
\hline $\begin{array}{l}\text { Government \& Organizations } \\
\text { Townships* }\end{array}$ & Dues \\
\hline Less than 10,000 employees & $\$ 1,250$ \\
$10,000+$ employees & $\$ 2,500$ \\
County & $\$ 10,000$ \\
\hline
\end{tabular}




\begin{tabular}{|l|l|}
\hline Employees & Dues \\
\hline I to I0 & $\$ 100$ \\
II to 25 & $\$ 150$ \\
25 to 50 & $\$ 300$ \\
$5 I$ to 75 & $\$ 400$ \\
76 to 100 & $\$ 500$ \\
IOI to 200 & $\$ 1,000$ \\
20 I to 300 & $\$ 1,500$ \\
$30 I$ to 500 & $\$ 2,000$ \\
50 I to 1000 & $\$ 2,500$ \\
I00I to 1500 & $\$ 3,000$ \\
I50I to 2000 & $\$ 3,500$ \\
$200 I+$ & $\$ 4,000$ \\
\hline
\end{tabular}

*Membership dues are based on the employees working within the municipality

*Membership dues are based on the average number of employees placed in jobs over the past two years.

\begin{tabular}{|l|l|}
\hline $\begin{array}{l}\text { Temporary/Employment } \\
\text { Agencies* }\end{array}$ & Dues \\
\hline Less than I,500 employees & $\$ 1,500$ \\
I,500+ employees & $\$ 2,000$ \\
\hline
\end{tabular}

\section{Example: Graduated Fee by Employees and Flat Fee for Municipalities}

\section{Airport Corridor Transportation Management Association}

Two Penn Center West Suite 120

Pittsburgh, PA 15276

Phone: (4I2) 788-II99

Fax: $\quad(412) 788-205 I$

http://trfn.clpgh.org/actal

* minimum of $\$ 250$

\begin{tabular}{|l|l|}
\hline Members & Dues \\
\hline Companies & $\$ 2.00$ per employee* \\
Municipalities & $\$ 2,000$ \\
\hline
\end{tabular}

\section{Example: Other Members/Associate Members}

\section{The Anaheim Transportation Network}

94 South Anaheim Boulevard

Anaheim, CA 92805

Phone: (7I4) 563-5287

Fax: $\quad$ (714) 563-5289

www.atnetwork.org 


\section{Employer:}

(Based on total number of employees)

$\$ 1.30$ per employee

$\$ 150.00$ Minimum

$\$ 3,250.00$ Maximum

\section{Hotel/Motel:}

(Based on total number of rooms)

$\$ 1.50$ per room

$\$ 150.00$ Minimum

$\$ 1,000.00$ Maximum

\section{Event Centers:}

(Based on estimated annual number of guests - most recently compiled figure. Event Centers pay both as event centers and as employers.)

$\$ 65.00$ per million visitors per venue

$\$ 150.00$ Minimum

$\$ 650.00$ Maximum

Associate Members: (non-voting, available to public agencies and companies outside Anaheim)

$\$ 150.00$ per year. 


\section{Reference Texts}

\section{Business Management Reference Texts}

\section{Non-Profits:}

- Starting and Managing a Nonprofit Organization:A Legal Guide, Bruce R. Hopkins, John Wiley \& Sons, 2000.

- How to Form Your Own Non-Profit Corporation $4^{\text {th }}$ Ed., Anthony Mancuso, Nolo Press, 1998.

- How to Form a Non-Profit in California (book and CD-ROM), Anthony Mancuso, Nolo Press, 2000.

- Managing a Nonprofit Organization in the Twenty-First Century, Thomas Wolf \& Barbara Carter, Fireside Publishing, 1999.

- "The Legal Obligations of Nonprofit Boards:A Guidebook for Board Members," written by Jacqueline Covey Leifer and Michael B. Glomb. National Center for Nonprofit Boards, Washington, D.C., revised 1997.

- IRS Publication No. 557, Tax Exempt Status for Your Organization, can be found at http://www.irs.ustreas.gov/forms pubs/pubs/p557toc.htm

\section{Marketing:}

- Kellogg on Marketing:The Kellogg Marketing Faculty Northwestern University, Dawn lacobucci and Philip Kotler, John Wiley \& Sons, 2000.

- Marketing Without Advertising $3^{\text {rd }}$ Ed., Marcia Phillips et al, Nolo Press, 200 I.

\section{Market Research:}

- Marketing Research:A Practical Approach for the New Millennium, Joseph F. Hair et al, Irwin/McGraw Hill Publishing, 1999.

- Focus Groups:A Practical Guide for Applied Research 3 ${ }^{\text {rd }}$ Ed., Richard A. Krueger, Mary Anne Casey, Sage Publications, 2000.

- Constructing Effective Questionnaires, Robert A. Peterson, Sage Publications, 1999.

\section{Business Plans:}

- The Successful Business Plan: Secrets \& Strategies $3^{\text {rd }}$ Ed., Rhonda M.Abrams, Oasis Press, 2000.

- The Start-Up Guide:A One-Year Plan for Entrepreneurs, David H. Bangs Jr., Upstart Publishing Co., 1998.

- Starting and Operating a Business in the U.S., Michael D. Jenkins, Running R Media, 1999.

\section{Financial Management:}

- The Complete Guide to Getting a Grant, Laurie Blum, John Wiley \& Sons, 1996.

- Finance \& Accounting for Non Financial Managers, William G. Droms, Prentice Hall, 1998.

- Cash Rules: Learn and Manage the 7 Cash-Flow Drivers for Your Company's Success, Bill McGuiness, Kiplinger Books, 2000.

- Finance \& Accounting for Non Financial Executives, J. Fred Weston \& Samuel C.Weaver, McGraw Hill, 200 I. 



\section{Articles of Incorporation}

\section{Sample TMA Articles of Incorporation}

This sample is for a $50 \mathrm{I}(\mathrm{c}) 4$ organization

I. Name

The name of the Corporation is "Sample TMA."

2. Purpose

The Corporation is formed for educational and social welfare purposes, and is not organized for the private gain of any person, as those terms are defined in Section 50 I (c)(4) of the Internal Revenue Code, I954, as amended. It is organized for the purpose of:

(a) Providing a forum for private developers, employers, and commercial and residential property owners to address common transaction concerns and to work cooperatively with local government to mitigate traffic congestion through a transportation demand management program;

(b) Reducing traffic congestion, air pollution and parking needs by organizing transportation programs including, but not limited to, transit, carpooling, vanpooling, flexible work hour programs and parking management programs and other related transportation alternatives;

(c) Promoting efficient transportation systems that will enhance the area's competitiveness and economic vitality and continue its image as an attractive place in which to live, work, and do business;

(d) Administering contributions and grants to the Corporation from public and private sources and funds under contracts with public agencies and private organizations, in accordance with the terms and conditions of such contributions, grants and contracts and in keeping with the carrying out of the purposes of the Corporation as stated in this Certificate of Incorporation and the bylaws of the Corporation; and,

(e) Exercising all rights and powers granted to non-profit corporations to fulfill its purposes, subject to such limitations as may be contained herein or in the bylaws of the Corporations.

\section{Duration}

The duration of the Corporation is perpetual.

4. Class

The Corporation is a non-stock corporation and shall have the classes of membership as set forth in the bylaws.

\section{Tax Status}

It is intended that this Corporation shall have the status of a corporation that is exempt from federal income taxation under Section 50I(c)(4) of the Internal Revenue Code of 1954, as amended.

\section{Limitations}

Notwithstanding any other provisions of this Certificate, the Corporation shall not carry on any other activities not permitted to be carried on by a corporation exempt from federal income tax under Section 50 I (c)(4). The Corporation shall not make loans to its directors, officers, employees or members. No dividends or earnings shall ever be paid by the Corporation and no part of its net earnings shall be distributed to or incur to the benefit of its directors, officers, members or any private person, firm, corporation or association except in reasonable amounts for services rendered or reimbursement of reasonable expenses incurred in connection with the Corporation's affairs.

\section{Principal Office}

The location of the principal office is at . The name of the agent therein is Board Chairman

8. Directors

The activities, property, and affairs of the Corporation shall be managed by a board of directors, the number of which 
are determined from time to time in accordance with the bylaws. The following persons whose names and addresses are listed below shall constitute the initial board of directors:

Name and Address

\section{Dissolution}

Upon the dissolution of this Corporation, the provisions of the (State) Non-Profit Corporation Act shall apply.The assets, if any, shall be distributed to such organization(s) formed and operated for similar purposes to which are determined to be exempt under the provisions of Section 50I(c)(4) of the Internal Revenue Code.

INWITNESSWHEREOF, we have made, signed, and acknowledged this Certificate of Incorporation, this (date) day of (month, year).

Incorporator

Incorporator

Incorporator

\section{Sample TMA Bylaws}




\section{Article I-Name}

The name of this organization shall be the "Sample TMA."

\section{Article II-Authority and Purpose}

The Corporation is organized exclusively for social welfare and educational purposes as those terms are defined and limited by Section 50 I (c)(4) of the Internal Revenue Code (1954), as amended, or any corresponding provisions of a subsequent federal law. The purpose of the Corporation is to coordinate the business community's efforts, including developers, corporations, commercial property owners and employers to address common transportation concerns, improve accessibility and mobility, provide transportation services, and work cooperatively with local government to mitigate traffic congestion. The Corporation will advocate and promote Transportation Demand Management strategies for the purpose of, but not limited to, such goals as (I) reducing traffic congestion, (2) reducing air pollution, (3) reducing commuting costs, (4) generating joint public/private sector approaches to solving transportation problems to/from the area served by the TMA, (5) creating a central information service for ridesharing, public transportation and other transportation-related subjects. The Corporation shall engage in activities necessary and proper to accomplish the purpose in accordance with the law.

\section{Article III-Board of Directors}

\section{Section I-Number}

The Corporation shall have directors and collectively they shall be known as the board of directors. The number may be changed by amendment of this bylaw, or, by respect of this bylaw and adoption of a new bylaw, as provided in these bylaws.

\section{Section 2-Powers of Directors}

Subject to the limitations provided by law, the Articles of Incorporation, or these bylaws, all corporate powers of the Corporation shall be exercised by or under authority of, and the business and affairs of the Corporation shall be controlled by, the board of directors. Without limiting the generality of the foregoing, the board of directors shall have the following powers:

(a) To select and remove any or all of the officers, agents and employees of the Corporation; prescribe such powers and duties for them as may not be inconsistent with law, with the Articles of Incorporation or the bylaws; fix their compensation and require from them security for faithful service.

(b) To conduct, manage and control the affairs and business of the Corporation, and to make such rules and regulations thereof not inconsistent with laws, with the Articles of Incorporation or the bylaws, as they deem best.

(c) To change the principal office for the transaction of business of the Corporation from one location to another within the area surveyed by the Sample TMA; to designate any directors', or members' meetings; and to adopt, make and use a corporate seal and to alter the form thereof from time to time as in their judgment they may deem best, provided such seal shall at all times comply with the provisions of law.

(d) To borrow money and incur indebtedness for the purposes of the Corporation, and to cause to be executed and delivered thereof in the corporate name, promissory notes, bonds, debentures, deeds of trust, mortgages, pledges, and securities.

(e) To solicit, collect, receive, acquire, hold and invest money and property, both real and personal, received by gift, contribution, bequest, devise or otherwise; to sell and convert property, both real and personal, into cash; and to use the funds of this Corporation and the proceeds, income, rents, issues and profits derived from any property of this Corporation for any of the purposes for which this Corporation is formed.

(f) To act as trustee under any trust created to furnish funds for the principal objectives of this Corporation and receive, hold, administer and expend funds and property subject to such trust.

(g) To purchase or otherwise acquire, own, hold, sell, assign, transfer or otherwise dispose of mortgage, pledge, or otherwise hypothecate or encumber, and to deal in with shares, bonds, notes, debentures or other securities or evidences of indebtedness of any person, firm, corporation or association and, while the owner or holder thereof, 
to exercise all rights, powers and privileges of ownership.

(h) To enter into, make, perform and carry out contracts of every kind for any lawful purpose without limit as to amount, with any person, firm, association or corporation, municipality, county, parish, state, territory, government (foreign or domestic) or other municipal or governmental subdivision.

\section{Section 3-Qualifications of Directors}

Directors are open to any person, natural or corporate, partnership or association, who is a developer of land (in any stage of development); owner of either commercial or retail projects; a tenant; or an employer of a business located within the area served by the Sample TMA. Directors shall be limited to a single representative or his/her designated alternate from each corporation, employer or association, which provides a minimum financial contribution to the Corporation. Minimum financial support levels shall be set by the board of directors and may vary based upon the size or type of organization.

\section{Section 4-Ex-Officio Directors}

Ex-officio non-voting seats shall include (identify appropriate organization that will designate representatives to participate in corporation).

\section{Section 5-Number of Directors}

The board of directors shall consists of not less than five (5) nor more than twenty-five (25), the exact number of which may be fixed by the board of directors from time to time.

\section{Section 6-Term of Office}

Each director shall hold office until the next annual meeting for election of the board of directors as specified in the bylaws and until his/her successor is elected and qualified.

\section{Section 7-Vacancies}

The power to fill vacancies for unexpired terms shall be vested in the majority vote of the directors then in office. Each qualified director so elected shall hold office for the designated term.

\section{Section 8-Limitation on Terms}

Directors shall be eligible to succeed themselves and there shall be no limitations on the number of consecutive terms a director may serve.

\section{Or}

Directors shall serve consecutively for a limit of two (2) one-year terms.

\section{Section 9-Compensation}

Directors shall serve without compensation for their services but may fix reasonable allowance for expenses actually incurred in connection with their duties.

\section{Section I0-Resignation or Removal}

Any director may resign by giving written notice to the secretary. Any qualified director may be removed from the board for failure to remain current in their financial commitment as established by the board. A board member will be designated as delinquent for failure to meet financial obligations within 60 days of the established due date.

\section{Section I I-Place of Meeting}

The board may hold meetings, annual, regular, or special, at such place as determined by the board of directors. 


\section{Section 12-Annual and Regular Meetings}

An annual meeting of the board shall be held in the month of (month) each year for the election of officers, for the appointment of committees, for the receipt of reports from committees and officers, and for the transaction of such other business as may properly come before the meeting. The annual meeting shall be held on the date and at the time and place as shall be stated in the notice of the meeting, which notice shall be in writing and shall be mailed at least seven days before the annual meeting, and members of the Corporation may be invited to attend the annual meeting. Regular meetings of the board shall be held on such dates and at such times and places: (a) as shall be specified in a resolution adopted by the board then in effect; or (b) if there shall not be any such resolution then in effect, as shall be specified in a notice of the meeting, given as provided in Article III, Section I 3 of these bylaws; or (c) as shall be specified in a waiver of notice thereof signed by all the directors then in office. If at the time any regular meeting of the board is to be held, the date, time and place of holding regular meetings of the board shall have been fixed by resolution of the board then in effect, then notice of such regular meeting need not be given.

\section{Section I3-Special Meetings, Notice and Waiver}

Special meetings of the board shall be held at the request of the chairman or the secretary of the Corporation, or any three directors. At least four day's written or oral notice of each such special meeting stating the time and place of the meeting shall be given to each director. Neither the business to be transacted at nor the purpose of any meeting of the board need be specified in the notice unless required by these bylaws. Any director may waive notice of any meeting.

\section{Section I4-Quorum, Adjournment and Manner of Acting}

A majority of the total number of voting members shall constitute a quorum of the transaction of business. The vote of a majority of the total number of directors shall be the act of the board, except as may be otherwise specifically provided by statute or these bylaws. If all the voting members or collectively consent in writing to any action to be taken by the Corporation, such action shall be as valid corporate action as though it had been authorized at a meeting of the board.

\section{Article IV-Members}

\section{Section I-Classes of Members}

The Corporation shall have two (2) classes of membership, to be established as follows:

(a) Regular Members

A class of regular voting members with qualifications established by the board of directors shall be established.

(b) Ex-Officio Members

A class of Ex-Officio non-voting members shall be established by the board of directors.

\section{Section 2-Qualification of Members}

All companies, businesses, agencies, both public and private, localized within the area served by the Sample TMA are qualified to become a member of their corporation.

\section{Section 3-Admission of Members}

Applicants shall be admitted to membership or making applications in writing accompanied by payment of annual dues, as specified in Section 4 of these bylaws.

\section{Section 4-Dues}

Dues and a membership fee structure shall be established by the board of directors.

\section{Section 5-Executive Committee}

There shall be an executive committee, which shall consist of the chairman and vice chairman of the board of directors, the executive director (without voting rights), the treasurer, and the secretary of the Corporation. The executive committee shall 
have, and may exercise, in the interim between meetings of the board of directors, all the designated authority of the board of directors, except that the executive committee shall not have the power to amend the bylaws or to appoint officers of the Corporation. All actions of the executive committee must be ratified by the board of directors at its next meeting. The Executive Committee will report its actions in the interim between meetings of the board at the next meeting of the board. Meetings of the executive committee shall be called by the chairman, or in his or her absence, by the secretary of the Corporation. A majority of the members of the executive committee shall constitute a quorum. The vote of a majority of the members present at a meeting at which a quorum is present shall be the act of the executive committee.

\section{Section 6-Powers of Voting Members}

Subject to the limitation provided by law, the Articles of Incorporation or these bylaws, all power of the Corporation shall be exercised by the board of directors under the authority of the voting members. After the class of members has been established, voting members shall elect the directors (except ex-officio members) and vote on any other action placed before them through resolution by the board of directors or ten percent of the voting membership.

\section{Section 7-Non-liability of Members}

A member of this Corporation is not, as such, personally liable for the debts, liabilities, or obligation of this corporation.

\section{Section 8-Notwithstanding of Membership}

No member may transfer for value a membership, or any right arising therefrom. All rights of membership cease upon membership termination.

\section{Section 9-Termination of Membership}

The membership of a member shall terminate upon notice of such termination in writing delivered to the executive director, or the secretary, personally by mail.

\section{Section 10—Other Committees}

The board may designate other committees with such membership and authority as shall be provided in the resolution of appointment.

a) The board may designate two or more directors to constitute any other committee it deems necessary. Any such committee shall have and may exercise all authority granted to it by the board as shall be provided in the bylaws or by resolution of the board.

(b) The board may appoint non-directors to any Committees, except the executive committee, as non-voting Committee members.

(c) The board shall have the power to prescribe the manner in which proceedings of any committee shall be conducted. In the absence of any such prescription, a committee shall have the power to prescribe the manner in which its proceedings shall be conducted. unless the board or the committee shall otherwise provide, the regular and special meetings and other actions of the committee shall be governed by the provisions of this Article applicable to meetings and actions of the board. Minutes shall be kept of each meeting of each committee.

\section{Article V-Officers, Agents and Employees}

\section{Section I-Number, Qualifications, Term and Election of Officers}

The officers of the Corporation shall be the chairman, vice chairman of the board, treasurer, and secretary, each of whom shall be elected by the board from among their members. There shall be an executive director appointed by the board.A director may jointly hold the offices of treasurer and secretary. Each officer shall hold office for a term from the time he or she is elected until the next succeeding annual meeting of the board and until his or her successor shall have been duly elected and qualified. The board may from time to time appoint such other officers, agents and employees as the board may deem necessary or advisable, each of whom shall hold office or employment for such period, have such authority, and perform such duties as the 
board may from time to time determine.

\section{Section 2-Removal}

Any officer of the Corporation may be removed with or without cause at any time by the act of the board.

\section{Section 3-Chairman of the Board}

The chairman shall be the chief executive officer of the Corporation. The chairman shall preside at each meeting of the board and at each meeting of the executive committee. The chairman shall be entitled to notice of and to attend meetings of all committees. The chairman shall see that all orders and resolutions of the board and of committees of the board are carried into effect.

\section{Section 4-Vice Chairman of the Board}

The vice chairman of the board (hereinafter called the vice chairman) will assist the chairman in carrying out his duties, as set forth in Section 3 of this Article. He or she shall preside in the chairman's absence at meetings of the board of directors, executive committee, and the members when such are called for under these bylaws. With the chairman and the board of directors, the vice chairman shall be responsible for the formation and implementation of the general policies of the Corporation. He or she shall also perform other duties as may be requested of him from time to time by the chairman, or the board. In case of the chairman's absence or inability to act, the vice chairman shall perform the duties of the chairman and when so acting shall have all the authority of and be subject to all the restrictions upon the chairman.

\section{Section 5-Treasurer}

The treasurer shall have charge and custody of and be responsible for all funds and securities of the Corporation; shall keep full and accurate accounts of assets, liabilities, receipts and disbursement and other transactions of the Corporation in books belonging to the Corporation; shall cause regular audits of such books to be made under the guidance and direction of the board; and shall deposit or cause to be deposited all moneys and other valuable effects in the name of and the credit of the Corporation in such banks or other depositories as may be designated by the board. The treasurer, with the authority of the chairman, shall disburse the funds of the Corporation as may be ordered by the board, taking proper vouchers for such disbursements. He or she shall render or whenever the board or chairman requires it, a statement of all transactions as treasurer and an account of the financial condition of the Corporation.

\section{Section 6-Secretary}

The secretary shall be responsible for supervising the recording and keeping minutes of all meetings of the board and of the executive committee. The secretary shall keep a register or the post office address of each member, which shall be furnished to him or her by such members, and shall cause to be given notice of all meetings of the board and of the executive committee. He or she shall be the custodian of the seal of the Corporation and shall affix the seal, or cause it to be affixed, to all documents the execution of which on behalf of the Corporation under its seal shall have been specifically or generally authorized by the board. He or she shall have the charge of the books, records and papers of the Corporation relating to its organization as a Corporation and shall see that the reports, statements and other documents required by law are properly kept or filed. He or she shall perform all the duties incident to the office of secretary and such other duties as may from time to time be assigned to him or her by the board or by the chairman.

\section{Section 7-Vacancies}

Except as otherwise provided in these bylaws, in case the office or the chairman, vice chairman, treasurer, secretary, or other person appointed by the board becomes vacant due to death, resignation or removal, the vacancy may be filled for the unexpired term by action of the sole remaining directors in office.

\section{Section 8-Resignations}

Any officer, agent or employee appointed by the board, may resign his or her office at any time by giving written notice of his or her resignation to the chairman or secretary of the Corporation. Such a resignation shall take effect at the time of its receipt, 
and the acceptance of the resignation shall not be necessary to make it effective.

\section{Section 9-Non-liability of Directors}

The director shall not be personally liable for the debts, liabilities, or other obligations of the corporation.

\section{Article VI-Personnel}

\section{Section I-Executive Director}

The board of directors may employ an executive director who shall be the chief operating and administrative officer of the Corporation, subject to the direction of the board. He or she shall be responsible for the Corporation's day to day operations, organization and staff. In general, he or she shall perform all duties incident to the position of administrative officer and such other duties as may from time to time be assigned to him by these bylaws, or by the chairman of the board. The board shall fix the compensation for such office and approve a salary structure.

\section{Section 2-Other Personnel}

The board of directors may also employ such other office and professional personnel and retain consultants as may be deemed necessary to attain the objectives of the Corporation.

\section{Article VII-Contracts, Income and Disbursements}

\section{Section I-Contracts}

The board may authorize any officer or agent of the Corporation, in addition to the officers so authorized by these bylaws, to enter into any contract or service agreement or to execute and deliver any instrument in the name of and on behalf of the Corporation.

\section{Section 2-Checks}

All checks, drafts, or orders for the payment of money, notes or other evidences of indebtedness issued in the name of the Corporation for an amount greater than fifteen hundred $(1,500)$ dollars shall be signed by two or the following: chairman, treasurer or executive director of the Corporation and in such manner as shall from time to time be determined by resolution of the board or by the executive committee in the absence of such determination by the board.All instruments for an amount of fifteen hundred $(I, 500)$ dollars or less, shall be signed by the executive director and in such manner as shall from time to time be determined by resolution of the board.

\section{Section 3-Service Fees}

The board of directors may set and collect fees and charges to be paid by corporations, agencies, partnerships, joint ventures, other organizations or individuals for services performed or to be performed by the Corporation in accordance with the Articles of Incorporation and these bylaws. Such fees and charges may vary in amount based upon the type and quantity of services and the type and size of organization receiving said services. The fair market value of in-kind services provided by such organizations may be counted against the total amount of fees or charged owed.

\section{Section 4-Gifts}

The board of directors may accept on behalf of the Corporation any contributions, gifts, bequests, or devices for the general purposes or for any special purpose of the Corporation. 


\section{Article VIII-Books and Records}

The Corporation shall keep correct and complete books and records of accounts and shall keep summaries of the proceedings of the meetings of its members, board of directors and Committees having any of the authority of the board of directors. The Corporation shall keep a record of names and addresses of members entitled to vote. At intervals of not more than twelve months, the Corporation shall prepare a balance sheet showing its financial condition as of a date not more than four months prior thereto and a statement of receipts and disbursements for the proceeding twelve month period.All books and records shall be kept at a location designated by the board and may be inspected by any member or his/her agent for any proper purpose during usual business hours.

\section{Article IX-Fiscal Year}

The fiscal year of the Corporation shall begin on the first day of (Month) in each year.

\section{Article X-Non-Liability}

No members of the Corporation and no contributor to the Corporation shall be liable for the acts of the Corporation, its board of directors, its agents, or its representatives. The Corporation shall indemnify any person who was or is a party, or was threatened to be made a party, to any threatened, pending or completed action, suit or proceeding civil, criminal, administrative or investigative when the person is/was a member, director, officer, employee or agent of the Corporation, except that the extent that such claims, suits, etc., shall arise by virtue of willful misconduct or gross negligence.

\section{Article XI-Amendments}

The bylaws may be amended, altered, or repealed or new bylaws adopted by a two-thirds $(2 / 3)$ vote of the directors at any meeting provided that the proposed action was stated in specific terms in the notice of the meeting. 



\section{Example, Office Procedures}

\section{Miami Beach TMA}

\section{A. BOARD OF DIRECTORS}

I. Board Responsibilities:

The primary responsibilities of the Board of Directors of the MBTMA includes: policy-making and planning, identifying and evaluating professional management staff, stewardship of the Association's finances including compliance with reporting requirements, Board development and fund-raising. Directors develop the goals of the Association in a mission statement. In addition, they develop the short and long range plans of the Association in the form of a work plan-to assess how goals are to be achieved.This affords opportunity for the Board to regularly evaluate the viability, and effectiveness of the MBTMA program activities.

2. Stewardship Function:

The Board most effectively fulfills its stewardship responsibility by establishing financial and management standards, delegating authority to an effective staff, monitoring the association's progress, financial performance, and compliance with the established financial and management standards. The Board may delegate any of the procedures described herein to an executive committee within the limits established by the By-Laws.

3. Governance and Management Standards:

The Board establishes the guidelines for the general and financial management of the Association. Periodically it is desirable for the Board to review and revise the established standards in light of changes that occur during the life of the Association.

4. Adoption of Work Program and Budget:

At the end of each year (November), the Board of Directors adopts a work-program for the following year, consistent with the Association's role and mission, and adopts an operating budget. The Executive Director is charged with responsibility for achieving the objectives of the Association within the limits of the adopted budget. The adopted budget will indicate the amount permitted to be spent for each of the budget categories. Funds may not be in excess of the budgeted amount. Periodically throughout the year, the results of the actual financial transactions are compared to the budget and it can be expected that the budget will require revision by the Board or Executive Committee based upon such review.

\section{Expenditure Operation:}

The authority to make expenditures or to make commitments for expenditures is another function of the Board. Generally, at the time that the Board adopts the budget it also indicates those categories that it authorizes staff to make commitments and draw against, and those other categories that it requires staff to obtain later expenditure authorization from the Board of the Executive Committee. In this way the known continuing needs of the Association are provided for at the beginning of each budget year, and those that are as yet unknown, or that the Board wishes to more specifically consider are subsequently authorized.

\section{Contractual Obligations:}

Contracts entered into by the Association require authorization by the Board of Directors of the Executive Committee. Contracts are required for all professional and personal service providers and other legal commitments of the Association. Generally, the President,Vice President and Secretary, are authorized to execute contracts approved by the Board, but the Board may authorize execution of approved contracts by other specially designated officers.

\section{Bank Signatories}

The Board of Directors designates those officers and staff members authorized to sign checks on behalf of the Association. All checks must bear two authorized signatures, not exceed budget amounts and be within a category of 
expenditure authorized by the Board. The Executive Director is authorized to sign checks under $\$ 100$ for payment of goods and services purchased by the Association and other checks specifically authorized by the Board. All checks in excess of $\$ 100$ must bear two signatures of the Executive Committee (President,Vice President, Secretary, Treasurer). The Executive Director is authorized to sign as a second signature of an Executive Committee member.

8. Monitoring Financial Performance:

Periodic financial statements provide the Board of Directors with information on the financial position and the results of its operations as well as a means to determine compliance with financial and management standards. At least monthly financial statements should be provided to the Board of Directors. At the end of the budget year the Board should review the annual financial statement and Internal Revenue Service Form 990.

\section{B. BOARD COMMITTEES}

\section{Board Committees:}

There shall be four standing committees of the Board of Directors: Executive Committee, By-Laws and Nominations Committee, Long Range and Finance Committee, and Membership Committee. There shall also be various Sub-Area Councils and Working Committees (i.e. Electric Shuttle Task Force etc.).

a) Executive Committee - The Executive Committee's role, composition, rules and delegated authority are set forth in the Corporate By-Laws.

b) By-Laws and Nominations Committee - This standing committee shall have two roles: First, to nominate candidates for election as directors and officers, and the appointment of replacements, advise the Executive Director on committee appointments, prepare balanced slates for election/appointment and serve as the repository of expertise for matters related to nomination and representation. Second, to prepare for approval of the Board of Directors the By-Laws of the MBTMA and to effectively monitor their compliance as required.

c) Long Range Plan and Finance Committee -This committee has two roles: First, to review the financial status of the MBTMA on a quarterly basis, to provide support/guidance for the Executive Director, and direction for the Association's Treasurer on issues related to the financial standing, budgets, expenditures, etc. of the Association as required, and to develop the annual budget. In addition, the committee shall develop, monitor, and review the Association's Long Range Plan on an annual basis.

d) Membership Committee - This committee recruits, promotes, and nurtures the development of the Association's membership, including dues structure, potential memberships, solicitation for membership, and supports the Executive Director in their efforts to expand the Association's membership.

2. Working Committees:

There may be as many working committees as deemed necessary by the Board. The Board of Directors and the Executive Director shall appoint all working committee members. Working committee members may include directors, staff, community stakeholders and other skilled persons. The role, tasks, duration, responsibilities and authority of working committees shall be delineated at their onset.

3. Sub-Area Councils:

There may be as many sub-area councils as deemed necessary by the Board of Directors or the Executive Director to effect the proper organization and representation of the interests of the MBTMA service area. The Board of Directors or the Executive Director appoints to sub-area councils following the guidelines negotiated with each sub-area council.

\section{STANDARDS OF CONDUCT}

I. Duties of Directors and Trustees: 
a) Commitment: Giving time, effort, and application to the business and affairs of the Association and its promotion.

b) Principle: Loyalty and concern for the interests of the Association over self or special interests. Acting in good faith, fairness, and openness, including identifying personal conflicts of interest when they arise.

c) Responsibilities: Compliance with the Mission, By-Laws, Articles, the Governance and Management Standards, and the adopted policies of the Association.

d) Dedication: Investing a stake in the well being of all the MBTMA service area.

2. Standards of Conduct Applicable to Procurement of Property and Services Federally Funded

Where prohibited by Federal grant requirements, no director, officer, employee, or agent shall participate in the procurement of supplies paid for by Federal funds if a conflict of interest, real or apparent would be involved.

Such a conflict would arise when:

a) The director, officer, employee or agent

b) Any member of his/her immediate family

c) His or her partner, or

d) An organization which employs, or is about to employ, any of the above has financial or other interest in the transaction.

3. Conflict of Interest

\section{General Rule:}

If a director, officer, employee or agent shall have a financial interest in a contract transaction or other matter before the Association, the director, officer, employee, or agent shall disclose the fact and nature of such interest and shall not participate in discussion, vote or be counted in a quorum regarding the matter. A director, officer, employee or agent is precluded from exercising any function of their office with respect to a matter in which they have a financial interest. A director shall receive no compensation from the Association for their services as a director.Annually, each director, officer, employee, or agent with purchasing responsibility shall file a financial disclosure of business affiliations and indicate any relationship with any company doing business with the Association.

The MBTMA shall comply with the Conflict of Interest requirements of its grant sources, as such requirements are applicable.

\section{Part II. FINANCIAL MANAGEMENT}

\section{A. RECEIPT OF FUNDS}

\section{Deposit of Funds:}

All funds received should be deposited in the bank, intact and on a timely basis. The deposit should be prepared by the Executive Director.The deposit should be prepared in duplicate indicating the source of funds and the reason received. The bank's validation slip should be attached to the back of the Association's copy. Payment advice accompanying funds received must be retained and properly filed.

\section{Cash Receipts:}

Any cash that is received must be immediately deposited in the bank, the source of the funds and the reason for receipt should be indicated on the duplicated deposit slip. The Association should issue a receipt for cash received 
when requested and maintain a duplicate.

\section{B. PROCUREMENT}

\section{Initiating Purchase Requests:}

The Executive Director is responsible for supervising purchases within budget limits and expenditure authorization in a manner consistent with these procurement policies.

2. Procedures:

Procurement of goods or services shall be made as follows:

a) Purchase procedure-appropriate for procurement of services, supplies or other property, costing more than $\$ 500.00$. Requires a minimum of three separate price comparisons.

b) Competitive sealed bids (formal advertising) are appropriate when required by funding source. Sealed bids are publicly solicited and a firm fixed price contract (lump sum or unit price) is awarded to the responsible bidder whose bid, conforming with all the material terms and conditions of the invitations for bids, is the lowest price.

c) Competitive negotiation-appropriate only when the item or service is available only from a single source, public exigency will not permit a delay incident to competitive solicitation, a noncompetitive negotiation, or after solicitation of a number of sources when competition is determined to be inadequate.

3. Determination by the Board:

Generally the continuing needs of the Association are met through the use of the small purchase price comparison procedure, which is available for the procurement of goods and services costing in the aggregate of not more than $\$ 500.00$. Formal advertising procedures are used only when required by government grant sources. The choice between competitive negotiation and noncompetitive negotiation is made depending upon the adequacy of supply and the time requirements. While the Executive Director is responsible for implementation of these procurement policies, nothing shall prevent the Board of Directors from specifically providing a particular procedure whether or not described herein for the procurement of specific goods or services in a specific case.

4. Compliance with Grant Requirements:

In all cases the procurement procedures shall be in compliance with the requirements of grant sources providing the funds for such procurement, and shall also avoid any conflict of interest. Generally grant sources permit the use of small purchase price comparison procedures for the purchase of goods and services costing less than $\$ 500.00$. It should be particularly noted that more restrictive requirements may be imposed by grant sources with respect to construction contracts.

5. Competitive Bidding Process:

The competitive bidding procurement process shall include the following procedures:

a) Documentation of the bidding and selection process

b) Adequate advertisement of request for competitive bids

c) Instructions to bidders shall be clear

\section{DISBURSEMENTS}

\section{Payments by Check:}

All disbursements are made by prenumbered checks. Generally the accompanying documentation is a supplier invoice or statement. 


\title{
2. Filing Documentation:
}

At the time of issuing the check (after the invoice is reviewed) the supporting documentation should be marked as follows:

\author{
"PAID” \\ DATE OF CHECK \\ CHECK NUMBER \\ AMOUNT OF PAYMENT
}

This documentation is then filed in a current "Paid Bills" file, which is used for the preparation of grant reimbursement requests. At the end of each budget year, the "Paid Bills" file is then placed in storage and a new series of files is opened.

\section{ACCOUNTING SYSTEM}

\section{SUMMARY OF SIGNIFICANT ACCOUNTING POLICIES}

\section{Cash and Accrual Basis:}

The books and interim financial statements are prepared on the cash basis of accounting.Annual financial statements are prepared on the accrual basis of accounting.

\section{Fund Accounting:}

In order to ensure observance of limitations and restrictions placed on the use of resources available to the Association, accounts are maintained in accordance with the principals of fund accounting. This is the procedure by which the resources for various purposes are classified into funds established according to their nature and purpose.

Restricted Resources:

Operating funds restricted by the grantor for particular operating purposes are deemed to be earned and reported as revenues when the Association has incurred expenditures in compliance with its specific restrictions. Such amounts received but not yet earned are reported in the financial statements as deferred grant income.

\section{Functional Allocation of Expenses:}

The costs providing the various programs and other activities are summarized in the financial statements on a functional basis. The functional classifications include the specific program services and supporting services, such as administration and fund raising. The cost of program activities should be reported separately from the cost of supporting activities. Certain costs that pertain to more than one function must be allocated to the separate functional categories on a basis that reasonably determines the portion of the cost related to each function.

\section{CHARTS OF ACCOUNTS}

The "Chart of Accounts" is the mechanism for categorizing the operations. It is prepared in a manner that enables each financial transaction of the Association to be adequately recorded. The Association uses these same accounts for the budget, the bookkeeping system and the internal financial statements. Thus, comparisons between budgeted and actual transactions are meaningful.

\section{CASH RECEIPTS JOURNAL}

All income is recorded in the "Cash Receipts" journal. As each item is received, income is listed in the total column and also appropriate category column. All columns are totaled monthly and the sum of separate category columns should agree with the total cash of the cash receipts column for the month. The cash receipts statements are supported by the duplicate deposit book and by a file containing a copy of each deposit including the deposit slip, the checks comprising the deposit and any grant source documentation that accompanied the checks. Whenever funds are 
received from grant sources a comparison should be made between funds actually received, and funds and expected to be received, and an appropriate memorandum should be in the file.

\section{CASH DISBURSEMENTS JOURNAL}

All expenditures are made by check. The check has a space that should be used for a brief description of the nature of the expense. The check book also has a space which can be used to record deposits and to keep a running balance, which should always be kept current.

\section{BANK RECONCILIATION}

The major control for completing the monthly journals is the preparation of a bank reconciliation, which should be done at the time of preparing the monthly financial statements reimbursement invoices (FDOT, city, etc.). The bank statement should be reconciled by the MBTMA Treasurer involved in the deposit of receipts or the writing of the checks.

\section{REPORTING}

Monthly reports are required to be submitted to each of the grant sources. Generally these reports describe what funds were spent during the month, the total funds spent and the balance of funds available.These reports are broken down by budget category. They are also used by the Association to request reimbursement for grant funds expended. It is necessary to attach to these grant reports, the documentation required by the grant source. At least monthly a financial statement is prepared in accordance with Board review. An annual financial statement should be prepared in accordance with generally accepted accounting procedures and reviewed by the Board of Directors. The Association is required to file IRS Form 990, Return of Organization Exempt From Federal Income Tax. The Association must also make required filings under the Florida Charitable Solicitations Statutes.

\section{E. TRAVEL AND TRANSPORTATION}

I. Travel: Those individuals who travel on behalf of the Association will be reimbursed for actual travel expenses incurred upon submission of adequate documentation of such expenses.

2. Local Transportation: Those members of staff who use their automobiles for local transportation on behalf of the Association will be reimbursed for actual transportation expenses.

3. Limitation: Reimbursements for travel and expenses shall not exceed per diem rates specified by the City of Miami Beach for travel expenses in specific metropolitan areas.

\section{PART III. PERSONNEL MANAGEMENT}

I. HIRING

The Board of Directors hires the Executive Director who is in turn responsible for hiring and terminating the other members of the staff. MBTMA is an Equal Opportunity Employer.

\section{PROBATION PERIOD}

Each staff member shall have a six month probation period.At any time during said period if the performance of the staff is unsatisfactory, the employee may be terminated by the Executive Director. During the probation period, the employee may earn but not use vacation leave. Sick leave may be used as earned.

\section{TERMINATION}

The Board of Directors shall have the authority at any time to terminate the employment of the Executive Director without the necessity of showing cause. Two weeks severance pay will be provided. The Executive Director has the authority to terminate the employment of other members of staff. Proper cause for termination shall be unsatisfactory work performance of the employee or the decision of the Association to terminate the position. In the event of termination because of the inability of the Association to fund the position, the decision of the Board of Directors shall be final. 


\section{COMPETITIVEWAGE SCALE}

It is the policy of the Association to engage staff at wages commensurate with the private sector for similar levels of responsibility, expertise, effort, and loyalty. MBTMA shall maintain current job descriptions and salary ranges for each position.

\section{FRINGE BENEFITS}

The Association provides its staff with the following fringe benefits:

a) Health Insurance is provided for all full time employees. Dependent coverage will be made available at each employee's own cost.

b) Sick pay is earned at the rate of one day per month and may be accumulated from year to year. No payment will be made upon termination or otherwise for sick days not used. An employee may accumulate no more than thirty sick pay days. Upon termination an employee shall not be entitled to payment for unused sick pay.

c) Vacation pay will be provided to the professional and support staff on the basis of twelve days per year.Vacation pay is earned ratably, month by month, and may be taken any time after it is earned upon prior written request of the employee with the agreement of the employer. Upon termination an employee shall not be entitled to payment for unused vacation pay in excess of vacation pay accrued within the preceding twelve months of employment.

d) Holidays: The following holidays will be observed: New Years Day, Presidents Day, Martin Luther King Day, Memorial Day, $4^{\text {th }}$ of July, Labor Day, Thanksgiving Day, Friday after Thanksgiving, Christmas Day, and one floating holiday (for birthday).

\section{PERFORMANCE EVALUATION}

At least annually the Executive Director shall provide a written evaluation of each staff member on a form designed to indicate evaluation of quantity and quality of work performed, work habits, interpersonal skills, and overall evaluation.A copy of the evaluation shall be provided to the employee.A copy of the evaluation signed and dated by the employee shall be filed in the employee's personnel file together with any response submitted by the employee.

\section{PERSONNEL FILES}

Personnel files shall be maintained and shall include applications, resumes, W-4 Forms and performance evaluations.

\section{HOURS OFWORK}

Current MBTMA hours of operating are from 7:00 a.m. to 4:00 p.m., unless there is a need to work overtime. Professional staff is not compensated for overtime. While secretarial staff is entitled to compensatory time off.

\section{PART IV. PROPERTY MANAGEMENT}
A. Records
A record shall be maintained of the fixed assets belonging to the Association that shall include: date acquired, descrip- tion, and original cost.

B. Annual Inventory

An annual inventory shall be conducted of the fixed assets owned by the Association. 
C. Record Retention and Access

I. Corporate Records: A corporate record book shall be maintained by the Executive Director throughout the life of the Association and should include the Articles of Incorporation, By-Laws, Governance and Management Standards and the minutes of annual membership, board of director and executive committee meetings.

2. Financial Records: Financial Records shall be kept for a period of three years.

3. Access to Records: Access to the records of the Association will be afforded to the public as further set out in Chapter I19, Florida Statutes.

4. Compliance with Grant Requirements: The Association will comply with all record retention and access requirements of grant sources.

D. Insurance Coverage

The Association will obtain the following insurance coverage:

I. public liability

2. professional liability

3. errors and omissions

4. individual liability of directors and staff

I HEREBY CERTIFY that the foregoing document was adopted as the Financial and Management Standards of the Miami Beach Transportation Management Association Inc. (MBTMA), by majority vote of the Board of Directors, duly convened at their meeting in Miami Beach, Florida.

President, MBTMA Board of Directors

Date 


\section{Director's Position}

\section{Job Descriptions-TMA Executive Director/Manager}

\section{TMA Executive Director or Manager, Sample TMA}

The executive director or program manager reports to the board of directors and is responsible for managing TMA activities.

\section{General Responsibilities}

- Implement the mission/purpose of the TMA through the day to day operation of the organization. Be accountable for all operations.

- Assist board of directors to formulate TMA policies, procedures and programs.

- Represent and promote the TMA and its programs in the community.

- Prepare budget, financial and progress reports.

- Hire, supervise, train and evaluate TMA staff.

\section{Specific Tasks}

Advocacy/Legislative

- Assess transportation service needs of local businesses and commuters.

- Participate in local and regional transportation planning organizations and committees. Coordinate with state, county and municipal officials on transportation issue.

- Apprise members of transportation-related legislation.

- Act as liaison between the public and private sectors.

Transportation Programs and Services

- Assist individual TMA member companies with development and implementation of appropriate services and programs.

- Coordinate joint programs for TMA members; (e.g. GRH, shuttles, vanpools).

- Coordinate area-wide programs for parking management, pedestrian/bicycle utilization, alternative work hours, employee coordinator network.

- Conduct market surveys to assess service feasibility.

\section{Operation}

- Establish TMA office and manage day-to-day operation of the TMA.

- Generate required staff reports to TMA board and government agencies.

- Operate existing programs.

- Create, implement, and maintain a system for tracking and monitoring progress.

- Organize TMA member and board meetings and provide staffing support to board of directors and TMA committees.

- Meet with TMA board of directors regarding project status and recommendations.

- Maintain membership database. 
- Prepare TMA financial documents and monitor financial activities and programs.

- Keep abreast of available funding sources through various local, state and federal agencies and make applications for appropriate funds.

- Administer grant programs, including invoicing, monitoring and evaluation, and preparing interim and final reports as required by granting agency.

Marketing/Membership

- Prepare and implement TMA marketing plan.

- Prepare and distribute materials promoting the TMA to potential members, and commuting alternatives to commuters.

- Conduct group information presentations to potential members, public agency representatives, employee transportation coordinators, and employees.

- Plan and conduct commuter information events (e.g. transportation fairs, meet-your-match gatherings, awareness days, bicycle week, etc.).

- Produce bi-monthly newsletter and other periodic information bulletins for members.

- Initiate and develop contacts among employers, advocate the benefits of the program to other significant players pursue active participation in program activities.

- Develop and maintain local demographic reports and survey information.

- Evaluate member services on an annual basis.

Planning

- Work with the board of directors to develop annual marketing strategy and work plan.

\section{Desirable Qualifications}

Have experience in the operation of nonprofit organizations, including knowledge of financial management, accounting practices, contract administration and insurance; at least two years experience in developing and managing employee transportation programs, or related experience; a working knowledge of marketing and promotions; good communication and people skills, including working for a board of directors and managing staff; experience working with businesses, employers, real estate developers and public agencies. 


\section{Job Description}

\section{Executive Director, South Natomas TMA}

Responsibilities:

Under the direction of the South Natomas TMA Board of Directors, the Executive Director will plan, develop and implement a variety of transportation and transportation system management (TSM) programs, services and promotional events for member companies.

Duties include recruiting new TMA members; administering, monitoring and evaluating programs such as the carpool matching, guaranteed ride home and bus pass program; handling the TMAs business affairs; presenting information on transportation programs and policies before local government boards; administering contracts; communicating with TMA members and local public agencies staff, organizing and facilitating board meetings, producing newsletters and staging promotional events and informational meetings.

Requirements:

Three-5 years experience in both marketing/sales, and transportation systems management, preferably with both public and private sector employers, and able to work with state and local government officials, employers, senior management, and developers.

Strong knowledge of the Sacramento community is desired.

A degree in communications, marketing, transportation planning, or urban planning is preferred.

Knowledge of transportation and air quality regulations is desirable.

The successful candidate must be self-motivated, energetic, well-organized and possess excellent verbal and written communication skills.

This is a one-person office and the candidate must be flexible and willing to complete wide range of tasks ranging from collating bulk mailings to policy meetings with public officials.

Time: This is a full time position.

Salary: $\quad \$ 43,000-48,000$ plus benefits.

Must supply automobile for work-related trips, which are reimbursed at the prevailing IRS rate. 



\section{Job Description}

\section{Projects Administrator, Downtown Minneapolis TMO}

\section{Job Responsibilities:}

\section{I) Oversee all employer outreach activities}

- Market transit benefit programs to employers through advertisements, phone calls, quarterly newsletter, website, etc.

- Create and update promotional materials on transit benefits

- Respond to customer requests for information by phone or at the Commuter Connection

- Conduct regular training sessions for employers

- Complete commuter surveys and transportation management plans for employers

- Schedule and attend regular commuter fairs at employment sites

- Maintain database of employer contacts and employer participation in transit programs

- Work closely with Metro Transit, Metro Commuter Services and other providers to provide seamless assistance to employers

- Work with building managers and city officials to promote transit programs to existing employers and employers relocating to downtown Minneapolis

- Provide training and follow-up assistance to employees of employers participating in regional transit benefit programs

II) Provide input and follow-up on TDM plans for new development

- Work with city officials and transportation consulting firms to develop customized TDM strategies for new developments

- Provide follow-up surveying and remedial TDM strategies to insure attainment of goals stipulated in TDM plans

III) Promote travel demand management strategies as a regional congestion-relief strategy.

- Assist Executive Director in educating the business community and public policy makers on the importance of investing in TDM

- Collect and share data on the success of a variety of TDM measures

- Work with the regional Bike, Bus or Pool (B-BOP) coalition to disseminate regional communications campaign

- Serve on local committees (i.e. City Bicycle Advisory Committee, Mn/DOT/Met Council Value Pricing Task Force, LRT Communications Comm.)

- Work with City Transportation and Public Works and Planning Departments to integrate TDM into on-going investment and planning activities 


\section{IV) Oversee Congestion Education Campaign}

- Seek speaking engagements and media exposure on congestion issue and how TMO services can assist employers and employees

\section{V) Miscellaneous}

- Serve as back-up staff to Commuter Connection resource center

- Assist in maintaining and expanding office systems - computers and software, network, printers, etc. 


\section{Job Description}

\section{Supervisor of Commuter Connection, Downtown Minneapolis TMO}

\section{Description:}

The Supervisor of Commuter Connection' is responsible for operating Commuter Connection. This includes staffing, bus pass inventory control, financial reports and customer service. In addition, the Supervisor provides or assigns administrative support services.

\section{Job Responsibilities:}

\section{Commuter Connection (CC) Operations}

- Hire, give reviews, discipline, fire staff who assist with store operations

- Write up expectations for CC staff; and provide procedures for discipline, etc. as necessary

- Provide periodic performance reviews

- Assure that all staff members are providing the highest level of customer service at all times; conduct or arrange periodic customer service training

- Train or arrange for training of staff on all TMO programs \& services

- Ensure that daily and monthly sales figures are reconciled

- Accountable for Metropass digital picture taking, spreadsheet, invoicing Metro Transit (MT), and sending information to $\mathrm{MT}$, and serve as liaison

- Serve as liaison with Metro Transit, MCS, Metro Mobility, TMO staff on all store related matters

- Assist the Ridepro Administrator

- Arrange for adequate staff coverage of CC at all times.

- Create and maintain a fairly consistent schedule for part-time employees, collect/oversee timesheets, send to Downtown Council

- Conduct periodic part-time staff meetings and one on ones

- Conduct a customer survey each year

- Identify and explore new opportunities for CC

\section{Providing or supervising TMO administrative assistance}

- Oversee, or personally do, administrative assistance activities such as mailings, faxing, answering the phone

- Identify and Oversee projects assigned to part-time staff

- Communicate protocol for administrative assistance services; including prioritizing activities

- Assist with data collection and analysis for the end of the year contract and calendar work program reviews

- Assist in designing annual work programs

- Attend staff meetings

- Take on new opportunities and responsibilities as requested 


\section{Completing "store related" financial reports}

- Generate monthly reports for Treasurer and Accountants

- Complete monthly sales analysis and reconciliation

- Assist Exec. Dir. in preparing annual and other budgets and conducting year - end analyses

- Prepare invoices for MT, MCS

- Complete tasks in Checkbook Solutions: recording daily receipts and reconciling bank statement 


\section{Job Description}

\section{Transportation Coordinator, Warner Center TMO}

\section{Job Responsibilities:}

- Assist Executive Director with administration of all TMO services

- Assist all ETC's special requests for assistance

- Mail new membership packets, process new members' registration forms for various services

- Maintain lists of all rosters, including lists for ETC, Full-membership, multi-company vanpool and all vanpools

- Assist with accounting of all TMO budgets, including the depositing, reconciling and reporting

- Assist with monthly reporting of Trust Fund grants to City

- Assist with Vanpool Incentive Program, including the review of incentive requests, program tracking and monitoring, and preparation of payments

- Coordinate vanpool placements, including responding to individual requests, responding to seat availability, and assisting with formation of new vanpool groups

- Coordinate Guaranteed Ride Home service, including maintaining records of usage, confirming eligibility requirements, reviewing invoices, and preparation of payments

- Coordinate Warner Center Bicycle Club activities, including setting seminar agendas and program, and distributing bike news 


\section{Job Description}

\section{Secretary, Warner Center TMO}

\section{Description:}

The Warner CenterTMO, a non-profit, volunteer organization made up of the larger employers and building owners of Warner Center, announces the open position of Secretary. This position will be full-time, and includes a good benefit package: Insurance package includes health, dental, vision, disability and life. Two-week vacation and one-week sick leave. Ideal candidate will possess strong organizational skills, know basic accounting procedures, be familiar with word processing and key board, and work well in a small office setting. Desired candidate will enjoy a variety of tasks, maintain professional manner, and enjoy assisting the TMO staff and our clients' needs. Interested candidates should submit a resume to the following immediately:

Chris Park

Executive Director

Warner Center TMO

21600 Oxnard, Suite 460

Woodland Hills, California 91367

(818) $710-7767$

\section{Job Responsibilities:}

- Provide clerical support to Executive Director and Transportation Coordinator

- Make needed copying and faxing

- Answer phones

- File TMO paperwork

- Receive and send all mailings

- Handle bus pass distributions, including the distribution, compiling, selling, collecting money, and reporting to RTD, Antelope Valley Express, and Simi Valley Express Service

- Handle carpool matching requests by accessing on-line computer to input, change, delete and print-out matchlists

- Handle Smog Alert Network alerts 


\section{Job Description}

\section{Employee Transportation Coordinator/TMA Liaison, South Natomas TMA}

\section{Description:}

This duty statement has been developed to assist companies in identifying the most appropriate person to serve as the liaison, or employee transportation coordinator (ETC), with the South Natomas Transportation Management Association (TMA).

ETCs act as a broker of transportation information, program administrator and marketing representative. ETCs help coordinate the best way to transport employees to the company's worksite(s), taking into consideration several variables such as employee and company needs, environmental conditions, and transportation alternative limitations. The time commitment is minimal and can be expanded to more involvement based upon the needs of the employees and interest of the ETC.

ETCs have direct influence over employee commute modes with a potential to have a significant impact on the environmental and traffic conditions in the South Natomas area. Therefore it is often helpful if the ETC uses alternative transportation him/herself, even if only occasionally.

\section{Job Responsibilities:}

Overseeing annual employee commute mode survey.

Annually, during the spring, the TMA will provide surveys for each employee to complete regarding their commute trips. The ETC is asked to distribute and collect the surveys.

\section{Disseminating information to employees.}

The TMA provides a monthly update to all ETCs via fax. ETCs are asked to share this information will all employees by the most efficient/acceptable means (e.g. e-mail, posting on bulletin board, announcements at staff meetings, etc.).

\section{Overseeing Transit Pass and Guaranteed Ride Home program documents.}

The TMA provides free transit passes to all member employees. It is a photo identification pass, which needs to be collected when an employee separates from employment.Additionally, employees who use alternative transportation two or more times/week are entitled to a ride home via taxi cab or rental car when there is an emergency. The ETC controls the vouchers, which pay for the taxi cab/rental car.

\section{Helping employees identify alternative commute modes.}

The TMA will provide the ETC information and training on the various alternative transportation options available through out Sacramento.The ETC needs to be frequently available and willing to help employees with carpool matching, identifying transit routes/connections, bicycle commuting and other trip reduction strategies.

In sum, the ETC needs to be accessible, personable and willing to act as a conduit of information between the TMA and the employees. For many companies, the ETC is either the office/facilities manager, personnel manager/staff or receptionist. TMA staff is willing to help you identify an ETC suitable for your worksite and employee needs. 


\section{Job Description}

\section{Board of Directors Duty Statement, South Natomas TMA}

\section{Description:}

To assist the South Natomas TMA staff in the pursuit of the TMA's mission and to work cooperatively on traffic mitigation and air quality issues. To further the TMA's purposes of developing and operating successful transportation programs that help reduce commute traffic and improve the air quality in Sacramento region.

A South Natomas TMA Board Director, as set forth in the South Natomas TMA Bylaws, is elected for a 3-year term and charged with guiding the TMA, transacting the business of the TMA and supervising its affairs, so that the TMA's mission is carried out and its purpose is achieved. The Board oversees the TMA's activities and has fiduciary responsibility in the governance of the Association's business. The TMA staff, an executive director, works at the pleasure of the Board of Directors and the TMA maintains Directors and Officers Insurance.

\section{Job Responsibilities:}

- Attend, on average, 70\% of the meetings. Meetings are held once a month on the first Wednesday from 8:00 a.m. to 9:00 a.m. at rotating locations among members' conference rooms

- Serve on special task sub-committees such as, but not limited to, Annual Commute Survey, Transportation Fair, Annual Meeting, and Nominating

- Participate in the TMA's programs and activities such as Annual Meetings, TMA Summit/Association for Commuter Transportation International Conferences, Transportation Fairs, New Member Orientations, and Annual Strategic Planning

- The South Natomas TMA Board of Directors consists of the Chair of the Board, President, Chief Financial Officer, Secretary, and up to 15 board members-at-large 


\section{Job Description}

\section{Board Standing Committees, Miami Beach TMA}

\section{Long Range Planning \& Finance Committee}

Purpose:

To review the financial status of the MBTMA on a quarterly basis, to provide support and guidance for the Executive Director, and direction for the Association's Treasurer. On issues related to the financial standing, budgets, expenditures, etc. of the Association as required, and to develop the annual budget for Board adoption. In addition, the committee shall develop, monitor, and review the Association's Long-Range-Plan on an annual basis.

\section{Bylaws \& Nominations Committee}

Purpose:

To nominate candidates for election as directors and officers of the MBTMA, and the appointment of replacements, to advise the Executive Director on committee appointments, prepare balanced slates for election/appointments and to serve as the repository of expertise for matters related to nomination and representation. Secondly, to prepare for approval of the Board of Directors the By-Laws of the MBTMA and to effectively monitor their compliance as required. 



\title{
Case Study-Working with Developers \& Property Owners
}

\author{
Coordinating Trip Reduction Efforts \\ Warner Center TMO
}

The Warner Center TMO, located in Los Angeles, has been instrumental in incorporating TDM into all facets of new development and large existing properties during the past II years.

Working with the City of Los Angeles, the TMO has assisted with language incorporated into the "Warner Center Specific Plan," which is a very detailed ordinance that allows the center to more than double in size if trips are mitigated properly. To encourage ridesharing, parking spaces are limited with required HOV ratios. Trip fees are required which fund a long list of transportation improvements and activities.

In addition to funding such traditional transportation improvements as added lanes and traffic signals, funds are also allocated for transit, TDM and the TMO.Although the TMO is primarily funded by private membership dues, the TMO has received ongoing funds from these fees to implement such programs as Guaranteed Ride Home, vanpool incentives and promotional activities. Large existing and new properties are required to submit and implement TDM plans, conduct annual transportation surveys of all tenants, have "rideshare-friendly" building designs, provide incentives, and identify whether or not the building is a TMO member. The goal is to achieve certain AVR (Average Vehicle Ridership) levels during the first phase of development.

New development will not occur in the future if trips are not maintained at reasonable levels. TMO membership is currently voluntary, but the City is considering requiring it. Currently, over $95 \%$ of all large properties are TMO members. Building owners who join the TMO do not need to prepare their own, separate TDM plans. Rather, they come under the umbrella of the master TDM plan of the TMO, which has been endorsed by the City.A TMA/TMO can be invaluable in ensuring trip reduction efforts are coordinated by property owners and managers. It is hoped that this example serves as a model to other cities and TMAs wondering how to effectively and reasonably involve building owners and new development in TDM.

For more information, contact Christopher Park of Warner Center TMO at (8I8) 7I 0-7767.

\section{Case Study-Working With Allied Organizations}

\section{Statewide and Regional Coordination Alliance of Southern California TMAs}

For over a decade, the TMAs/TMOs in California have been networking together, both on a statewide and regional basis, on a variety of issues, activities, shared services and actual coordinated grant awards. The seventeen TMAs in Southern California even created a logo and legally incorporated their alliance during the mid-90s, called ASCTMA (pronounced "AskTMA"), which stood for Alliance of Southern California Transportation Management Associations. This alliance received a substantial grant to be coordinated among the recipients.

In addition to the grant award, alliance activities throughout the years have involved sharing information and resources, promoting TMAs, sharing bulk discounts, identifying alliance members to liaison with various public agencies, defining a TMA and appropriate funding criteria, clarifying appropriate service roles to be provided by various public agencies, including the regional rideshare provider and TMAs, creating a special website, and establishing mentor exchange programs for fellow TMAs.

For more information, contact Christopher Park of Warner Center TMO at (8/8) 7I 0-7767. 


\title{
Case Study-Working with Allied Organizations
}

\author{
Partnering for Services and Promotions \\ Downtown Minneapolis TMO
}

\section{Creation of a "How - to Guide" for Transit Benefits}

During the year 2000, the Downtown Minneapolis TMO worked with several partners to create and disseminate a step-by-step guide for employers to offer transit benefits. These included the state transit pass tax credit, federal transit tax benefits, and regional discount bus pass programs. The TMO worked with Metro Transit (bus operator), Metro Commuter Services (regional TDM provider), the Downtown Council (business group), Minnesotans for an Energy Efficient Economy (advocacy group that spearheaded state tax credit legislation) and a local tax attorney to create this well-received guide. Partners provided critical input on the content and style of the Guide and collaborated to host an employer seminar to introduce the Guide.

\section{Bike, Bus or Pool (B-BOP)}

The Downtown Minneapolis TMO is a regular partner in the regional B-BOP campaign, conducted yearly since 1991. Other partners include other TMOs, Metro Commuter Services, Metro Transit, Mn/DOT, State of MN, Dept. of Administration and Pollution Control Agency, VPSI and a private employer or two. B-BOP has used a downtown parade, a relay race, a commuter race and other promotions to draw attention to alternative commuting options. Last year, with a TMO staff member as co-chair of B-BOP, the coalition focused on bringing B-BOP to employers through a training/networking breakfast and a month-long series of commuter fairs at employment sites.

\section{Congestion Education Campaign}

Since 1998, the Downtown Minneapolis TMO has partnered with the Metropolitan Regional Rail Authority, Mn/DOT and the Metropolitan Council (MPO) to produce a PowerPoint-based presentation on the traffic congestion issue. The presentation covers how traffic congestion affects individuals, businesses and our communities, traffic trends, what the region is doing to address congestion, and how businesses can be a partner in managing congestion. The campaign allowed for an unbiased, multi-modal depiction of the rapidly growing congestion problem at a critical juncture in the consideration of major new infrastructure investments.

\section{Parking Cash-out Project}

In partnership with Metro Commuter Services and the St. Paul TMO, the Downtown Minneapolis TMO conducted a research project during the years 1999-2000 on parking cash-out. The project investigated the extent of parking subsidies, the effect of cashing-out employer-paid parking, and the use of transit and other alternatives to driving alone. The project was funded by the federal EPA, with local grant supervision by the Minnesota Pollution Control Agency. The project dovetailed nicely with Metro Transit marketing of Metropass (a discount program for employers). Also, results of the project were incorporated into a regional forum on parking policies and as part of the exploration of value pricing (market based congestion relief strategies) by the Minnesota Department of Transportation.

For more information about partnering, contact Theresa Wernecke, at (6 I 2) 370-3987 or twernecke@uswest.net. 


\section{Case Study-Working with Allied Organizations}

\section{Creating a Community-based TMA North Natomas TMA}

The North Natomas Community Plan was the result of decades of collaboration among residents, environmentalists, planners, developers, business owners and others, resulting in the potential to be one of the most "livable communities" in the nation. Located north of downtown Sacramento, the Plan includes 7,388 acres that at buildout, will include 32,500 dwelling units with a population of 66,000 residents and 71,000 employees.

The City of Sacramento envisions a new urban form for North Natomas consisting of a well-integrated mixture of land uses, interdependent on quality transit service and other forms of transportation. The North Natomas Transportation Management Association (NNTMA) is a key component of the Plan.While the area is expected to ultimately generate 700,000 average daily trips, the overall goal is to reduce trips by $35 \%$ and reduce air pollution emissions by $35 \%$ at build-out.

NNTMA is truly community based, with membership including commercial, business and residential entities. NNTMA is charged with providing commute trip reduction and air quality mitigation support to all residents and businesses in North Natomas. The TMA Board consists of representatives from residential, commercial, industrial, and office interests.

The NNTMA was formed in advance of the development of the North Natomas community. As such, it will be a proactive force in the implementation of alternate transportation usage before congestion problems arise.

The City of Sacramento implemented a community-financing district (CFD) to provide reliable long-term funding for the TMA, with area-wide participation in the CFD. The NNTMA must pay the City and County Administrative costs of the CFD, which are approximately $30.5 \%$ of their tax revenue. As both residential and non-residential land uses receive benefit from the NNTMA, each is subject to the maximum special tax. For example, single family units pay $\$ 18$ per unit and multi-family units pay $\$ 14$ per unit. Office parcels pay $\$ .06$ per sq. ft., commercial parcels pay $\$ .10$ per sq. ft., industrial parcels pay $\$ .03$ per sq. $\mathrm{ft}$, and the sports complex pays $\$ 200$ per square $\mathrm{ft}$.

The TMA provides advocacy on transportation and air quality issues and serves the North Natomas area with one-stop commute alternative information.

In addition to traditional programs and services, NNTMA also plans to offer a local shuttle program that will "feed" existing transit routes, bonus trip reduction services for people who live and work in North Natomas, evening and weekend staffing to provide access for residents, and the development of child care services, a job clearinghouse and telecommuting centers to support trip reduction.

For more information, contact Rhonda Abell at (916) 648-2099 or pinesend@pacbell.net. 


\title{
Case Study-Working With Allied Organizations
}

\author{
Organization By-Laws \\ TMO Coordination Group from the Tampa Bay area, Florida
}

\author{
Transportation Management Organization \\ Coordinating Group (TMOCG) \\ Organization and By-Laws \\ Amended and Effective November 16, 2000
}

\begin{abstract}
Mission: To encourage the development of an effective and efficient regional transportation system by exchanging ideas; identifying common needs; and informing \& advising transportation service-providers of issues, needs, and solutions that best serve the TMO areas.
\end{abstract}

Purpose: The Organization and By-Laws document exists to create a balanced division of TMOCG responsibilities among members, encourage the personal growth and development of all members and strengthen the relationship among all members. Additionally, this serves to officially formalize the organization, which began and operated as an informal group.

Membership: The TMOCG shall have four (4) levels of membership. Membership levels and qualifications to be establishes as follows:

(I) Primary Members with full voting privileges:To qualify as a Primary Member, the organization must consider the advocacy and promotion of alternative modes of commuter transportation its primary function and/or business activity. The following organizations are currently identified as Primary members of the TMOCG:

Bay Area Commuter Services, Inc. (BACS)

Hillsborough Area Regional Transit Authority (HART)

Pinellas Suncoast Transit Authority (PSTA)

St. Petersburg Downtown Transportation Management Organization (SPDTMO)

Tampa Downtown Partnership Transportation Management Organization (TDPTMO)

Westshore Alliance Transportation Management Organization (WATMO)

University North Transportation Initiative (UNTI)

As other TMOs/TMAs are formed, the voting members will consider that organization for Primary Member status.

(2) Advisory Members with limited voting privileges *: To qualify as an Advisory Member, the organization must be regularly involved in providing services and/or products to the TMOCG. The following organizations are identified as Advisory members of the TMOCG:

Bay Area Vanpool (BAV)

The Center for Urban Transportation Research (CUTR)

(3) Ex-Officio Members with limited voting privileges *:To qualify as an Ex-Officio member, the organization must be regularly involved in providing funding and/or administrative guidance to the TMOCG. The following organizations are identified as ExOfficio members of the TMOCG:

Florida Department of Transportation, District VII (FDOT)

Hillsborough County Metropolitan Planning Organization (HMPO)

Pinellas County Metropolitan Planning Organization (PMPO)

(4) General Members with no voting privileges:All other organizations accepted for membership.All organizations, both public and private that are interested in the advocacy and promotion of commute alternatives, and localized within the five (5) counties of FDOT District Seven (Hillsborough, Pinellas, Pasco, Hernando and Citrus) served by the TMOCG are qualified to become a member of the organization. The TMOCG shall accept requests for membership in the TMOCG.Admission as a member shall be granted by majority vote of all voting members. 
Requirements of Members: All voting members shall participate in the annual election of a Chairperson (Chair) and ViceChairperson (Vice-Chair) and shall be expected to vote on all other actions placed before them as applicable. All members shall comply with the outcome of required/requested votes.

Conducting Business: All power and actions of the TMOCG shall be governed by the members under the authority of the Primary members. Only Primary members are permitted to cast a vote for TMOCG business. A simple majority $(5 \mathrm{I} \%)$ of Primary members must be present to conduct business and/or for a vote to take place. No Primary member may abstain from casting a vote unless a direct conflict exists. In the event of a tie vote, the organizations identified as Advisory members shall vote as the "tie-breakers." In the event there is still a tie, the Ex-Officio members shall vote as the "tie-breakers." Each member organization shall be entitled to only one vote regardless of how many representatives of the organization attend a meeting. The TMOCG chair shall officiate all votes.

Financial \& Contract Administration: BACS shall be the entity which requests and officially enters into all contract and joint participation agreements (JPA) on behalf of the TMOCG. As the contract/JPA administrating agency, BACS shall administer all funds of the TMOCG. Any administrative expenses designated in such contracts/JPAs shall be received by BACS and considered regular and reasonable expenses for serving as the contract/JPA administrator on behalf of the TMOCG.

Expenditure of Funds: No funds received by BACS, while acting on behalf of the TMOCG may be expended without the prior approval from a majority of primary members of the TMOCG.Approval may be granted by majority vote at any meeting of the full TMOCG with prior notice. In the event that financial expenditures must be made prior to the next meeting of the fullTMOCG, BACS shall contact the Chair for approval of such payments. In the event that financial contributions are requested of members for special projects and/or needs, member participation shall be strictly voluntary.

Election of Officers: Officer duties shall rotate annually, with the term of responsibility running from January Ist through December $3 \mathrm{Ist}$ of each year. Only primary members shall be eligible to serve as officers and any primary member may decline to serve if they so desire. Two consecutive terms cannot be served in the same position unless all other primary members decline to serve. Individuals may be nominated by any TMOCG member.All voting members shall cast a written ballot to register their vote. A separate nomination and ballot process will be conducted for each position with the election of the Chair occurring first. Elected individuals shall perform the duties of the office as long as they remain employed by a primary TMOCG member organization and serve as the primary representatives of those organizations.

Chairperson (Chair) Responsibilities: The Chair shall serve as the chief operating member of theTMOCG.The Chair shall preside at all regular and special meeting of the TMOCG. The Chair shall be entitled to notice of and attendance at allTMOCG committee meetings. The Chair shall see that all orders, votes and requirements of the members are carried into effect. Duties of the Chair shall also include the preparation and distribution of TMOCG meeting agendas.

Vice-Chairperson (Vice-Chair) Responsibilities: The Vice-Chair will assist the Chair in carrying out his/her duties and shall perform other duties as requested by the Chair and/or the primary members. The Vice-Chair shall preside in the Chair's absence at meetings of the full TMOCG. Duties of the Vice-Chair shall also include preparation and distribution of meeting notices and the coordination and preparation of the following years meeting schedule, sites and assigning a designee for taking minutes. In case of the Chair's absence or inability to act, the Vice-Chair shall perform the duties of the Chair and when doing so will have all of the authority normally reserved for the Chair.

Meetings: Regular, monthly meetings of theTMOCG shall be held on dates and at times and sites as specified by theVice-Chair and approved by all voting members. All voting members shall share the responsibility of recording, transcribing preparing and distributing meeting minutes. Meeting minutes shall be distributed within 10 business days of the meetings conclusion. Special meetings of the TMOCG shall be called by the Chair at the Chairs discretion and/or at the request of any three Primary members. Advance notice of all meetings must be given to all members. The date, time and location of all meetings shall be shown on each meeting notice and/or agenda.

Minute Keeping and Archival Responsibility: One (I) original copy of all meeting minutes and agenda packets shall be provided to BACS and the Chair for filing/recording purposes. BACS shall maintain a complete set of all TMOCG minutes and agenda packets in perpetuity.

Amendments: Additions, deletions, changes, updates and amendments to this Organization and By-Laws document must be approved by a $2 / 3$ majority of all voting members of the TMOCG. 
Members with limited voting privileges will vote:As "Tie-breakers" for TMOCG business and on all matters involving the annual election of officers, on all matters involving the admittance or removal of members, on all matters involving the establishment of an annual meeting schedule, on all matters involving amendments to the TMOCG Organization and By-Laws document and on all other issues at the discretion of the TMOCG Chairperson.

The Organization and By-Laws document of the TMOCG are available for review and revision as needed subsequent to a simple majority (5I\%) approval of such a review.

For more information, contact the executive director of one of the TMAs listed above under Membership. 


\section{Case Study-TMA Services}

\section{Creating One Voice for the Membership}

\section{TranSComm}

Boston University Medical Center is an urban medical center located in the Historical South End of Boston serving over 8,000 employees, 26,000 inpatients, 355,000 outpatients and 400,000 visitors annually. TranSComm, formerly the Interinstitutional Transportation Management Association (ITMA), was incorporated in I99I and coordinates the transportation needs of the hundreds of people that receive care from, are employed by or study at our sponsoring institutions. Those institutions are: Boston Medical Center, Boston University Schools of Medicine, Public Health and Dental Medicine and the Boston Public Heath Commission, City of Boston.

A transportation survey conducted in 1999 compared to the same survey distributed in 1992 showed the drive-alone share dropped $12 \%$ while the transit share increased about $9 \%$. TranSComm has achieved its success with major roadway construction happening at its doorstep and development surging in its activity center. The encouraging statistic is partly because all the pilot programs have been continued by the medical center.

Successful pilot programs include the evening transit shuttle, guaranteed ride home, transportation newsletter, bike maintenance and safety check-up, educational and informational marketing, incentive programs, a statewide website and an alternative transportation commuter video.

On the other hand, TranSComm discontinued its midday shuttle pilot project in 1994 after six months because the MBTA was putting its crosstown express bus on the road serving the same route. In the six-month period, TranSComm diverted part of the market for the T's service. Because we wanted the public service to succeed, we discontinued the private one.

TMA members appreciate the transportation demand management programs because it creates "one voice" from the medical center community dealing with transportation issues. Whether the TMA is advocating for additional bus service, procuring new bike racks or dealing with Central Artery issues, TranSComm represents a unified constituency.

For more information, contact Maureen Lacey Flaherty at (6 I 7) 638-7473 or maureen.flaherty@bmc.org

\section{Case Study-TMA Services}

\section{Three for Free Transit Incentive}

\section{CommuteWorks/MASCO (Medical Academic and Scientific Community Organization, Inc.)}

This is an example of how a TMA has successfully tailored incentives to serve its unique market. CommuteWorks serves the Longwood Medical and Academic Area (LMA), a 210-acre community of health care, educational, and religious institutions located three miles south of downtown Boston. There are 19 members representing commuters composed of 30,000+ employees and 15,000+ students. Parking in the LMA is a scarce and highly prized commodity, with multi-year waiting lists for close-in spaces.

The "Three for Free" Transit Incentive is a pilot transportation demand management (TDM) program designed by CommuteWorks/MASCO to reduce vehicle miles traveled (VMT), vehicle trips, and congestion emissions produced by drive alone employees. In the program employees who are registered parkers at MASCO member institutions receive a free transit pass (up to $\$ 65$ ) for three months if they agree to give up their parking space. There is a guaranteed return of the parking space at any time the employee wishes to return to driving. 
Funding for the "Three for Free" program came from a $\$ 50,000$ federal Congestion Mitigation Air Quality (CMAQ) grant awarded to CommuteWorks through a Massachusetts Transportation ManagementAssociation (TMA) Assistance Grant. Matching funds of $\$ 50,000$ were provided by MASCO.

This program is being done to look at how a 100\% transit subsidy can reduce the total number of drive alone commuters in the LMA, the emissions that they produce and the demand for parking. It is hoped that the success of this program will show members that they can reduce the number of parking spaces they lease by providing a higher transit subsidy, allowing more drive alone commuters to take benefit of transit and save both the institution and the employee money.

In the incentive's ninth month of operation, the TMA reported that 61 employees were currently participating, with an additional 15 commuters registered for future months. Of the $16 \mathrm{I}$ commuters who have completed the incentive program, 76 gave up their parking spaces, 33 returned to driving alone, 3 were biking/walking and 6 were no longer working in the medical area. Information was not available from the remaining commuters. CommuteWorks/MASCO is currently looking into the possibility of continuing the "Three for Free" program after its completion in December 2000. The program would remain the same and CommuteWorks/MASCO would dedicate a part of its budget to pay for the passes.

The biggest lesson learned is that there needs to be a continuous bombardment of information and promotion. Many of the employees who signed up had to hear about the program three or four times before they actually acted on the offer to register. Actively marketing the program in various ways is important for success. Assistance from member institutions in spreading the word via email was the most successful marketing tool, as well as direct marketing to parkers with flyers at the parking lots.

The use of Commuter Checks was a great way to provide the subsidy to employees who required a commuter rail pass. Since, by law we can only provide up to $\$ 65$ a month for a transit subsidy CommuteWorks/MASCO was able to issue those participants Commuter Checks and let them purchase their pass on their own. This way CommuteWorks did not have to deal with trying to get reimbursed by each employee for the remaining cost of the commuter rail pass.

For more information, contact Sarah Hamilton at (6 17) 632-2776 or shamilton@masco.harvard.edu.

\section{Case Study-TMA Services}

\section{Hotel Employee Shuttle}

\section{Tampa Downtown Partnership TMO}

While it is possible for many of downtown Tampa's early morning and late night shift employees to make one way trips using transit, the challenge has been for them to find adequate transportation when transit service is not available. A zip code analysis showed that a majority of these employees lived either west or north of the Downtown core. The shuttle was created as a pilot project, to provide service to these areas. Financial obstacles and irregular work schedules were some of the major hurdles addressed by the project.

For more information, contact James Cloar, Executive Director, Tampa Downtown Partnership, Tampa, FL (8 I 3) 22 I-3686. 


\section{Case Study-TMA Services}

\section{Community Shuttle}

\section{Emeryville TMA}

The main program of the Emeryville (Calif) TMA is the operation of a shuttle service. The Emeryville TMA contracts out for the provision of shuttle buses and drivers.

The TMA is funded $95 \%$ by private companies (employers, developers) who pay TMA dues of $\$ 3,000$ a year plus an optional assessment per square footage of their properties if the member wants shuttle service. The current square footage rate is 15 cents/foot. What members pay for the shuttle ranges from $\$ 5,000$ to over $\$ 100,000$ per year. The total budget is $\$ 1$ million this year.

Shuttle participation is governed by Membership Agreements signed by all the contributors who agree to a certain level of service and other specifications. Everyone who pays full cost for shuttle participation has voting rights for shuttle matters; those who are just TMA members have no vote on shuttle matters.

The entire Emeryville community uses the shuttle, with ridership over 600,000 . The TMA is now exploring a community wide property based assessment district for future funding.

For more information, contact Wendy Silvani, at wlspr@aol.com.

\section{Case Study-TMA Services}

\section{Successful Promotions}

\section{CobbRides}

CobbRides, a program of the Town Center Area Community Improvement District (CID), is one of six (6) metro Atlanta TMAs. Its mission is to build public awareness about transportation issues and alternatives to single occupancy vehicle travel and to mobilize the business community to support recommendations and change commuting behavior. Our participants are a mixture of large corporations and small businesses.

CobbRides is funded in part through a federal CMAQ grant in conjunction with the Atlanta Regional Commission's Commute Connections program and the Georgia State Department of Transportation.Additionally, we are supported by the Town Center Area Community Improvement District (CID), and dues from participating companies that are not part of the CID. CobbRides also provides limited opportunities for sponsorships. The revenues are devoted entirely to traffic improvements for access, safety and quality of life in the area.

CobbRides officially began in January, 1999. On January $5^{\text {th }}$, www.CobbRides.com was launched with traffic management programs, clean air facts and links to supporting organizations. By February, a power point presentation was developed for promoting behavioral change in driving habits.

CobbRides utilized the momentum the new governor had initiated in his support of transportation solutions. Capitalizing on his statement, "If anyone has a magic wand, let them come forth," CobbRides used it as the opening on the website and printed collateral. The governor participated in the kick-off event in April by arriving in an alternative fueled automobile.

Our demographics indicate suburban sprawl...families with children and a car for everyone that can drive. Transit is not a viable solution for this area. CobbRides took the high road and felt its best approach was to sell "a way of life" and that "way of life" had to include healthy, clean air. CobbRides leased a billboard along a road that accommodates some of the area's highest traffic counts. During the last week of April, the billboard went up signaling the beginning of Smog Season May I through September 30 with the CobbRides logo and website. 
CobbRides developed an e-mail database of over 200 participants. Every PSG alert was passed on to the database recipients. Selling clean air became a community project. CobbRides designed a $3 \times 5$ flag to be flown announcing a smog alert. The first order was for a minimum of flags, the response was so strong that CobbRides reordered twice. Businesses, schools, municipalities and the Health Dept requested flags to support "a cleaner community." Each flag carries the CobbRides website.

CobbRides negotiated a deal with Cobb County's government channel to provide four 3-minute vignettes that were professionally produced and provided environmental updates from CobbRides. Cobb County has received rave reviews and it has been a win-win situation for both parties. The vignettes address health hazards, public awareness of air quality and traffic management...the series was shown a minimum of twenty five times a week.

For the efforts above, CobbRides received the Blue Horizon Award from Georgia's Partnership for a Smog-free Georgia for an energetic and effective campaign about transportation and the air pollution problem in metro-Atlanta.

For more information, contact Mary Lou Stephens at (770)974-9080 or Info@CobbRides.com.

\section{Case Study-TMA Services}

\section{Georgia-Pacific Employee Transportation Coordinator}

\section{Cumberland Transportation Network}

One of the Cumberland Transportation Network's (CTN) most successful partnerships is with Georgia-Pacific (G-P) Division Headquarter in Wildwood.The Distribution Division Headquarter houses over I,000 employees in Cumberland. G-P originally approached CTN in search of solutions to a parking crisis. The company needed to reduce parking demand by I 30 spaces or expand its surface lot - at a cost of $\$ 100,000$ a year. Aware of CTN's free services and of the benefits the company could derive, G-P entered partnership with CTN to address its business concerns.

At the time, G-P's corporate office offered a transportation program for area employees. However, few Distribution Division Headquarter employees took advantage of it. To increase participation, CTN and G-P added CTN's services to the current transportation program and planned a strong promotional campaign to raise awareness.

G-P already offered a $\$ 30$ monthly subsidy for bus and rail riders. The company enrolled in CTN's TransAdvantage program and added an additional $30 \%$ discount to their subsidy.Vanpool riders also benefit. G-P pays the lease price of full vanpools while CTN provides $\$ 600$ for each new vanpool. G-P takes advantage of federal tax benefits by deducting their cost as a business expense.

To promote the program, CTN sponsors annual Transportation Fairs in the cafeteria during lunch hours. Letters, e-mails and a permanent information board also spread the word. Periodic Lunch n' Learns help identify potential vanpools. G-P's wisest move was to identify a coordinator to promote the program to employees on an on-going basis. With the property manager's help, G-P reserves parking spaces for vanpools and carpools. G-P also offers CTN's Guaranteed Ride Home program for participating employees.

Over 85 employees carpool, over 100 vanpool in eight vans and 65 employees ride transit. By early 1999, the company reduced about 6,000 miles each day. Meanwhile, transit riders have saved over $\$ 65,000$ and vanpoolers over $\$ 35,000$ annually. In addition, over 65 employees are registered in the Guaranteed Ride Home program although few have used it.

What began as a parking crisis evolved into a program that benefits employees' quality of life. Because of G-P's strong commitment to its business, community and employees, the company continues to be a visionary leader through its partnership with the Cumberland Transportation Network.

For more information, contact Ms. Robin Taylor at (770) 22 I-2533 or RRTAYLOR@GAPAC.com 


\section{Case Study-TMA Services}

\section{Marriott Employee Transportation Coordinator}

\section{Cumberland Transportation Network}

The Marriott Worldwide Reservations Center (MWR) is one of the company's international call centers. Prior to 1997,40\% of the potential recruits could not be hired due to the lack of transportation services to the site - a major recruitment problem. A partnership between Marriott and the Cumberland Transportation Network (CTN) focused the Reservations Center's program around public transit and carpooling in order to address the company's recruitment and retention needs.

CTN began by assessing MWR's transit needs.A customer-service organization, MWR's hours are non-traditional.After consulting with the Cobb Department of Transportation, CTN proposed an extension to CCT bus service hours to accommodate one of MWR's primary shifts. An additional CCT bus was also added to the route to accommodate the late-shift workers. MWR enrolled in CTN's TransAdvantage program to take advantage of 30\% discounts. Over 45 employees now ride transit.

MWR achieved similar success with carpools. Through pizza parties and information displays, many employees were successfully matched and now 220 employees now carpool. MWR also has three employees who walk to work and a biker. To support the program, CTN and MWR implemented an assortment of incentives, including preferential work schedules and up to a week of vacation.

Due to their efforts, MWR's turnover decreased in one year $87 \%$-- a savings of $\$ 200,000$. Over $75 \%$ of employees participate in the transportation program. The program allowed the company to expand from 90 employees to 350 over a two-year period. The company's success lies in MWR's Human Resource Manager who has made it a priority to aggressively promote the program through his personal attention and MWR's outstanding incentive package.

MWR has won extensive awards for their efforts, including a corporate award chosen over I,700 Marriott locations around the world. Marriott's home office is so impressed, they are interested in applying many of the strategies to other locations. Marriott's program has been acclaimed in the Atlanta Journal/Constitution, Georgia Trend, the Atlanta Business Chronicle, the Marietta Daily Journal and more.

The cooperative effort between Marriott and the Cumberland Transportation Network continues to benefit the company and the community and serves as an excellent example of the results a company can achieve.

For more information, David Barwick at (404) 497-4504. 



\title{
TMA Survey Results
}

\section{The Evolving TMA:}

\author{
Results from the 1998 ACT TMA Council Operational Survey
}

\section{TDM Review article \\ Reprinted with permission from Stuart Anderson}

\section{Written by David W. Ungemah and Stuart M.Anderson, of Urban \& Transportation Consulting}

In the early 1990s, several commute trip reduction mandates ended and many Transportation Demand Management (TDM) professionals questioned the practical longevity of Transportation Management Associations (TMAs). However, in the mid-to-late 1990s,TMAs enjoyed a rebirth, even in areas recently foregoing mandates, as many communities expressed the desire to develop comprehensive alternative transportation programs.

From California to Vermont, numerous TMAs have sprung up, virtually overnight, to develop viable TDM programs. TMA growth has increased 17 percent since 1993, and, as of mid-1998, I35 known TMAs actively help commuters explore the potential benefits TDM may offer.

In early 1998, the ACTTMA Council conducted a survey of these TMAs to learn how these organizations have evolved since the last survey over five years ago. The survey received a 70 percent response rate from the 135 TMAs. Overall, a sharp diversity of organizations call themselves TMAs. Differences abound in terms of the organizations' size, commuter representation, staffing, policy-making, and services. However, all TMAs have one element in common: aiding the commuter's overall transportation experience. This article explores the differences and similarities between TMAs throughout the nation. For averaging purposes, a median value was selected over a mean value, as significant bias (in favor of either small or large organizations) was present with mean values.

\section{Survey Results}

In 1993 most TMAs were located in the more densely populated coastal states, such as California, Florida, and New Jersey. By the time the 1998 survey was conducted,TMAs had been established throughout the United States. The survey showed that the greater diversity in TMA location also yields greater diversity in organization types. The following synopsis of the survey statistics best illustrates this diversity.

\section{Size of Organization}

TMA service areas range in size from an office park to an entire metropolitan region.Almost 30 percent of TMAs have a regional scope, with an additional 20 percent servicing a central business district. The remaining 50 percent of TMAs are comprised of citywide, corridor, suburban, development, and site-specific jurisdictions.

Organizations range in size from three to 65,000 members and I 80 to 200,000 commuters, with an average of 25 members and 25,000 commuters. This finding belies the notion that TMAs must serve large commuter populations. In fact, many of the responding organizations represent smaller communities, like the TMA created in 1996 to serve the city of Missoula, Montana.

Overall, communities throughout the United States

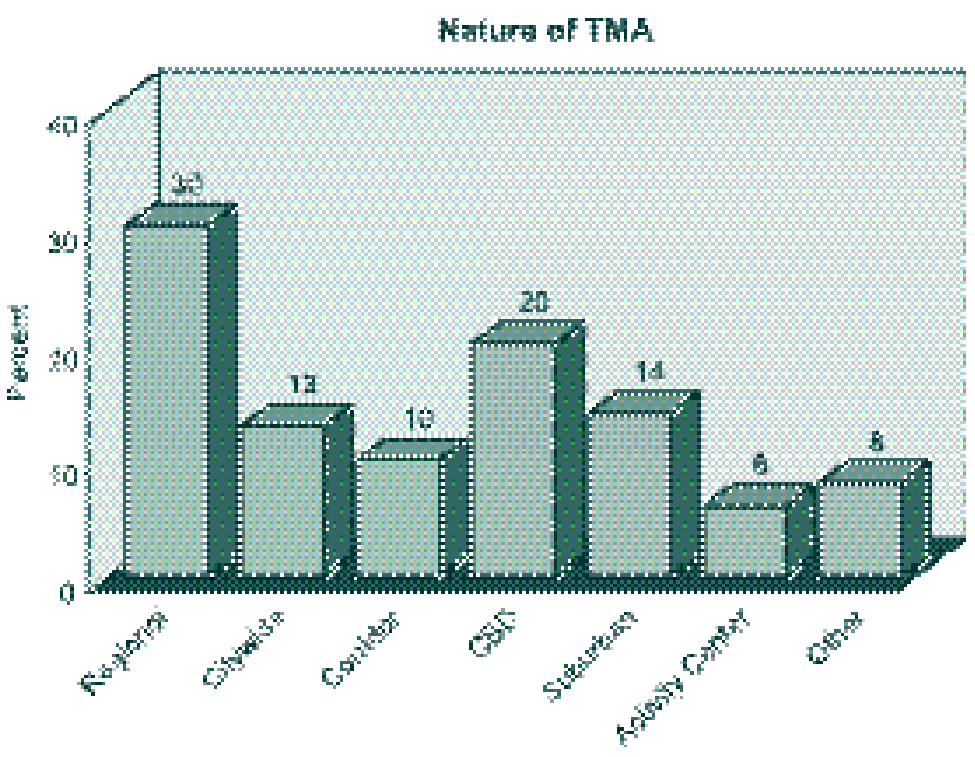




\begin{tabular}{|c|c|c|c|c|}
\hline Nature of TMA & $\begin{array}{l}\text { Total \% } \\
\text { all TMAs }\end{array}$ & Members & Commuters & $\begin{array}{l}\text { Percentage of } \\
\text { all employers }\end{array}$ \\
\hline Regional & $30 \%$ & 25 & 30,000 & $8 \%$ \\
\hline Citywide & $13 \%$ & 30 & 22,000 & $8 \%$ \\
\hline Corridor & $10 \%$ & 23 & 30,000 & $30 \%$ \\
\hline Central Business District & $20 \%$ & 28 & 28,000 & $15 \%$ \\
\hline Suburban & $14 \%$ & 30 & 30,000 & $60 \%$ \\
\hline Activity Center & $6 \%$ & 5 & 16,600 & $75 \%$ \\
\hline Other / Non-contigious service area & $8 \%$ & 23 & 18,000 & $13 \%$ \\
\hline
\end{tabular}

have found different motivations for establishing TMAs. This report offers comparisons primarily between the different types of TMAs: regional, citywide, corridor, central business district, suburban, and activity center.

Regional, corridor and suburban TMAs tended to have the largest average commuter representation, averaging 30,000 commuters each. Citywide (single jurisdiction) and suburban TMAs had the highest median membership, with 30 members. Suburban and activity center TMAs reflect the highest average participation rates in a TMA. The high participation rates at activity centers reflect their jurisdictional nature - many of these TMAs are extensions of new developments or office parks.

\section{Membership and Recruitment}

TMA members consist mainly of businesses and employers. This group also provides 75 percent of the TMAs contributions. Governmental agencies and non-profit organizations made up a smaller percentage of membership, 14 percent and nine percent respectively. However, on average,TMAs represent only eleven percent of all employers in a TMA district.

Organizations use a variety of techniques to recruit members.TMAs are not predisposed toward certain recruitment techniques based upon the nature of their organization. Peer-to-peer and direct contact methods are used by the majority of nationalTMAs. Only 16 percent of TMAs have mandatory membership. Interestingly, at least one TMA reported using mandatory membership for all service area types, including regional, corridor, and citywide. Only three percent of TMAs recruit members through a discounted rate, however approximately half of TMAs offer different categories and cost of membership.

Peer-to-peer contact is perceived by half of TMA directors to be the most successful method for recruitment. The only other methods receiving significant support were a letter from the executive director, and mandatory membership. It should be noted that only 62 percent of TMAs with mandatory membership also remarked that this was the most successful method for recruitment. This suggests that other methods of contact are necessary to ensure the TMA's visibility.

\section{Governance of the TMA}

The majority (57 percent) of TMAs' authority comes solely from its membership. When examined by TMA type, as shown in the table below, this holds true regardless of the TMA district extent. An additional one-quarter of TMAs share authority between members and local government. Interestingly, only five percent of TMAs are controlled by a chamber of commerce, despite a greater percentage of TMAs who maintain their office space at chamber organizations.

\section{TMA Services}

TMAs offer a variety of services to their members and,

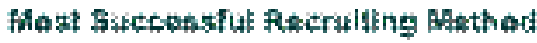

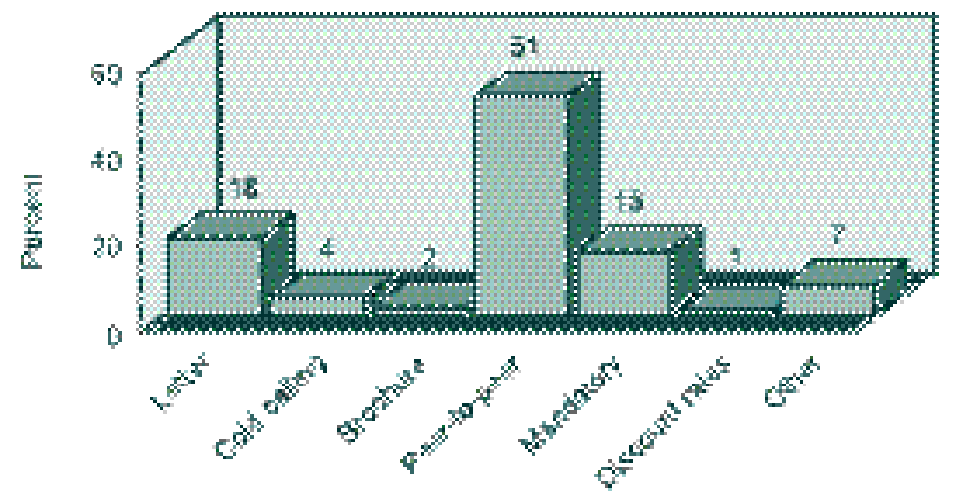




\begin{tabular}{|c|c|c|c|c|c|c|c|}
\hline & Regional & Citywide & Corridor & CBD & Suburban & $\begin{array}{r}\text { Activity } \\
\text { Center }\end{array}$ & Other \\
\hline Membership only & $50 \%$ & $50 \%$ & $50 \%$ & $50 \%$ & $64 \%$ & $100 \%$ & $83 \%$ \\
\hline Members and Government & $29 \%$ & $20 \%$ & $38 \%$ & $25 \%$ & $18 \%$ & & $17 \%$ \\
\hline Chamber & $4 \%$ & $20 \%$ & & & $9 \%$ & & \\
\hline Improvement District & $4 \%$ & & & $6 \%$ & $9 \%$ & & \\
\hline Appointed / Committee & & & & $13 \%$ & & & \\
\hline Other & $13 \%$ & $10 \%$ & $13 \%$ & $6 \%$ & & & \\
\hline Total & $100 \%$ & $100 \%$ & $100 \%$ & $100 \%$ & $100 \%$ & $100 \%$ & $100 \%$ \\
\hline
\end{tabular}

in some cases, to non-members. Overall, the majority of TMAs provide rideshare promotion, regional advocacy, promotional materials, and promotional events. Conversely, only a small number of TMAs offer subsidized transit passes, a local shuttle or other transit, parking services, and parking pricing. Although many services and products of TMAs are available to both members and non-mem bers,ETC training, guaranteed ride home, subsidized transit passes, site design assistance, vanpool subsidies, parking services, and parking pricing are primarily offered to members only.

TMAs tend to act as promotional entities, rather than direct service providers. This finding suggests that existing and prospective members may see equal, if not greater, value in promotion and advocacy than in tangible services. However, with only II percent of all businesses in an area participating, it is possible that they might actually be looking for more services.

\section{TMA Personnel and Policies}

On average,TMAs employ one full-time employee and one parttime employee. However, the difference in staffing between TMAs can be dramatic. Respondents had as few as zero and as many as 20 full-time employees. Almost half of TMAs outsource the services they provide. The two most common services given to contractors were shuttle service and ridematching. However, 30 percent of respondents listed additional services that are outsourced. Approximately half of these responses pertained to either marketing or administration of the TMA.

\section{Executive Directors}

More than half of TMA directors have either primary or secondary experience in transportation. However, it is interesting to note that, of those, only two-fifths had primary transportation experience Other directors reported experience in marketing (27 percent), planning ( 23 percent), and administration ( 20 percent). The average TMA executive director has served at her or his TMA for three years and has approximately six years of direct experience in TDM. Almost all TMA executive directors hold at least a Bachelors degree, and an additional 45 percent of respondents also have a Masters degree. Two-fifths (43 percent) of TMA executive director salaries fall between $\$ 30,000$ and $\$ 50,000$ per year.An additional quarter of respondents (27 percent) have an annual salary between 550,000 and 570,000 per year. In terms of salary a significant correlation was found between executive director salary and his or her educational attainment, years at the TMA, and years in TDM.

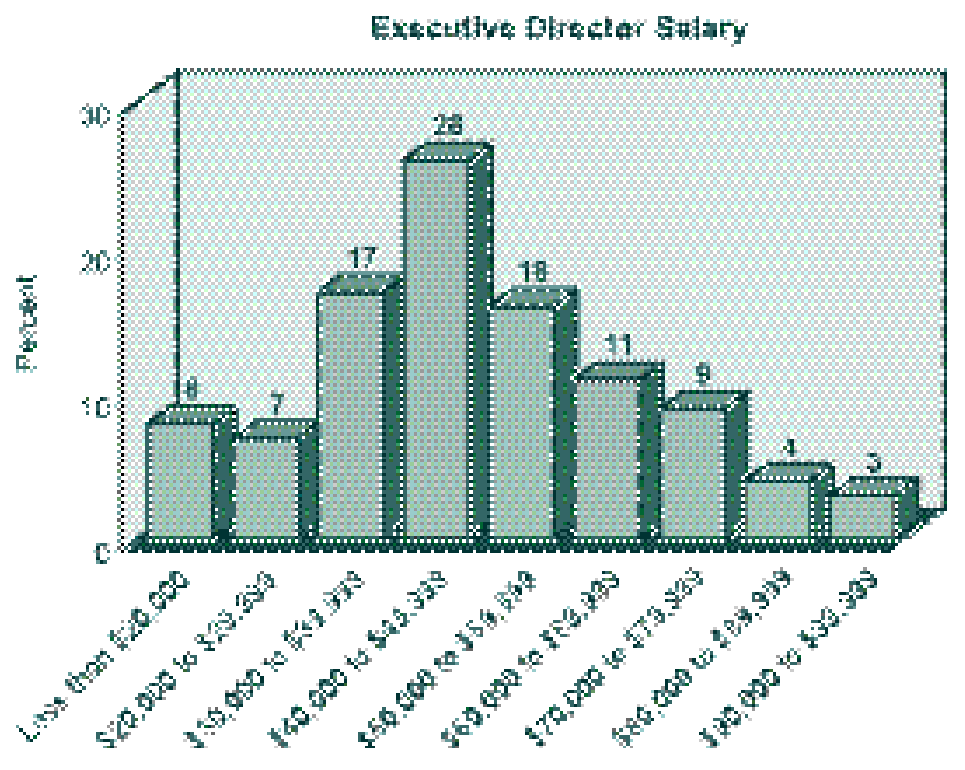




\section{Employee Benefits}

The majority of TMAs offer their employees paid holidays, access to seminars, payment of professional membership dues, and a medical insurance plan. Additionally, at least one-third ofTMAs provided vision/ dental insurance, transportation expenditures, free parking, and life insurance to staff members.

\section{Financial Characteristics of TMAs}

The TMAs surveyed have widely varying budgets, from less than $\$ 50,000$ to more than $\$ 300,000$ per year. Generally, there was a significant correlation between the number of commuters the TMA services and its budget - the greater the number of commuters, the greater the budget. There was no correlation, however, between the size of the TMA membership and its annual budget.

Interestingly, only 20 percent of expenditures are devoted to member services. Conversely, almost half of annual budgets are devoted to office operations, including staff salaries and benefits. Marketing comprises another one-fifth of expenditures. For income, almost half of an average TMA's income is derived from grants and other district revenues. An additional one-third of revenues are the result of member dues.

An annual financial statement is provided to members by 57 percent of TMAs. An annual audit of its financial records is conducted by three-fourths of TMAs. Finally, 68 percent of TMAs conduct an annual meeting to review TMA actions.

\section{Organization of the TMA}

The average TMA has been in operation for six years. Respondents cited TMA formation as early as 1959 and as recent as July 1998. Sixty-nine percent of TMAs were incorporated during 1998. The majority of those incorporated were tax-exempt, either as a $50 \mathrm{I}(\mathrm{C})(3)(37$ percent of all TMAs), 50I(C)(4) (I7 percent), or 50I(C)(6) (I7 percent).

The majority of TMAs maintain four organizational documents: a mission statement ( 94 percent), objectives (77 percent), strategic plan (67 percent), and by laws ( 63 percent). Of the TMAs maintaining a strategic plan, 56 percent revise it every year. An additional 15 percent revise the plan every other year. Over half (54 percent) of TMAs have officers and directors insurance. However, only 21 percent of TMAs hold professional liability insurance and less J尹AA Encerye Soursers (I5 percent) hold fiduciary liability insurance. Legal

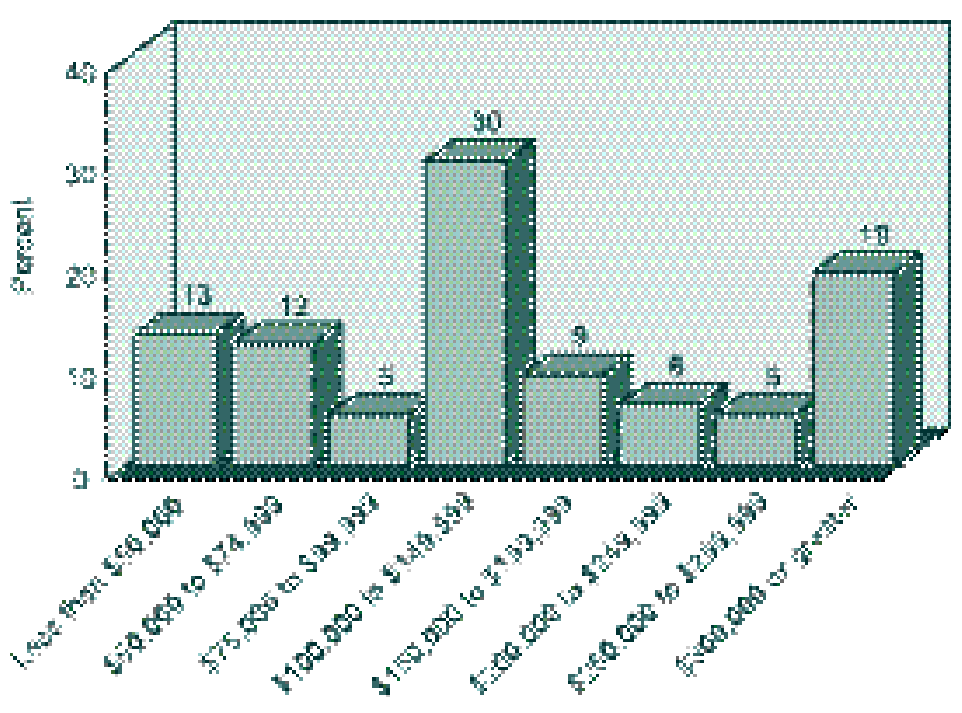
counsel is retained by 55 percent of TMAs. Of those, 28 percent have in-house council or from a volunteer member. An additional 25 percent hire counsel either on an as-needed basis or for general services. Only II percent of TMAs require legal counsel at Board meetings.

Half of respondents stated they maintain a World Wide Web site, 29 percent operate a dial-up bulletin board system, and 19 percent use e-mail distribution lists.A list of TMA websites is available from ACT as a product of this survey.

\section{Remarks}


TMAs continue to grow throughout the United States. The total number of TMAs has increased I7 percent since the last ACT TMA Council survey was conducted in 1993. However, some of the TMAs existing in 1993 are no longer in operation, particularly in areas that once mandated employer trip reduction programs (principally in California). New TMAs have emerged in non-regulated environments that are experiencing significant growth in population and traffic congestion, including such states as Georgia (0 in 1993, 5 in 1998) and Colorado (0 in 1993, 7 in 1998). TMAs are also serving smaller communities where quality of life issues can be addressed through a coordinated TDM effort.

TMAs are less likely than in 1993 to rely on traditional membership dues for funding. Many executive directors report that securing membership dues can be time consuming and costly. In 1993, membership contributions accounted for nearly one-half of the TMA's total revenues; in 1998, they represent only onethird. Increasingly, TMAs are looking to state and local agencies to provide ongoing funding for key services that benefit the public within the TMA's service area.

This is evident by the increasing percentage of central business district and community-wide TMAs and decreasing percentage of activity center and corridor TMAs. Some TMAs have been successful in creating or tapping into business and community improvement districts to fund local transportation services. A blend of both public and private funding is typical with most TMAs.

TMA services have not changed significantly since 1993.Advocacy and rideshare promotion continue to be the most frequently offered services. However, there has been a decrease in the number of TMAs providing trip reduction plan assistance and an increase in site design assistance.

As previously noted,TMAs are spending less than 20 percent of the annual budget on direct member services. This is a decrease from the 1993 results. Follow-up discussions with some executive directors indicate that today's TMAs, may be operating more as service brokers and advo catesrather than as direct service providers, although it should be noted that labor costs were not broken down by activity. Further research is needed to clarify the use of TMA funds.

The promising conclusion is that interest in TMAs has increased in recent years. TMAs can now be found throughout the United States and are playing an important role in creating and sustaining partnerships and supporting the delivery of transportation services. 



\section{Helpful Resources}

(listed alphabetically)

\section{American Planning Association (APA)}

1776 Massachusetts Ave., NW

Washington, D.C. 20036-1904

Phone: (202) 872-0611

Fax (202) 872-0643

www.planning.org

The American Planning Association provides leadership in the development of vital communities by advocating excellence in community planning, promoting education and citizen empowerment, and providing the tools and support necessary to effect positive change.

\section{American Public Transportation Association (APTA)}

1666 K Street NW

Washington, D.C. 20006

www.apta.com

APTA serves and leads its diverse membership through advocacy, innovation and information sharing to strengthen and expand public transportation.

\section{American Society of Association Executives (ASAE)}

I575 I Street NW

Washington, D.C. 20005-II 03

Phone: (202) 626-2723

Fax: (202) $37 \mathrm{I}-8825$

www.asaenet.org

ASAE's core purpose is to advance the value of voluntary associations to society and to support the professionalism of the individuals who lead them.

\section{Association for Commuter Transportation (ACT)}

P. O. Box 15542

Washington, DC 20003-0542

Phone: (202) 393-3497

Fax: $\quad$ (202) 546-2196

Email: act@act.hq.com

www.actweb.org

ACT's primary mission is to provide alternatives to the solo commute, resulting in decreased traffic congestion and improved air quality.ACT publishes a yearly directory containing TMA members, web sites and affiliated organizations as well as information resources by peer referral.ACT also provides guidance and information for employers and employees on how to implement Commuter Choice programs. This information can be found at www.commuterchoice.com 


\section{Community Transportation Association of America (CTAA)}

I34 I G Street NW, I0 $0^{\text {th }}$ Floor

Washington, D.C. 20005

Phone: (202) 628-1480

Fax: $\quad$ (202) 737-9197

www.ctaa.org

CTAA is an association of organizations and individuals committed to improving mobility for all people.

\section{Federal Highway Administration (FHWA)}

\section{USDOT}

4007 th Street, SW

Washington, D.C. 20590

www.fhwa.dot.gov

FHWA provides technical training, education and assistance to state and local transportation agencies, develops regulations, policies and guidelines to achieve safety, access and economic development, promotes safety practices and technologies in highway design, construction and operations, implements state of the art technologies, and provides financial assistance and grants to a variety of programs.

\section{Federal Transit Administration (FTA)}

\section{USDOT}

$4007^{\text {th }}$ Street, SW

Washington, D.C. 20590

Phone: (202) 366-4043

Fax: $\quad$ (202) 366-3472

www.fta.dot.gov

FTA provides financial assistance to develop new transit systems and maintain, improve and operate existing systems to hundreds of state and local transit providers for the purposes of affordable mobility, congestion management and support to neighbor-

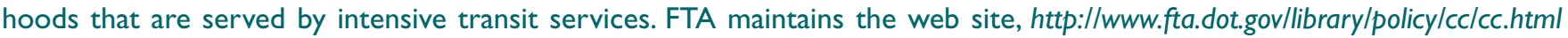
which provides links to information on Commuter Choice programs.

\section{Institute of Transportation Engineers (ITE)}

1099 I $4^{\text {th }}$ Street, NW, Suite 300 West

Washington, D.C. 20005-3438

Phone: (202) 289-0222

Fax: (202) 289-7722

Email: ite_staff@ite.org

www.ite.org

The Institute of Transportation Engineers, an international individual member educational and scientific association, is one of the largest and fastest-growing multimodal professional transportation organizations in the world. ITE members are traffic engineers, transportation planners, and other professionals who are responsible for meeting society's needs for safe and efficient surface transportation through planning, designing, implementing, operating and maintaining surface transportation systems worldwide. ITE's I I area-of-interest Councils serve as forums to define issues and develop solutions. Activities include the development of standards and recommended practices, informational reports, handbooks, conferences, issue briefings and newsletters. 


\section{Internal Revenue Service}

www.irs.ustreas.gov

The Internal Revenue Service web site provides information, publications and rules and regulations regarding issues pertinent to TMAs, including 26 CFR Parts I and 602, Qualified Transportation Fringe Benefits, published in the Federal Register/Vol. 66, No. 8/Thursday, January I I, 200 I/Rules and Regulations; and IRS Publication No. 557, Tax Exempt Status for Your Organization, which will be available soon.

\section{International Telework Association and Council (ITAC)}

204 E Street, NE

Washington, D.C. 20002

Phone: (202) 547-6157

Fax (202) 547-6348

Email: info@telecommute.org

www.telecommute.org

ITAC studies, develops and recommends tools, techniques and processes that promote the benefits of work independent of location.

\section{League of American Bicyclists}

1612 K Street NW

Suite 401

Washington, D.C. 20006-2082

Phone: (202) 822-1333

Fax (202) 822-I334

Email: bikeleague@bikeleague.org

www.bikeleague.org

The League of American Bicyclists promotes bicycling for fun, fitness and transportation and works through advocacy and education for a bicycle-friendly America.The League's key programs include national sponsorship of Bike Month and Bike to Work Day, national, state and local bicycle advocacy, bicycle safety and education, and the Bicycle Friendly Communities Program.

\section{National Center for Nonprofit Boards}

1828 L Street, NW

Suite 900

Washington, D.C. 20036-5 I I4

Phone: (202) 452-6262 or (800) 883-6262

Fax (202) 452-6299

Email: ncnb@ncnb.org

www.nenb.org

This organization is dedicated to increasing the effectiveness of nonprofit organizations by strengthening their boards of directors. 


\section{National TDM and Telework Clearinghouse}

University of South Florida

College of Engineering

4202 E. Fowler Avenue, CUT 100

Tampa, FL 33620-5375

Phone: (813) 974-3120

Fax: $\quad(813) 974-5168$

www.nctr.usf.edu/clearinghouse

The Clearinghouse is funded as part of the National Center for Transit Research to provide technical assistance on transportation demand management and telework. The Clearinghouse provides a means to conduct information searches on a TDM database, find information about operating TDM and telework programs at worksites, find resources to help public agencies operate effective TDM and telework programs, gain access to timely research reports and data, and discover education and research opportunities for students. Through contact with vendors, the Clearinghouse also helps transportation professionals identify existing or developing products that can be used in TDM or telework programs. The Clearinghouse also identifies individuals and organizations with particular areas of expertise, provides short-term technical assistance to TDM and telework programs and maintains two email listservs for peer exchange of information.

\section{Promotional Materials Clearinghouse}

The Marketing Institute

Florida State University

College of Business

32 I RBB

Tallahassee, FL 32306- I I I I

Phone: (850) 644-2509

Fax: (850) 644-623 I

tmi.cob.fsu.edu

Funded by the National Center for Transit Research, the Promotional Materials Clearinghouse is an archive of transit and TDM marketing materials and other resources that facilitate sharing of ideas among public transportation professionals throughout the U.S. and Canada.

\section{Surface Transportation Policy Project (STPP)}

$110017^{\text {th }}$ Street NW

$10^{\text {th }}$ Floor

Washington, D.C. 20036

Phone: (202) 466-2636

Fax: (202) 466-2247

Email: stpp@transact.org

www.transact.org Transportation Action Network

www.tea2 I.org Tea-2I Users Guide

STPP is an organization that works to ensure a diversified transportation system. 


\section{U. S. Environmental Protection Agency}

Ariel Rios Building

I 200 Pennsylvania Avenue, NW

Washington, D.C. 20460

Phone: (202) 260-2090

Fax: (202) 50I-1450

www.epa.gov 
